\title{
BORON/ALUMINUM SKINS \\ FOR THE DC-10 AFT PYLON
}

\author{
FINAL REPORT
}

by

\section{S.Y.ELLIOTT}

\section{Prepared under Contract NAS1-13029 \\ McDonnel1 Douglas Corporation \\ Douglas Aircraft Company \\ 3855 Lakewood Blvd \\ Long Beach, California 90846}

\author{
May 1975 \\ for \\ Langley Research Center \\ Hampton, Virginia 23366
}

NATIONAL AERONAUTICS AND SPACE ADMINISTRATION 


\section{ABSTRACT}

Four boron/aluminum aft pyion "boat tail" skins are designed and fabricated and three of them are installed on three DC-10 aircraft for a 5 -year flight service demonstration test. The fourth skin is retained as a spare and all skins will be replaced at the end of the service period by their titanium counterparts. Inspection and tests of the exposed skins will establish the ability of the boron/aluminum composite to withstand long time flight service conditions, which include exposures to high temperatures, sonic fatigue, and flutter. The results of a preliminary testing program yield room temperature and elevated temperature data on the tension, compression, in-plane shear, interlaminar shear, bolt bearing, and tension fatigue properties of the oriented 11 ply boron/ aluminum laminates and this information together with a stress analys is are used to obtain FAA approva1. Present state-of-the-art technology (emphasizing low cost) was used in the fabrication of the skins and these are installed on the existing titanium substructure with the same number of the same sized mechanical fasteners as are used for the present titanium skins. The boron/aluminum skins measure approximately $20.32 \times 170.18 \mathrm{~cm}$ $(8 \times 67$ inches $)$ and are $2.032 \mathrm{~mm}(0.080 \mathrm{inch})$ thick. A1 though maximum weight saving was not sought, the $1.56 \mathrm{Kg}(3.45 \mathrm{lb})$ weight of the constant thickness boron/aluminum skin is $26 \%$ less than the chemically milled titanium skin. 
FOREWORD

This report was prepared by the Douglas Aircraft Company (DAC), Long Beach, California of the McDonnell Douglas Corporation under the terms of contract NASI-13029. It is the final report on this program and covers the work that was completed between 28 February and 31 0ctober 1974. The program was sponsored by the National Astronautics and Space Administration's Langley Research Center, Hampton, Virginia. Dr.John G.Davis, Jr, was the technical monitor.

The following Douglas Aircraft Company personnel were the principal contributors to the program: Dr Steven Y.Elliott, technical director; T.W.Gladhill and E:R.Wogulis, specimen and component design; A.Cominsky, structural analysis; Dr T.L.Mackay, S.M.Weiman, R.W.Ross, R.L.Radecky, M.L.Marcoux, Materiais, QC, NDT, and testing; R.T.Hartunian, tooling and manufacturing.

All numerical values used in measurements and calculations in this report are expressed in International (SI) System of Units. Equivalent US Customary Units are given in parentheses following the SI values. 


\section{CONTENTS}

INTRODUCTION ANO SUMMARY

DESIGN STUDIES, MATERIALS, PROCESSING, AND FABRICATION 2

Design Criteria and Loads 3

Preliminary Design 4

Specimen Design 5

Specimen Fabrication 6

Definition of Manufacturing Procedures 8

COMPONENT DESIGN AND ANALYSIS

Component Design 8

Stress Analysis 9

DEMONSTRATION TESTS 14

Tension Tests 14

Compression Tests $\quad .20$

Rail Shear Tests $\cdot 23$

Interlaminar Shear Tests $\quad 25$

Bolt Bearing Tests $\quad \cdot 25$

Tension Fatigue Tests $\quad 28$

Summary of Demonstration Test Data . 30

COMPONENT FABRICATION 30

Fabrication Plan 30

$Q C$, and NDT 33

Composite Skin Fabrication and Installation 33

Cost Analysis 34

FLIGHT TESTS " $\quad 35$

Flight Service Demonstration Test $\quad \cdot 35$

Skin Inspection and NDT 35

Skin Replacement .35

Skin Shipment to NASA . . . . 35

CONCLUSIONS

REFERENCES . $\quad 37$

APPENDIX A - Material Procurement Diffusion Bonded Boron/
Aluminum Composite Sheets

APPENDIX B - DPS 3.67-67 Hole Preparation and Trimming of Boron/ APPENDIX C - Fabrication Plan for Boron/Aluminum Aft Pylon Skin.
AVB7097-30

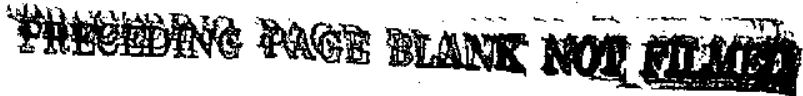




\section{TABLES}

PAGE

1. Aerodynamic Loads on the Aft-Engine-Pylon Trailing Edge 3

2. Qualification and Demonstration Tests

3. Results of Tension Tests at Room Temperature $505 \mathrm{~K}\left(450^{\circ} \mathrm{F}\right)$ and at Room Temperature after 1000 Hours Aging at $505 \mathrm{~K}$ $\left(450^{\circ} \mathrm{F}\right)$

4. Modulus of Elasticity and Strain at Failure from Tension Tests at Room Temperature and at Room Temperature after Aging 1000 Hours at $505 \mathrm{~K}\left(450^{\circ} \mathrm{F}\right)$

5. Results of Compression Tests at Room Temperature, Elevated Temperature, and at Room Temperature after 1000 Hours Aging at $505 \mathrm{~K}$ ( $\left(450^{\circ} \mathrm{F}\right)$

6. Modulus of Elasticity and Strain at Failure from Compression Tests at Room Temperature and at Room Temperature after Aging. 1000 Hours at $505 \mathrm{~K} \cdot\left(450^{\circ} \mathrm{F}\right)$

7. Results of Rail Shear Tests at Room Temperature, Elevated Temperature, and at Room Temperature after 1000 Hours Aging at $505 \mathrm{~K}\left(450^{\circ} \mathrm{F}\right)$

8. Results of Interlaminar Shear Tests at Room Temperature, $505 \mathrm{~K}\left(450^{\circ} \mathrm{F}\right)$, and at Room . Temperature after 1000 hours

\section{Aging at $505 \mathrm{~K}\left(450^{\circ} \mathrm{F}\right)$}

9. Results of Bolt Bearing Tests

10. Results of Fatigue Tests of $2.54 \mathrm{~cm}(1.00$. inch)Wide Tension Specimens with a $4.775 \mathrm{~mm}(0.188$ inch) Hole in the Center

11. Suggested Material Properties of Boron/Aluminum Composite with $90^{\circ}, 45^{\circ}, 90^{\circ}, 0^{\circ},-45^{\circ}, 0^{\circ},-45^{\circ}, 0^{\circ}, 90^{\circ}, 45^{\circ}, 90^{\circ}$ Filament Orientation

12. Material Properties of Boron/Aluminum Composite with $90^{\circ}, 45^{\circ}$, $90^{\circ}, 0^{\circ},-45^{\circ}, 0^{\circ},-45^{\circ}, 0^{\circ}, 90^{\circ}, 45^{\circ}, 90^{\circ}$ Filament Orientation with Commercialiy Pure Titanium 
FIGURES

PAGE

1. DC-10 Tail Pylon 39

2. DC-10 Typical Mission Profile 40

3. Estimated Aerodynamic Loads on Aft-Engine-Pylon Trailing Edge

4. Estimated Acoustic Loads for 3-Engine Ground Runup at Take-off Thrust using JT90-15 Engine (Aft Pylon Fairing) 42

5. Engine Fairing Temperature During Reverse Thrust 43

6. Specimen Assembly-Modified IITRI Tension Test 44

7. Specimen Assembly-Composite Honeycomb Sandwich Beam Test 45

8. Specimen Assembly-Composite Rail Shear Test 46

9. Specimen-Composite Interlaminar Shear Test 47

10. Composite Specimen-Bolt Bearing Test ... 48

11. Specimen-Composite Tensile Fatigue Test . 49

12. Cutting Boron/Aluminum with Diamond Coated Wheel 50

13. Hole Produced by $0.635 \mathrm{~cm}(0.250 \mathrm{in})$ Diameter Steel Drill 51

14. Hole Produced by $0.566 \mathrm{~cm}(0.223 \mathrm{in})$ Diameter Steel Punch ${ }^{-} 52$

15. Hole Produced by $0.566 \mathrm{~cm}(0.223 \mathrm{in})$ Diameter Steel Punch Followed by $0.579 \mathrm{~cm}(0.228 \mathrm{in})$. Diameter Steel Ream 53

16. Hole Produced by $0.635 \mathrm{~cm}(0.250 \mathrm{in})$ Diameter Steel Punch
Followed by $0.640 \mathrm{~cm}(0.252 \mathrm{in})$ Diameter Diamond Ream

17. Drawing AVB7129-Rework-Lower Fairing Skin, Tail Pylon 55

18. Specimen 11 - Room Temperature Tension Stress Strain Curve 56

19. Specimen 11 - (3rd Run Only) Room Temperature Tension Stress-Strain Curve. 57.

20. Specimen 12 - Room Temperature Tension Stress-Strain Curve 58

21. Specimen 13 - Room Temperature Tension Stress-Strain Curve 59

22. Specimen 14 - Room Temperature Tension Stress-Strain Curve ' 60

23. Specimen 15-Room Temperature Tension Stress-Strain Curve 61

24. Specimen 16 - Room Temperature Tension Stress-Strain Curve 62

25. Specimen 77 - Room Temperature Tension Stress-Strain Curve 63

26. Specimen 18 - Room. Temperature Tension Stress-Strain Curve 64

27. Specimen 19 - Room Temperature Tension Stress-Strain Curve 65

28. Specimen 20 - Room Temperature Tension Stress-Strain Curve 66

29. Specimen 21 - Room Temperature Tension Stress-Strain Curve after 1000 Hours Aging at $505 \mathrm{~K}\left(4.50^{\circ} \mathrm{F}\right)$

30. Specimen 22 - Room Temperature Tension Stress-Strain Curve after 1000 Hours Aging at $505 \mathrm{~K}\left(450^{\circ} \mathrm{F}\right)$

31. Specimen 23 - Room Temperature Tension Stress-Strain Curve after 1000 Hours Aging at $505 \mathrm{~K}\left(450^{\circ} \mathrm{F}\right)$

32. Specimen 24 - Room Temperature Tension Stress-Strain Curve after 1000 Hours Aging at $505 \mathrm{~K}\left(450^{\circ} \mathrm{F}\right)$

33. Specimen 25 - Room Temperature Tension Stress-Strain Curve after 1000 Hours Aging at $505 \mathrm{~K}\left(450^{\circ} \mathrm{F}\right)$

34. Specimen 26 - Room Temperature Tension Stress-Strain Curve after 1000 Hours Aging at $505 \mathrm{~K}\left(450^{\circ} \mathrm{F}\right)$

35. Specimen 27 - Room Temperature Tension Stress-Strain Curve after 1000 Hours Aging at $505 \mathrm{~K}\left(450^{\circ} \mathrm{F}\right)$

36. Specimen 28 - Room Temperature Tension Stress-Strain Curve after 1000 Hours Aging at $505 \mathrm{~K}\left(450^{\circ} \mathrm{F}\right)$ 
37. Specimen 29 - Room Temperature Tension Stress-Strain Curve after 1000 Hours Aging at $505 \mathrm{~K}\left(450^{\circ} \mathrm{F}\right)$

38. Specimen 30 - Room Temperature Tension Stress-Strain Curve

after 1000 Hours Aging at 505K (450. F)

39. Schematic of Typical Tension Stress-Strain Curve 77

40. Specimen 11 (Side \#1) Poisson's Ratio vs Tension Stress 78

41. Specimen 11 (Side \#2) Poisson's Ratio vs Tension Stress 79

42. Specimen 12 Poisson's Ratio vs Tension Stress

43. Specimen 13 Poisson's Ratio vs Tension Stress 81

44. Four-Point Bending Honeycomb Sandwich Compression Test 82

45. Specimen 11 Room Temperature Compression Stress-Strain curve

46. Specimen 12 Room Temperature Compression Stress-Strain Curve

47. Specimen 13 Room Temperature Compression Stress-Strain Curve

48. A Tested and An Untested Room Temperature Honeycomb Sandwich Compression Specimen

49. Specimen 14 Room Temperature Compression Stress-Strain Curve

50. Specimen 15 Room Temperature Compression Stress-Strain Curve

51. Specimen 16 Room Temperature Compression Stress-Strain Curve

52. Specimen 17 Room Temperature Compression Stress-Strain

53. Surve 18 Room Temperature Compression Stress-Strain Curve

54. Specimen 19 Room Temperature Compression Stress-Strain Curve.

55. Specimen 20 Room Temperature Compression Stress-Strain Curve

56. Compression Specimen Failure Surface

57. Specimen 21 Room Temperature Compression Stress-Strain Curve after 1000 Hours Aging at $505 \mathrm{~K}\left(450^{\circ} \mathrm{F}\right)$

58. Specimen 22 Room Temperature Compression Stress-Strain curve after 1000 Hours Aging at $505 \mathrm{~K}\left(450^{\circ} \mathrm{F}\right)$

59. Specimen 23 Room Temperature Compression Stress-Strain Curve after 1000 Hours Aging at $505 \mathrm{~K}\left(450^{\circ} \mathrm{F}\right)$

60. Specimen 24 Room Temperature Compression Stress-Strain curve after 1000 Hours Aging at $505 \mathrm{~K}\left(450^{\circ} \mathrm{F}\right)$.

67. Specimen 25 Room Temperature Compression Stress-Strain Curve after 1000 Hours Aging at $505 \mathrm{~K}\left(450^{\circ} \mathrm{F}\right)$

62. Specimen 26 Room Temperature Compression Stress-Strain

63. Specimen 27 Room Temperature Compression Stress-Strain Curve after 1000 Hours Aging at $505 \mathrm{~K}\left(450^{\circ} \mathrm{F}\right)$

64. Specimen 28 Room Temperature Compression Stress-Strain Curve after 1000 Hours Aging at $505 \mathrm{~K}\left(450^{\circ} \mathrm{F}\right)$

65. Specimen 29 Room Temperature Compression Stress-Strain Curve after 1000 Hours Aging at $505 \mathrm{~K}\left(450^{\circ} \mathrm{F}\right)$ 
66. Specimen 30 Room Temperature Compression Stress-Strain

Curve after 1000 Hours Aging at $505 \mathrm{~K}\left(450^{\circ} \mathrm{F}\right)$

104

67. Poisson's Ratio vs Compression Stress

68. Failed Rail Shear Specimens

106

69. Failed Rail Shear Specimen

107

70. Shear Specimen Failure Surface

71. Specimen 11 Room Temperature Rail Shear Stress-Strain Curve

72. Specimen 12 Room Temperature Rail Shear Stress-Strain Curve

73. Specimen 13 Room Temperature Rail Shear Stress-Strain Curve

74. Mode of Failure of Bolt Bearing Specimen

108

75. SEM Pictures of Bolt Bearing Specimen in the Vicinity of the Hi-Lok Bolt Head

109

110

17

112

113

76. Constant Load Tensile Fatigue $R=.1(0 / 45 / 0 / 90 /-45 / 90)_{S}$ Loaded in $0^{\circ}$ Direction $2.54 \mathrm{~cm}$ (in) Wide Specimen with a

77. Failed Fatigue Specimen

78. Fatigue Crack in Edge of Hole of Fatigue Specimen

79. SEM Pictures of Fatigue Specimen 2 Tested Staticaliy in Tension to Failure

80. SEM Pictures of Fatigue Specimen 3. ffailed on the $2,362,000$ th cycle of a Maximum Alternating Tensile Stress of $242.8 \mathrm{MPa}(35,222 \mathrm{psi})$

81. Fatigue Properties Comparison

82. Surface Blemishes on Second Boron/Aluminum Aft Pylon Skin 120

83. Boron/Aluminum Aft Pylon Skin-Edges and Corner Trimmed and Holes Punched

84. Punching Holes in Boron/Aluminum Skin

85. Installation of the Boron/Aluminum Skin Onto the Substructure

86. Installation of the Aluminum Upper Skins Onto the Substructure 
BORON/ALUMINUM SKINS

FOR THE DC-10 AFT PYLON

By S.Y.ELLIOTT

Douglas Aircraft Company

Long Beach, California 90846

\section{INTRODUCTION AND SUMMARY}

Structural applications of advanced metal matrix composites have received increasing attention during the past 10 years because of the excellent potential in weight savings and increased strength and stiffness at elevated temperatures. Most of these applications have been oriented toward military aircraft, jet engines, or space vehicles. A few of these applications have reached the flight test stage, but as yet no major structural component involving metal matrix composite has been exposed to the long-term continuous flight service operation that will be required for commercial aircraft.

An extended period of apprenticeship is highly desirable for every new structural material for proper assessment of its service performance. Because the utilization of commercial vehicles is consistently much greater than the military or space vehicles, it is possible to log considerably more flight hours on such a vehicle in a given time period. Introduction of advanced metal matrix filamentary composites into commercial aircraft would benefit military and space programs as we11, because the larger potential market would reduce the cost

of raw materials and the burden of other development and testing costs.

The selection of the DC-10 commercial aircraft was particularly appropriate as it is representative of the new generation of wide-bodied aircraft which will dominate the commercial scene for many years to come. The DC-10 is already in service with 22 airlines and its use will become even more widespread in the near future. Its immediate availability ensured a practical and realistic approach to the program.

This report describes a flight demonstration development proaram which will demonstrate the use of advanced metal matrix composite material. The program objectjue was to design, fabricate, and install boron/aluminum skins on three DC-10 aft pylon boat tail" assemblies for flight service evaluation (Figure 1). The flight service demonstration of the completed assemblies commenced with the establishment of United Air Lines interface and after FAA approval.

The design philosophy was to substitute a $1.56 \mathrm{~kg}(3.45 \mathrm{lb})$ boron/aluminum skin for a $2.111 \mathrm{~kg}(4.65 \mathrm{lb})$ titanium skin, using the existing titanium substructure with little alteration. Present state-of-the-art technology (emphasizing low cost) was used in the fabrication of the skins rather than new approaches. 
The existing internal riveted rib-type construction was used. This approach resulted in a component which was as simple to fabricate and assemble as the existing design.

After the program was started, a number of the DC-10 domestic carriers, including United Air Lines, eliminated the use of the thrust reversers on the \#2 engines during the landing operation. Elimination of this operation meant that the peak heating of the aft pylon boron/aluminum skin of up to $589 \mathrm{~K}\left(600^{\circ} \mathrm{F}\right)$ during each landing would not occur, so that part of the anticipated high temperature operating environment would be different from that originaliy anticipated.

The program consisted of a 6-month effort which involved the development of the design, materials, processing, fabrication, and quality control verification of three components, and static and fatigue tests of specimens. Flight service demonstration testing of the three completed assemblies for a period of five years is scheduled to start in July $1975^{\circ}$ and has involved securing FAA and commercial airline approval. A fourth boron/aluminum skin was fabricated and delivered to NASA Langley Research Center for storage and possible installation at a later date.

\section{DESIGN STUDIES, MATERIALS, PROCESSING, AND FABRICATION}

This section contains the design criteria, and external loads of the boron/ aluminum panel for the $D C-10$ tail pylon (Figure 1). Preliminary design studies of the panel are discussed and the design and fabrication of the supporting data specimens are described. The definition of manufacturing procedures for the specimens and the production panels concludes this task.

\section{Design Criteria and Loads}

The boron/aluminum panel for the $D C-10$ aft pylon is little more than a skin fairing to reduce turbulence and aerodynamic drag. Four types of loads affect the design of this panel, ie;

1. Aerodynamic loads act normal to the surface of the panel. Airplane yaw conditions are critical (Reference 1 ).

2. Acoustic loads are maximum for the 3-engine ground run up at takeoff thrust.

3. Temperature variations over the surface of the panel produce thermally induced stresses. Maximum temperatures occur during landing with thrust reverser operation (Figure 2). If the thrust reverser is not used during landing, the maximum temperature during landing and up to 15 minutes after landing is between 339 and $367 \mathrm{~K}\left(150\right.$ and $\left.200^{\circ} \mathrm{F}\right)$.

4. Inertia loads are induced in the panel by flutter or resonance during flight.

The panel itself is secondary structure and is considered failsafe as its loss will in no way reduce the controllability of the aircraft.

The aerodynamic loads on the aft-engine-pylon trailing edge of the DC- 10 for two design conditions are shown in Figure 3 (taken from Reference 1) and summarized in Table 1. 
TABLE T

AERODYNAMIC LOADS ON THE AFT-ENGINE-PYLON

TRAILING EDGE

\begin{tabular}{|c|c|c|c|c|c|c|c|c|}
\hline \multirow[t]{2}{*}{ CONDITION } & \multirow{2}{*}{$\begin{array}{l}\text { Mach } \\
\text { Number } \\
\text { M }\end{array}$} & \multicolumn{2}{|c|}{$\begin{array}{c}\text { Air Speed } \\
V \\
\end{array}$} & \multicolumn{2}{|c|}{$\begin{array}{c}\text { Dynamic } \\
\text { Pressure, } \\
\mathrm{q}\end{array}$} & \multirow{2}{*}{$\begin{array}{l}\text { Rudder } \\
\text { Angle } \\
\delta_{r}\end{array}$} & \multirow{2}{*}{$\begin{array}{c}\text { Fuselage } \\
\text { Angle of } \\
\text { Attack } \\
\alpha_{F}\end{array}$} & \multirow{2}{*}{$\begin{array}{c}\text { Fuse lage } \\
\text { Yaw } \\
\text { Angle } \\
\beta\end{array}$} \\
\hline & & KMEAS & KEAS & $K P A$ & PSF & & & \\
\hline $\begin{array}{l}\text { 1. Steady Side } \\
\text { Slip. Flap } \\
\text { Angle, } \delta_{F=25^{\circ}}\end{array}$ & 0.33 & 407.66 & 220 & 7.85 & 164 & $13.5^{\circ}$ & $2^{\circ}$ & $13^{\circ}$ \\
\hline $\begin{array}{l}\text { 2. Max Dynamic } \\
\text { Pressure, }, q \\
\text { where } q=v^{2} / 2\end{array}$ & 0.78 & 796.79 & 430 & 29.93 & 625 & $4^{\circ}$ & $0^{\circ}$ & $3.6^{\circ}$ \\
\hline
\end{tabular}

NOTE: KMEAS $=$ Kilometers per hour equivalent air speed

KEAS = Knots equivalent air speed

$\mathrm{KPA}=$ KiloPascals, or KiloNewtons per square meter

PSI = Pounds per square foot

The maximum $\beta q$ condition was also analyzed, but it resulted in less load than the maximum $q$ condition and is therefore not presented. The results for the lowspeed condition are presented to show the relative magnitude of loads between the low-speed and the high-speed conditions.

The load differential acting on the pylon may be applied to any thrust condition. (The load differential is considered independent of engine thrust level).

The aft-pylon load differentials are based on wind-tunnel test pressure data obtained on a $4.7 \%$ scale model DC-10 (LB-241C) in the North American Rockwe 11 $213.36 \times 335.28 \mathrm{~m}(7 \times 11$ foot) low-speed wing tunnel (NAL 574), and on a $3.25 \%$ scale model DC-10 (LB-244B) in the Cornel1 Aeronautical Laboratory high-speed wind tunnel. (CAL820-023).

The direction of loads is as viewed from the rear. Positive $\delta_{r}$ is trailing edge left and positive $\mathcal{B}$ is airplane nose left. The loads may be applied uniformly over the aft-engine-nacelle pylon from FS2340 aft. airloads.

Limit aerodynamic loads will be multiplied by 1.5 to obtain design ultimate

The acoustic loading in the center portion of the boron/aluminum panel is shown in Figure 4.

The variation in skin temperature during landing with reverse thrust is shown in Figure 5. After the program was started, a number of the $\mathrm{DC}-10$ domestic carriers, including United Air Lines, eliminated the use of the thrust reversers on the \#2 engines during the landing operation. Elimination of this operation meant that the peak heating of the aft pylon boron/aluminum skin of up to $589 \mathrm{~K}\left(600^{\circ} \mathrm{F}\right)$ during 
each landing would not occur, so that part of the anticipated high temperature operating environment would be different from that originally anticipated.

However, it has been determined that after each engine shutdown the rising hot air from the \#2 engine heats the aft pylon skin to a temperature of up to $367 \mathrm{~K}$ $\left(200^{\circ} \mathrm{F}\right)$ for a period of about 15 minutes. On a hot day it is estimated that the temperature from this engine shutdown condition may reach $395 \mathrm{~K}\left(250^{\circ} \mathrm{F}\right)$.

\section{Preliminary Design}

The design of the lower skin of the aft pylon was directed toward complete interchangeability with the present metal structure and toward certification as a structural component suitable for use on a commercial aircraft in regular passenger carrying operations. The internal reinforcing substructure was not to be changed and only the outer skin segment would be changed from the present titanium to aluminum matrix/boron filament composite material. Because the titanium skin is $2.032 \mathrm{~mm}(0.080 \mathrm{inch})$ thick, the number of boron filament layers was thereby established to be 11 (ie; 11 layers $\times 1.829 \mathrm{~mm} /$ layer $(0.0072 \mathrm{in} /$ layer) $=2.012 \mathrm{~mm}(0.0792$ in)). The boron filaments were $1.422 \mathrm{~mm}(0.0056 \mathrm{inch})$ in diameter and were required to meet the McDonnel1 Douglas specification (Reference 2). The aluminum matrix alloy was 6061 . The finished sheet was furnished in the as-fabricated condition and required to meet the specification listed in Appendix $A$.

The present $2.032 \mathrm{~mm}(0.080$ inch) annealed skin measures approximately $20.32 \mathrm{x}$ $170.18 \mathrm{~cm}(8 \times 67$ inches) as shown in Figure 1 and has a sight curvature. Approximately 50 percent of the area of this skin is now chemically milled to a $1.016 \mathrm{~mm}$ (0.04 inch) thickness leaving a scalloped doubler arrangement around its perimeter. For aerodynamic loading purposes, the $1.016 \mathrm{~mm}(0.040 \mathrm{inch})$ thickness would have been adequate, but the $2.032 \mathrm{~mm}(0.080$ inch) perimeter thickness had to be added to prevent edge cracking as a result of a flutter condition and to provide sufficient thickness for the countersunk heads of monel rivet fasteners. Because it was not the objective of this program to demonstrate maximum weight savings, and because a similar scalloping of the boron/aluminum skin would have increased its fabricating cost substantially, it was left as a solid $2.032 \mathrm{~mm}(0.080$ inch) thick skin. Nevertheless, because of its lower density, its total weight was $26 \%$ less than the chemically milled titanium skin. It was proposed that a rectangular boron/aluminum skin slightly larger than $20.32 \times 170.18 \mathrm{~cm}(8 \times 67$ inches $)$ would be fabricated by a selected manufacturer and then machined to exact size.

The present mechanical fasteners include 33 titanium screws $4.762 \mathrm{~mm}(3 / 16$ inch diameter) flush tri-wing head along the top surface and 77 monel rivets 3.175 , 3.972 , and $4.762 \mathrm{~mm}(1 / 8,5 / 32$, and $3 / 16$ inch) flush head along the bottom and sides. The heads of these fasteners are countersunk for reduction of aerodynamic drag. Because drilling and countersinking holes in boron/aluminum is difficult and expensive, it was determined to eliminate the countersinks in the boron/aluminum by adding a thin external titanium strip along the bottom of the panel to contain the required countersinks and by using protruding fasteners with low head profiles across the top and down the sides. Preliminary riveting tests of drilled boron/ aluminum strips revealed that the diametral growth of the required rivets when they were impacted was sufficient to split the composite. For this reason, rivets were completely eliminated and removable Hi-Lok screw fasteners were substituted. These threaded type mechanical fasteners have the additional advantage that when the boron/aluminum skins are replaced by the standard titanium skins after the 5year flight service program, installation will be facilitated by elimination of drilling out monel rivets. 
In another set of preliminary tests, it was determined that the fastener pull-out strength of boron/aluminum composite formed from $0^{\circ}-90^{\circ}$ oriented plies alone might be marginal for the application and, of course, much less than the similar fastener strength of titanium sheet. The three potential methods of increasing this property in boron/aluminum composite are: incorporating layers of thin titanium foils among the $0^{\circ}-90^{\circ}$ plies, incorporating layers of thin stainless steel woven screens, and incorporating $+45^{\circ}$ plies of boron filament layers among the $0^{\circ}-90^{\circ} \mathrm{plies.}$. As a result of some preliminary laboratory tests it was determined that the third method was the most suitable and required no new fabricating developments or risks.

With the number of plies established at 11 and with the filament orientations established as $0^{\circ}, 90^{\circ},+45^{\circ}$, the only remaining requirement was to select an orientation arrangement tha $\bar{t}$ was symmetrical about the neutral axis and which did not place two identically oriented layers together. This latter requirement was considered to be important from the standpoint of preventing fiber nesting and hence, permitting aluminum matrix squeeze out and possibly leading to undesirable fiber contact. The final fiber orientation selected as a result of the preliminary design effort therefore was:

$$
90^{\circ}, 45^{\circ}, 90^{\circ}, 0^{\circ},-45^{\circ}, 0^{\circ},-45^{\circ}, 0^{\circ}, 90^{\circ}, 45^{\circ}, 90^{\circ}
$$

where the $0^{\circ}$ direction was the long direction of the skin. The four $90^{\circ} \mathrm{plies}$ at the outside of this composite arrangement insured that the skin would have greater bending strength across the short direction of the pressure loaded plate and the remaining $0^{\circ}$ and $+45^{\circ}$ layers were primarily needed to insure adequate fastener pull-out strengt $\bar{h}$ in all directions.

\section{Specimen Design}

The demonstration test specimens, consisting of tension, compression, rail shear, interlaminar shear, bolt shear, and tensile fatigue specimens, were designed to help demonstrate the suitability of the boron/aluminum skin for its application to the DC-10 aft pylon.

1. The tension specimen (Z4941424), a modified IITRI design shown in Figure 6, used (as did all of the test specimens) a ply layup and thickness identical to the boron/aluminum aft pylon skin. Fiberglass phenolic was used for the tabs because it had good matching of thermal coefficients with boron/aluminum which assured a strain-free bond and a low modulus which reduced the tendency of the tabs to create a stress concentration in the grip area. Scarfing the tabs reduced peel stresses at the tip of the tab. The room temperature specimens were bonded with Hysol EA951, a "ductile" adhesive which allowed a more even distribution of shear stress in the bond than that of a. "brittle" adhesive. Because ductile adhesives lose strength radically at temperatures above $367 \mathrm{~K}\left(200^{\circ} \mathrm{F}\right)$, a high temperature adhesive, HT424, was chosen for the $505 \mathrm{~K}\left(450^{\circ} \mathrm{F}\right)$ tests.

2. The honeycomb sandwich beam type of compression test (Figure 7) was chosen because it provided support for the specimen in compression and therefore helped insure a compression failure only instead of the buckling or brooming failure more likely to be encountered in an edge- 
loaded compression test. The specimen had two different core types. The outer core was dense to support the high shear loads introduced by the four point loading, whereas the inner core which experienced no shear was lighter to lessen the interaction between the core and the boron/aluminum in the test region. The tension side of the beam was a steel sheet which minimized beam deflections when a high compressive load was developed in the boron/aluminum. The room temperature specimens were bonded with Metlbond 329 because the shear stresses in the bond line were already uniform so the ductility of Hysol EA951 was unnecessary. HT424 was used to bond the high temperature test specimens.

3. The rail shear specimen (Figure 8) was chosen for obtaining shear data because it used standard $2.032 \mathrm{~mm}(0.080$ inch) flat boron/ aluminum sheet and produced relatively pure shear in the test section. The rails were tapered to provide uniform shear introduction into the specimen and were bonded to the boron/aluminum with Hysol EA951 for the room temperature tests and with $\mathrm{HT} 424$ for the $505 \mathrm{~K}\left(450^{\circ} \mathrm{F}\right)$ tests.

4. The length of the interlaminar shear specimen (Figure 9) was chosen to accommodate a $8.128 \mathrm{~mm}(0.32$ inch) test span (determined from a span-to-depth ratio of 4 as specified in ASTM (D2344-72) for specimens with filament moduli greater than $31.05 \mathrm{kPa}\left(4.5 \times 10^{6} \mathrm{psi}\right)$ with an overhang of $5.08 \mathrm{~mm}(0.2$ inch) on both ends of the span.

5. The bolt shear specimen (Figure 10) was designed to simulate the aft pylon where the boron/aluminum skin is fastened to $1.016 \mathrm{~mm}$ (0.040 inch) thick titanium ribs by bolts--principally of 3.969 and $4.762 \mathrm{~mm}(5 / 32$ and $3 / 16$ inch) diameters. The specimen made optimum use of the boron/aluminum test strip, testing it twice. First the specimen was pulled by both titanium strips until one joint failed, then the remaining joint was tested by gripping the failed end of the boron/ aluminum. Thus, two data points were obtained from one specimen.

6. A center hole tensile fatigue specimen (Figure 11) was chosen . to enable comparison of its fatigue data with similar existing data for titanium. Holes were punched into the specimens to study their effect on the strength and fatigue iife of the laminate. This was of interest because the boron/aluminum aft pylon skin had many fastener holes and was in a fatigue environment. Steel tabs were chosen for strength. The hole through the steel tabs accommodated a pin which transferred the fatigue loading from the testing machine to the specimen. Hysol EA951 was used so that the shear in the bond would be distributed more evenly.

\section{Specimen Fabrication}

The selection of a fabricator for the boron/aluminum composite panels for the specimens and skins was based on considerations of quality, capability, cost, and confidence. The company selected was Hamilton Standard of Windsor Locks, Connecticut, who are represented on the West coast by DWA (Dolowy Webb Associates) Composite Specialties, Inc. The purchase of all material for the specimen test program was based on a material procurement specification reproduced in Appendix $A$. The quality of the panels fabricated and received was determined by means of tensile 
tests of specimens cut from the edges of each panel in both the $0^{\circ}$ and $90^{\circ}$ directions and by $X-r a y$ and $C-s c a n$ type NDT inspections. A1l materials used for test specimens complied with the requirements of Appendix $A$.

When a new material is proposed for use on a commercial transport, FAA certification must be secured even though the material is only intended for a temporary flight test. Receipt of such certification involves the following steps:

1. A report is submitted to the local FAA office summarizing the steps which will be followed in securing FAA certification of the flight test. It contains a specimen test plan.

2. A material specification document is prepared and submitted to the FAA which is used to control the quality of the incoming materials.

3. Drawings of the qualification specimens which will be used to generate the required design data are prepared and submitted to the FAA.

4. A Testing and Development document is prepared by the Structural Design - Engineering department and submitted to the Testing department authorizing the preparation of specimens and the conduction of the design data tests in accordance with the test plan.

5. The Testing department prepares a Development Release Order authorizing the Planning department to prepare the necessary planning papers.

6. The Planning department prepares a series of Fabricating Orders for each of the types of specimens describing in detail the sequential operations to be performed by each department in their preparation and testing.

7. As the specimens are fabricated, inspection reports guaranteeing that the specimens comply with the drawings and the Fabrication orders are signed and submitted to the FAA.

8. As the specimens are tested, FAA inspectors and approved witnesses check the test machines, jigs, and procedures. Copies of all raw test data generated are submitted to the FAA.

9. When all the tests are completed, a report summarizing the results and analyzing their significance in the establishment of the adequacy of the material is prepared and submitted to the FAA.

Specimen fabrication primarily involved cutting the large panels into the proper sized rectangular strips using a rotating diamond coated whee1, Figure 12, punching holes as required into the composite with a hand operated punch tool, bonding reinforcing tabs or honeycomb cores with selected adhesives as described in the specimen drawings, and finally bonding strain gages to the surfaces of the test specimens as required. Each of these operations was performed in accordance with written procedural directions. No unsolvable problems were encountered and all specimens were eventually successfully completed and approved for testing. 


\section{Definition of Manufacturing Procedures}

A specification describing the cutting of boron/aluminum and the preparation of holes was written, approved, and published. Its title is DPS 3.67-67, Hole Preparation and Trimming of Boron/Aluminum, and a copy is included in Appendix $B$. Preliminary tests determined that the most suitable hole preparation method was punching followed by sufficient reaming to enlarge the holes to the exact desired size, if necessary. Figures 13 through 16, for example, show enlargements of four holes through boron/aluminum skins produced by four different techniques, ie;

Figure 13 - Hole produced by $0.635 \mathrm{~cm}(0.250 \mathrm{inch})$ diameter steel dril1 Figure 14 - Hole produced by $0.566 \mathrm{~cm}(0.223$ inch) diameter steel punch Figure 15 - Hole produced by $0.566 \mathrm{~cm}(0.223$ inch) diameter steel punch followed by $0.579 \mathrm{~cm}(0.228 \mathrm{inch})$ diameter steel ream

Figure 16 - Hole produced by $0.635 \mathrm{~cm}(0.250$ inch) diameter steel punch followed by $0.640 \mathrm{~cm}(0.252$ inch) diameter diamond ream

Of these four techniques, the first involving the steel drill alone showed unacceptable edge roughness, but the other three techniques all produced approximately similar quality holes. It was concluded, therefore, that since punching alone was the least expensive, it would be the preferred method and that additional reaming with either steel or diamond coated reamers would be performed, if needed, to enlarge the holes to the exact desired size.

It was also determined by laboratory testing that the boron fibers in boron/ aluminum are attacked by the standard anodizing process that is usually employed to provide corrosion protection to aluminum in exterior structural applications. For this application, therefore, the alodine (chromate conversion) process, which does not attack boron fibers was selected as the boron/aluminum surface treatment. In addition, the inner surface of the skin would have to be epoxy primed and all mechanical fasteners installed with wet sealant.

\section{COMPONENT DESIGN AND ANALYSIS}

This section contains a description of the component design and a stress analysis of the boron/aluminum skin. The result of the design effort was a complete engineering working drawing which replaced the present drawing of the titanium counterpart. The stress analys is followed from the Design Criteria and Loads and was also furnished to the FAA for their certification.

\section{Component Design}

The boron/aluminum skin panel was designed to fulfill the same requirements as its titanium counterpart. It had the same external dimensions, including the same hole spacings and edge distances, differing only in that the boron/aluminum was not chemically milled. The $2.032 \mathrm{~mm}(0.080$ inch) thick annealed titanium sheet was chemically milled to $i .016 \mathrm{~mm}$ (0.040 inch) over $50 \%$ of its area, leaving the effect of a scalloped doubler around its perimeter. The weight of the chemically milled titanium sheet was $2.111 \mathrm{Kg}$ ( 4.65 pounds), ie; $0.545 \mathrm{Kg}$ (1.20 pounds) more than the boron/aluminum skin, $1.566 \mathrm{~kg}$ (3.45 pounds), even though the boron/aluminum skin occupied a larger, unmilled volume. Hence the weight saving provided in the substitution of the boron/aluminum skin for the titanium skin was $26 \%$. The Rework Drawing (Dwg AVB7129) showing the installation of the boron/aTuminum skin is shown in Figure 17. 
The titanium skin was fastened to the pylon by a variety of fasteners, including bucked, flush-head rivets and flush-head bolts. It was undesirable to use bucked rivets in the boron/aluminum design because they expand and strain their holes, and promote crack formation in the boron/aluminum.

Flush-head fasteners were undesirable because their bearing area for bolt shear is less than that available from protruding head fasteners. Where flushhead bolts were used across the top of the titanium skin, pan-head bolts were substituted. Where flush, bucked rivets were used along the forward and aft edges of the titanium skin, protruding head, clearance fit Hi-Loks were substituted. Where flush, bucked rivets held the titanium skin to the rib beneath the seal, flush Hi-Loks, sunk into a titanium strip were substituted. The flush-head bolts attaching the seal retainers remained unchanged because they were countersunk into the retainers only. The result of these fastener substitutions was to eliminate countersinks in the boron/aluminum and bucked rivets from the design.

The selected orientation of plies in the boron/aluminum skin was $\left(90^{\circ}, 45^{\circ}\right.$, $90^{\circ}, 0^{\circ},-45^{\circ}, 0^{\circ}, 45^{\circ}, 0^{\circ}, 90^{\circ}, 45^{\circ}, 90^{\circ}$ ). The four plies in the $90^{\circ}$ direction provided strength across the width of the skin panel and the $\pm 45^{\circ}$ plies provided a higher bolt shear strength. The total number of plies (11) was dictated by the thickness of the titanium panel $2.032 \mathrm{~mm}(0.080 \mathrm{inch})$ which was replaced since it was. necessary that the boron/aluminum panel be flush with the surrounding structure.

The processing specification (DPS 3.67-67) referenced on the drawing described the cutting and hole fabrication processes for the boron/aluminum skin and is the same as Appendix $B$ of this report.

\section{Stress Analys is}

The boron/aluminum composite panel was analyzed as a flat panel, acted upon by normal air pressure. The critical loads for the aft-engine-pylon trailing edge of the DC-10 occur for a maximum dynamic pressure, $q$, yaw condition designated as design condition number 2 in Figure 3 . The question of satisfactory strength for acoustic loads and adequacy. for flutter or resonance during flight was approached by determining that the boron/aluminum panel was stiffer than the original titanium panel (which has demonstrated satisfactory service for these considerations).

According to the lowest curve shown on the critical design condition 2 of Figure 3 (ie; Pylon Left Side corresponding to Fuselage Station 2363), the maxis. mum limit air pressure is $3.59 \mathrm{kPa}$ (10.52 $\mathrm{psi})$. Hence, the maximum ultimate air pressure is $1.5 \times 3.59=5.38 \mathrm{kPa}(1.5 \times 0.52=0.78 \mathrm{psi})$.

Although the left skin shown in Figure 1 was not rectangular, its average dimensions were approximated by a $147.32 \times 20.32 \mathrm{~cm}$ (58 x 8 inch) rectangular plate with a thickness of $2.032 \mathrm{~mm}(0.080 \mathrm{inch})$. Assuming a11 edges simply supported the formula for the maximum bending stress in the center of a rectangular plate subjected to a normal pressure is taken from page 203 of Reference 3 for bending around the horizontal axis.

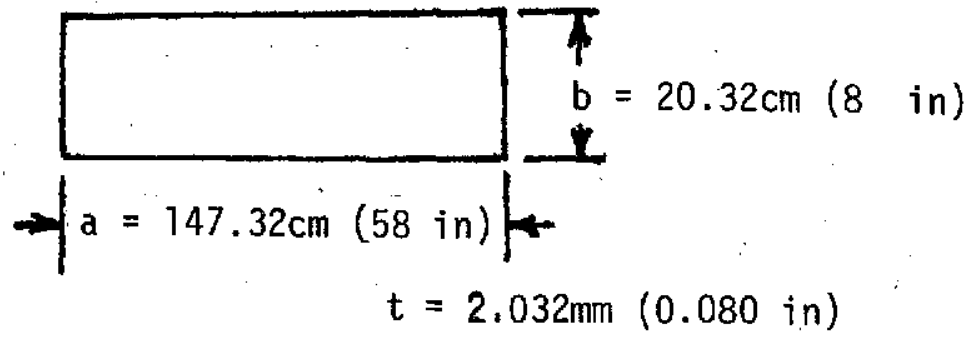




$$
S_{b}=\frac{0.75 w^{2}}{t^{2}\left(1+1.61 \alpha^{3}\right)}
$$

where $w=$ normal pressure, $\mathrm{Pa}$ (psi)

$b=$ shorter dimension, $\mathrm{cm}$ (in)

$\mathrm{a}=$ longer dimension, $\mathrm{cm}$ (in)

$\alpha=b / a=20.32 / 147.32=(8 / 58)=0.138$

Substituting appropriate values:

$$
S_{b}=\frac{0.75 \times 5.378 \times(20.32)^{2}}{(0.2032)^{2}\left[1+1.61(0.138)^{3}\right]}=40.17 \mathrm{MPa} \quad(5825 \mathrm{psi})
$$

From Reference 4 the formula for bending around the vertical axis is:

$$
\begin{aligned}
S_{a} & =\frac{w b^{2}\left(0.225+0.382 \alpha^{2}-0.320 \alpha^{3}\right)}{t^{2}} \\
& =\frac{5.378(20.32)^{2}\left(0.225+0.382(0.138)^{2}-0.320(0.138)^{3}\right)}{(0.2032)^{2}} \\
& =12.45 \mathrm{MPa} \quad(1805 \text { psi })
\end{aligned}
$$

The other critical static stress condition checked was the magnitude of the skin stress in the vicinity of the mechanical fasteners. For this case the maximum bending stress at the center of the long edge of a rectangular plate with fixed edges and subjected to a normal air pressure is given by the following formula on page 205 of Reference 3 :

$$
\begin{aligned}
s_{b} & =\frac{0.5 w b^{2}}{t^{2}\left(1+0.623 \alpha^{6}\right)} \\
& =\frac{0.5(5.378)(20.32)^{2}}{(0.2032)^{2}\left(1+0.623(0.138)^{6}\right)}=26.89 \mathrm{MPa} \quad(3900 \text { psi) }
\end{aligned}
$$

This is the stress that would exist if there were no fastener holes at the edge of the plate, but since there are $6.35 \mathrm{~mm}(1 / 4 \mathrm{inch})$ diameter attachment holes at a pitch of $2.54 \mathrm{~cm}$ (1 inch), the net bending stress is:

$$
S_{b}=26,890 \times \frac{2.54}{2.54-0.635}=35.85 \mathrm{MPa} \quad(5200 \mathrm{psi})
$$

Assuming a stress concentration factor for the hole of 3.0 , the design stress was: Design $S_{b}=3.0 \times 35,850=107.55 \mathrm{MPa}(15,600 \mathrm{psi})$ 
The stiffness of the boron/aluminum skin is calculated as follows:
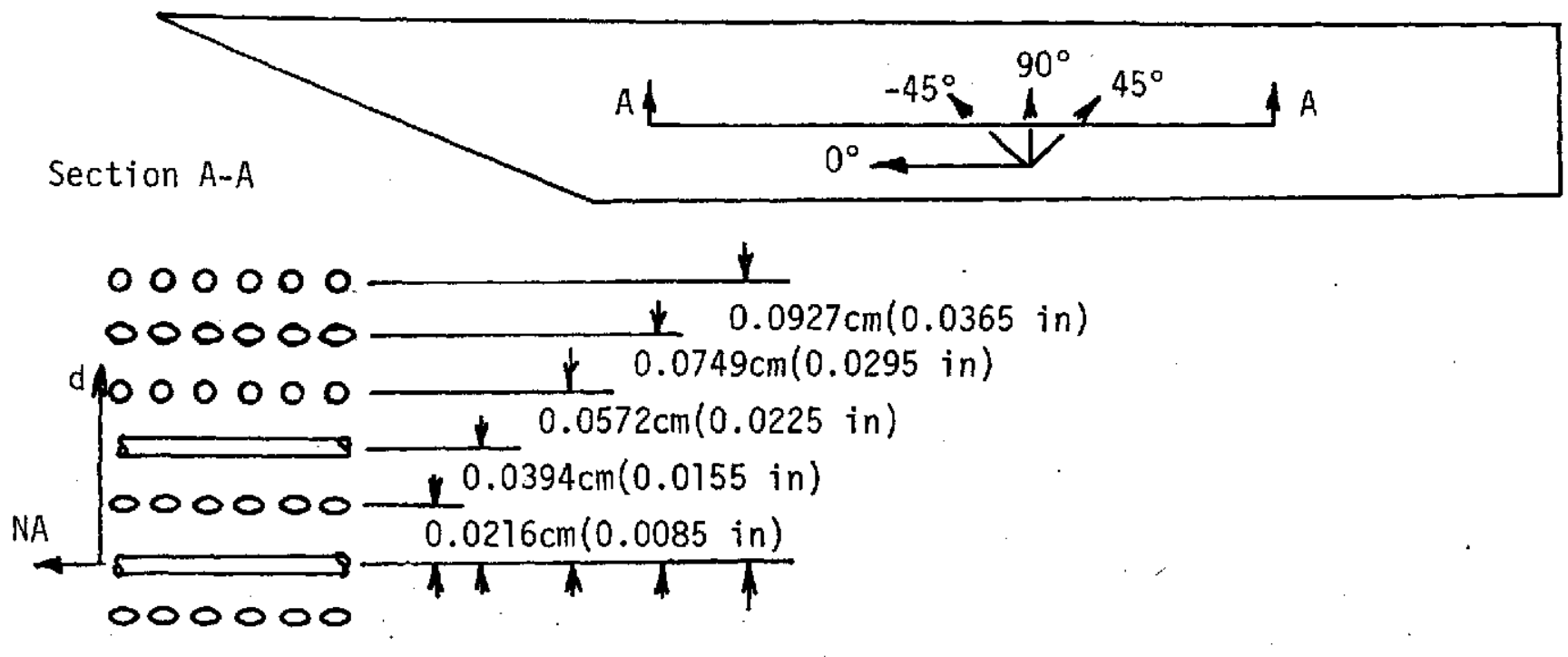

000000

000000

000000

\begin{tabular}{|c|c|c|c|c|c|c|}
\hline \multirow{2}{*}{$\begin{array}{l}\text { PLY } \\
\text { ORIENTA- } \\
\text { TION }\end{array}$} & \multicolumn{2}{|c|}{$E$} & \multicolumn{2}{|c|}{ d } & \multicolumn{2}{|c|}{$E d^{2}$} \\
\hline & $\mathrm{GPa}$ & PSI & $\mathrm{cm}$ & in. & GN & $7 \mathrm{~b}$ \\
\hline $90^{\circ}$ & 221 & $32 \times 10^{6}$ & 0.0927 & 0.0365 & 1.896 & 42,600 \\
\hline $45^{\circ}$ & 124 & 18.0 & 0.0749 & 0.0295 & 0.696 & 15,700 \\
\hline $90^{\circ}$ & 221 & 32 & 0.0572 & 0.0225 & 0.722 & 16,200 \\
\hline $0^{\circ}$ & 135 & 19.5 & 0.0394 & 0.0155 & 0.209 & 4,690 \\
\hline$-45^{\circ}$ & 124 & 18.0 & 0.0216 & 0.0085 & 0.058 & 1,300 \\
\hline $0^{\circ}$ & 135 & 19.5 & 0 & 0 & 0 & 0 \\
\hline$-45^{\circ}$ & 124 & 18.0 & -0.0216 & -0.0085 & 0.058 & 1,300 \\
\hline $0^{\circ}$ & 135 & 19.5 & -0.0394 & -0.0155 & 0.209 & 4,690 \\
\hline $90^{\circ}$ & 221 & 32 & -0.0572 & -0.0225 & 0.722 & 16,200 \\
\hline $45^{\circ}$ & 124 & 18 & -0.0749 & -0.0295 & 0.696 & 15,700 \\
\hline $90^{\circ}$ & 221 & 32 & -0.0927 & -0.0365 & 1.896 & 42,600 \\
\hline & & & & $\Sigma$ & 7.162 & 160,980 \\
\hline
\end{tabular}

Panel thickness $=0.2032 \mathrm{~cm}(0.080 \mathrm{in})$

Thickness per ply, $t=0.2032 \div 11=0.0185 \mathrm{~cm}(0.0073 \mathrm{in})$ Weight, $W_{B / A}=\rho \mathrm{t}=2.72 \mathrm{gr} / \mathrm{cm}^{3}(0.2032 \mathrm{~cm})=0.553 \mathrm{gr} / \mathrm{cm}^{2}\left(0.00785 \mathrm{lb} / \mathrm{in}^{2}\right)$ Stiffness of boron/aluminum skin, $(E I)_{B / A}=t \sum\left(E d^{2}\right)=0.0185(7.162)$ $=0.001323 \mathrm{GNm}(1171 \mathrm{lb}$ in $)$ 
According to Appendix $A$ the target ultimate tensile strength of the boron/aluminum composite skin in the $90^{\circ}$ orientation is $503.3 \mathrm{MPa}(73,000 \mathrm{psi})$. Assuming a conservative $413,700 \mathrm{MPa}(60,000 \mathrm{psi})$ value for design purposes, the margin of safety is:

$$
M S=\frac{F_{t u}}{S_{b}}-1=\frac{413.7}{107.6}-1=2.85
$$

which is, of course, very adequate.

The adequacy of the boron/aluminum composite skin design for the flutter condition was determined by comparing its stiffness with that of the present chemicaliy milled titanium skin shown below:

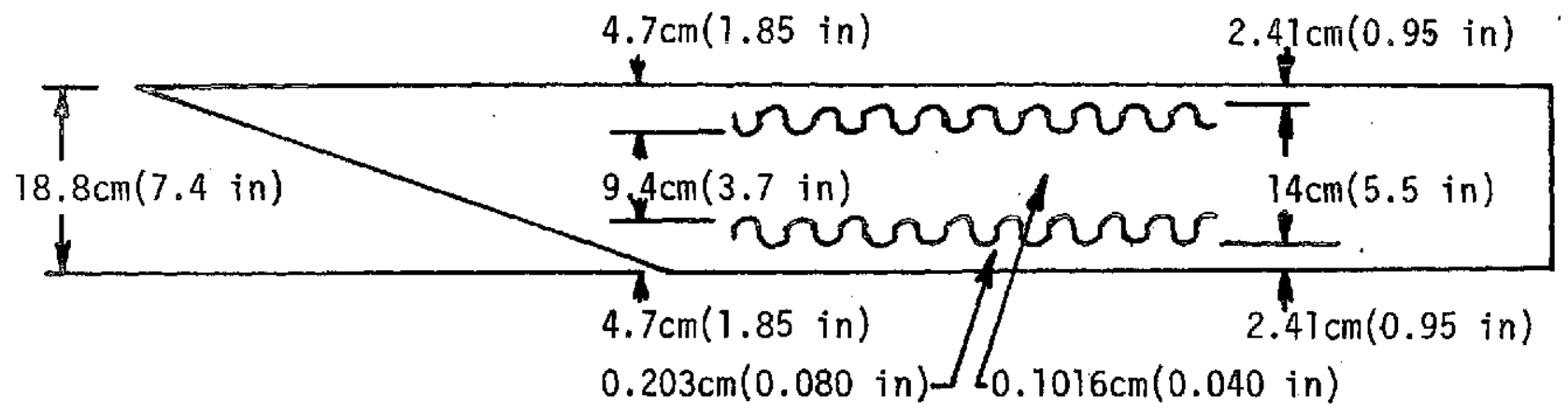

Average thickness, $t=\frac{1}{18.8}[18.8 \times 0.1016+2 \times 2.41 \times 0.1016+(4.7-2.41) 0.1016]$

$$
\begin{aligned}
& =\frac{1}{18.8}[1.91+0.49+0.23] \\
& =0.14 \mathrm{~cm}(0.0551 \text { inch })
\end{aligned}
$$

Weight, $w_{T}=\rho \mathrm{t}=4.53 \mathrm{gr} / \mathrm{cm}^{3} \times 0.14 \mathrm{~cm}=0.634 \mathrm{gr} / \mathrm{cm}^{2}\left(0.0091 \mathrm{~b} / \mathrm{in}^{2}\right)$

Modulus of elasticity for titanium, $E_{T}=110.3 \mathrm{GPa}\left(16 \times 10^{6} \mathrm{psi}\right)$

Moment of Inertia, $I_{T}=\frac{1}{12}(t)^{3}=\frac{(0.14)^{3}}{12}=2.286 \times 10^{-4} \mathrm{~cm}^{4} / \mathrm{cm}\left(13.95 \times 10^{-6} \mathrm{in}^{4} / \mathrm{in}\right)$

Stiffness of titanium skin $(E I)_{T}=110.3 \mathrm{GPa} \times 2.286 \times 10^{-4} \mathrm{~cm}^{3}$

$=0.000252 \mathrm{GNm}(223.5 \mathrm{lb}$ in $)$

The formula for natural frequency of a beam on two supports is given on page 379 of Reference 4 as:

$$
f_{i}=k \sqrt{\frac{g E I}{w L^{4}}}
$$


where $K=$ Constant

$$
\begin{aligned}
& \mathrm{g}=980 \mathrm{~cm} / \mathrm{sec}^{2}\left(386 \mathrm{in} / \mathrm{sec}^{2}\right) \\
& E=\text { Young's modulus, } \mathrm{Pa} \quad \text { (psi) } \\
& I=\text { Moment of Inertia, } \mathrm{cm}^{4}\left(\mathrm{in}^{4}\right) \\
& W=\text { Weight of a Unit Length of Beam, } \mathrm{Kg} / \mathrm{in}(1 \mathrm{~b} / \mathrm{in}) \\
& \mathrm{L}=\text { Beam Length, } \mathrm{cm} \text { (in) }
\end{aligned}
$$

For equivalent resistance to acoustic fatigue or panel flutter, the boron/ aluminum panel should have an equal or greater natural frequency than the original titanium panel.

$$
\begin{aligned}
f_{i} \text { (titanium) } & =f_{i} \text { (boron/aluminum) } \\
K \sqrt{\frac{g E_{T}^{I_{T}}}{W_{T} L_{T}^{4}}} & =K \sqrt{\frac{g E_{B-A} I_{B-A}}{W_{B-A} L_{B}^{4}-A}} \\
\frac{E_{T} I_{T}}{W_{T} L_{T}^{4}} & =\frac{E_{B-A} I_{B-A}}{W_{B-A} L_{B-A}^{4}} .
\end{aligned}
$$

minimum required stiffness of boron/aluminum skin is:

$$
\begin{aligned}
\min \text { reqd }(E I)_{B-A} & =\frac{W_{B}-A}{W_{T}} \cdot \frac{L_{B}^{4}-A}{L_{T}^{4}} \cdot(E I)_{T} \\
& =\frac{0.553}{0.634} \times\left(\frac{18.8}{18.8}\right)^{4} \times 0.000252 \\
& =0.000220 \mathrm{GNm}(195 \mathrm{lb} \text { in })
\end{aligned}
$$

Since the calculated actual stiffness of the boron/aluminum skin is

$$
\text { actual }(E I)_{B-A}=0.001323 \mathrm{GNm}(1171 \mathrm{lb} \text { in) }
$$

the stiffness of boron/aluminum is approximately six times greater than required and hence, acoustic fatigue and/or panel flutter will not be a problem. 


\section{DEMONSTRATION TESTS}

The demonstration of the suitability of the boron/aluminum composite skin for the aft-pylon application relied primarily on specimen testing combined with the stress analysis. The specific types and numbers of tests and specimens are summarized in Table 2. These tests primarily involved tension, rail shear, interlaminar shear, and bolt bearing tests of specimens under varjous environments. In addition to these static type tests, dynamic tests were also conducted to determine tension fatigue properties of boron/aluminum composite specimens containing center holes. Metallographic and scanning electron microscope tests were made on selected failed specimens to study their mode of failure. Alt details describing the proposed tests were first summarized in a TEST PLAN, Reference 5 , which was furnished to the FAA. The results of the tests were used to establish the initial stress levels and also to establish the strength requirements for the material specification.

\section{Tension Tests}

The calculated tensile strengths of all tension specimens tested are summarized in Table 3 . The $2.54 \mathrm{~cm}$ (1-inch) wide by $25.4 \mathrm{~cm}(10$-inch) 1ong parallel edge composite strips had al1 been reinforced at the ends by bonded $1.524 \mathrm{~mm}(0.06$ inch) thick and $7.62 \mathrm{~cm}$ ( 3 -inch) long fiberalass end tabs with a $2.54 \mathrm{~cm}$ (1 inch) scarfed edge adjoining the test section. This method of protection from grip damage is quice satisfactory because in all but four tests the failures were well within the $10.16 \mathrm{~cm}$ (4 inch) gage length section. Even in those four specimens where the failures were at, or near, the edge the calculated values were quite high. Comparing the average room temperature tensile strength of $565 \mathrm{MPa}(81,930 \mathrm{psi})$ with the $555 \mathrm{MPa}(80,562 \mathrm{psi})$ average obtained at room temperature after 1000 hours aging at $505 \mathrm{~K}\left(450^{\circ} \mathrm{F}\right)$ and the $602 \mathrm{MPa} \cdot(87,300 \mathrm{psi})$ average obtained at $505 \mathrm{~K}$ $\left(450^{\circ} \mathrm{F}\right)$, it is seen that not only is very little strength lost by this material from long term aging at $505 \mathrm{~K}\left(450^{\circ} \mathrm{F}\right)$; but it even becomes stronger when heated briefly at $505 \mathrm{~K}\left(450^{\circ} \mathrm{F}\right)$ and then tested. The significance of this observation coupled with the test results of the interlaminar shear specimens is that although the aluminum matrix is softened and slightly weakened by $505 \mathrm{~K}\left(450^{\circ} \mathrm{F}\right)$ temperature, it is still adequately strong to maintain laminate continuity and enable the unaffected boron filaments to predominately support tensile loads. Indeed, the increased ductility (and hence toughness) : of the aluminum at $505 \mathrm{~K}$ $\left(450^{\circ} \mathrm{F}\right)$ may even be beneficial in reducing local stress concentrations or residual stresses and thereby lead to some tensile strength improvement at moderately elevated temperatures.

Stress-strain curves of tension specimens tested at room temperature are shown in Figures 18 through 28 . Figures 18 through 21 were plotted with strain data obtained from strain gages, whereas Figures 23 through 28 were obtained using an extensometer. As a check on the uniformity of loading by the tension grips, the first strain gaged specimen had longitudinal strain gages on opposite faces. Figure 19 indicated that both gages gave nearly identical readings which demonstrated that the specimens were being loaded axially. In addition, to obtain Poisson's ratio, the first three specimens had transverse strain gages as well as longitudinal gages. Because extensometers are too delicate to survive the shock, they must be removed prior to failure of the specimen so the final portion of the stress-strain history is not measured. The dotted portions of the stress-strain curves of Figures 22 through 28 , therefore indicate they have been obtained by extrapolation. 
TABLE 2

QUALIFICATION AND DEMONSTRATION TESTS

\begin{tabular}{|c|c|c|c|}
\hline TYPE OF TEST & $\begin{array}{l}\text { TEST } \\
\text { TEMP } \\
(\mathrm{K}) \\
\end{array}$ & $\begin{array}{c}\text { No. OF } \\
\text { SPECIMENS }\end{array}$ & MEASURED DATA \\
\hline TENSION $\mathrm{in})$ & $\begin{array}{l}\text { RT } \\
505 \\
\text { RT after } \\
1000 \mathrm{hrs} \\
\text { at } 505\end{array}$ & $\begin{array}{l}10 \\
10 \\
10\end{array}$ & $\begin{array}{l}F_{t u}, E_{t}, v, \epsilon_{x} \\
F_{t u} \\
F_{t u}\end{array}$ \\
\hline $\begin{array}{l}\text { COMPRESSION } \\
2.54 \mathrm{~cm}(1 \mathrm{in})=55.88 \mathrm{~cm}(22 \mathrm{in})=1\end{array}$ & $\begin{array}{l}\quad \text { RT } \\
420 \& \\
505 \\
\text { RT after } \\
1000 \text { hrs } \\
\text { at } 505\end{array}$ & $\begin{array}{l}10 \\
10\end{array}$ & $\begin{array}{l}F_{c u}, E_{c}, \nu, \epsilon_{x} \\
F_{c u} \\
F_{c u}\end{array}$ \\
\hline $\begin{array}{l}\text { IN-PLANE SHEAR } \\
6.07 \mathrm{~cm} \times 7.62 \mathrm{~cm} \\
2.4 \text { in } \times 3 \text { in })\end{array}$ & \begin{tabular}{|l|} 
RT \\
367 to \\
505 \\
RT after \\
1000 hrs \\
at 505 \\
\end{tabular} & $\begin{array}{l}10 \\
10\end{array}$ & $\begin{array}{l}F_{\text {su }}, G \\
F_{\text {su }} \\
F_{\text {su }}\end{array}$ \\
\hline $\begin{array}{l}\text { INTERLAMINAR SHEAR } \\
0.635 \times 3.048 \mathrm{~cm} \\
(0.25 \times 1.2 \mathrm{in})\end{array}$ & $\begin{array}{l}\text { RT } \\
505 \\
\text { RT after } \\
1000 \text { hrs } \\
\text { at } 505\end{array}$ & $\begin{array}{l}10 \\
10 \\
10\end{array}$ & $\begin{array}{l}F_{\text {su }} \\
F_{\text {su }} \\
F_{\text {su }}\end{array}$ \\
\hline $\begin{array}{l}\text { BOLT SHEARING } \\
2.85 \mathrm{~cm} \times 10.16 \mathrm{~cm} \\
(1.12 \text { in } \times 4 \text { in) } \\
2 \text { Configurations }\end{array}$ & RT & 20 & $P_{u}$ \\
\hline METALLOGRAPHY & & 3 & $\begin{array}{l}\text { BOND QUALITY AND } \\
\text { UNIFORMITY, FILAMENT } \\
\text { DISTRIBUTION AND } \\
\text { DEGRADATION }\end{array}$ \\
\hline $\begin{array}{l}\text { SCANNING ELECTRON FRACTO- } \\
\text { GRAPHY (TO BE PERFORMED ON } \\
\text { SELECTED FAILED SPECIMENS) }\end{array}$ & & 5 & BOND QUALITY \\
\hline $\begin{array}{l}\text { TENSION } \\
\text { FATIGUE }\end{array}$ & RT & 10 & CYCLES TO FAILURE \\
\hline
\end{tabular}


TABLE 3

RESULTS OF TENSION TESTS AT ROOM TEMPERATURE $505 \mathrm{~K}\left(450^{\circ} \mathrm{F}\right)$ AND AT ROOM TEMPERATURE AFTER 1000 HOURS AGING AT 505K $\left(450^{\circ} \mathrm{F}\right)$

(BORON/ALUMINUM $-90^{\circ}, 45^{\circ}, 90^{\circ}, 0^{\circ},-45^{\circ}, 0^{\circ},-45^{\circ}, 0^{\circ}, 90^{\circ}, 45^{\circ}, 90^{\circ}$ )

\begin{tabular}{|c|c|c|c|c|c|c|c|c|}
\hline \multicolumn{9}{|c|}{ ULTIMATE TENSILE STRENGTH } \\
\hline \multicolumn{3}{|c|}{$\begin{array}{l}\text { AT ROOM } \\
\text { TEMP }\end{array}$} & \multicolumn{3}{|c|}{ AT $505 \mathrm{~K} \quad\left(450^{\circ} \mathrm{F}\right)$} & \multicolumn{3}{|c|}{$\begin{array}{l}\text { AT ROOM TEMP AFTER } \\
1000 \text { HRS AT } 505 \mathrm{~K} \quad\left(450^{\circ} \mathrm{F}\right)\end{array}$} \\
\hline $\begin{array}{l}\text { SPEC } \\
\text { NO }\end{array}$ & $\mathrm{MPa}$ & PSI & $\begin{array}{l}\text { SPEC } \\
\text { NO }\end{array}$ & $\mathrm{MPa}$ & PSI & $\begin{array}{l}\text { SPEC } \\
\text { NO }\end{array}$ & $\mathrm{MPa}$ & PSI \\
\hline 11 & 470.9 & 68,296 & 1 & 557.5 & 80,856 & 21 & 540.8 & 78,438 \\
\hline 12 & 628.4 & 91,136 & 2 & 606.1 & 87,905 & 22 & 599.0 & 86,875 \\
\hline 13 & 635.4 & 92,158 & 3 & 632.9 & 91.791 & 23 & 554.4 & 80,413 \\
\hline 14 & 629.9 & 91,364 & 4 & 628.6 & 91,165 & 24 & 576.0 & $83,543^{\star}$ \\
\hline 15 & 623.7 & 90,463 & 5 & 626.8 & 90,909 & 25 & 563.1 & 81,665 \\
\hline 16 & 546.6 & 79,276 & 6 & 631.2 & 91,551 & 26 & 555.9 & 80,625 \\
\hline 17 & 528.7 & 76,683 & 7 & 623.9 & 90,486 & 27 & 529.9 & 76,851 \\
\hline 18 & 495.5 & $71,859 *$ & 8 & 560.9 & 81,351 & 28 & 532.7 & $77,261^{*}$ \\
\hline 19 & 517.8 & $75,094 * *$ & 9 & 566.2 & 82,115 & 29 & 549.2 & 79,660 \\
\hline 20 & 572.1 & 82,974 & 10 & 585.3 & 84,893 & 30 & 553.6 & 80,290 \\
\hline AVG & 564.9 & 81,930 & & 601.9 & 87,302 & & 555.5 & 80,562 \\
\hline $\begin{array}{l}\text { STD } \\
\text { DEV }\end{array}$ & 61.7 & 8,950 & & 31.4 & 4,550 & & 20.6 & 2,979 \\
\hline
\end{tabular}

NOTE: * Failure occurred at edge of scarfed end tab

** Failure occurred at $3.18 \mathrm{~mm}(1 / 8 \mathrm{in})$ within scarfed 
In testing Specimen 11 (Figure 18) the grips (which consisted of thick serrated steel plates clamped against the specimen with six bolts) slipped and the specimen had to be unloaded and the plate bolts tightened. This happened twice but the third time the bolts and grip plates held and the specimen was successfully tested to failure. When the stress-strain curve of Figure 18 was plotted however, it was observed that each time the speciment had been unloaded it retained a "permanent set" which was equal to about one-third of the maximum strain that had been reached prior to unloading. This behavior was checked again with Specimen 15 (Figure 23), Specimen 16 (Figure 24), Specimen 17 (Figure 25), and Specimen 18 (Figure 26). Finally in the case of Specimen 20 (Figure 28) the grips slipped once again and had to be tightened before the specimen could be loaded to failure. In these six specimens, the respective strains from which the specimens were unloaded varied from about 10 to $95 \%$ of the maximum strain at failure, but in each case the "permanent set" was approximately one-third of the strain prior to unloading.

Stress-strain curves of tension specimens tested at room temperature after 1000 hours aging at $505 \mathrm{~K}\left(450^{\circ} \mathrm{F}\right)$ are shown in Figures 29 through 38. Strain readings were all obtained by means of an extensometer and therefore dotted line extensions of each curve indicate the approximate extrapolations to failure. As in the case of the previous room temperature tension tests, six of the specimens were unloaded prior to failure and then loaded again to determine whether the magnitude of the "permanent set" had been effected by the aging, ie; Specimen 23 (Figure 31), Specimen 24 (Figure 32), Specimen 25 (Figure 33), Specimen 26 (Figure 34), Specimen 27 (Figure 35), and Specimen 28 (Figure 36 ). In this group of six specimens each unloading occurred when the tensile stress reached 345MPa $(50,000 \mathrm{psi})$ and the corresponding "permanent set" was consistently about one-quarter of the maximum strain reached prior to unloading: Because these specimens had not been unloaded completely (about $41.4 \mathrm{MPa}$ (6000 psi). stress remaining) the curves had to be extrapolated to zero stress to obtain an approximate strain at zero stress reading. Nevertheless, the smaller ratio of "permanent set" indicated that the 1000 hours aging at $505 \mathrm{~K}\left(450^{\circ} \mathrm{F}\right)$ may have metallurgically effected the aluminum matrix and increased its resistance to incurring "permanent set".

Additional observation of the stress-strain curves of Figures 18 through 38 indicated that all curves followed a characteristic bilinear pattern with an initial slope or "primary modulus". Which was relatively brief but about twice as large as the much more extensive subsequent slope or "secondary modulus". As illustrated in the schematic, Figure 39, when the specimen was unloaded and then reloaded prior to failure; the reloading curve essentially paralleled the higher initial slope up to the unloading point and then continued along the lower second slope. Although it is primarily speculative, a plausible explanation of this behavior has been devised as follows: "When boron aluminum composite with a multiple ply orientation including $0^{\circ}, 90^{\circ}$, and $+45^{\circ}$ layers is cooled from its bonding temperature, the greater coefficient of contraction of the aluminum matrix. leads to a residual stress condition where the compression in the $0^{\circ}$ boron fibers is balanced by tension in the matrix. Upon initial loading, a complete rearrangement of residual and imposed stresses takes place with the boron compressive stresses reducing to zero and the aluminum tensile stresses rising higher. With the aluminum supporting an appreciable proportion of the load, the primary modulus is relatively high but because of the strain magnification in the matrix of the $90^{\circ}$, fibers and because of the rotation of the $+45^{\circ}$ fibers in the direction of the tensile load, gradual microcracking and slipping of the matrix occurs which cannot be reversed completely when the specimen is unloaded. After the knee of the curve is passed, the aluminum matrix, which is now plastic, no longer picks up additional load and 
the secondary slope or modulus is controlled primarily by the elastic elongation of the boron alone. If the specimen is unloaded prior to failure, it will exhibit a permanent set which indicates that the residual stresses are now reversed and the tension in the fibers is balanced by compression in the matrix. Furthermore, when the specimen is reloaded, the matrix contributes to supporting the load as long as some of its compression remains and hence the primary slope region is repeated and increased. But when the same stress is reached from which the specimen was previously unloaded, then the residual compression in the aluminum is completely reduced and again, the aluminum yields plastically, microcracks and $45^{\circ}$ fiber alignment continue, and the stress-strain curve proceeds along the lower secondary modulus slope".

The primary and secondary slopes or moduli taken from the tensile specimens shown in Figures 18 through 38 , together with the maximum strains obtained either from actual strain gage readings or extrapolated data are summarized in Table 4. It can be seen that the primary modulus is consistently about twice as high as the secondary modulus and that the ranges and averages of both modul $i$ ' as well as the strain at failure was about the same in both groups of specimens. It was concluded that the 1000 hours aging at $505 \mathrm{~K} \quad\left(450^{\circ} \mathrm{F}\right)$, had no appreciable effect on the moduli or the maximum strains of the boron aluminum composite.

To obtain information on the Poisson's ratio of boron/aluminum composites tested in tension, both sides of specimen 11 had been instrumented with longitudinal and lateral strain gages. As previously discussed, specimen 11 slipped twice in the grips during the testing so it was loaded and unloaded three times as shown in Figure 18. During each run the calculated ratio of the lateral and longitudinal strain gage readings (ie; Poisson's ratio) varied from run to run, from one side to the other side and from the beginning of the run to the end of the run. These data have been plotted on Figures 40 and 41 . Although there was considerable scatter in the calculated results, the trend that appeared was that during initial loading, the Poisson's ratio remained approximately constant at a value of about 0.20 as stress increased. Upon unloading and reloading, the rearrangement of the residual stress distribution in some way effected this trend so the Poisson's ratio started low and increased asymptoticaliy to the same value of about 0.20 as stress increased. As the stresses at which unloading increased, the initial value of Poisson's ratio decreased proportionally. Specimens 12 and 13 were instrumented with longitudinal and lateral strain gages (on one side only) and the calculated Poissan's ratio curves are shown in Figures 42 and 43 . Again there was considerable scatter but the results were consistent with the first loading of Specimen 11 in that Poisson's ratio did not vary much from the 0.20 as stress increased. 
TABLE 4

MODULUS OF ELASTICITY AND STRAIN AT FAILURE FROM

TENSION TESTS AT ROOM TEMPERATURE AND AT ROOM

TEMPERATURE AFTER AGING 1000 HOURS AT $505 \mathrm{~K}\left(450^{\circ} \mathrm{F}\right)$

(BORON/ALUMINUM $-90^{\circ}, 45^{\circ}, 90^{\circ}, 0^{\circ},-45,0^{\circ}$,

$\left.-45^{\circ}, 0^{\circ}, 90^{\circ}, 45^{\circ}, 90^{\circ}\right)$

(SPECIMENS LOADED IN $90^{\circ}$ DIRECTION)

\begin{tabular}{|c|c|c|c|c|c|c|}
\hline \multirow{2}{*}{$\begin{array}{l}\text { SPEC } \\
\text { NO. }\end{array}$} & \multirow{2}{*}{$\begin{array}{l}\text { AGING AT } \\
505 \\
\left(450^{\circ} \mathrm{F}\right) \\
\text { HOURS }\end{array}$} & \multicolumn{2}{|c|}{$\begin{array}{l}\text { PRIMARY } \\
\text { MODULUS }\end{array}$} & \multicolumn{2}{|c|}{$\begin{array}{l}\text { SECONDARY } \\
\text { MODULUS }\end{array}$} & \multirow[t]{2}{*}{$\begin{array}{l}\text { STRAIN AT } \\
\text { FAIURE }\end{array}$} \\
\hline & & $\frac{G N}{m^{2}}$ & PSI & $\frac{\mathrm{GN}}{\mathrm{m}^{2}}$ & $\overline{\text { PSI }}$ & \\
\hline 11 & 0 & 751.0 & $21.9 \times 10^{6}$ & 79.3 & $11.5 \times 10^{6}$ & 0.0052 \\
\hline 12 & 0 & 153.8 & 22.3 & 89.6 & 13.0 & 0.0059 \\
\hline 13 & 0 & 129.6 & 18.8 & 80.0 & 11.6 & 0.0072 \\
\hline 14 & 0 & 193.7 & 28.1 & 88.3 & 12.8 & 0,0072 \\
\hline 15 & 0 & 137.9 & 20.0 & 83.4 & 12.1 & 0.0071 \\
\hline 16 & 0 & 151.7 & 22.0 & 84.1 & 12.2 & 0.0061 \\
\hline 17 & 0 & 166.9 & 24.2 & 82.0 & 11.9 & 0.0057 \\
\hline 18 & 0 & 151.0 & 21.9 & 86.9 & 12.6 & 0.0053 \\
\hline 19 & 0 & 163.4 & 23.7 & 87.6 & 12.7 & 0.0055 \\
\hline 20 & 0 & 163.7 & 23.6 & 86.9 & 12.6 & 0.0061 \\
\hline$A V G$ & & 156.3 & 22.7 & 84.8 & 12.3 & 0.0061 \\
\hline $\begin{array}{l}\text { STO } \\
\text { DEV }\end{array}$ & & 17.3 & 2.5 & 3.6 & 0.5 & 0.0008 \\
\hline 21 & 1000 & 142.0 & 20.6 & 84.1 & 12.2 & 0.0062 \\
\hline 22 & 1000 & 134.4 & 19.5 & 80.0 & 11.6 & 0.0071 \\
\hline 23 & 1000 & 137.9 & 20.0 & 84.1 & 12.2 & 0.0063 \\
\hline 24 & 1000 & 126.9 & 18.4 & 84.1 & 12.2 & 0.0067 \\
\hline 25 & 1000 & 162.0 & 23.5 & 84.1 & 12.2 & 0.0065 \\
\hline 26 & 1000 & 141.3 & 20.5 & 83.4 & 12.1 & 0.0066 \\
\hline 27 & 1000 & 129.6 & 18.8 & 84.1 & 12.2 & 0.0061 \\
\hline 28 & 1000 & 182.0 & 26.4 & 86.9 & 12.6 & 0.0060 \\
\hline 29 & 1000 & 156.5 & 22.7 & 84.8 & 12.3 & 0.0062 \\
\hline 30 & 1000 & 142.0 & 20.6 & 86.2 & 12.5 & 0.0060 \\
\hline AVG & & 145.5 & 21.1 & 84.2 & 12.2 & 0.0064 \\
\hline $\begin{array}{l}\text { STD } \\
\text { DFV }\end{array}$ & & 16.8 & 2.4 & 1.8 & 0.3 & 0.0004 \\
\hline
\end{tabular}


Compression Tests

The first three room temperature compression specimens were strain-gaged and loaded in a four point bending (Figure 44). Their stress-strain plots are shown in Figures 45, 46, and 47. A tested and an untested compression specimen are shown together in Figure 48 .

The first specimen was tested four times before it failed because the limits set on the strain recording instruments were exceeded three times. Each time a strain limit was exceeded the specimen was brought back to zero load and the strain instrumentation adjusted before resuming the test. When the strain limit was exceeded the strain reading was lost, so the magnitude of permanent set at zero load was also lost. Therefore, the graph of specimen \#11 plotted all four runs as starting from zero longitudinal strain. The presence of permanent set in specimen 11 can be surmised from the graph of specimen $12^{\prime}$ 's response to multiple loadings, Figure 46. Having determined the maximum strain settings for the instrumentation from specimen 11 , specimen 12 was loaded up to $521 \mathrm{MPa}(75,525$ psi), then unioaded to $174 . \mathrm{MPa}(25,175 \mathrm{psi})$, loaded to $1041 \mathrm{MPa}(151,050 \mathrm{psi})$, unloaded back to $174 \mathrm{MPa}(25,175 \mathrm{psi})$, loaded to $1388 \mathrm{MPa}(201,400 \mathrm{psi})$, unloaded back to $174 \mathrm{MPa}(25,175 \mathrm{psi})$, then finally loaded to failure at $1875 \mathrm{MPa}$ (27),890 psi). It is apparent that most of the permanent set occurred in the first loading amounting to $0.0024 \mathrm{~cm} / \mathrm{cm}$, or $12.5 \%$ of the total strain to failure. As with the tension specimens, the modulus varied with load, higher near zero stress and lower at higher stresses.

The stress-strain plots of the remaining seven room temperature compression specimens are shown in Figures 49 through 55 . The strain data for these specimens was obtained with an extensometer rather than with strain gages. Apparentiy the two strain measuring techniques are not equivalent because the slopes, or moduli, determined from the stress-strain curves of the former were about $25 \%$ greater than those of the latter. The calculated compression strengths of all room temperature specimens tested are summarized in Table 5, and the primary and secondary moduli together with the maximum strain gage readings are summarized in Tabie 6 . Comparing the tension and compression tests data obtained from strain gaged specimens 7 isted in Tables $3,4,5$, and 6 , the compression strengths and strains at failure are more than three times greater, the primarily moduli are approximately $9 \%$ less, the secondary moduli are approximately $12 \%$ greater. The ratio of primarily to secondary moduli for tension and compression tests is 7.75 and 1.40 , respectively. observation of the failed compression specimens. (Figure 56) indicated that when failure occurred it was very catastrophic with a massive combination of crushing and shearing of the aluminum matrix. and buckling of the filaments.

The results of the room temperature tests of the 10 specimens aged at $505 \mathrm{~K}$ $\left(450^{\circ} \mathrm{F}\right)$ for 1000 hours are also shown in Tables 5 and 6 . The averages reflect a slight decrease in moduli, compression strengths, and strain at failure from the room temperature tests, but only on the order of 3 to $10 \%$. The stress-strain curves for the 1000 hour-aged specimens are shown in Figures 57 to 66 .

The 10 elevated temperature specimens were originally to be tested at $505 \mathrm{~K}$ $\left(450^{\circ} \mathrm{F}\right)$, but after the first five experienced adhesive failures at that temperature, the test temperature was lowered to $422 \mathrm{~K}\left(300^{\circ} \mathrm{F}\right)$. As can be seen in Table 5 , the $422 \mathrm{~K}\left(300^{\circ} \mathrm{F}\right)$ temperature raised the adhesive strength somewhat, but not sufficiently to produce a consistently good boron/aluminum failure. The calculated stresses for the boron/aluminum (when the adhesive failed) are still quite 
TABLE 5

RESULTS OF COMPRESSION TESTS AT ROOM TEMPERATURE, ELEVATED TEMPERATURE, AND AT ROOM TEMPERATURE AFTER 1000 HOURS AGING AT $505 \mathrm{~K}\left(450^{\circ} \mathrm{F}\right)$

(BORON/ALUMINUM - $90^{\circ}, 45^{\circ}, 90^{\circ}, 0^{\circ},-45^{\circ}, 0^{\circ},-45^{\circ}, 0^{\circ}, 90^{\circ}, 45^{\circ}, 90^{\circ}$ )

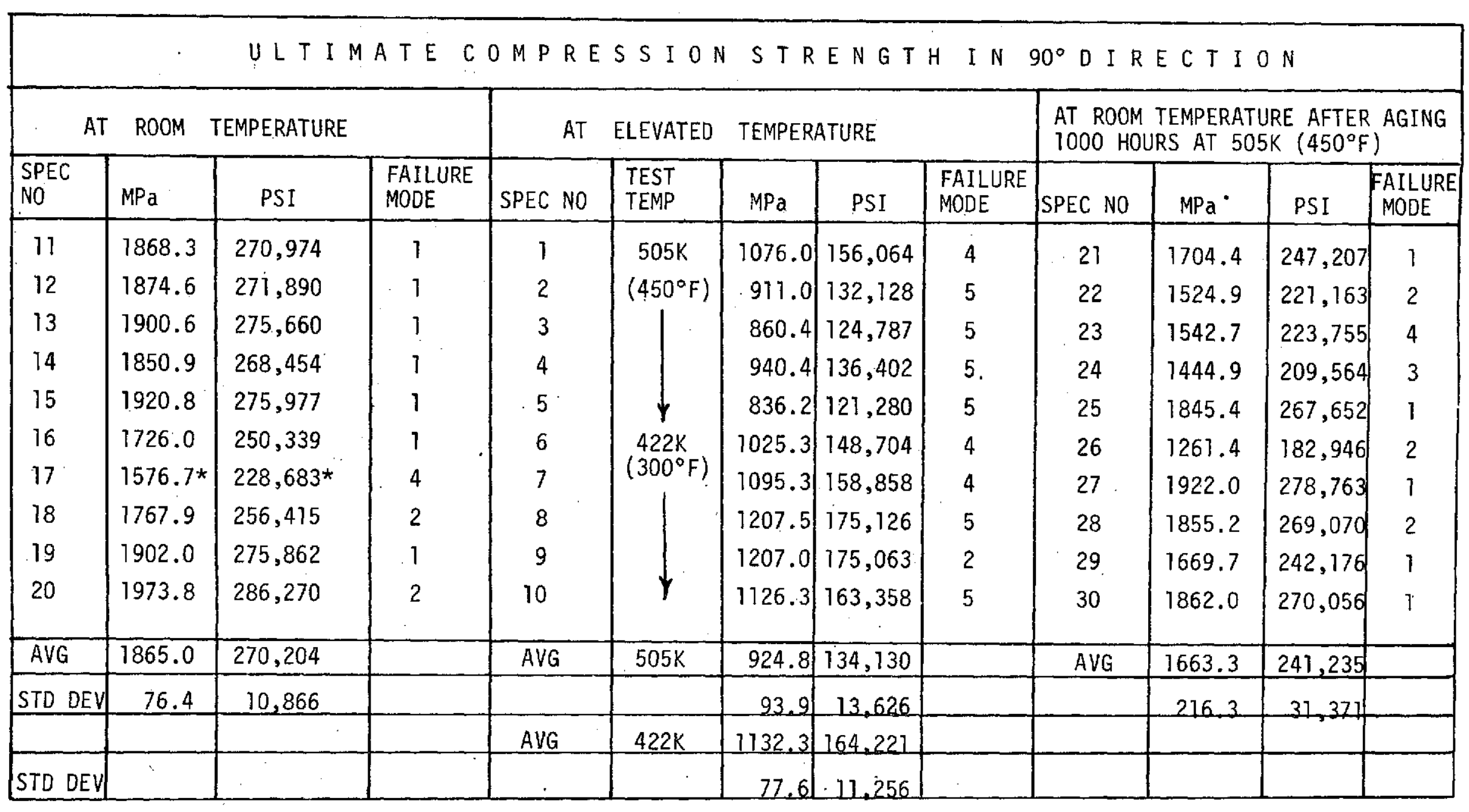

NOTES: * Data not used in calculation of average

FAILURE MODE 1 - Compression Failure of $B / A T$ between Load Points 2 - B/AT faiture at Load Point

3 - B/A1 failure outside of Load Points

4 - Adhesive failure under B/AT Face

5 - Adhesive failure under Steel Face 
TABLE 6

MODULUS OF ELASTICITY AND STRAIN AT FAILURE FROM COMPRESSION TESTS AT ROOM TEMPERATURE AND AT ROOM

TEMPERATURE AFTER AGING 1000 HOURS AT $505 \mathrm{~K}\left(450^{\circ} \mathrm{F}\right)$

(BORON/ALUMINUM- $90^{\circ}, 45^{\circ}, 90^{\circ}, 0^{\circ},-45^{\circ}, 0^{\circ},-45^{\circ}, 0^{\circ}$, $\left.90^{\circ}, 45^{\circ}, 90^{\circ}\right)$

(SPECIMENS LOADED IN $90^{\circ}$ DIRECTION)

\begin{tabular}{|c|c|c|c|c|c|c|}
\hline \multirow{2}{*}{$\begin{array}{l}\text { SPEC } \\
\text { NO }\end{array}$} & \multirow{2}{*}{$\begin{array}{l}\text { AGING AT } \\
505^{K} \\
\left(450^{\circ} \mathrm{F}\right) \\
\text { HOURS }\end{array}$} & \multicolumn{2}{|c|}{ PRIMARY MODULUS } & \multicolumn{2}{|c|}{ SECONDARY MODULUS } & \multirow{2}{*}{$\begin{array}{l}\text { STRAIN AT } \\
\text { FAILURE }\end{array}$} \\
\hline & & $\mathrm{GPa}$ & PSI & GPa & PSI & \\
\hline 11 & 0 & 145.5 & $21.1 \times 10^{6}$ & 91.7 & $13.3 \times 10^{6}$ & 0.0190 \\
\hline 12 & 0 & 131.7 & 19.1 & 94.5 & 13.7 & 0.0191 \\
\hline 13 & 0 & 120.7 & 17.5 & 97.9 & 14.2 & 0.0191 \\
\hline 14 & 0 & 116.5 & 16.9 & 80.7 & 11.7 & 0.0216 \\
\hline 15 & 0 & 106.2 & 15.4 & 82.7 & 12.0 & 0.0217 \\
\hline 16 & 0 & 102.0 & 14.8 & 81.4 & 11.8 & 0.0202 \\
\hline 17 & 0 & 104.8 & 75.3 & 82.7 & 12.0 & 0.0174 \\
\hline 18 & 0 & 104.2 & 15.4 & 78.6 & 11.4 & 0.0198 \\
\hline 19 & 0 & 106.9 & 15.5 & 80.7 & 11.7 & 0.0216 \\
\hline 20 & 0 & 102.0 & 14.8 & 78.6 & 17.4 & 0.0227 \\
\hline$A \cup G$ & & 114.7 & 16.6 & 85.0 & 12.3 & 0.0202 \\
\hline \multicolumn{2}{|c|}{ STD DEV } & .14 .7 & 2.1 & 7.0 & 1.0 & 0.0016 \\
\hline 21 & 1000 & 106.2 & $15.4 \times 10^{6}$ & 83.4 & $12.1 \times 10^{6}$ & 0.0188 \\
\hline 22 & 1000 & 94.5 & 13.7 & 75.8 & 11.0 & 0.0176 \\
\hline 23 & 1000 & 102.7 & 14.9 & 82.7 & 12.0 & 0.0170 \\
\hline 24 & 1000 & 95.8 & 73.9 & 77.9 & 11.3 & 0.0164 \\
\hline 25 & 1000 & 111.7 & 16.2 & 83.4 & 12.1 & 0.0204 \\
\hline 26 & 1000 & 109.6 & 15.9 & 82.7 & 12.0 & 0.0133 \\
\hline 27 & 1000 & 95.8 & 13.9 & 79.3 & 11.5 & 0.0202 \\
\hline 28 & 1000 & 96.5 & 14.0 & 82.7 & 12.0 & 0.0212 \\
\hline 29 & 1000 & 102.0 & 74.8 & 81.4 & 11.8 & 0.0189 \\
\hline 30 & 1000 & 106.9 & 15.5 & 79.3 & 11.5 & 0.0215 \\
\hline AVG & & 102.2 & 14.8 & 80.9 & 11.7 & 0.0185 \\
\hline \multicolumn{2}{|c|}{ STD DEV } & 6.3 & 0.9 & 2.6 & 3.8 & 0.0025 \\
\hline
\end{tabular}


high compared to the tension strength, averaging $924.8 \mathrm{MPa}(134,130 \mathrm{psi})$ for the $505 \mathrm{~K}\left(450^{\circ} \mathrm{F}\right)$ compression tests and $1132 \mathrm{MPa}\left(164,221\right.$ psi) for the $422 \mathrm{~K}\left(300^{\circ} \mathrm{F}\right)$ compression tests.

To obtain information on the Poisson's ratio of the boron aluminum composites tested in compression specimens 11, 12, and 13 were instrumented with longitudinal and lateral strain gages. This data is shown in Figure 67 . As in the case of most of the tensile Poisson's ratio curves shown in Figures $40,41,42$, and 43 , some of the compression Poisson's ratio curves were obtained after the specimens had been loaded and unloaded several times prior to plotting of the data. Although there was considerable difference between the curves of the three specimens, the trend (as with the tension Poisson's ratio curves) that appeared was that during initial loading the Poisson's ratio started low and increased asymptotically to a constant value. Whereas this value was about 0.2 in the case of the tension Poisson curves, it was considerably higher (ie; from 0.29 to 0.34 ) in the case of the compression Poisson curves.

\section{Rail Shear Tests}

The room and elevated temperature rail shear specimen test results are given in Table 7. It was found that the elevated temperature adhesive, HT424, was good only for about $9.65 \mathrm{~Pa}(1400 \mathrm{psi})$ shear at $505 \mathrm{~K}\left(450^{\circ} \mathrm{F}\right)$, so the steel rails sheared off before the boron/aluminum failed. Knowing that the adhesive's strength would increase with lower temperatures, the sixth specimen was tested at $422 \mathrm{~K}\left(300^{\circ} \mathrm{F}\right)$. Since the adhesive still failed before the boron/aluminum (although at a higher adhesive stress than at $\left.505 \mathrm{~K}\left(450^{\circ} \mathrm{F}\right)\right)$, the test temperature was lowered to $394 \mathrm{~K} \quad\left(250^{\circ} \mathrm{F}\right)$. Although the adhesive shear strength again improved, it still was insufficient to fail the boron/aluminum, so the test temperature was reduced to $367 \mathrm{~K}\left(200^{\circ} \mathrm{F}\right)$, and a boron/aluminum failure was achieved with two of the remaining three specimens at that temperature. Figure 68 shows two specimens, 8 and 10. Specimen 10 is on the left and is typical of the specimens with adhesive failure. \#8, on the right; displays the failure of the boron/aluminum. A close-up of 8 is shown in Figure 69. This failure apparentily traversed along one rail bondline edge and then jumped to the other edge along a $45^{\circ}$ plane at about the middle of the specimen. It, too, is typical of those specimens which failed in the boron/ aluminum. SEM observation of the failure surface along the bondline edge (Figure 70) indicated that the $0^{\circ}$ and $90^{\circ}$ fibers failed in shear whereas some of the $45^{\circ}$ fibers failed in tension at the interface between the fibers and the aluminum matrix.

The room temperature rail shear specimens using a different adhesive, Hysol EA951, al1 failed the boron/aluminum. The average boron/aluminum shear stress at failure was $338.7 \mathrm{MPa}(49,131 \mathrm{psi})$. The first three specimens tested were straingaged and their stress-strain curves are shown in Figures 71-73. The shear modulus at higher stresses is seen to be approximately $17.2 \mathrm{GPa}\left(2.5 \times 10^{6} \mathrm{psi}\right)$, and at lower stresses to be about $41.4 \mathrm{GPa}\left(6 \times 10^{6} \mathrm{psi}\right)$.

The primary and secondary slopes or moduli taken from the shear specimens shown in Figures 71 through 73 together with the maximum strains are summarized in Table 8 . As with the tensile test results summarized in Table 4, the primary moduli were approximately twice as high as the secondary moduli. The magnitude of the shear moduli, however, were only about a quarter of the respective tensile moduli.

To determine whether unloading before failure in shear resulted in a similar "permanent set" as in the case of the tension and compression, one of the specimens (\#13) was unloaded before failure and reloaded again. This permanent set was approximately one quarter of the shear strain prior to unloading. 
TABLE 7

RESULTS OF RAIL SHEAR TESTS AT ROOM TEMPERATURE, ELEVATED TEMPERATURE AND AT ROOM TEMPERATURE AFTER 1000 HOURS AT $505 \mathrm{~K}\left(450^{\circ} \mathrm{F}\right)$

(BORON/ALUMINUM- $90^{\circ}, 45^{\circ}, 90^{\circ}, 0^{\circ},-45^{\circ}, 0^{\circ},-45^{\circ}, 0^{\circ}, 90^{\circ}, 45^{\circ}, 90^{\circ}$ )

(SPECIMENS LOADED PARALLEL TO $90^{\circ}$ DIRECTION

ULTIMATE RAIL SHEAR STRENGTH

\begin{tabular}{|c|c|c|c|c|c|c|c|c|c|}
\hline \multicolumn{3}{|c|}{ AT ROOM TEMPERATURE } & \multicolumn{4}{|c|}{ AT ELEVATED TEMPERATURE } & \multicolumn{3}{|c|}{$\begin{array}{l}\text { AT ROOM TEMP AFTER AGING } \\
1000 \mathrm{HRS} \text { AT } 505 \mathrm{~K} \quad\left(450^{\circ} \mathrm{F}\right)\end{array}$} \\
\hline $\begin{array}{l}\text { SPEC } \\
\text { NO. }\end{array}$ & $\mathrm{MPa}$ & PSI & $\begin{array}{l}\text { SPEC } \\
\text { NO. }\end{array}$ & $\begin{array}{l}\text { TEST } \\
\text { TEMP }\end{array}$ & $\mathrm{MPa}$ & PSI & $\begin{array}{l}\text { SPEC } \\
\text { NO. }\end{array}$ & $\mathrm{MPa}$ & PSI \\
\hline 1 & 294.1 & 42,658 & 11 & $505 K$ & 216.3 & $31,371^{*}$ & 21 & 282.4 & 40,964 \\
\hline 2 & 302.3 & 43,849 & 12 & $\left(450^{\circ} \mathrm{F}\right)$ & 219.1 & $31,781 *$ & 22 & 289.5 & 41,986 \\
\hline 3 & 380.3 & 55,158 & 13 & & 228.2 & $33,097^{*}$ & 23 & 307.6 & 44,614 \\
\hline 4 & 300.8 & 43,625 & 14 & & 230.3 & $33,401 *$ & 24 & 289.6 & 42,002 \\
\hline 5 & 361.2 & 52,390 & 15 & $y$ & 199.1 & $28,875^{\star}$ & 25 & 362.3 & 52,552 \\
\hline 6 & 342.7 & 49,702 & 16 & $\begin{array}{l}422 \mathrm{~K} \\
\left(300^{\circ} \mathrm{F}\right)\end{array}$ & 250.9 & $36,391 *$ & 26 & 284.0 & 41,194 \\
\hline 7 & 359.1 & 52,083 & 17 & $\begin{array}{l}394 \mathrm{~K} \\
\left(250^{\circ} \mathrm{F}\right)\end{array}$ & 271.6 & $39,395^{*}$ & 299.8 & 299.8 & 43,487 \\
\hline 8 & 362.5 & 52,579 & 18 & $\begin{array}{l}367 \mathrm{~K} \\
\left(200^{\circ} \mathrm{F}\right)\end{array}$ & 285.2 & 41,362 & 28 & 301.6 & 43,737 \\
\hline 9 & 376.2 & 54,563 & 19 & & 299.6 & 43,448 & 29 & 274.6 & 39,826 \\
\hline 10 & 308.2 & 44,706 & 20 & $y$ & 247.3 & $35,874 *$ & 30 & 269.2 & 39,047 . \\
\hline AVG & 338.7 & 49,131 & AVG & $\begin{array}{l}367 \mathrm{~K} \\
\left(200^{\circ} \mathrm{F}\right.\end{array}$ & 292.4 & 42,405 & AVG & 296.1 & 42,941 \\
\hline STE & 33.9 & 4,911 & & & 10.2 & 1,475 & & 26.2 & 3,797 \\
\hline
\end{tabular}

* Cohesive failure of adhesive; boron/aluminum did not fail, Data not used in calculation of average 


\section{Interlaminar Shear Tests}

Table 8 summarizes the results of the room temperature interlaminar shear tests. Specimens \#1 and \#2 were tested with the testing jig set at a span of $8.13 \mathrm{~mm}$ (0.32 inch) which is representative of a 4 to 1 span to thickness ratio. Because both specimens failed in tension rather than interlaminar shear, the jig was adjusted to its minimum span of $6.35 \mathrm{~mm}$ ( $0.25 \mathrm{inch})$ which is representative of a 3 to 1 span to thickness ratio. Most of the remaining specimens failed at slightly higher loads, but the failures were still all tensile rather than interlaminar shear. It was concluded that because the specimens were so thin and because the fiber orientations were varied rather than unidirectional, it would not be possible to induce an interlaminar shear failure prior to tensile failure. Consequently, the shear stresses reported in Table 8 are on the low bound. Nevertheless, the magnitudes of the calculated stresses reported were appropriately high and were in the range of values normal for unidirectional boron/aluminum composites.

Table 8 also summarizes the results of the interlaminar shear tests at $505 \mathrm{~K}$ $\left(450^{\circ} \mathrm{F}\right)$ and at room temperature after the specimens had been aged 1000 hours at $505 \mathrm{~K}\left(450^{\circ} \mathrm{F}\right)$. As in the case of the room temperature tests, al 1 specimens failed in tension rather than interlaminar shear, even though the span was kept at the minimum $6.35 \mathrm{~mm}(0.25 \mathrm{inch})$. Comparison of the average interlaminar shear strength values of Table 8 indicate that the reductions from room temperature strengths were modest, ie; about $20 \%$ after 1000 hours aging at $505 \mathrm{~K}\left(450^{\circ} \mathrm{F}\right)$ and about $30 \%$ while at $505 \mathrm{~K}\left(450^{\circ} \mathrm{F}\right)$.

\section{Bolt Bearing Tests}

The bolt bearing test specimen, as shown in Figure 9 , consisted of a $2.86 \mathrm{~cm}$ (1 $1 / 8$ inch) wide by $10.16 \mathrm{~cm}$ ( 4 inch) long strip of $2.03 \mathrm{~mm}(0.08$ inch) thick boron/aluminum mechanically fastened to two strips of $2.86 \mathrm{~cm}(11 / 8$.inch) wide by $10.16 \mathrm{~cm}$ ( 4 inch) long by $1.02 \mathrm{~mm}(0.04$ inch) thick titanium. This specimen was gripped and pulled in tension until one of the two fastened ends failed, after which the remaining two fastened pieces were regripped and pulled in tension until the other fastened end failed. Two different fastener sizes and types were tested, ie; 3.97 and $4.76 \mathrm{~mm}(5 / 32$ and $3 / 76$ inch) titanium Hi-Loks. The 20 results of the 10 specimens tested are summarized in Table 9 . The first fastener failure load of each of the specimens was designated as "A." and the second as " $B$ ". Test scatter of similar specimens was low and the preloading that the "B" laps received when the "A" laps failed did not seem to reduce their values. The average failure load of the $3.972 \mathrm{~mm}$ (5/32 inch) Hi-Lok fastened specimens was $636.5 \mathrm{~N}$ (1431 pounds) and the corresponding average failure load of the $4.762 \mathrm{~mm}$ ( $3 / 16 \mathrm{inch}$ ) Hi-Lok fastened specimens was $7,353 \mathrm{~N}$ (1653 pounds). The typical mode of failure of mest of the specimens is illustrated in Figure 74 . When the ultimate load was reached, two tension cracks simultaneously started at location"A". This increasing crack length rapidly raised the tensile stress at location " $B$ " until a second crack started in a direction perpendicular to the first two cracks. When the specimens finally failed, the two square corners around the hole were completely torn from the specimen ends and the Hi-Lok fastener had been pulled out. 
TABLE 8

RESULTS OF INTERLAMINAR SHEAR TESTS AT ROOM

TEMPERATURE, $505 \mathrm{~K}\left(450^{\circ} \mathrm{F}\right)$, AND AT ROOM

TEMPERATURE AFTER 1000 HOURS AGING AT

$505 \mathrm{~K}\left(450^{\circ} \mathrm{F}\right)$

(BORON/ALUMINUM- $90^{\circ}, 45^{\circ}, 90^{\circ}, 0^{\circ},-45^{\circ}, 0^{\circ},-45^{\circ}$, $\left.0^{\circ}, 90^{\circ}, 45^{\circ}, 90^{\circ}\right)$

\begin{tabular}{|c|c|c|c|c|c|c|c|c|}
\hline \multicolumn{9}{|c|}{ INTERLAMINAR SHEAR STRENGTH (1) } \\
\hline \multicolumn{3}{|c|}{ AT ROOM TEMPERATURE } & \multicolumn{3}{|c|}{ AT $505 \mathrm{~K} \quad\left(450^{\circ} \mathrm{F}\right)$} & \multicolumn{3}{|c|}{$\begin{array}{l}\text { AT ROOM TEMP AFTER } \\
1000 \text { HRS AT } 505 \mathrm{~K} \quad\left(450^{\circ} \mathrm{F}\right)\end{array}$} \\
\hline $\begin{array}{l}\text { SPEC } \\
\text { NO. }\end{array}$ & $\mathrm{MPa}$ & PSI & $\begin{array}{l}\text { SPEC } \\
\text { NO. }\end{array}$ & $\mathrm{MPa}$ & PSI & $\begin{array}{l}\text { SPEC } \\
\text { NO. }\end{array}$ & $\mathrm{MPa}$ & PSI \\
\hline 1 & $123.3(2)$ & $17,878(2)$ & 11 & 91.1 & 13,214 & 21 & 107.6 & 15,611 \\
\hline 2 & $121.1(2)$ & $17,568(2)$ & 12 & 81.9 & 11,879 & 22 & 110.3 & 16,000 \\
\hline 3 & $127.2(3)$ & $18,449(3)$ & 13 & 89.4 & 12,961 & 23 & 105.0 & 15,228 \\
\hline 4 & 132.0 & 19,152 & 14 & 88.5 & 12,830 & 24 & 105.3 & 15,278 \\
\hline 5 & 132.3 & 19,195 & 15 & 89.7 & 13,009 & 25 & 99.9 & 14,494 \\
\hline 6 & 132.7 & 19,242 & 16 & 89.7 & 13,005 & 26 & 98.7 & 14,313 \\
\hline 7 & 132.6 & 19,236 & 17 & 86.5 & 12,547 & 27 & 103.2 & 14,965 \\
\hline 8 & 124.4 & 18,048 & 18 & 88.1 & 12,785 & 28 & 103.7 & 15,036 \\
\hline 9 & 122.0 & 17,692 & 19 & 82.6 & 11,974 & 29 & 94.9 & 13,759 \\
\hline 10 & 131.7 & 19,098 & 20 & 88.5 & 12,841 & 30 & 107.4 & 15,584 \\
\hline AVG & $129.4(4)$ & $18,764(4)$ & AVG & 87.6 & 12,705 & $A \vee G$ & 103.6 & 15,027 \\
\hline $\begin{array}{l}\text { STD } \\
\text { DEV }\end{array}$ & 4.3 & 616 & & 3.2 & . 446 & & 9.6 & 675 \\
\hline
\end{tabular}

NOTES: (1) Shear stress was calculated from formula, $F_{S}=0.75 \mathrm{P} / \mathrm{wt}$

(2) For these two tests, the simple beam span was $8.128 \mathrm{~mm}(0.32 \mathrm{in})$

(3) For specimens \#3 to \#30 inclusive, the simple beam span was reduced to $6.35 \mathrm{~mm}(0.25 \mathrm{in})$, which was the mirimum obtainable with available equipment

(4) This average interlaminar shear stress is for specimen \#3 through $\# 10$ only 
TABLE 9

RESULTS OF BOLT BEARING TESTS

\begin{tabular}{|c|c|c|c|c|}
\hline \multirow[b]{2}{*}{$\begin{array}{l}\text { SPEC } \\
\text { NO. }\end{array}$} & \multicolumn{2}{|c|}{$\begin{array}{l}\text { TITANIUM HI-LOK } \\
\text { SIZE }\end{array}$} & \multicolumn{2}{|c|}{ FAILURE LOAD } \\
\hline & $\mathrm{mm}$ & in & $N$ & $1 b$ \\
\hline $1 A$ & 3.97 & $5 / 32$ & 6343 & 1426 \\
\hline $1 B$ & & & 6583 & 1480 \\
\hline $2 A$ & & & 6263 & 1408 \\
\hline $2 \mathrm{~B}$ & & & 6236 & 1402 \\
\hline $3 A$ & & & 6405 & 1440 \\
\hline $3 B$ & & & 6389 & 1436 \\
\hline $4 A$ & & & 6343 & 1426 \\
\hline $4 B$ & & & 6485 & 1458 \\
\hline $5 A$ & & & 6085 & 1368 \\
\hline $5 B \cdot$ & $\gamma$ & $y$ & 6512 & 1464 \\
\hline$A V G$ & & & 6364 & 1431 \\
\hline \multicolumn{3}{|l|}{$\begin{array}{l}\text { STD } \\
\text { DEV }\end{array}$} & 146 & 33 \\
\hline $6 \mathrm{~A}$ & \multirow{10}{*}{4.76} & \multirow{10}{*}{ 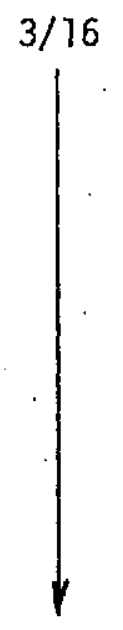 } & 7117 & 1600 \\
\hline $6 B$ & & & 7206 & 1620 \\
\hline $7 A$ & & & 7633 & 1716 \\
\hline $7 \mathrm{~B}$ & & & 7784 & 1750 \\
\hline $8 A$ & & & 7579 & 1704 \\
\hline $8 B$ & & & 7330 & 1648 \\
\hline $9 A$ & & & 7482 & 1682 \\
\hline $9 \mathrm{~B}$ & & & 7562 & 1700 \\
\hline $10 A$ & & & 7277 & 1636 \\
\hline $10 B$ & & & 7001 & 1574 \\
\hline AVG & & & 7397 & 1663 \\
\hline \multicolumn{3}{|l|}{$\begin{array}{l}\text { STD } \\
\text { DEV }\end{array}$} & 250 & 56 \\
\hline
\end{tabular}


Additional examination of the failed specimens indicated that because single lap joints undergo considerable bending at the fastener by the time they fail, the head of the $\mathrm{Hi}$-Lok fastener left a severe dent in the surface of the boron/ aluminum composite. Scanning electron microscope (SEM) pictures (Figure 75) of this area demonstrated that the denting produced severe crushing damage of the surface layers of filaments.

To obtain a comparison of the bolt bearing strength of boron/aluminum composite with that of titanium, two of the undamaged strips of titanium were bolted together with a $4.762 \mathrm{~mm}(3 / 16$ inch) titanium Hi-Lok and then pulled until failure occurred. The failure load for the $1.016 \mathrm{~mm}(0.04$ inch) thick titanium strip specimen was $7517 \mathrm{~N}$ (1690 pounds). This value compared closely with the 7397 (1663 pounds) average for the boron/aluminum specimens with the same fastener but of course the titanium was only half as thick as the boron/aluminum.

Tension Fatigue Tests

Tenson fatigue tests were conducted on boron aluminum specimens which were $2.54 \mathrm{~cm}(1.00$ inch) wide and contained a $4.775 \mathrm{~mm}(0.188 \mathrm{inch})$ hole in their centers. The $R$ value (ie; minimum stress to maximum stress ratio) for all specimens was 0.1 . Two of the specimens were tested statically in tension to obtain the first point on the $\mathrm{S}-\mathrm{N}$ fatigue curve and the strengths of these together with the cycled test data are summarized in Table 10 and Figure 76. At a stress of $242.8 \mathrm{MPa}(35,222 \cdot \mathrm{psi})$, which represented 66.6 percent of the $364.5 \mathrm{MPa}(52,867 \mathrm{ps} i)$ average of the statically tested specimens, the number of cycles to failure exceeded the desired $10^{6}$ cycle limit and hence this stress was determined to be the "fatigue strength" of the material. One of these two specimens reached $3,139,000$ cycles before faiture occurred (in the bonded steel extension plates, Figure 77). All the other specimens failed in tension at the minimum cross-sectional area in the vicinity of the hole. It was interesting to observe that in all of the specimens cracks appeared at the edges of the hole even after a relatively low number of cycles, but after progressing onty about $0.794 \mathrm{~mm}$ (1/32 inch), a second pair of cracks opened up, as shown in Figure 78, in a direction parallel to the load and grew progressively longer until catastrophic failure occurred when the cracks again turned perpendicular to the load.

It was theorized that the cracks perpendicular to the loading direction occurred first because of the local damage to the longitudinal fibers just under the surface, at the edges of the holes produced by the hole punching process, ie; see figures $13,14,15$, and 16 . Subsequent fatigue loading then produced cracks parallel to the loading direction in the aluminum because of differential straining between those boron fibers, which were broken and hence supported no tensile load, and those that were not broken and hence produced a high stress concentrated load.

SEM photos were taken of the fractured surface of Specimen 2 which wa's tested statically to failure (Figure 79) and the fractured surface of Specimen 3 (Figure 80) which was cycled 2,362,000 times at a maximum alternating tensile stress of $242.8 \mathrm{MPa}(35,222 \mathrm{psi})$. Whereas the former showed clean, sharp, splits across filaments as well as the matrix, the latter showed a fragmented, worn, surface at the edges of the hole as the cracks gradually spread from fiber to fiber. 
TABLE 10

RESULTS OF FATIGUE TESTS OF $2.54 \mathrm{~cm}(1.00$ inch) WIDE TENSION SPECIMENS WITH A $4.775 \mathrm{~mm}(0.188$ inch) HOLE IN THE CENTER

SPECIMENS LOADED IN $0^{\circ}$ DIRECTION

BORON/ALUMINUM $90^{\circ}, 45^{\circ}, 90^{\circ}, 0^{\circ},-45^{\circ}, 0^{\circ},-45^{\circ}, 0^{\circ}, 90^{\circ}$, $45^{\circ}, 90^{\circ}$

\begin{tabular}{|l|l|l|l|}
\hline \multirow{2}{*}{\begin{tabular}{|}
$|c|$ \\
NOEC
\end{tabular}} & STRESS & \multicolumn{1}{l|}{ CYCLES TO FAILURE } \\
\hline 1 & 365.8 & 53,058 & Tested statical1y to failure \\
2 & 363.2 & 52,676 & Tested statically to failure \\
3 & 242.8 & 35,222 & $2,362,000$ \\
4 & 242.8 & 35,222 & $3,139,000 *$ \\
5 & 291.6 & 42,300 & 210,000 \\
6 & 291.6 & 42,300 & 178,000 \\
7 & 328.2 & 47,600 & 300 \\
8 & 311.6 & 45,200 & 59,000 \\
9 & 273.7 & 39,700 & 453,000 \\
10 & 255.1 & 37,000 & 394,000 \\
\hline
\end{tabular}

* Failed in Grip at Bearing Hole 


\section{Summary of Demonstration Test Data}

Table 11 contains the minimum values of the demonstration tests summarized in this section and has therefore been labeled "Suggested Material Properties".

The original aft pylon skin panel was made of commercially pure titanium (annealed with $F_{t u}=551.6 \mathrm{MPa}(80,000 \mathrm{psi})$ ). Table 12 gives a comparison between the material properties for this titanium derived from Mil-Hdbk-5B and the results of Table 11 for the particular substituted boron/aluminum composite.

Figure 81 gives a comparison of the fatigue properties for commercially pure titanium (annealed with $F_{\text {tu }}=551.6 \mathrm{MPa}(80,000 \mathrm{psi})$ ) derived from the fatigue properties of Ti-8Al-1Mo-1V titanium taken from Mil-Hdbk-5B and the fatigue properties of the particular substituted boron/aluminum composite.

\section{COMPONENT FABRICATION}

This section contains the description of the fabrication of the boron/ aluminum skin components, their assembly onto the substructure, and the associated quality control and non-destructive testing that was exercised to ensure the quality of the components. From records of the time and material expended, a cost analys is of the fabrication of the four boron/ aluminum component skins was conducted and a comparison made with the existing titanium skins. Of the four boron/aluminum skins received, three were used for flight service demonstration tests and the fourth. was delivered to NASA Langley Research Center for storage and possible installation at a later date.

\section{Fabrication Plan}

After the fabrication developments described in Section II and the component design drawings described in Section III were completed, the Fabrication Plan (included as Appendix C) was prepared. This plan contained the exact details of the fabrication of the skins as well as the punching, trimming, and 


\section{TABLE 11}

SUGGESTED MATERIAL PROPERTIES OF BORON/ALUMINUM COMPOSITE WITH $90^{\circ}$, $45^{\circ}, 90^{\circ}, 0^{\circ},-45^{\circ}, 0^{\circ},-45^{\circ}, 0^{\circ}$, $90^{\circ}, 45^{\circ}, 90^{\circ}$ FILAMENT ORIENTATION (a)

\begin{tabular}{|c|c|c|c|c|c|c|}
\hline \multirow{2}{*}{$\begin{array}{l}\text { MATERIAL } \\
\text { PROPERTY }\end{array}$} & \multicolumn{2}{|c|}{ ROOM. TEMPERATURE } & \multicolumn{2}{|c|}{ 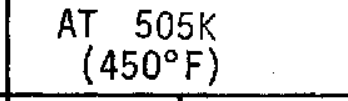 } & \multicolumn{2}{|c|}{$\begin{array}{l}\text { AT ROOM TEMP AFTER } \\
1000 \text { HRS AT } 505 \mathrm{~K}\end{array}$} \\
\hline & $\mathrm{MPa}$ & PSI & $\mathrm{MPa}$ & PSI & $\mathrm{MPa}$ & PSI \\
\hline$F_{t u}$ & 470.9 & 68,296 & 557.5 & 80,856 & 529.9 & 76,851 \\
\hline$F_{c y}$ & 1726.0 & 250,339 & 836.2 & 121,280 & 1704.4 & 247,207 \\
\hline $\mathrm{F}_{\text {su }}($ In-Plane $)$ & 294.1 & 42,658 & $>230.3$ & $>33,401$ & 269.2 & 39,047 \\
\hline $\begin{array}{c}F_{\text {su }} \quad \text { (Inter- } \\
\text { laminar) }\end{array}$ & 2122.0 & $>17,692$ & $>81.9$ & $>11,879$ & $>94.9$ & $p 13,759$ \\
\hline$F_{\text {bru }} \frac{4.76 \mathrm{~mm}}{(3 / 16 \mathrm{in})}$ & 723.5 & 104,933 & - & - & - & - \\
\hline $\begin{array}{l}\text { TENSION } \\
\text { FATIGUE } \\
\text { STRENGTH } \\
K=2.52\end{array}$ & 242.8 & 35,222 & - & - & - & - \\
\hline
\end{tabular}

(a) Al1 properties except fatigue were measured in the $90^{\circ}$ direction. Fatigue specimens were loaded in the $0^{\circ}$ direction. 


\section{TABLE 12}

MATERIAL PROPERTIES OF BORON/ALUMINUM COMPOSITE WITH $90^{\circ}, 45^{\circ}, 90^{\circ}, 0^{\circ},-45^{\circ}, 0^{\circ},-45^{\circ}, 0^{\circ}, 90^{\circ}, 45^{\circ}, 90^{\circ}$ FILAMENT 'ORIENTATION COMPARED WITH COMMERC IALLY'PURE TITANIUM

(PROPERTIES MEASURED IN $90^{\circ}$ DIRECTION)

\begin{tabular}{|c|c|c|c|c|c|c|c|c|}
\hline \multirow{3}{*}{$\begin{array}{l}\text { MATERIAL } \\
\text { PROPERTY }\end{array}$} & \multicolumn{4}{|c|}{ BORON/ALUMINUM COMPOSITE } & \multicolumn{4}{|c|}{ COMMERCIALLY PURE TITANIUM } \\
\hline & \multicolumn{2}{|c|}{ ROOM TEMP } & \multicolumn{2}{|c|}{ AT $505 \mathrm{~K}\left(450^{\circ} \mathrm{F}\right)$} & \multicolumn{2}{|c|}{ ROOM TEMP } & \multicolumn{2}{|c|}{ AT $505 \mathrm{~K}\left(450^{\circ} \mathrm{F}\right)$} \\
\hline & $\mathrm{MPa}$ & PSI & $\mathrm{MPa}$ & PSI & $\mathrm{MPa}$ & PSI & $\mathrm{MPa}$ & PSI \\
\hline$F_{t u}$ & 470.9 & 68,296 & 557.5 & 80,856 & 557.6 & 80,000 & 297.9 & 43,200 \\
\hline $\mathrm{F}_{c y}$ & 1726.0 & 250,339 & 836.2 & 121,280 & 482.6 & 70,000 & 217.2 & 31,500 \\
\hline $\mathrm{F}_{\text {su }}(\mathrm{In}-\mathrm{Pl}$ lane $)$ & 294.1 & 42,658 & $>230.3$ & $>33,401$ & 289.6 & 42,000 & 171.0 & 24,800 \\
\hline $\mathrm{F}_{\text {su }}($ Interlaminar $)$ & $>122.0$ & $>17,692$ & $>81.9$ & $>11,879$ & 289.6 & 42,000 & 171.0 & 24,800 \\
\hline$F_{\text {bru }} \begin{array}{l}4.76 \mathrm{~mm} \\
(3 / 16 \text { in })\end{array}$ & 710.2 & 103,000 & - & - & 827.4 & 120,000 & 496.4 & 72,000 \\
\hline $\mathrm{E}_{\mathrm{x}}^{\mathrm{tu}}$ & $\begin{array}{c}79,300 \\
\text { to } \\
193,700\end{array}$ & $\begin{array}{c}11.5 \times 10^{6} \\
\text { to } \\
28.1 \times 10^{6} \\
\end{array}$ & - & - & 106,869 & $\left.15.5 \times 10^{6}\right]$ & - & - \\
\hline$E_{x}^{c u}$ & $\begin{array}{c}78,600 \\
\text { to } \\
145,500 \\
\end{array}$ & $\begin{array}{r}11.4 \times 10^{6} \\
\text { to } \\
21.1 \times 10^{6} \\
\end{array}$ & - & - & 110,316 & $16.0 \times 10^{6}$ & - & - \\
\hline G & $\begin{array}{c}17,099 \\
\text { to } \\
42,265 \\
\end{array}$ & $\begin{array}{c}2.48 \times 10^{6} \\
\text { to } \\
6.13 \times 10^{6}\end{array}$ & - & - & 44,816 & $6.5 \times 10^{6}$ & - & - \\
\hline
\end{tabular}


mechanical fastener installation of the skins onto the internal structure. This plan and the drawing were in turn translated by planning engineers into Fabrication Orders which were detailed, step-by-step instruction sheets to be followed by the assigned production technician and approved at each step by the cognizant engineer. As changes evolved after the Fabrication Orders were written, Engineering Orders were prepared instructing and authorizing the changes so the Fabrication Orders, at all times, were kept current.

\section{QC and NDT}

When the first two boron/aluminum skins were received and visually inspected, it was determined that one was acceptable but that the other had numerous surface blemishes on both sides (Figure 82). This had been caused, according to the supplier, by a reaction between a graphite release agent left on the part during its trimming and the liquid coolant used during cutting. In spite of its cosmetic appearance, however, this panel's tension test QC results were entirely satisfactory and no premature specimen failures were initiated by the surface blemishes. Initially, it was planned that the fabricator, Hamilton Standard, would supply another panel to replace the blemished one, but because the aft pyion production schedule could not be delayed and the replacement skin schedule could not be accelerated, the rejection of this skin by Inspection was overruled by its acceptance by Engineering and it was used for the production of the second aft pylon skin.

Both skins had been U7trasonically $\mathrm{C}$-scan inspected by means of the process described in Appendix A. Although the blemished panel had no voids, some voids were detected in one corner of the unblemished panel. Fortunately, it was possible to so orient this panel that these voids were entirely removed when the diagonal cut across the corner (Figure 83) was made and so it too was accepted for production of the first aft pylon skin.

When the third boron/aluminum skin was received, its appearance and ultrasonic C-scan NDT results were satisfactory, but Hamilton Standard had reported that their QC tension tests of specimens cut from the panel were low in the $90^{\circ}$ layup direction, ie; $379.2 \mathrm{MPa} \quad(55,000 \mathrm{psi})$ instead of the $503.3 \mathrm{MPa}$ (73,000 psi) target property specified in the procurement document Appendix $A$. To check Hamilton Standard's claim that the low results were attributable to poor specimen quality (the material for the tests being taken from the edge of the panel) and that the rest of the panel was satisfactory, additional specimens were fabricated and tested by Douglas. When these specimen strengths met the target tensile strength of Appendix A, this panel was accepted for production of the third aft pylon skin.

When the fourth panel was received, its NDT and QC results satisfactorily met the requirements of Appendix $A$; and it was accepted for production as the spare fourth aft pylon skin for NASA's retention.

\section{Composite Skin Fabrication and Installation}

After each of the four skins were accepted for production, they were cut to the correct outline and their holes were located and punched (Figure 8.4) in 
accordance with the Manufacturing Plan outlined in Appendix $C$, and the trimming and hole preparation processes described in Appendix B. Both surfaces were alodined and the interior surface was painted with FR epoxy primer. Each skin was then given to the production department where its holes were used as a template to drill the holes in the substructure. After installing the boron/aluminum skin onto the substructure (Figure 85 ), the remaining aluminum skins were also added (Figure 86 ). When the entire aft pylon was fabricated, it was delivered to the paint shop where it was cleaned and its aluminum skins were painted with the United Airlines characteristic blue and white colors. In accordance with the painting drawing, since the engine exhaust and heat would scorch and discolor the lower titanium panels, these are normally left unpainted and hence, the boron/aluminum substitutes were also left unpainted. To preclude the possibility that during their five year service, the boron/aluminum skins might be damaged, discarded, and replaced by United Airlines service personnel, both sides were lettered with the words "BORON/ALUMINUM COMPOSITE PROPERTY

OF DOUGLAS AIRCRAFT COMPANY, IF DAMAGED, NOTIFY NEAREST DOUGLAS REPRESENTATIVE FOR DISPOSITION".

\section{COST ANALYSIS}

Direct labor manhours actually expended for the fabrication of each of the three boron/aluminum composite aft pylon skins were as follows:

$$
\begin{aligned}
& \text { 1. Trimming and cutting - } 8 \text { manhours } \\
& \text { 2. Punching holes - } 6 \text { manhours } \\
& \text { 3. Alodining and priming - } 2 \text { manhours } \\
& \text { 4. Inspection } \\
& \text { - } 1 \text { manhour } \\
& \text { Total } 17 \text { manhours }
\end{aligned}
$$

Because this total does not include the cost of direct labor supervisory and other support personnel, it is customary to multiply it by a factor of 1.8 to obtain the true total manhour cost, ie;

\section{$17 \times 1.8=30.6$ manhours}

This total is obviously very high, even for the first to the third new part. However, it was not an object of this program to develop low cost fabricating approaches or to emphasize cost competitiveness between boron/aluminum composites and titanium. This total cost should therefore not be considered as representative of typical fabrication costs of other similar applications. Furthermore, as a simple flat skin with a number of holes, it does not represent a particularly sophisticated application from which much extrapolation can be made to the prediction of costs of more complicated metal composite structures.

At $\$ 496 / \mathrm{Kg}(\$ 225 / \mathrm{lb})$ each of the as received blanks of boron/aluminum weighing $2.125 \mathrm{~kg}(4.68 \mathrm{lb})$ cost $\$ 1,053$. This material cost included tensile spec. imen $\mathrm{QC}$ testing and $\mathrm{C}$-scan ultrasonic NDT testing. When machined to final dimensions, the boron/aluminum skin weighed $1.566 \mathrm{Kg}(3.45 \mathrm{lb})$. Hence, the 
actual finished material cost was

$$
\begin{aligned}
& \$ 1053 \div 1.566 \mathrm{Kg}=\$ 672 / \mathrm{Kg} \text { or } \\
& \$ 1053 \div 3.45 \mathrm{lbs}=\$ 305 / 1 \mathrm{~b}
\end{aligned}
$$

This actual material cost is also very high and no possibility of any reasonable comparison with similar costs of finished titanium skins exists.

\section{FLIGHT TESTS}

This section briefly describes the flight service demonstration testing that will follow in June 1975, after delivery of the three (3) particular DC-10 aircraft to United Airlines that include the three (3) boron/aluminum composite aft.pylon skins.

\section{Flight Service Demonstration Tests}

These tests will include the installation, periodic inspection, flight testing, removal and replacement of the three aft pylon boron/aluminum skins with the present titanium skins. With the delivery of the three DC-10 aircraft into flight service in July: 1975, the scheduled fiveyear demonstration test will continue until July 1980.

2. Skin Inspection and. NDT

During the five-year flight service demonstration period, yearly visual inspections of the three boron/aluminum skins will be conducted at the participating airline's maintenance facilities. These in-service checks will be scheduled to coincide with the regularly scheduled maintenance checks. Of particular concern will be the inspection of possible delaminations, fatigue cracks, evidences of erosion, corrosion, or overheating.

3. Skin Replacement

At the conclusion of the five-year period of exposure, Douglas will arrange for the removal of the three boron/aluminum skins and the replacement of the original titanium skins.

4. Skin Shipment to NASA

After visual and non-destructive inspection by Douglas, the three exposed boron/aluminum skins will be shipped to NASA Langley for further examination and any other desired testing. 


\section{CONCLUSIONS}

1. The structural adequacy of the boron/aluminum skin panel was demonstrated by the satisfactory results of the structural tests designed to simulate operating environmental extremes for the aft pylon of the DC-10 aircraft. The performances of the boron/aluminum material in compression and in fatigue were particularly noteworthy.

2. Based on the fabrication of the specimens and the four skin panels, the fabrication methods developed were shown to be suitable for the intended application. From a manufacturing standpoint, the methods of fabricating flat skins have sufficient growth potential to apply to larger and.more complicated aircraft structural areas.

3. Although the saving of weight was not an objective of the program, the substitution of a boron/aluminum skin panel for a similar sized titanium panel resulted in a weight saving of $26 \%$. No attempt was made to develop tooling or fabrication techniques that would result in lower costs. As a result, the manufacturing and material costs for boron/aluminum were not comparable in a complementary manner with those for titanium.

4. Examination of tension, compression, and shear data of cross-plied boron/ aluminum specimens indicated considerable nonlinearity in its stress/ strain curves and the retention of significant "permanent set" when it had been loaded and unloaded. Since such nonlinearity and permanent set is undesirable from a structural application standpoint, it is recommended that suitable material and fabrication approaches be developed to reduce this inelastic behavior. 


\section{REFERENCES}

1. MDC J0717, VOL II, Section 3C - Aerodynamic Data for Stress AnalysisModels DC-10-20, and DC-10-30 Jet Transport.

2. MCDonnell Douglas Material Specification MMS-583, Class C.

3. A J Roark, Formulas for Stress and Strain, McGraw-Hil1, 3rd Edition, 1954.

4. A H Church, Mechanical Vibrations, John Wiley and Sons, 2nd Edition, 1957.

5. MDC J654l, DC-10 Boron/Aluminum Aft Pylon Boat-tail Panel-Test Plan. 


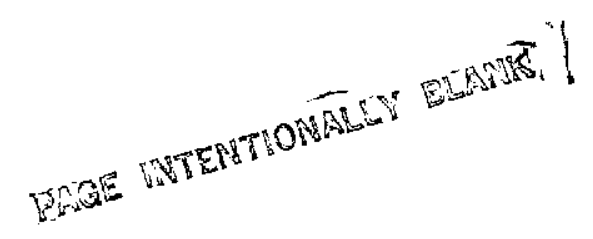




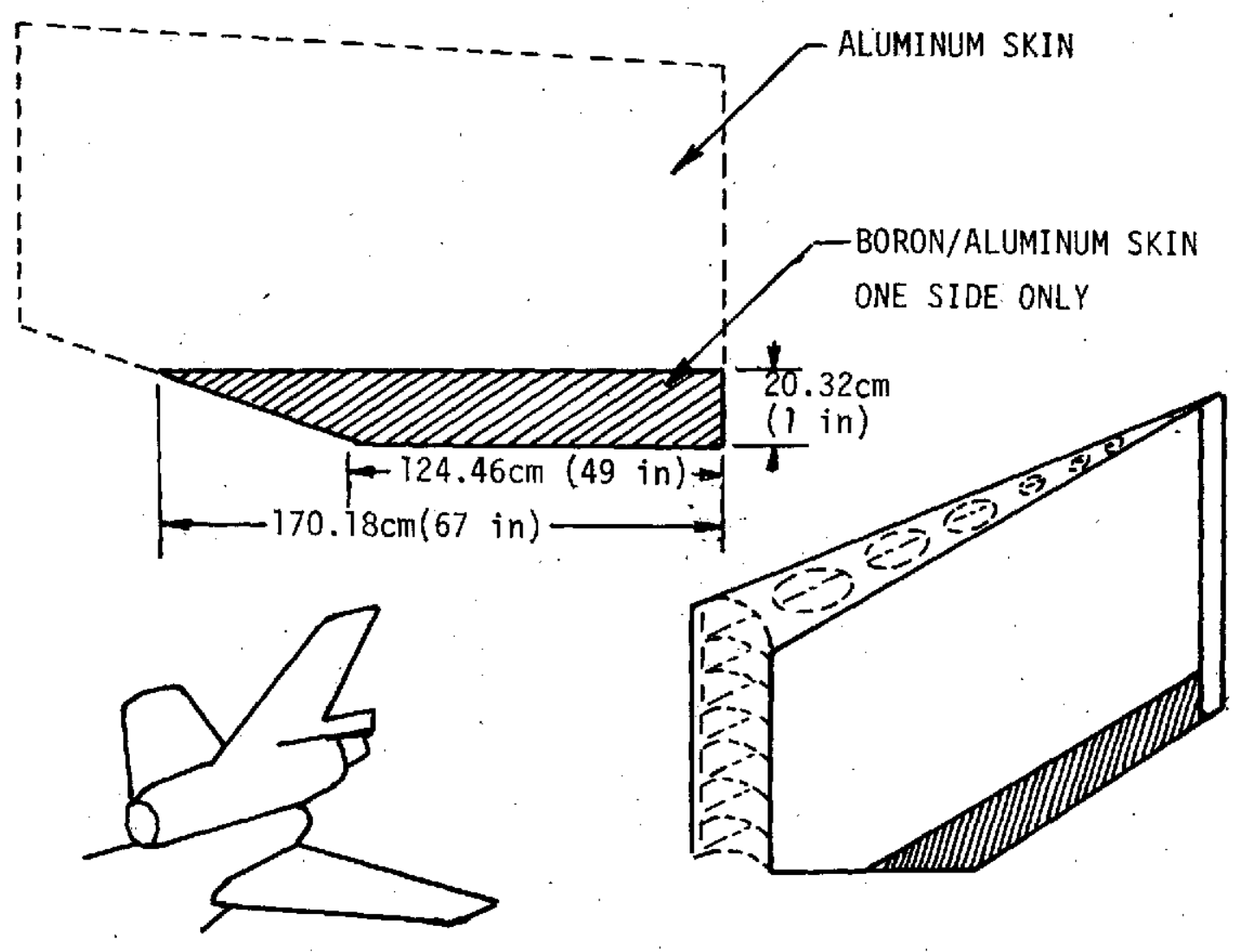

Figure 1. DC-10 Tail Pylon 


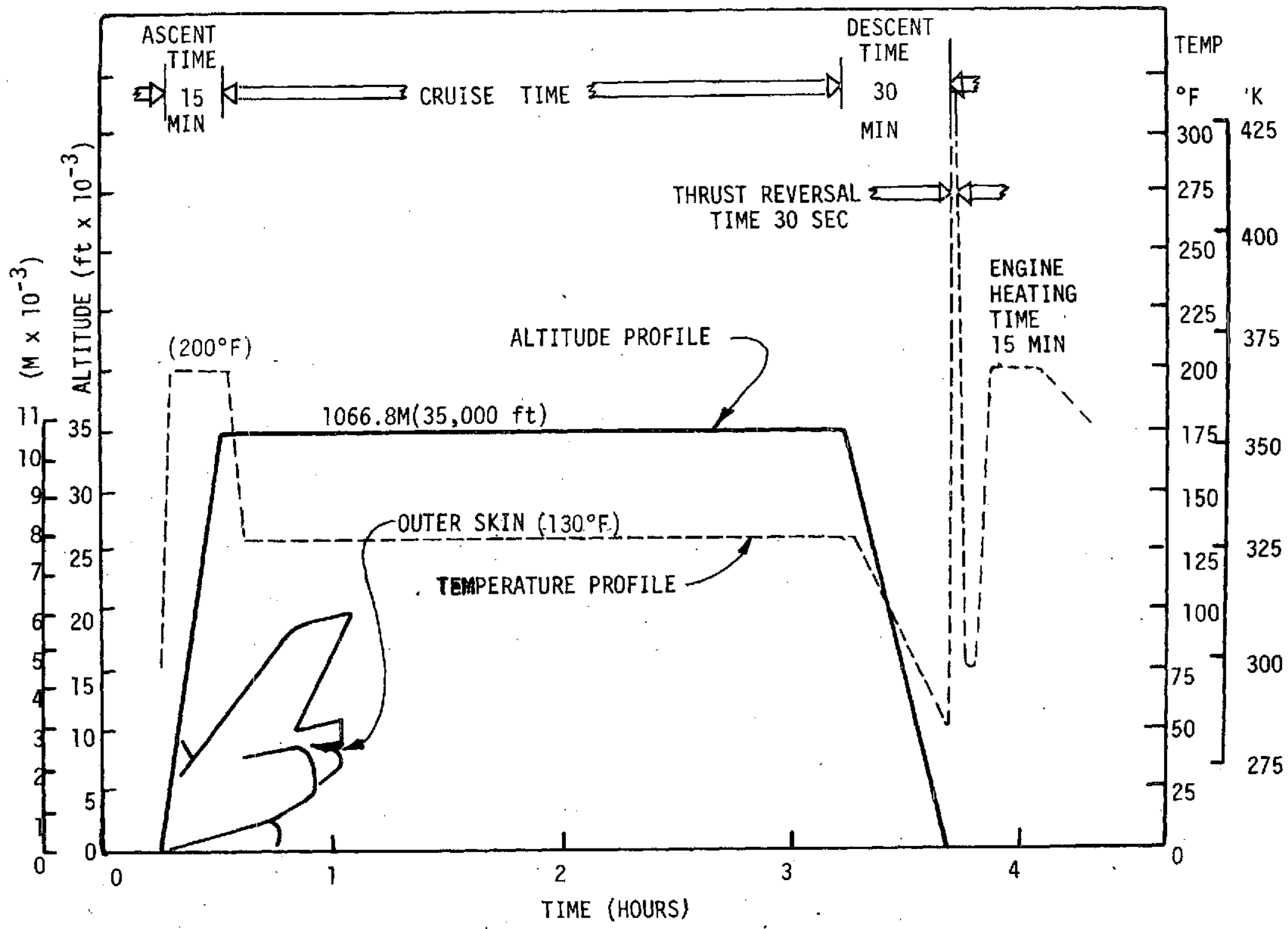

Figure 2. DC-10 Typical Mission Profile 


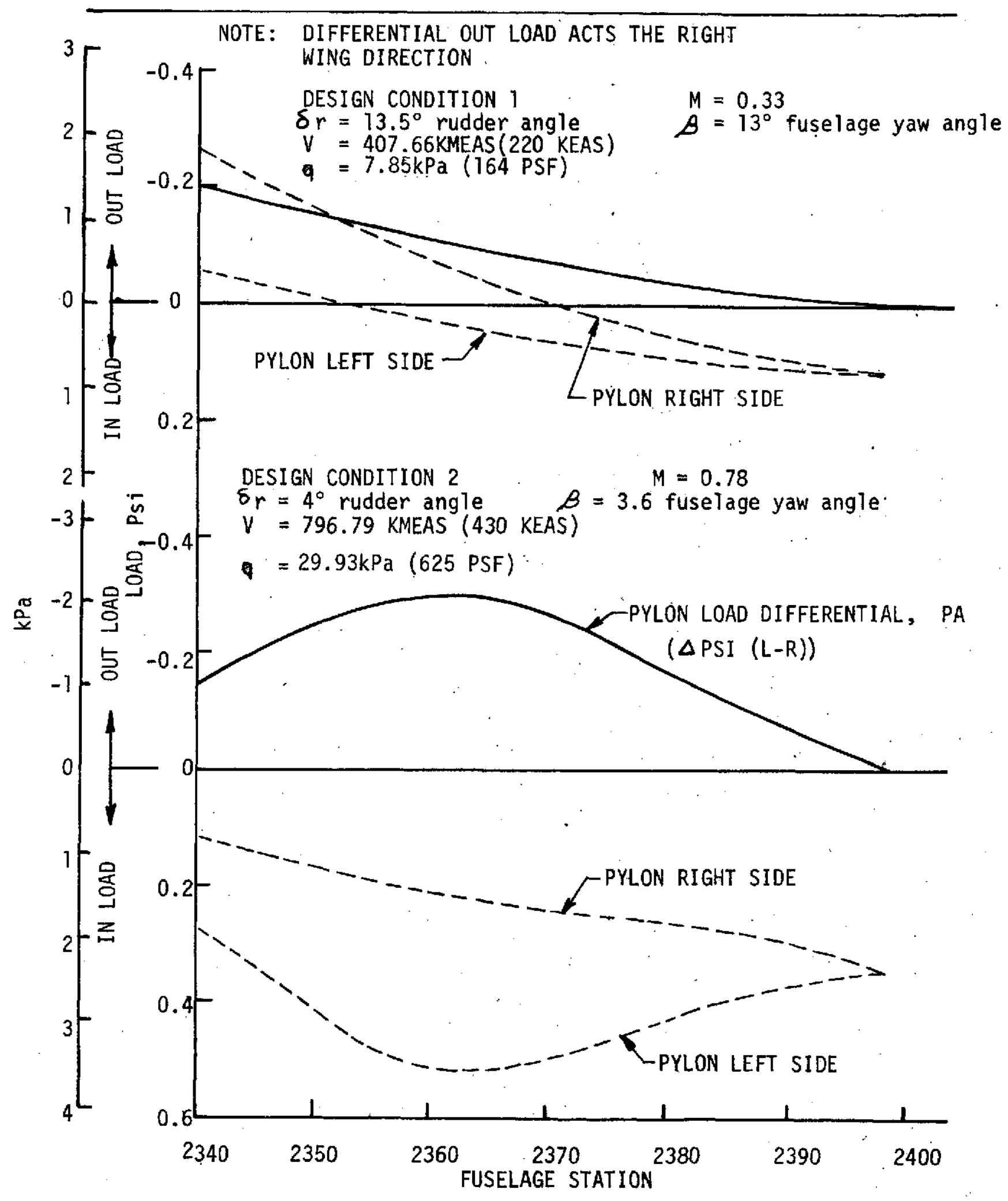

Figure 3. Estimated Aerodynamic Loads on Aft-Engine-Pylon Trailing Edge 


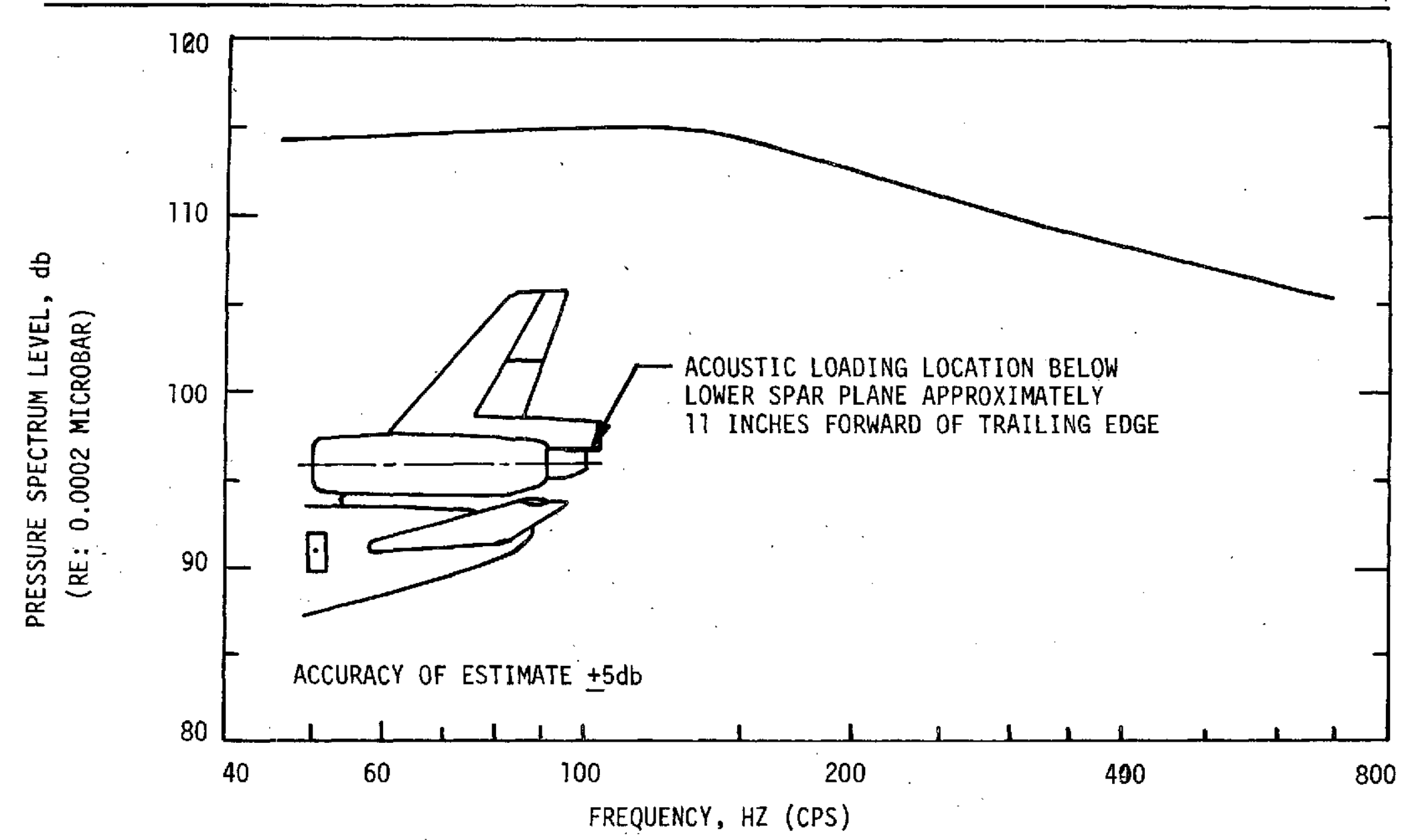

Figure 4. Estimated Acoustic Loads for 3-engine Ground Runup at Takeoff Thrust Using JT9D-15 Engines (Aft Pylon Fairing) 


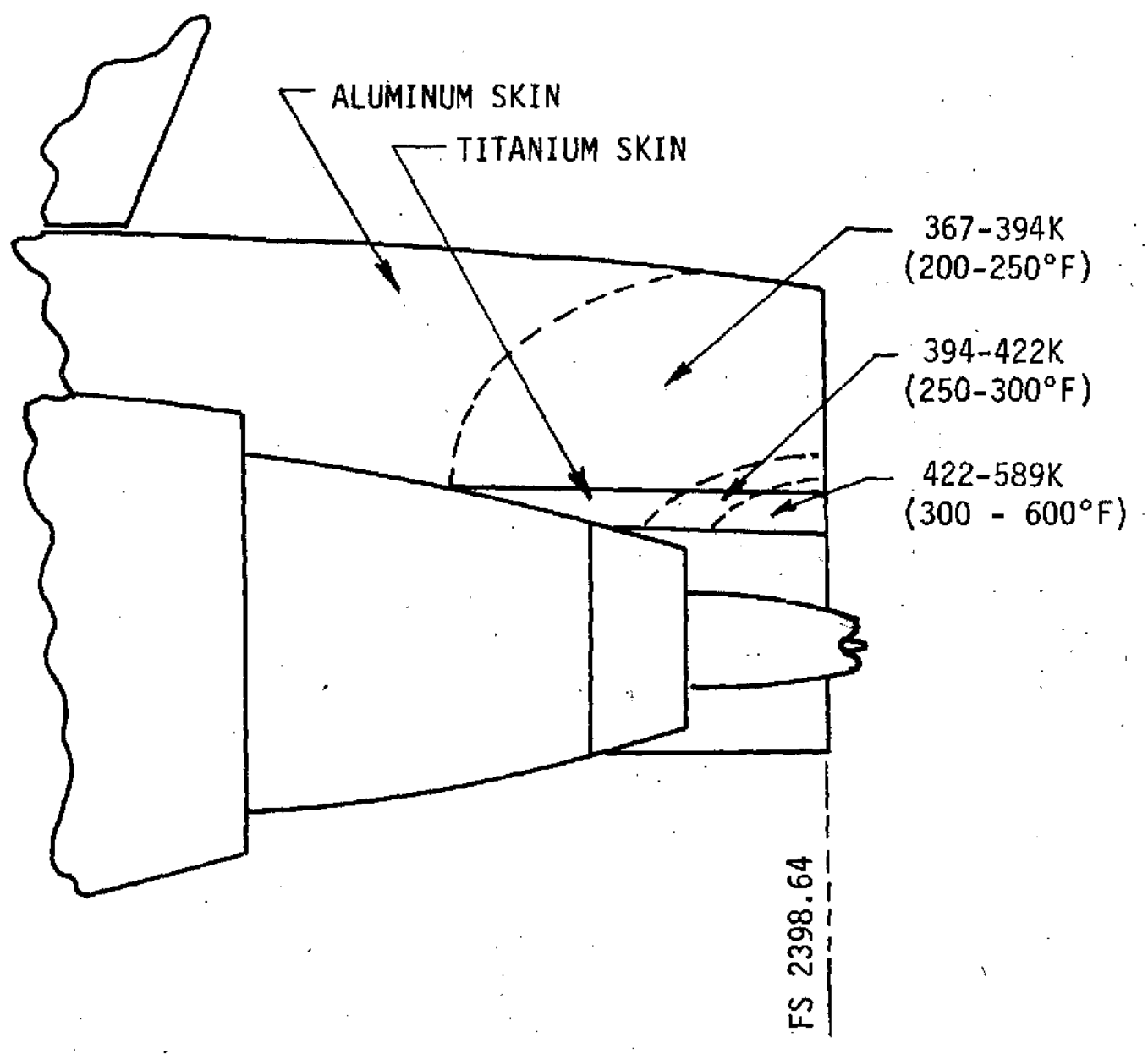

Figure 5. Engine Fairing Temperature During Reverse Thrust

43 

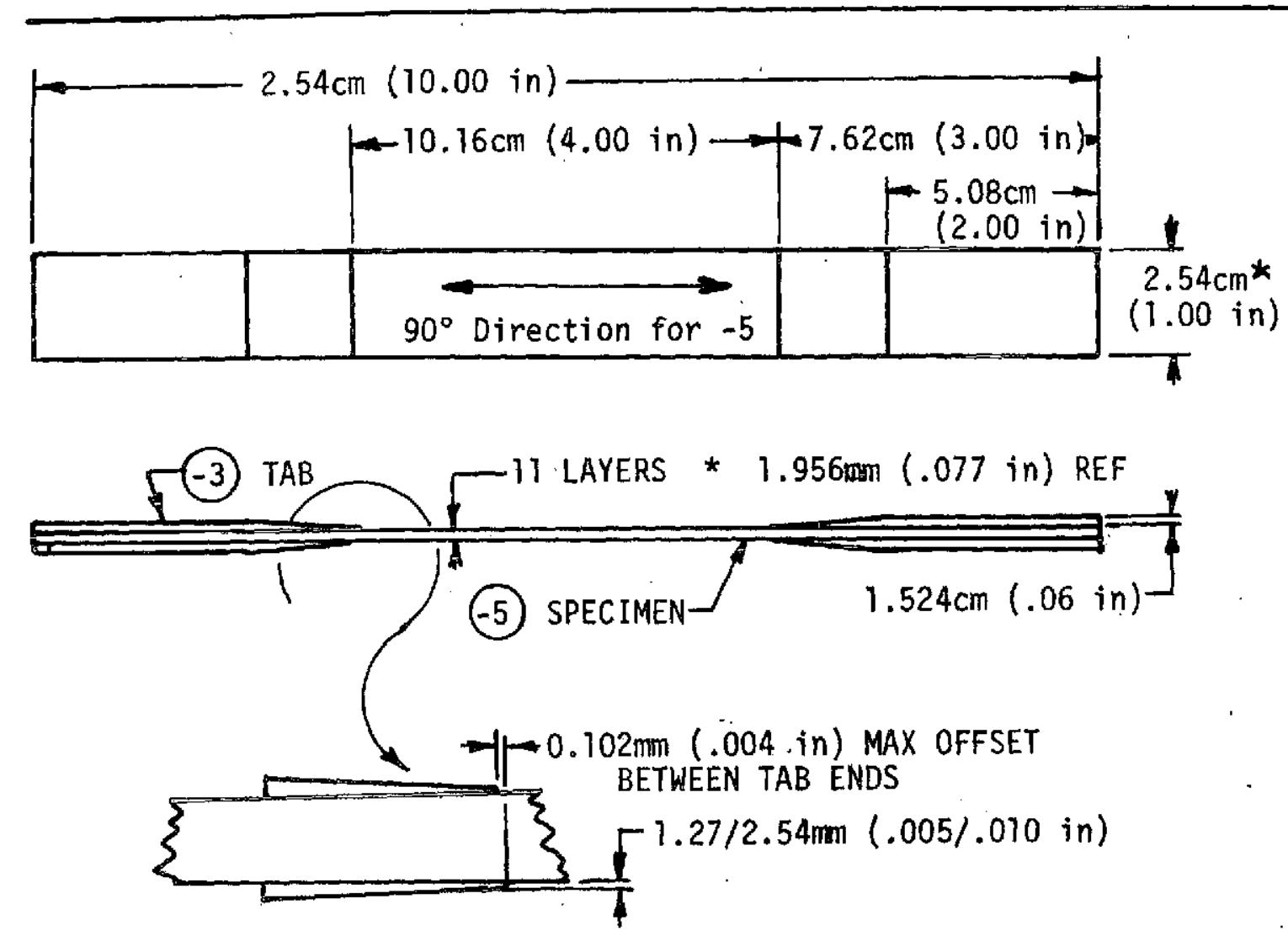

GENERAL NOTES

1. ORIENTATION OF -3 TAB TO BE IN THE $0^{\circ}, 90^{\circ}$ DIRECTION

2 BOND -3 BI-DIRECTIONAL PHENOLIC GLASS LAMINATE TABS TO -5 SPECIMEN

WITH HT424 FOR ELEVATED TEMPERATURE TEST WITH HYSOL EA951 FOR RT TEST

3. DIMENSIONS NOTED THUS (*) TO BE TAKEN IN TEST SECTION AND RECORDED BEFORE TEST

4. FABRICATION STANDARDS PER APPENDIX B

5. FABRICATE BORON/ALUMINUM PER APPENDIX A

Figure 6. Specimen Assembly - Modified IITRI Tension Test 


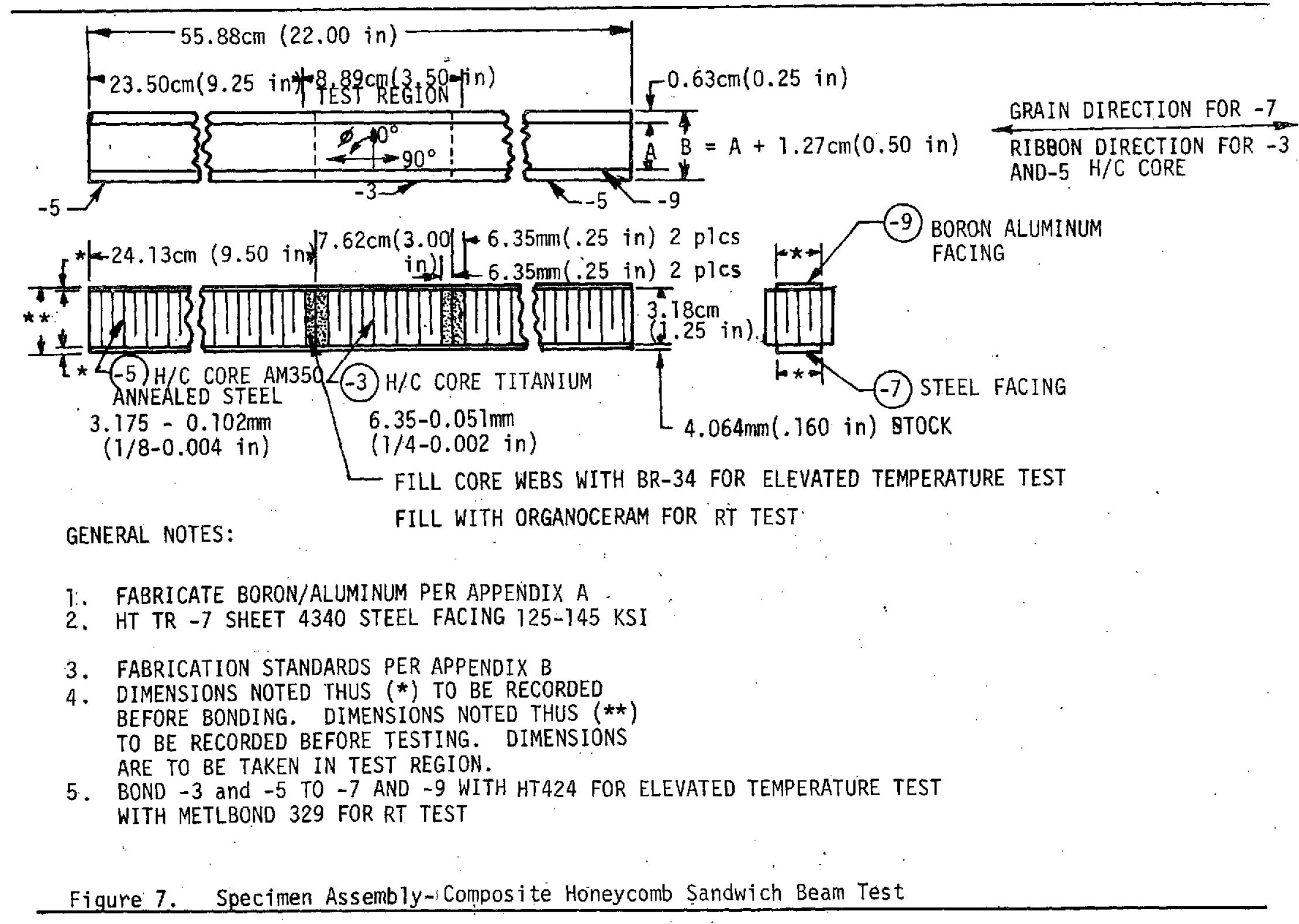




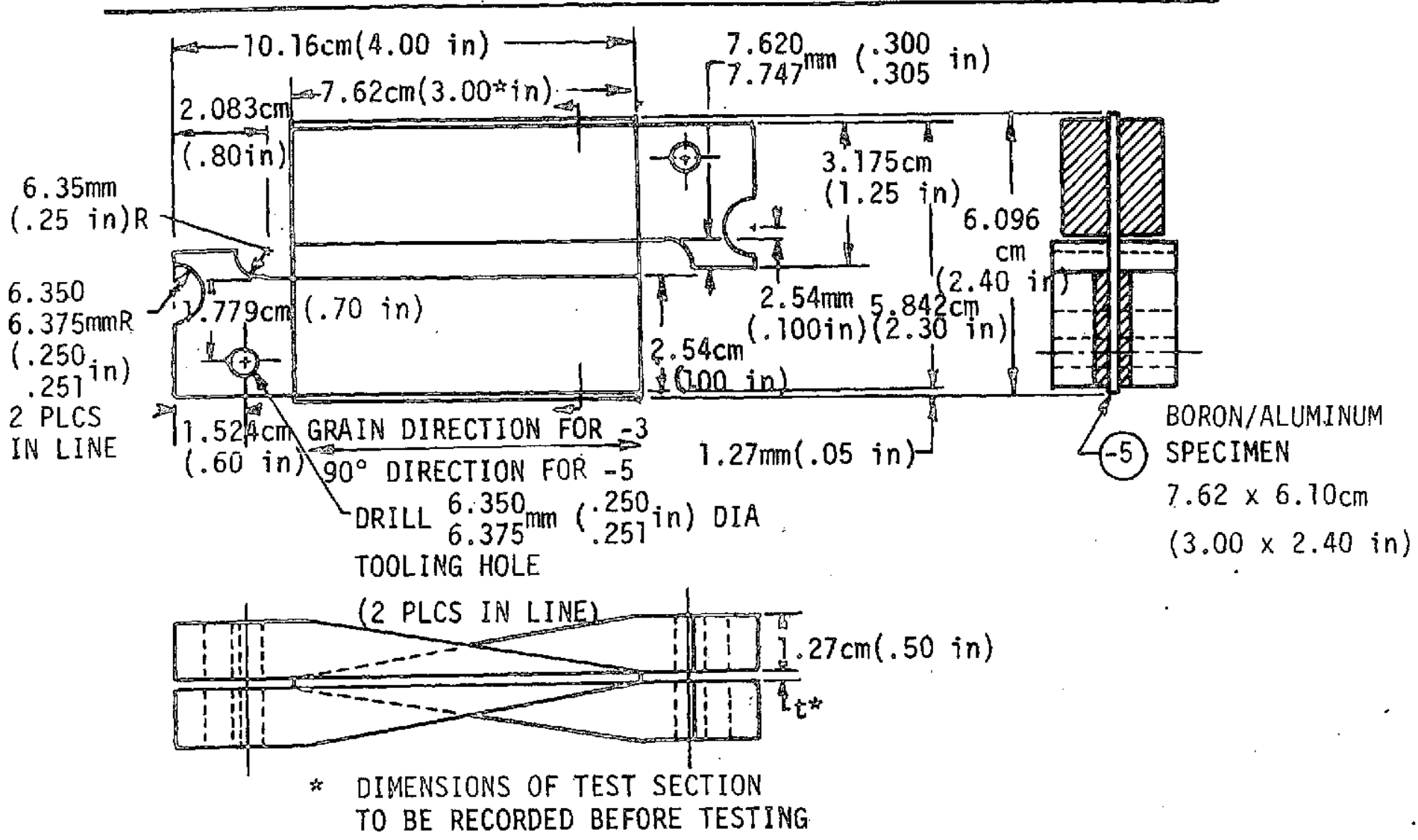

GENERAL NOTES:

1. FABRICATE BORON/ALUUMINUM PER APPENDIX A

2. FABRICATION STANDARDS APPENDIX B

3. BOND -3 AND - 4 'RAILS TO -5 SPECIMEN WITH HT424 FOR ELEVATES TEMPERÁTURE TEST WITH METLBONO 329 for RT TEST

4. MARK -3 AND -4 RAILS A AND B AS SHOWN TO INDICATE MATCHED PAIRS.

5. TOOLING FIXTURE REQUIRED DURING BONDING TO MAINTAIN DISTANCE BETWEEN -3 AND -4 RAILS AND TO LOCATE MATCHED PAIRS OF -3 AND -4 RAILS.

6. FABRICATE -3 AND -4 RAILS FROM 4130 STEEL PLATE

Figure 8. Specimen Assembly-Composite Rail Shear Test 


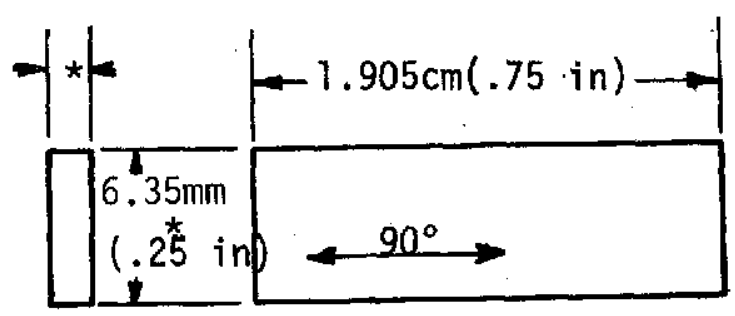

GENERAL NOTES

1. FABRICATION STANDARDS PER APPENDIX B

2. DIMENSIONS NOTED THUS (*) TO BE RECORDED BEFORE TEST.

3. FABRICATE PER APPENDIX A 


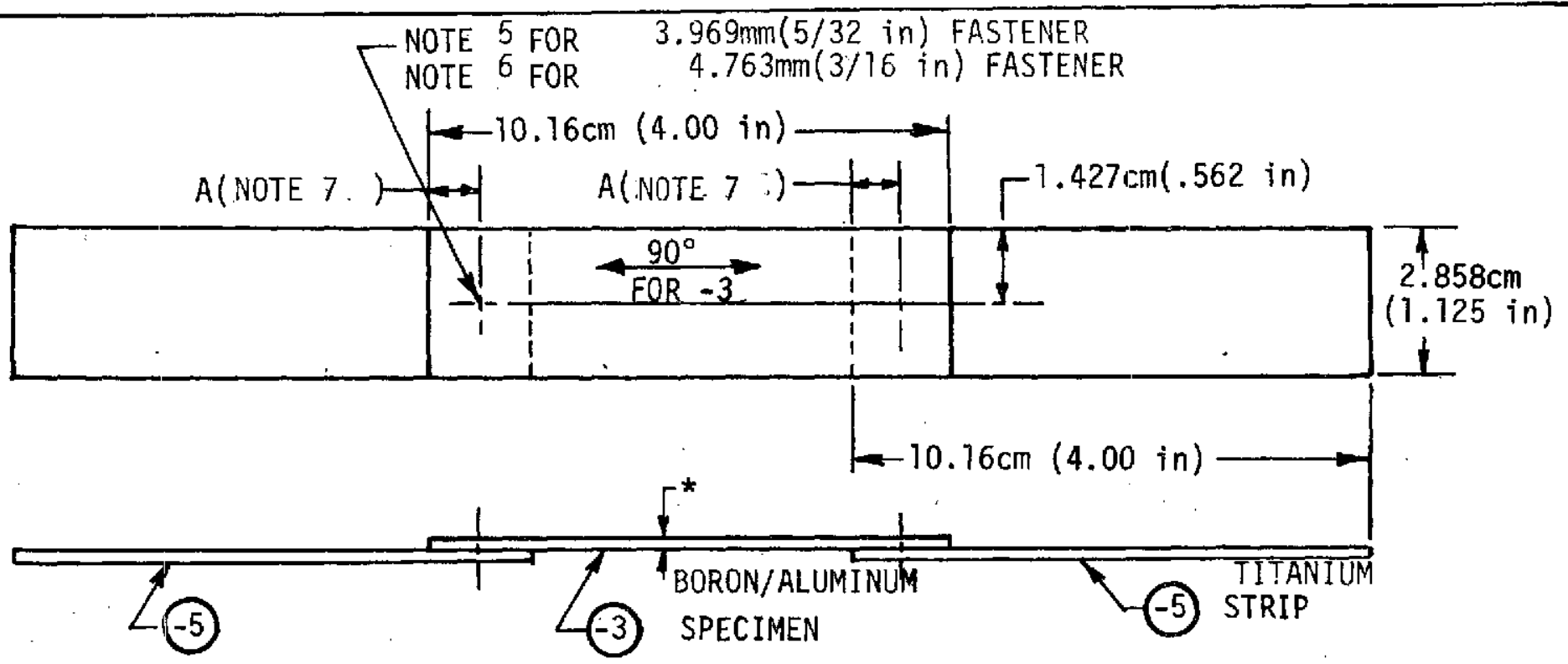

GENERAL NOTES:

i. FABRICATION STANDARDS PER APPENDIX B

2. DIMENSIONS NOTED THUS $(*)$ TO BE RECORDED BEFORE TESTING.

3. INSTALL HI-LOKS PER S7933651-11

4. FABRICATE BORON/ALUMINUM PER APPENDIX A

5. HTL334-6-2 HI-LOK WITH MS21043-3 NUT AND AN960C10 WASHER

6. $3.518 \mathrm{~mm}(.1385$ in) DIA HOLE. BREAK EDGE PER S7933654-11. PUNCH HOLE UNDERSIZE AND REAM TO FIT.

7. HLT334-4-2 HI-LOK WITH MS21043-06 NUT AND AN960C6 WASHER.

8. DIMENSION $A$ is $0.793 \mathrm{~cm}(0.312$ in) FOR $3.969 \mathrm{~mm}(5 / 32 \mathrm{in})$ FASTENER AND $1.113 \mathrm{~cm}(0.438 \mathrm{in})$ FOR $4.763 \mathrm{~mm}(3 / 16 \mathrm{in})$ FASTENER

Figure 10. Composite Specimen - Bolt Bearing Test 


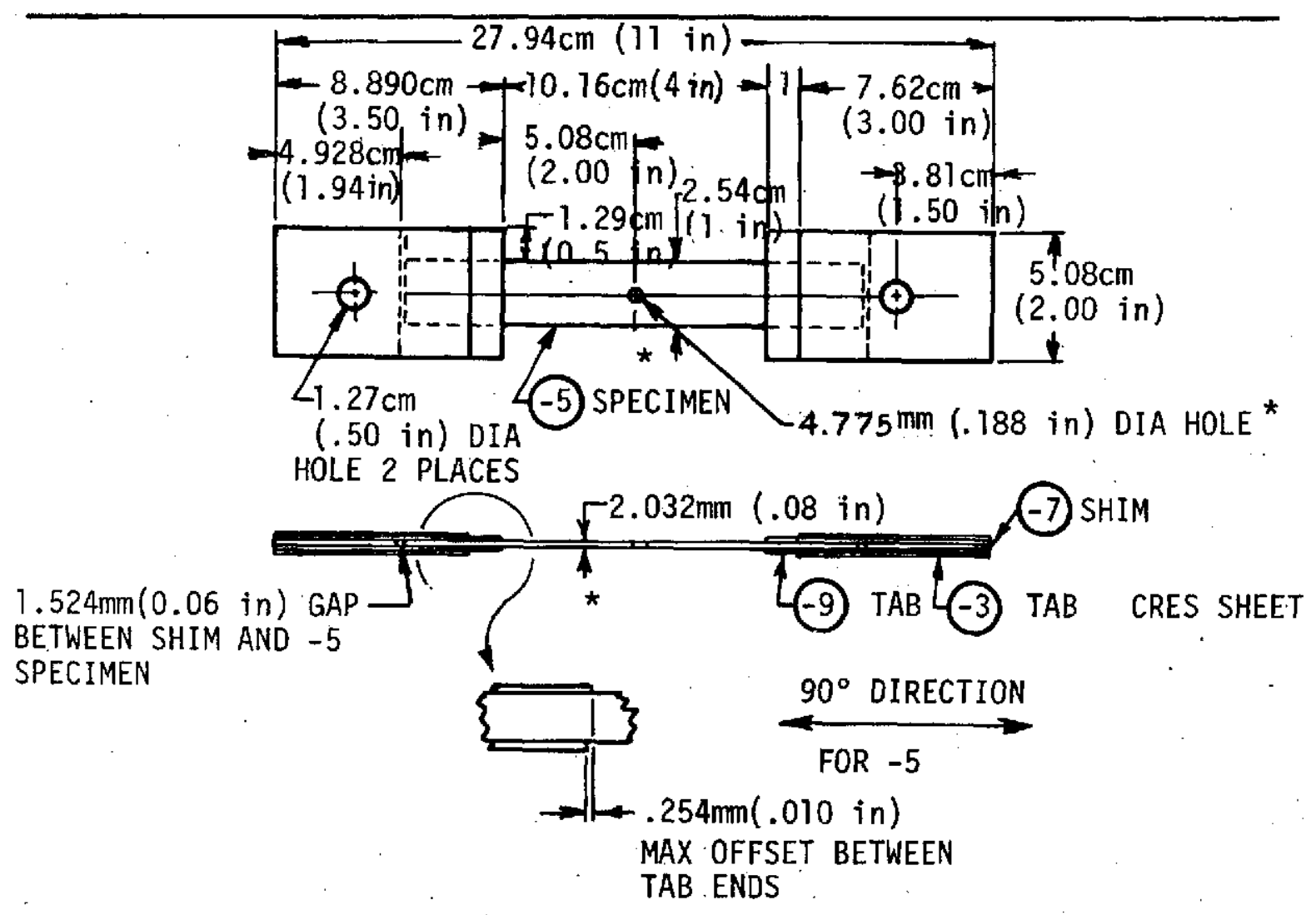

GENERAL NOTES:

1. DIMENSIONS NOTED THUS (*) TO BE RECORDED BEFORE TEST.

2. FABRICATION STANDARDS PER APPENDIX B

3. BOND - 9 TABS TO -3 TABS AND TO -5 SPECIMEN AND -7 SHIMS WITH HYSOL EA951 ADHESIVE,

4. FABRICATE BORON/ALUMINUM PER APPENDIX A

5. HOLES SHOWN ON CENTERLINE TO BE WITHIN $.096 \mathrm{~mm}$ (.003 in) EITHER SIDE OF THE CENTERL INE. 


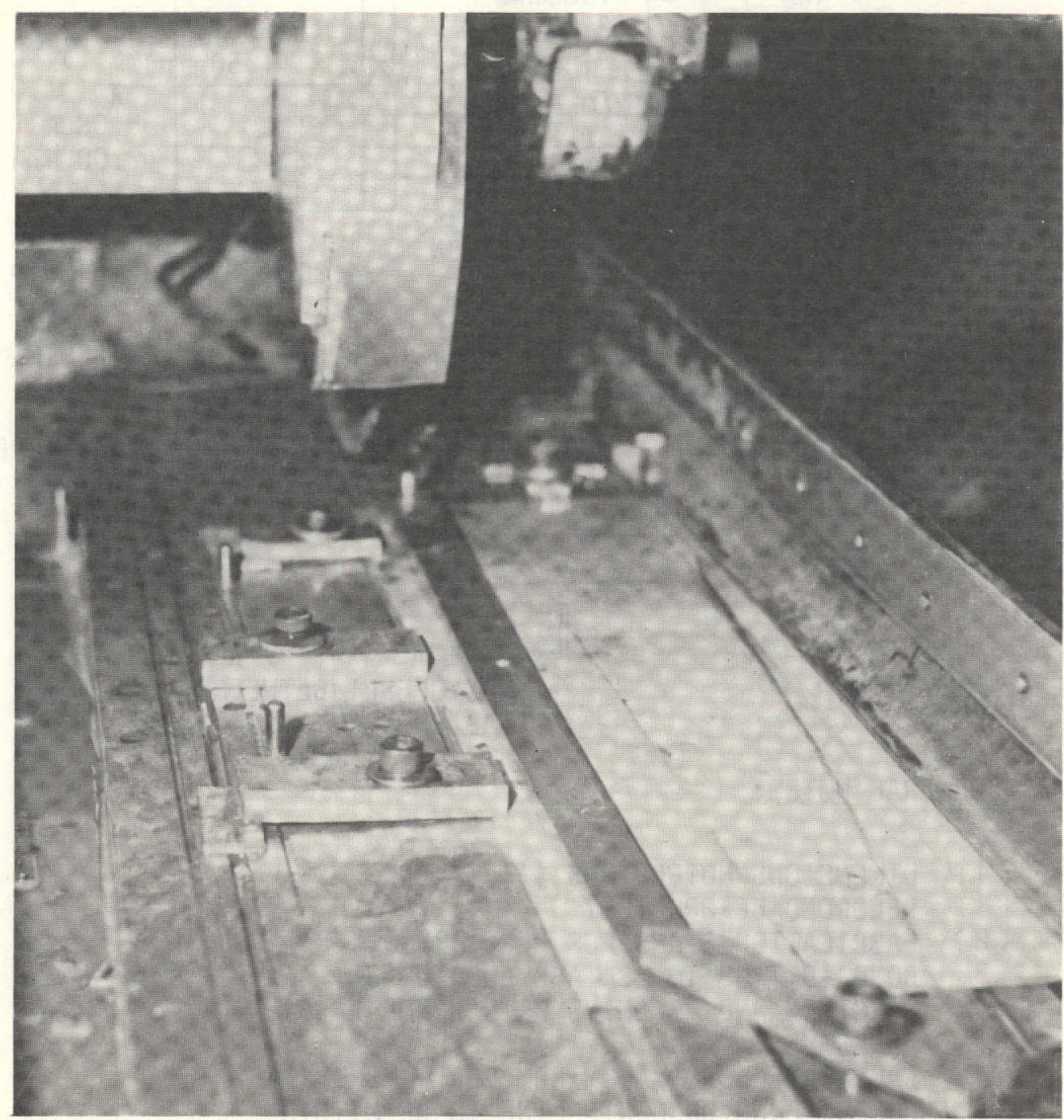

Figure 12 Cutting Boron/Aluminum with Diamond Coated Wheel 


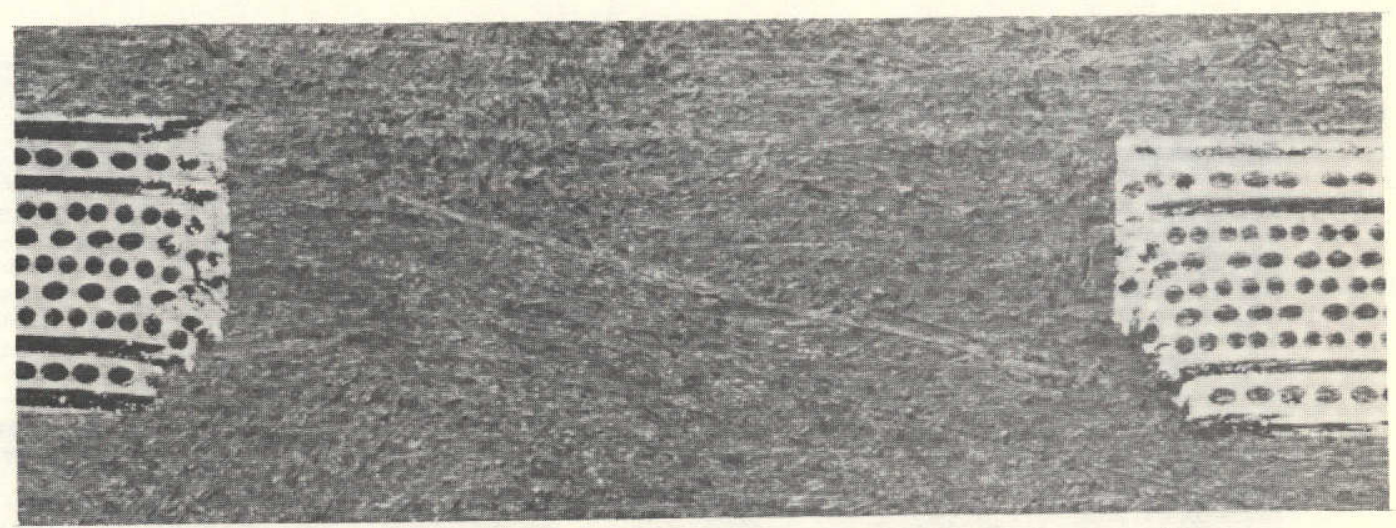

$14.75 \times$

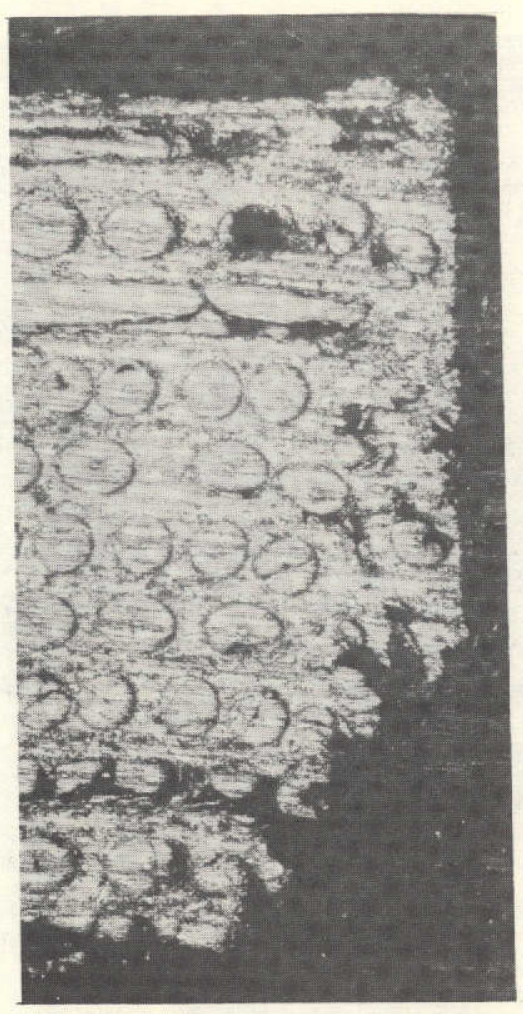

$40 \times$

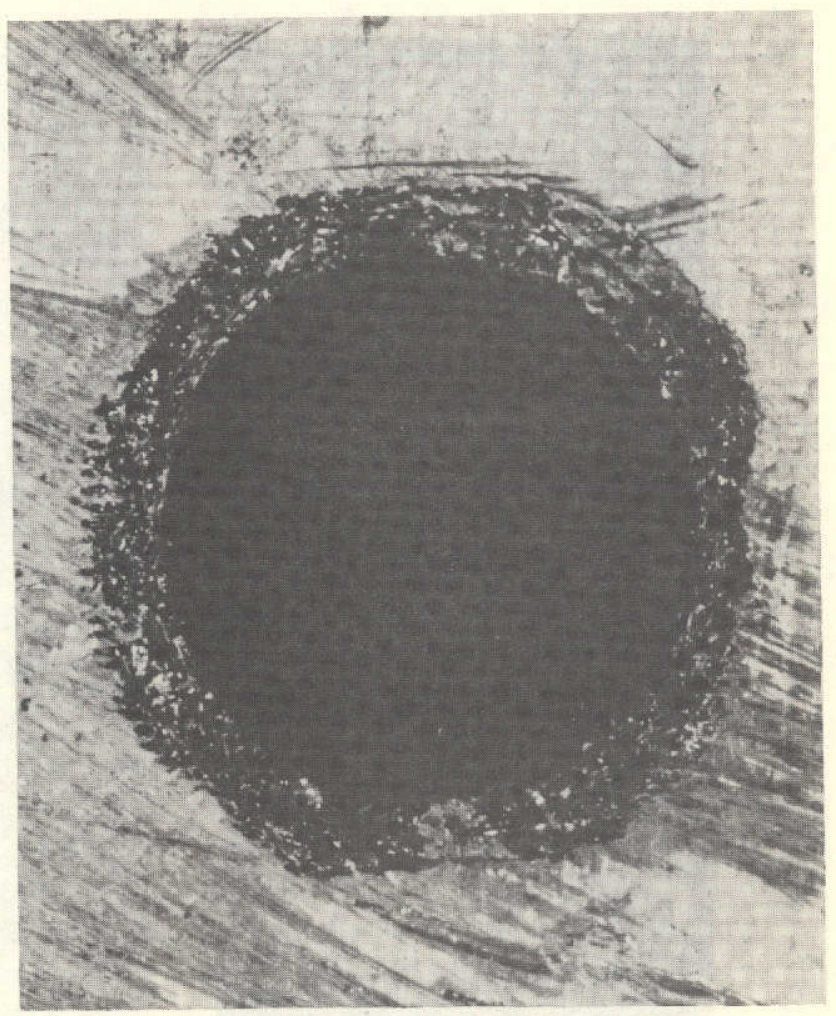

$8.4 x$

Figure 13 Hole Produced by $6.350 \mathrm{~mm}(0.250$ in) Diameter Steel Drill 


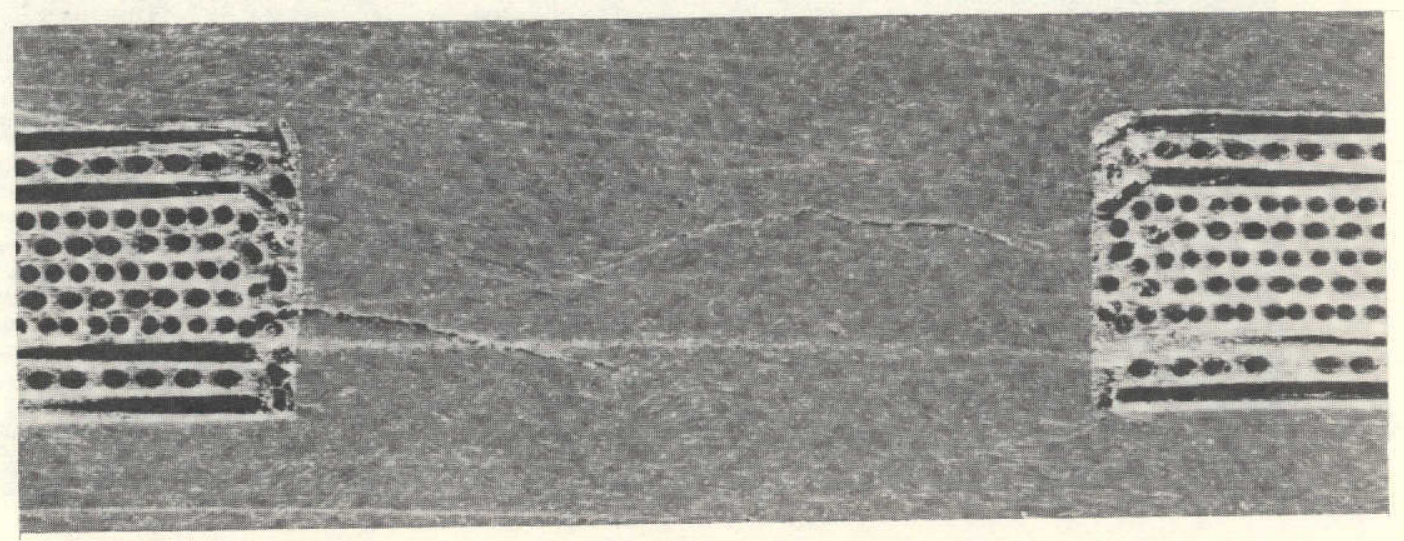

$14.75 \times$

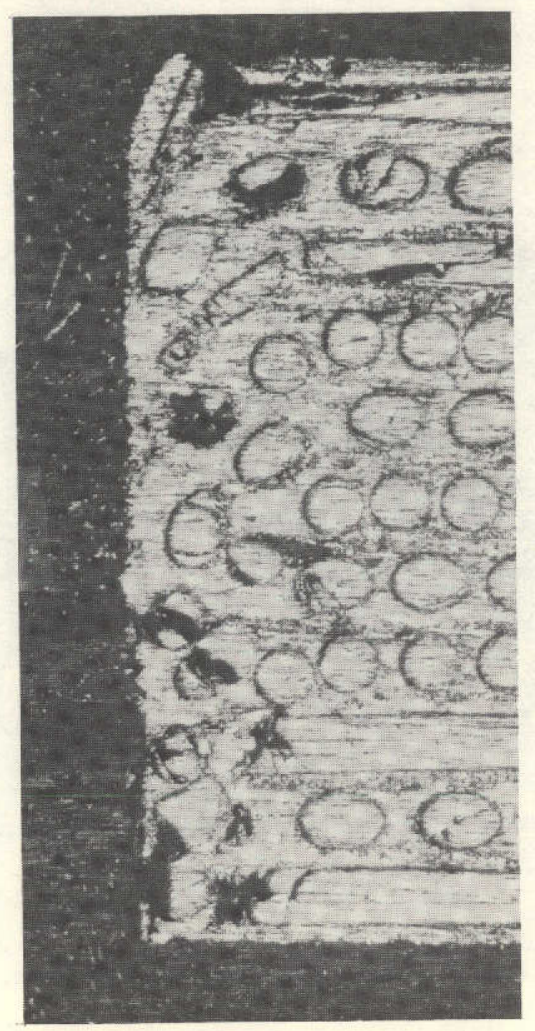

$40 \times$

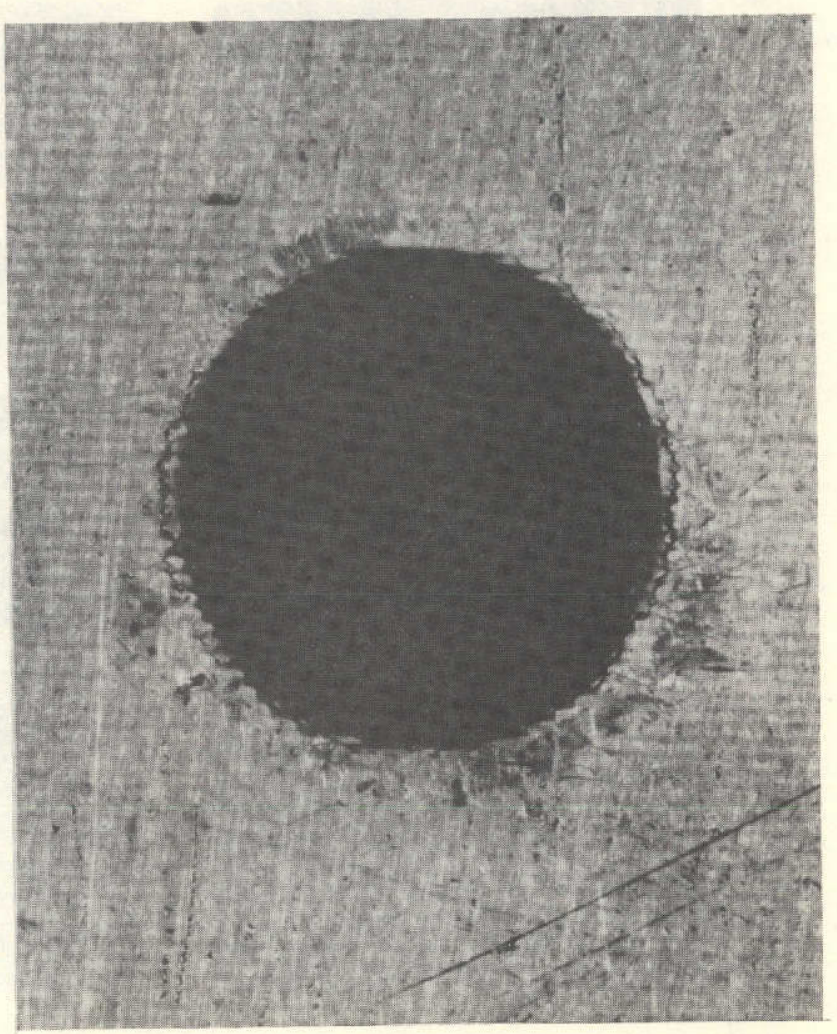

$8.4 \times$

Figure 14 Hole Produced by $5.664 \mathrm{~mm}(0.223 \mathrm{in})$ Diameter Steel Punch 


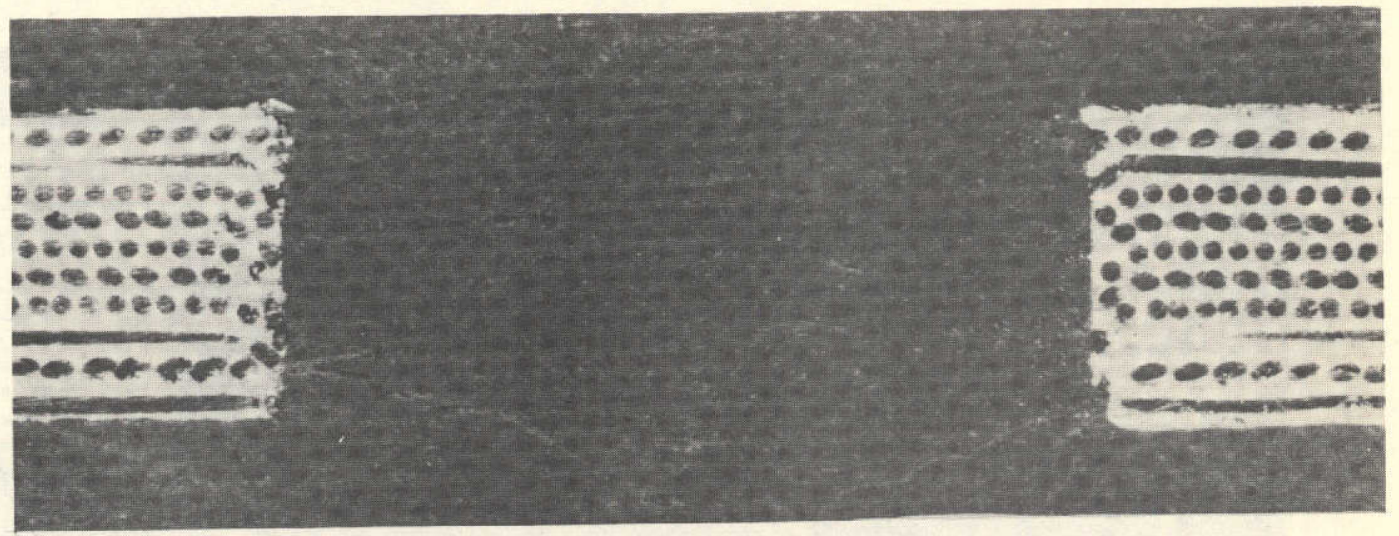

$14.75 \times$

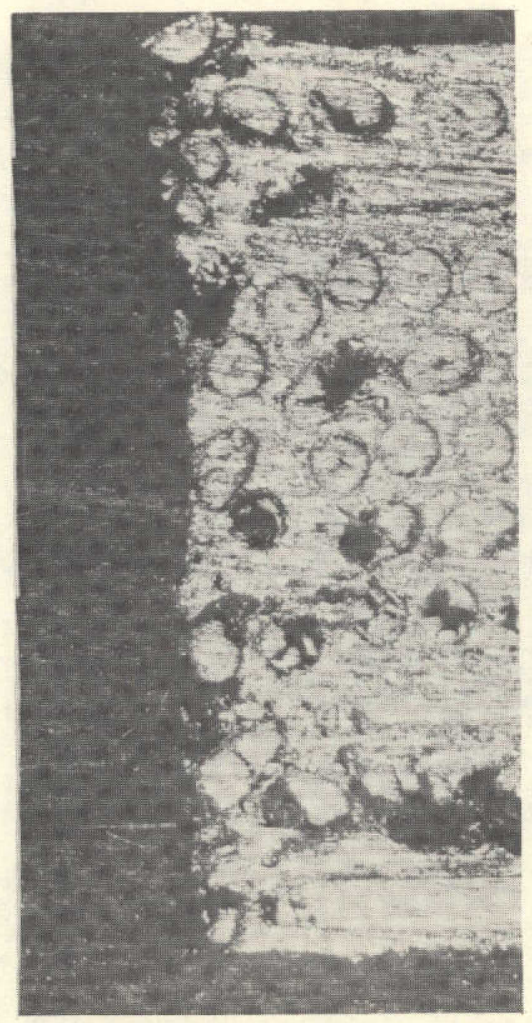

$40 \times$

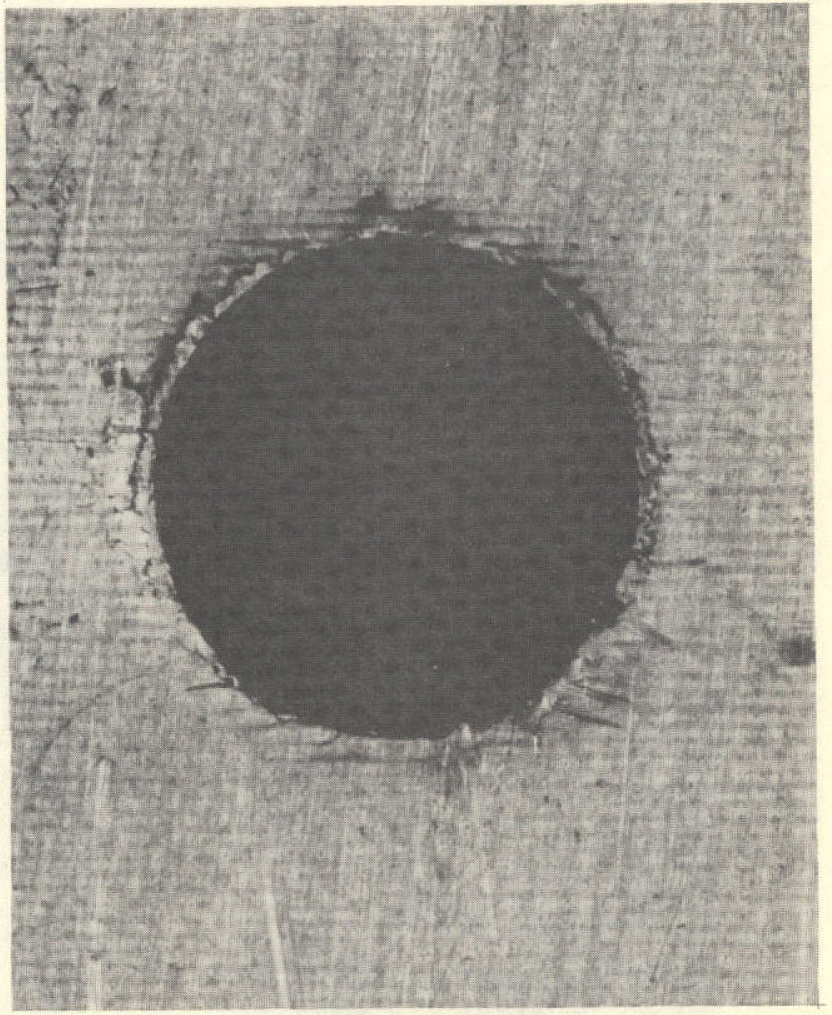

$8.4 \times$

Figure 15 Hole Produced by $5.664 \mathrm{~cm}(0.223$ in) Diameter Steel Punch Followed by $5.791 \mathrm{~mm}(.228$ in) Diameter Steel Ream 


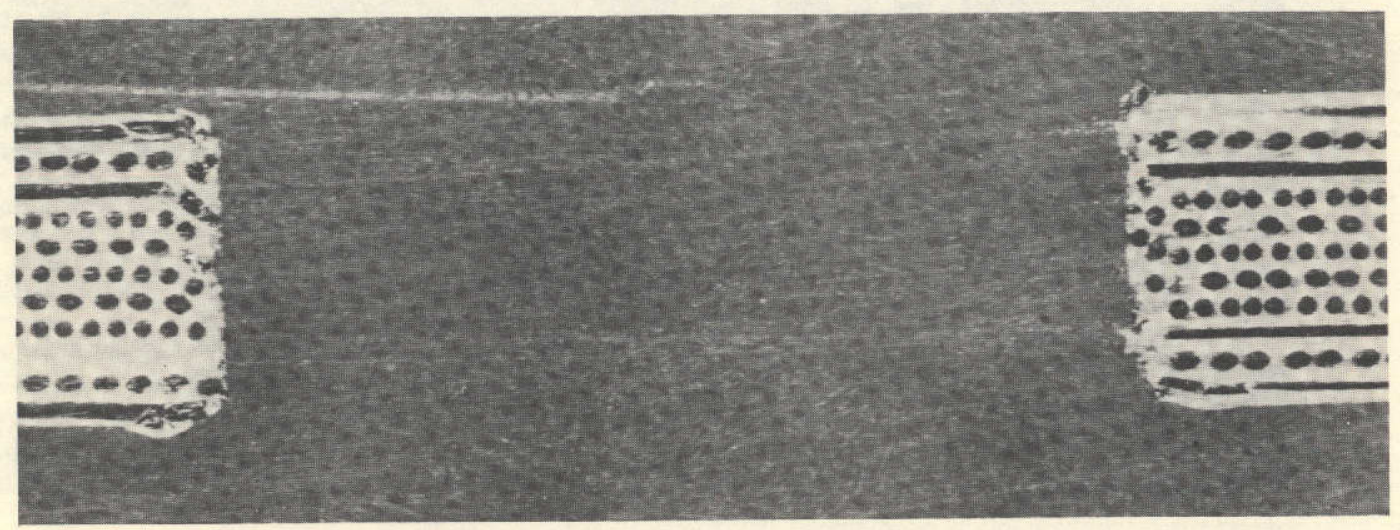

$14.75 \times$

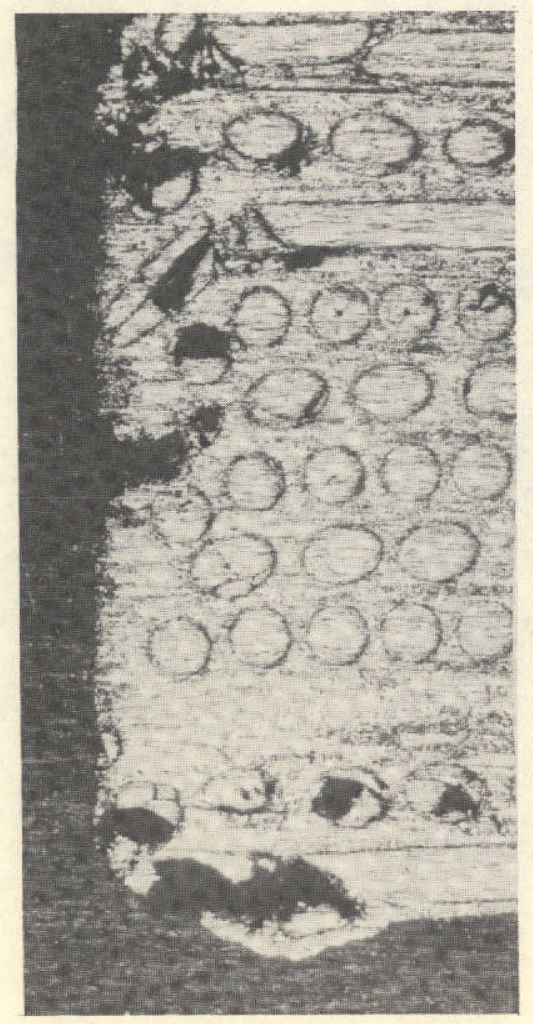

$40 \times$

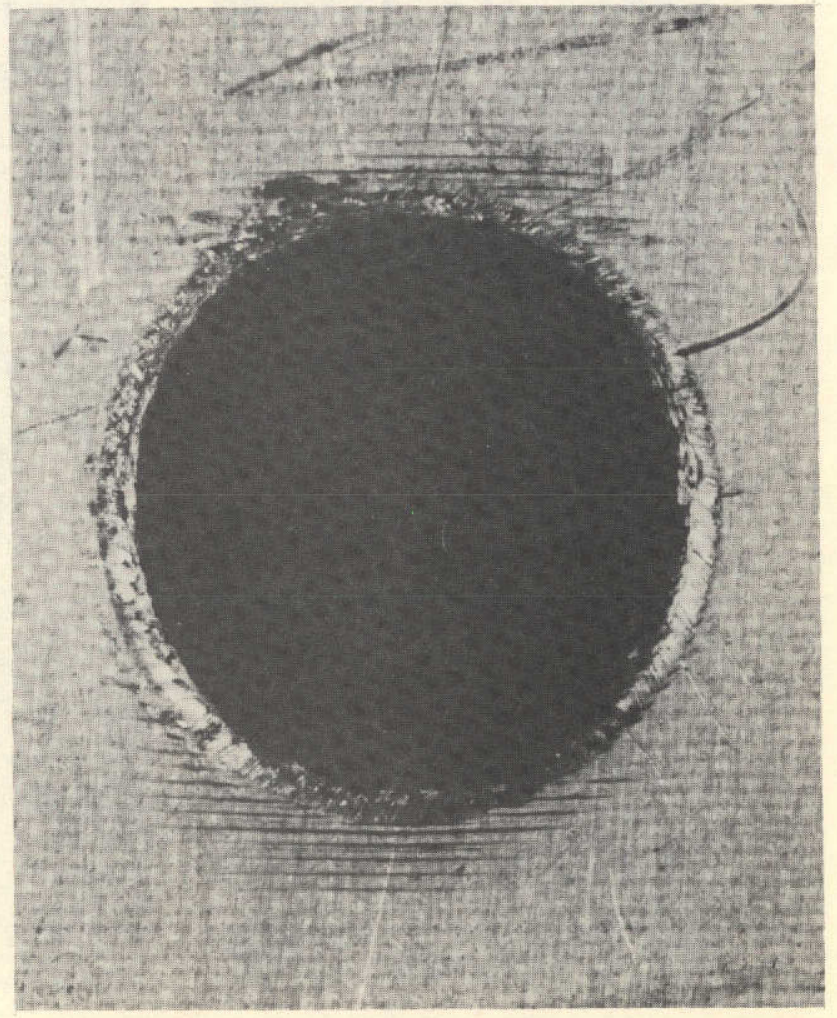

$8.4 \times$

Figure 16 Hole Produced by $6.350 \mathrm{~mm}(0.250$ in) Diameter Steel Punch Followed by $6.401 \mathrm{~mm}(0.252$ in) Diameter Diamond Ream 


\section{Page intentionally left blank}




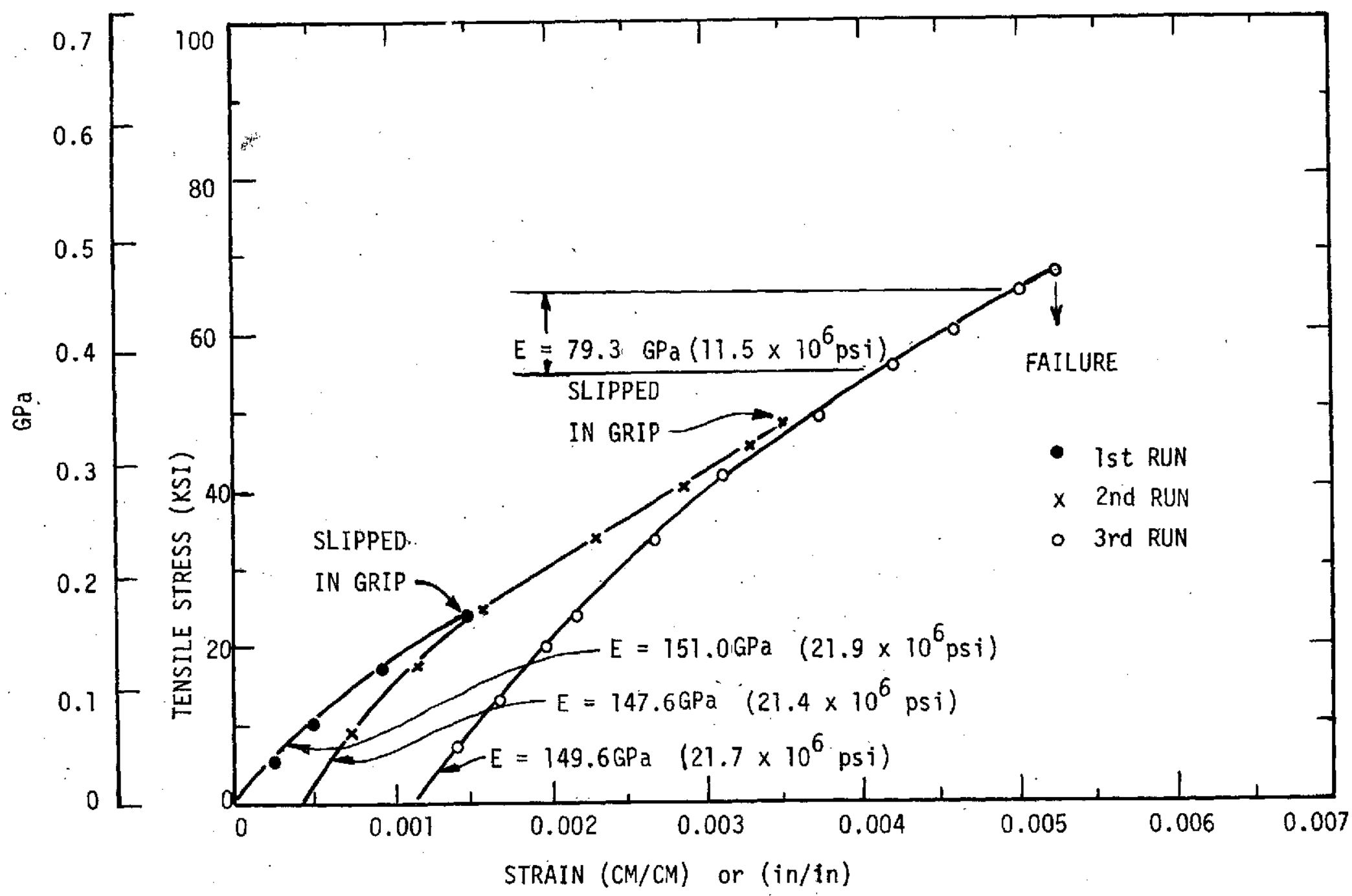

Figure 18 Specimen 11 - Room Temperature Tension Stress/Strain Curve 


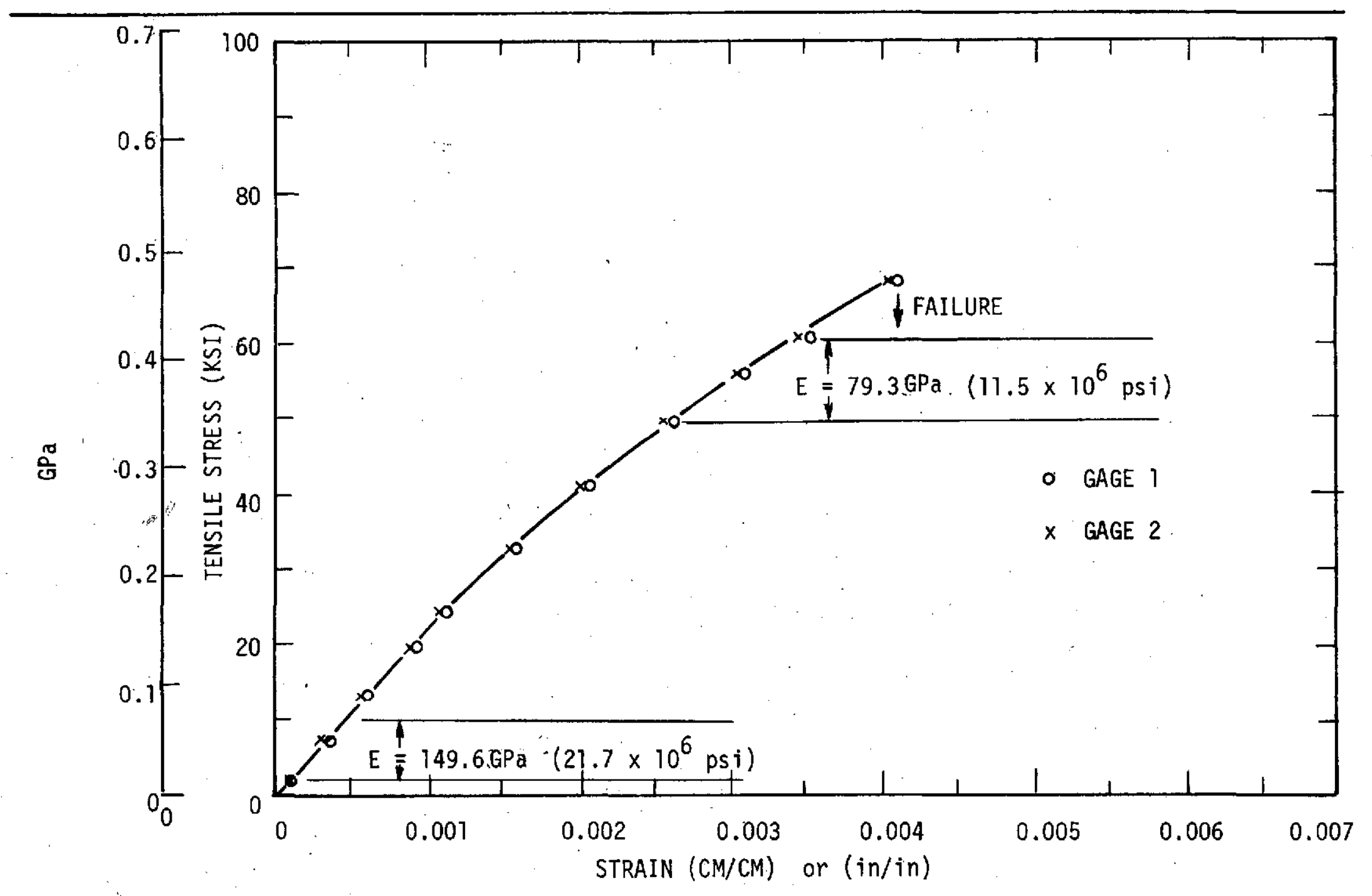

Figure 19 - Specimen $11-(3 r d$ Run Only) Room Temperature Tension Stress/Strain Curve 


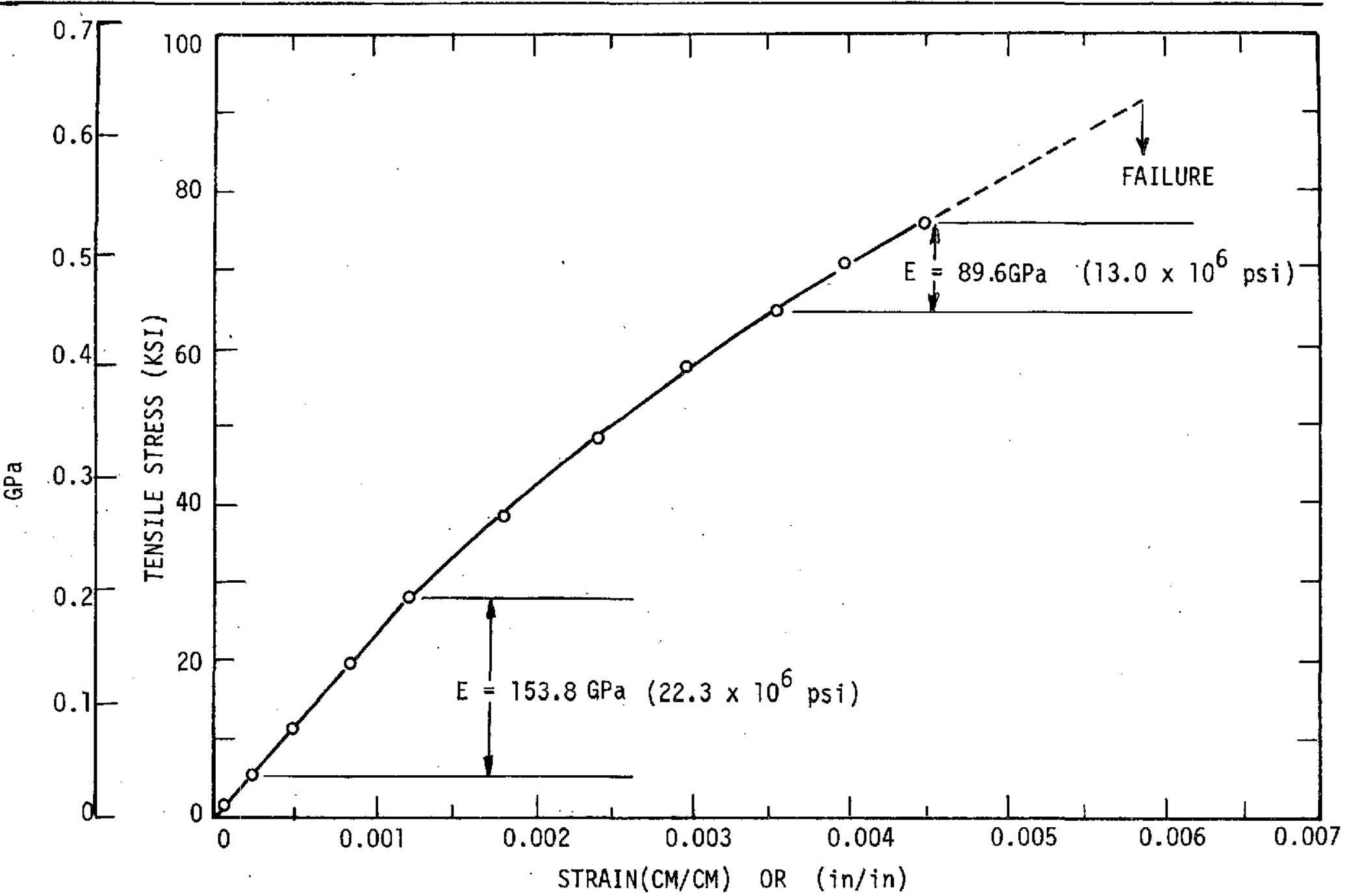

Figure 20 - Specimen 12 - Room Temperature Tension Stress/Strain Curve 


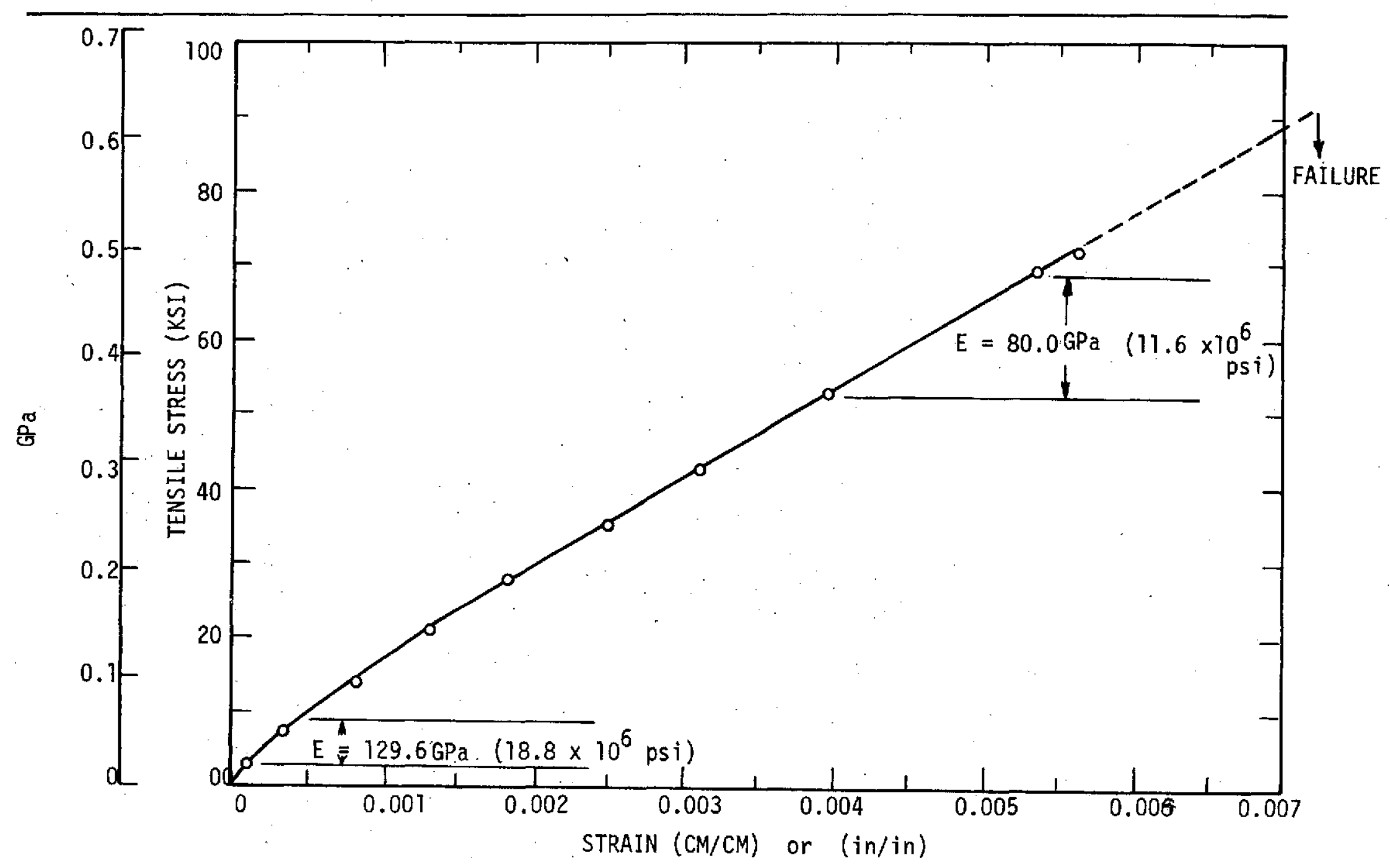

Figure 21 Specimen 13 - Room Temperature Tension Stress/Strain Curve 
os

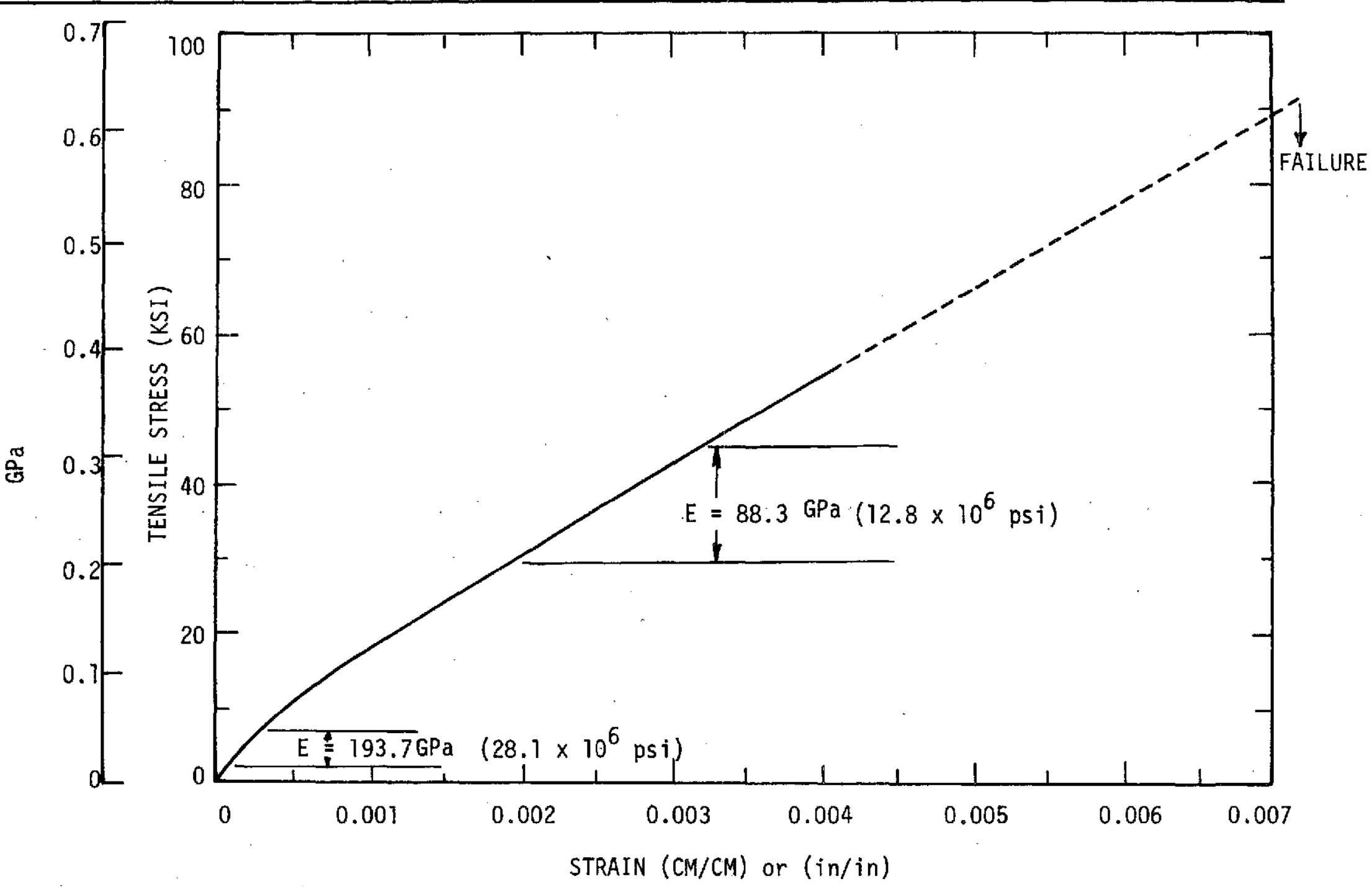

Figure 22 - Specimen $14-$ Room Temperature Tension Stress/Strain Curve 


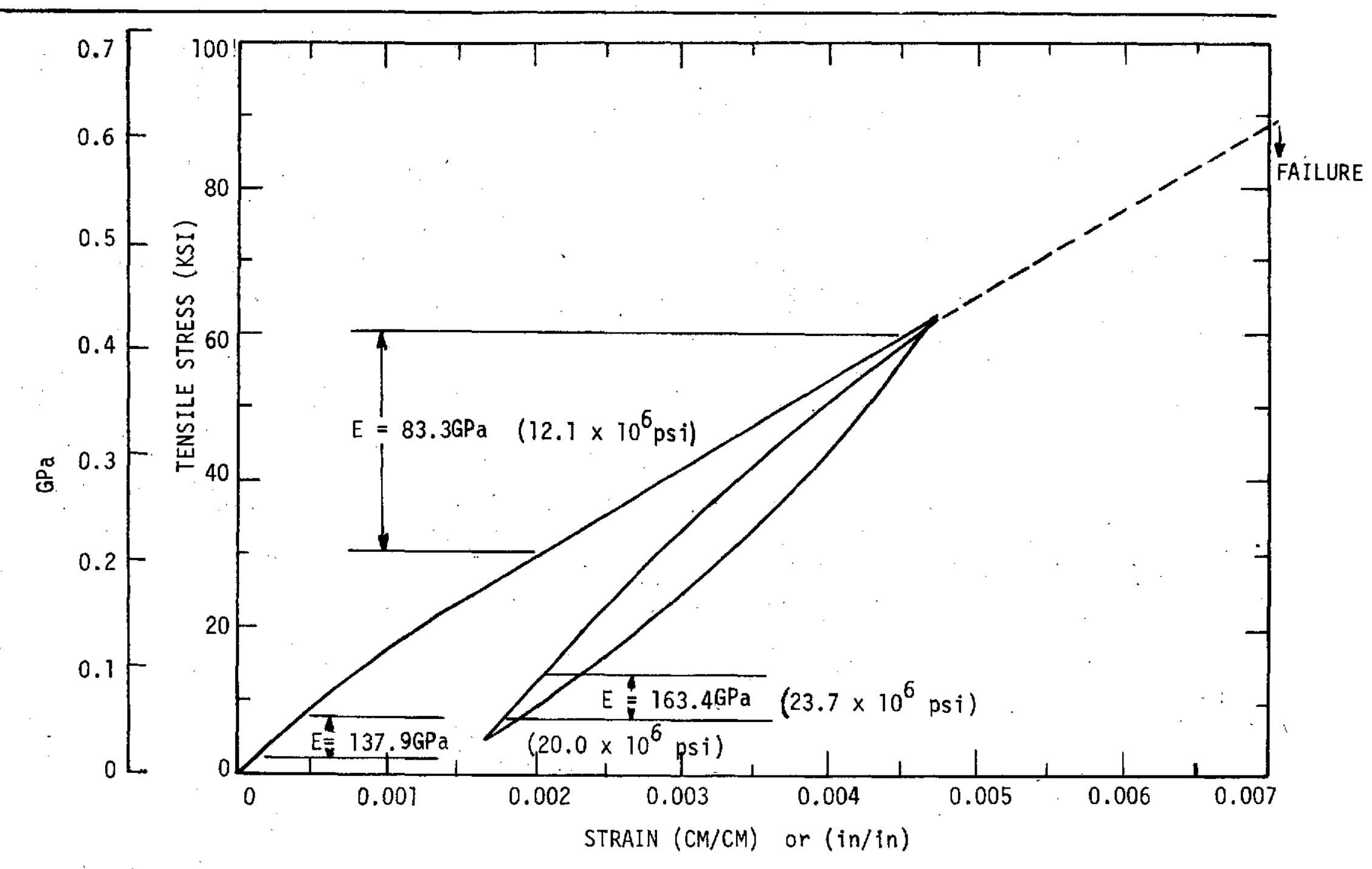

Figure 23 Specimen 15 - Room Temperature Tension Stress/Strain Curve 


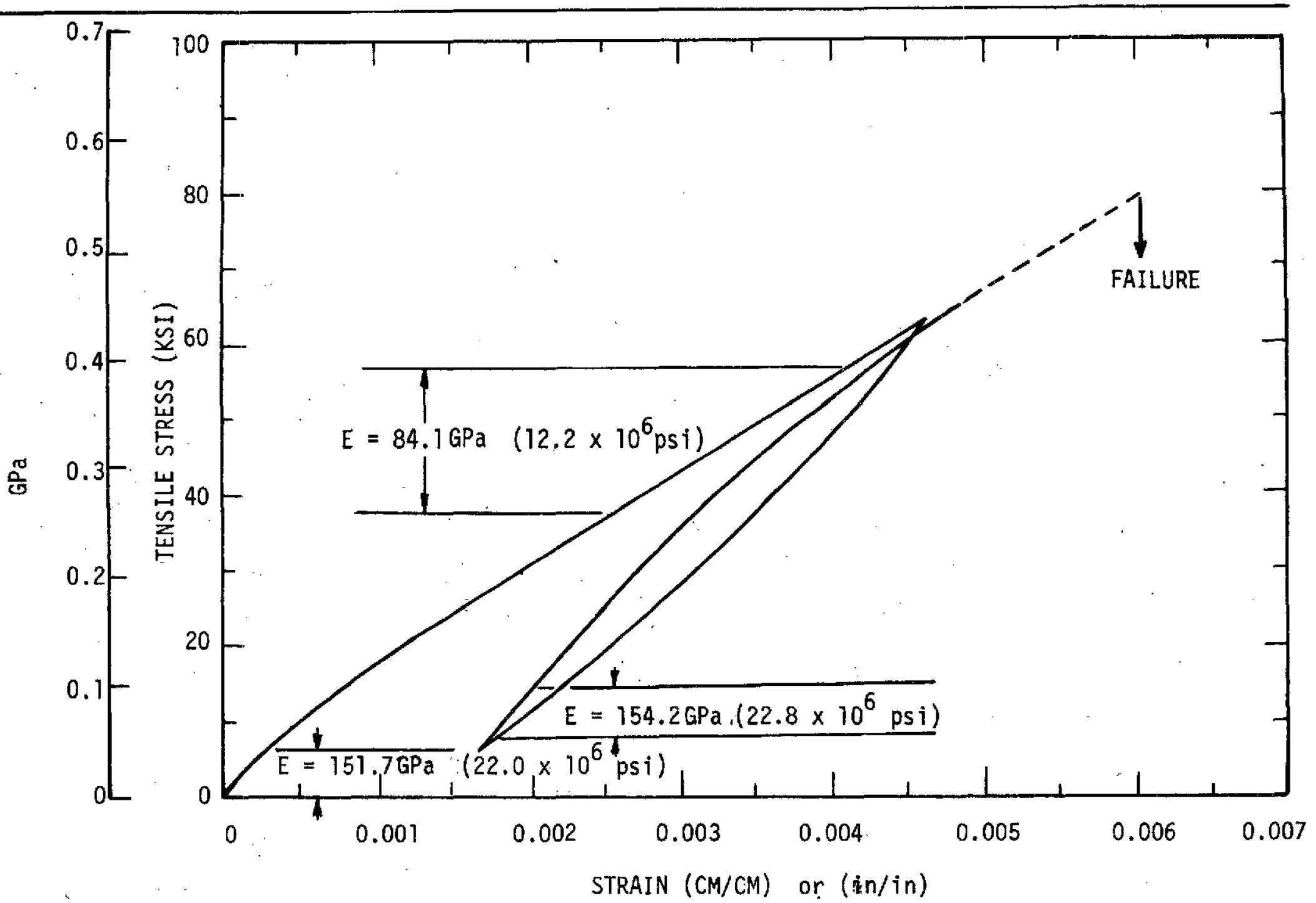

Figure 24 Specimen 16 - Room Temperature Tension Stress/Strain Curve 


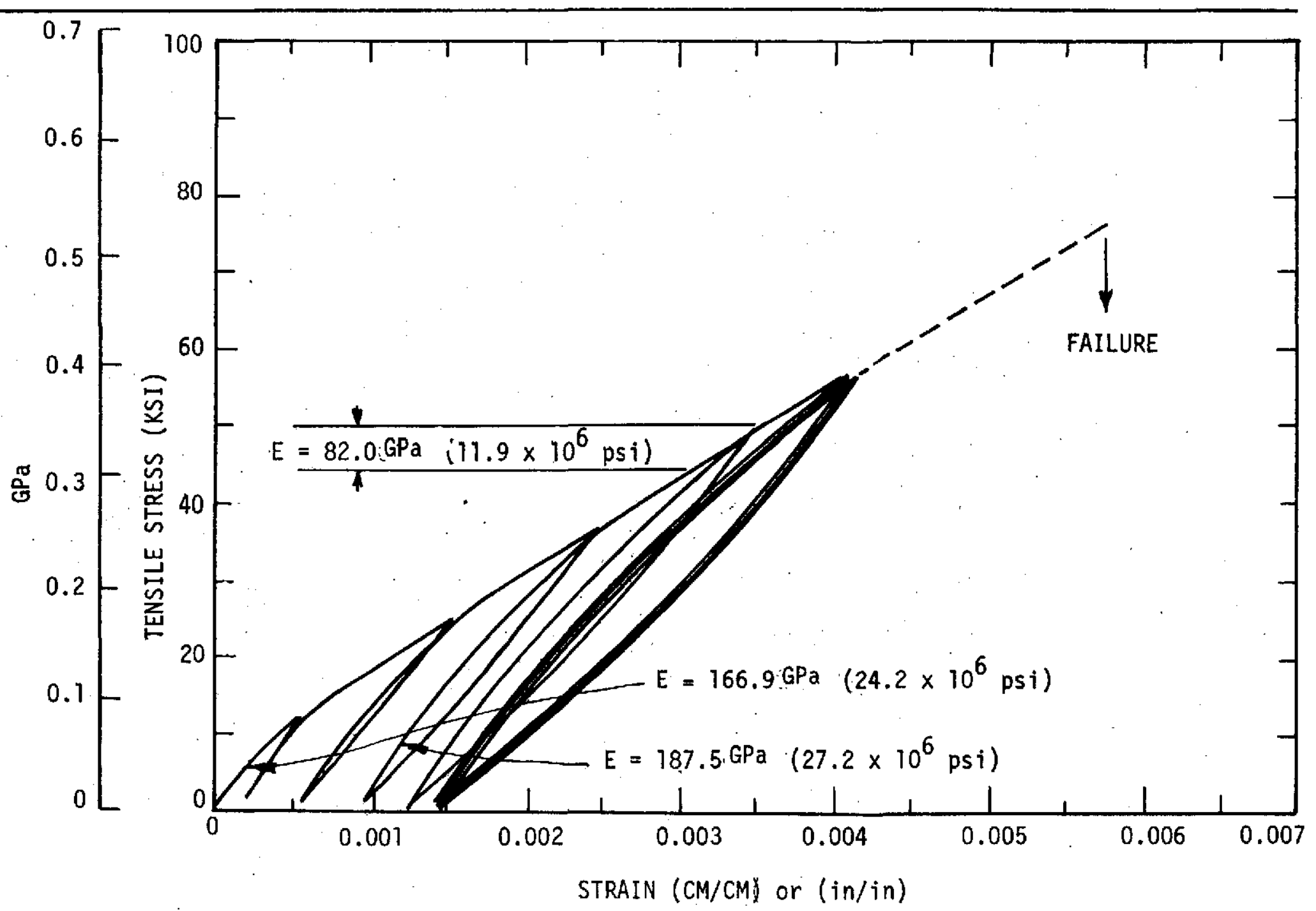

Figure 25 Specimen -17 - Room Temperature Tension Stress/Strain Curve 


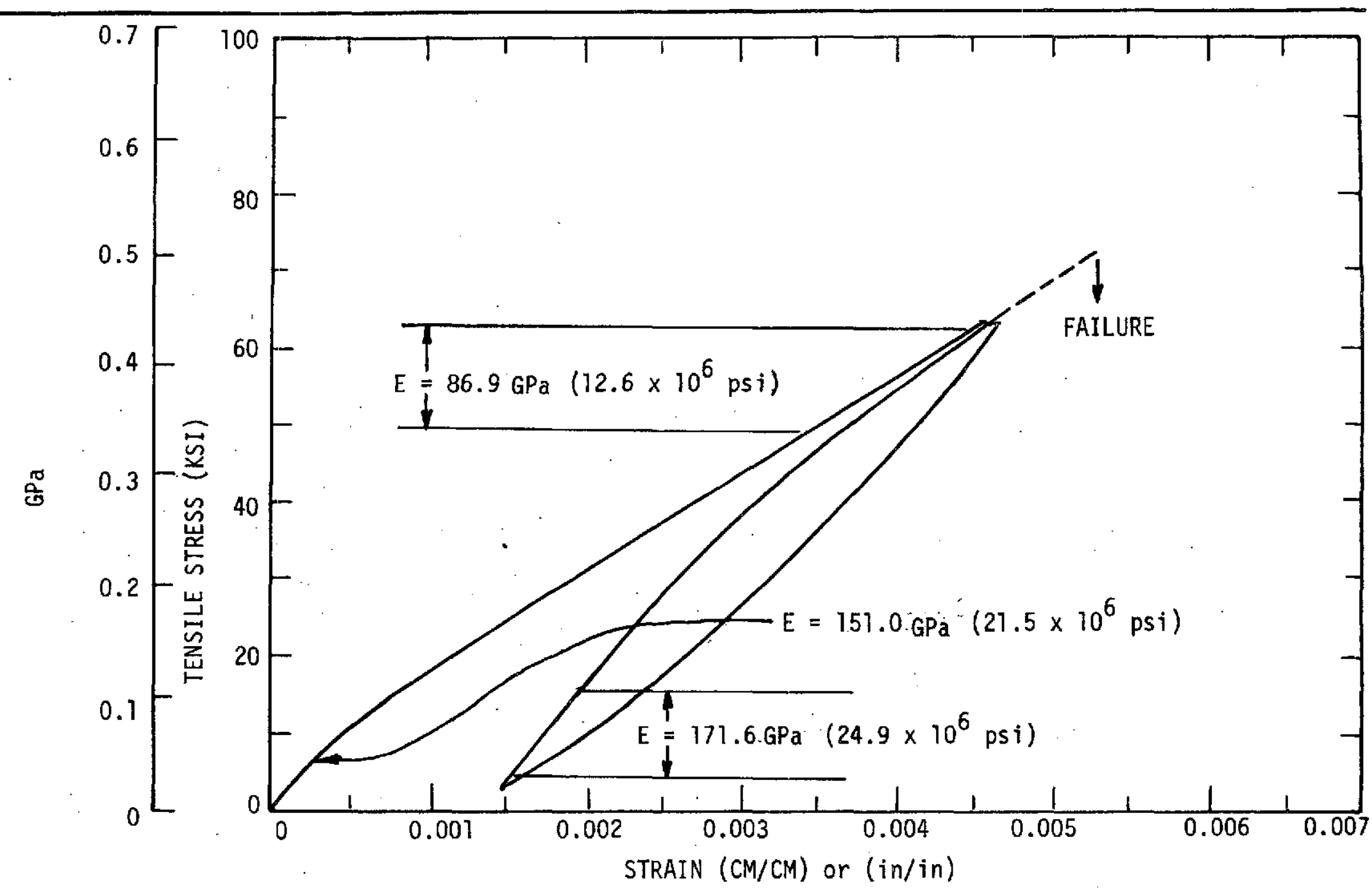

Figure 26 Specimen 18 - Room Temperature Tension Stress/Strain Curve 


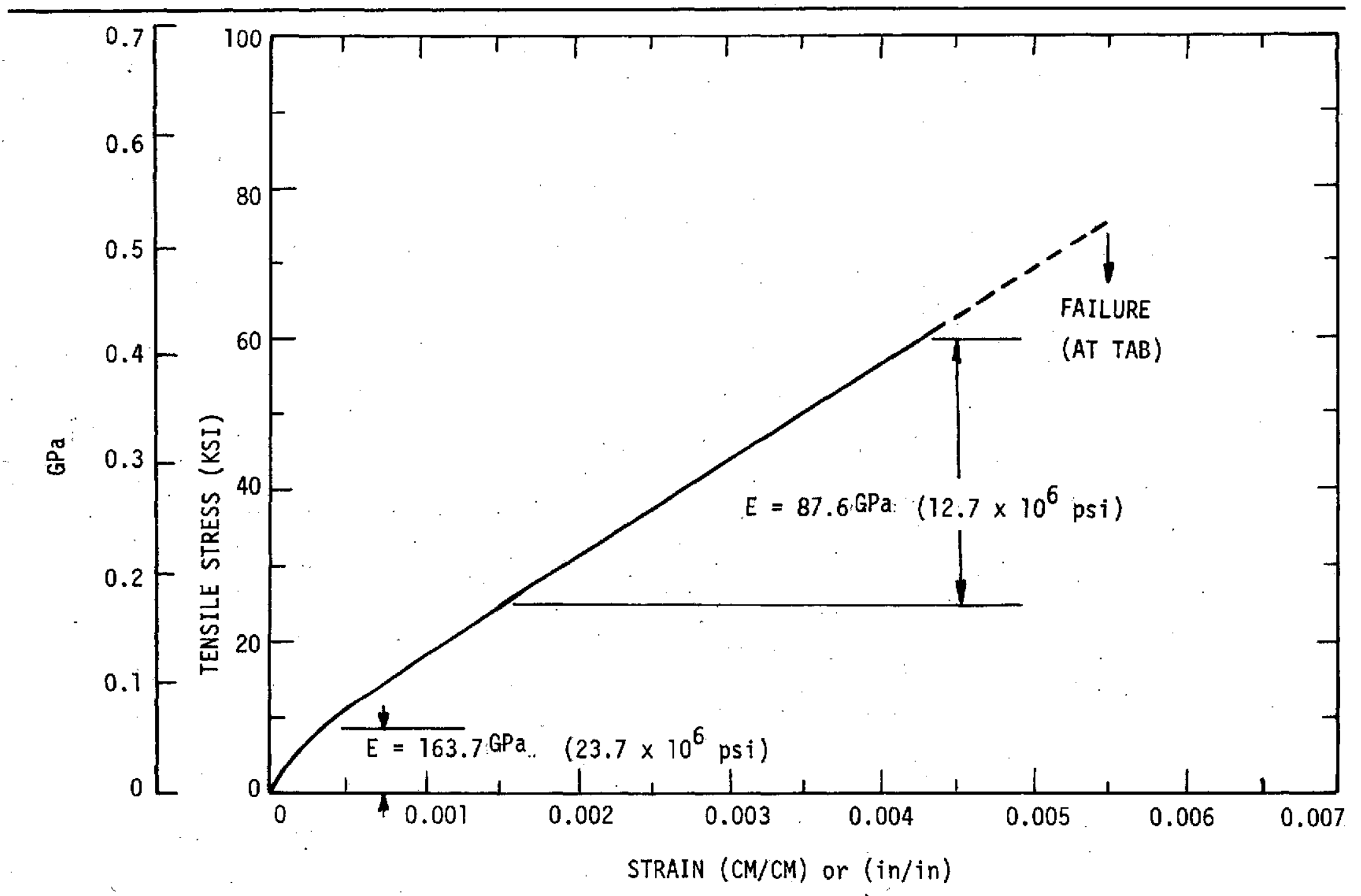

Figure 27 Specimen 19 - Room Temperature Tension Stress/Strain Curve 


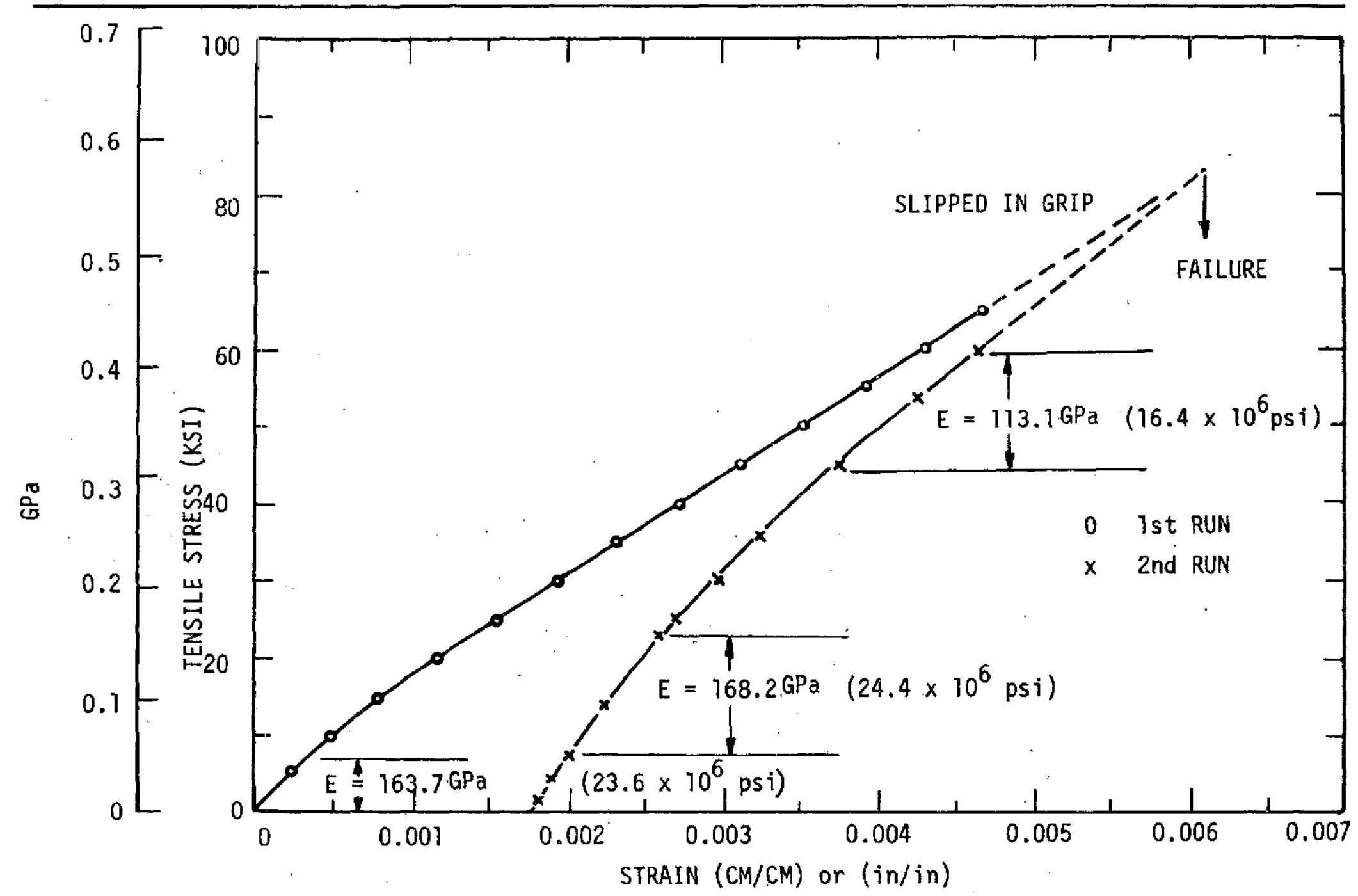

Figure 28 Specimen 20 - Room Temperature Tension Stress/Strain Curve 


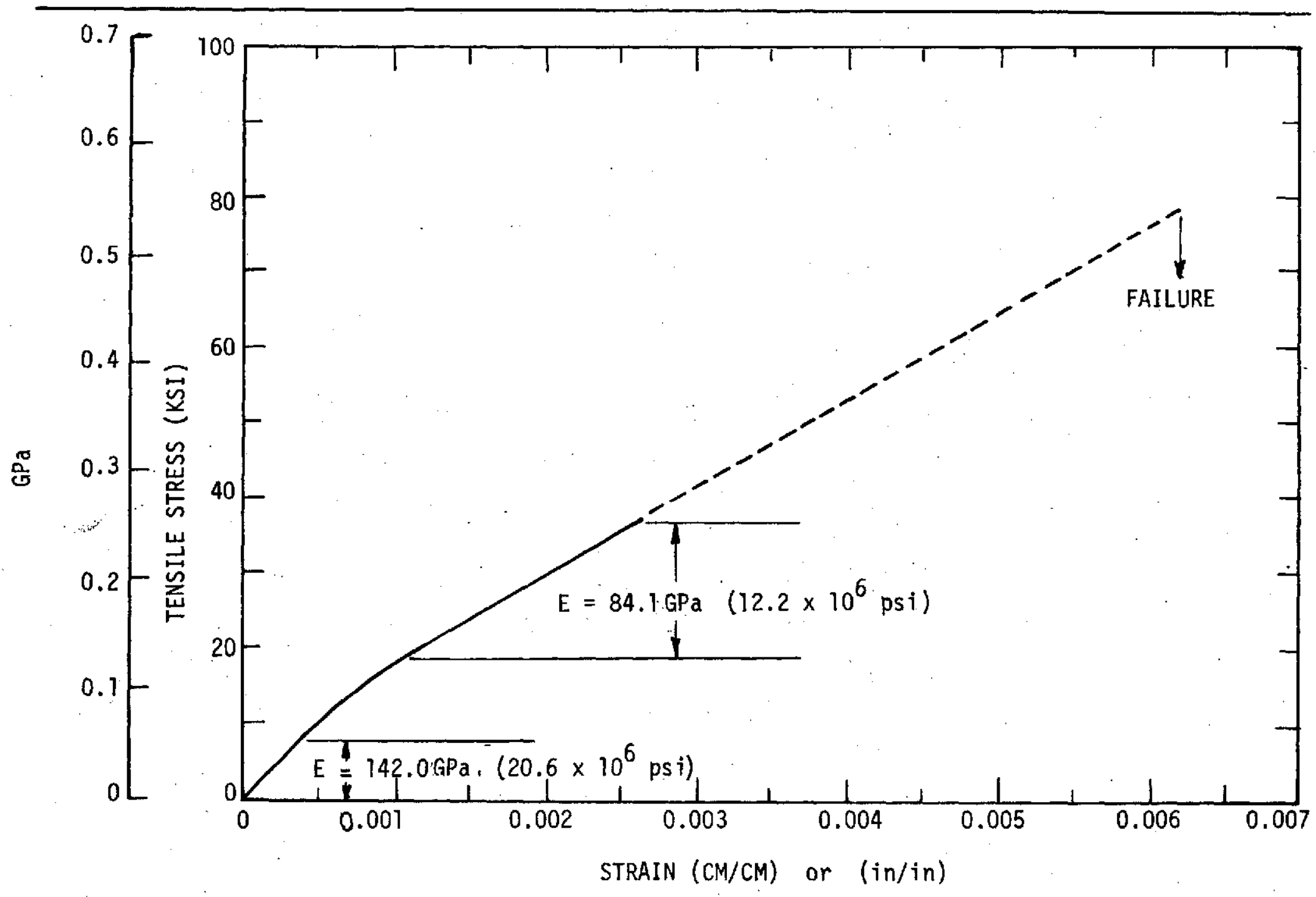

Figure 29 Specimen 21 - Room Temperature Tension Stress/Strain Curve after 1000 Hours Aging at $505 \mathrm{~K}\left(450^{\circ} \mathrm{F}\right)$ 


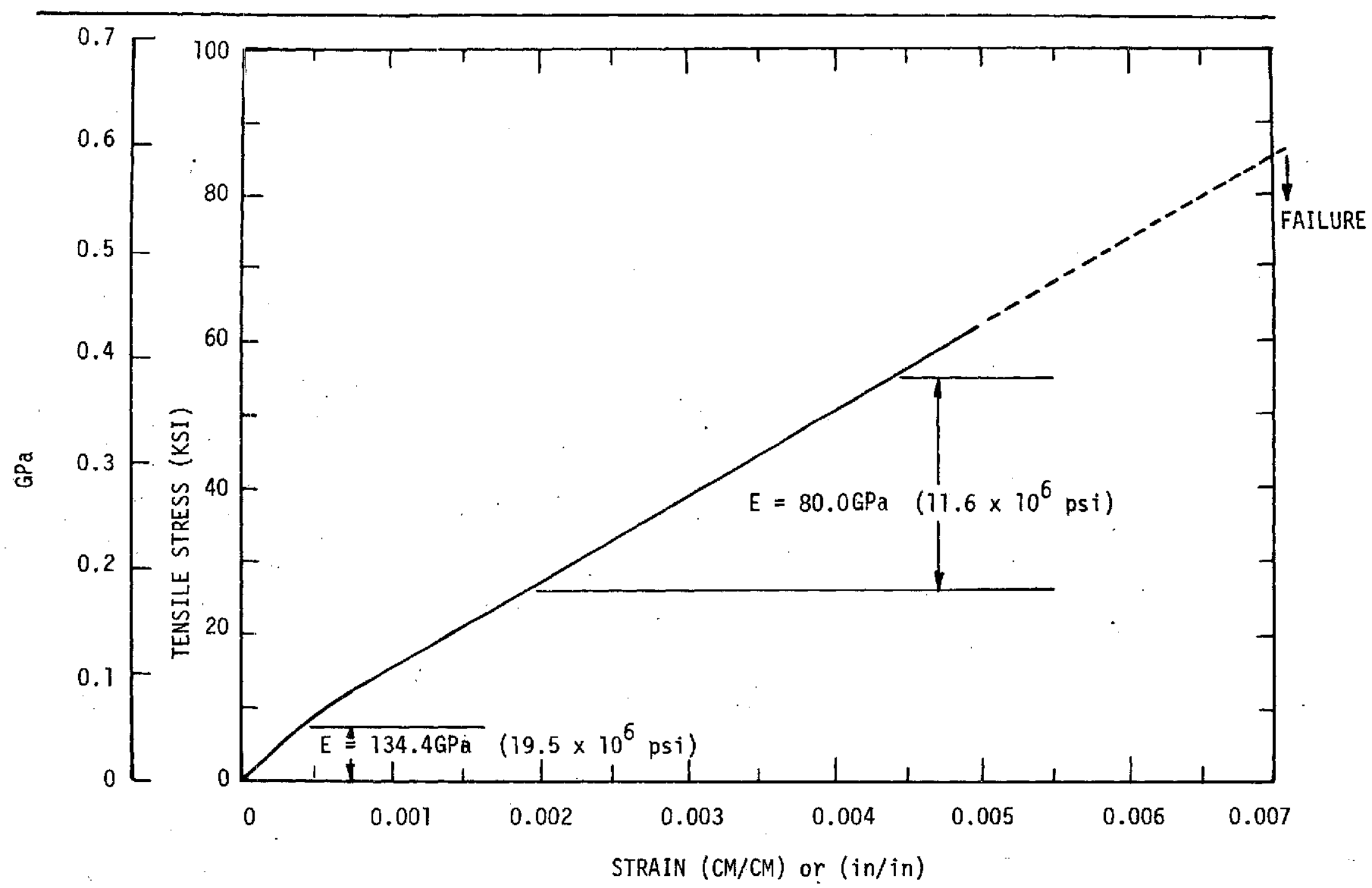

Figure 30 Specimen 22 - Room Temperature Tension Stress/Strain Curve after 1000 Hours Aging at $505 \mathrm{~K}\left(450^{\circ} \mathrm{F}\right)$ 


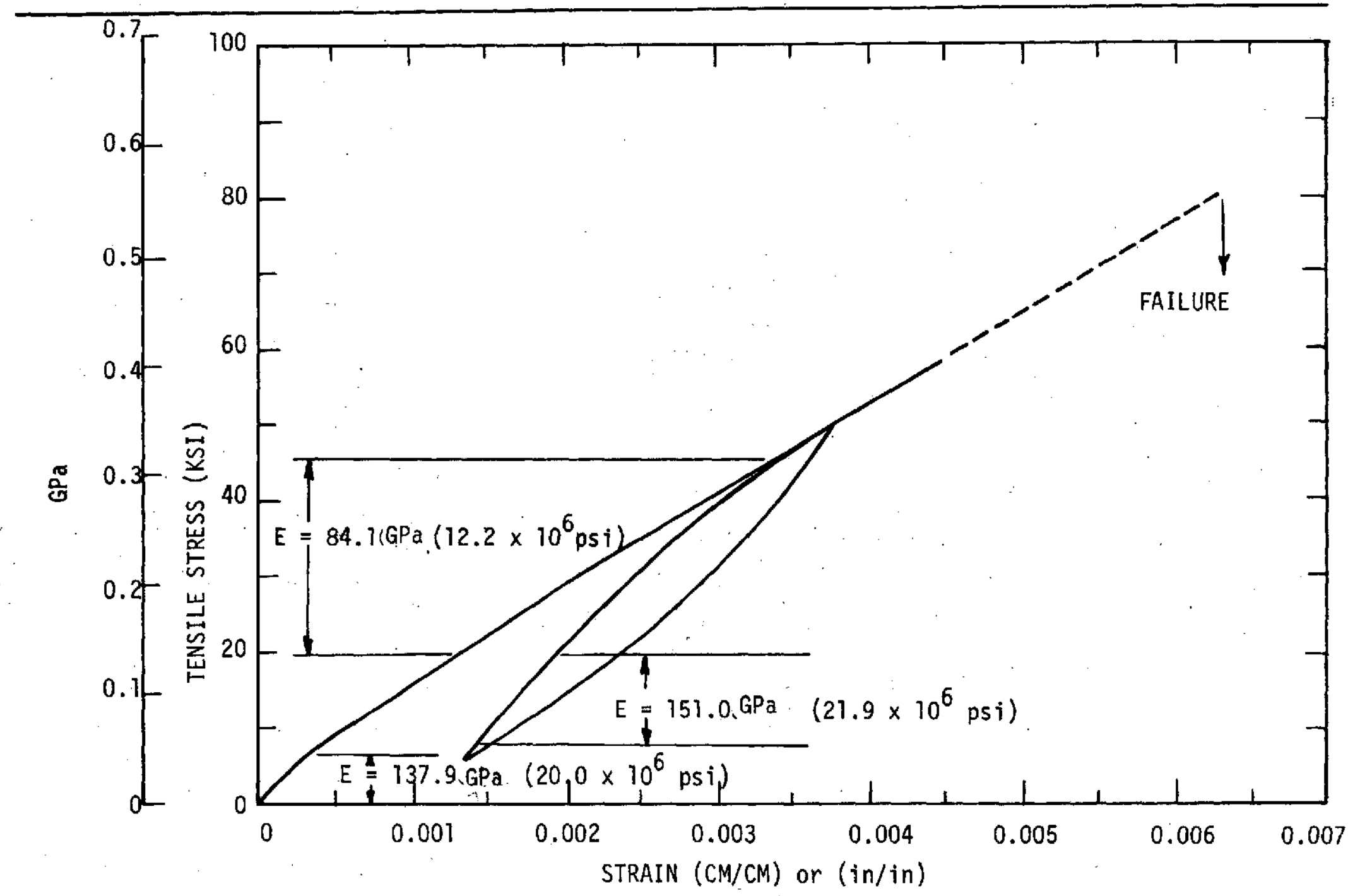

Figure 31 Specimen 23 - Room Temperature Tension Stress/Strain Curve after 1000 Hours Aging at $505 \mathrm{~K}\left(450^{\circ} \mathrm{F}\right)$ 


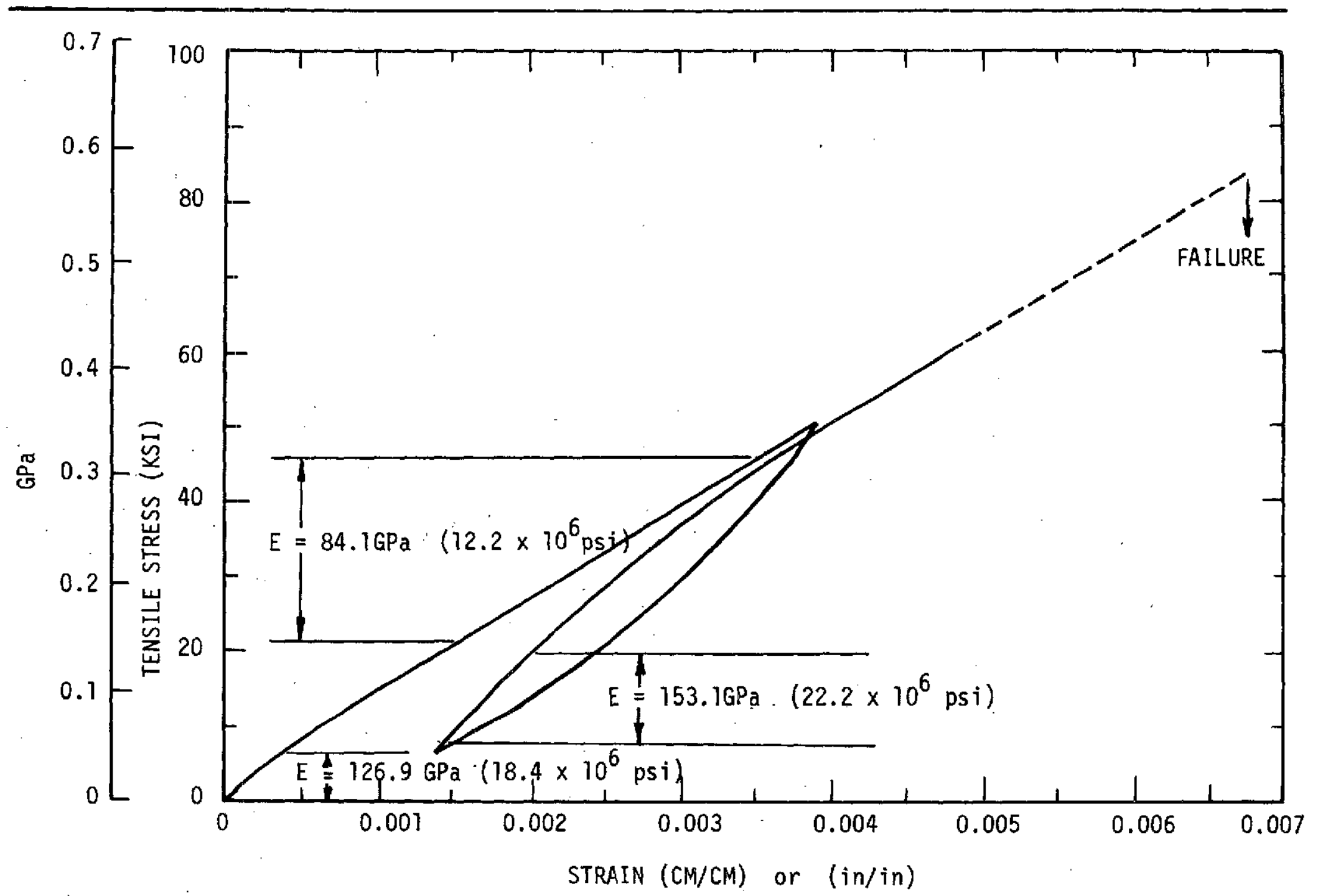

Figure 32 Specimen 24 - Room Temperature Tension Stress/Strain Curve after 1000 Hours Aging at $505 \mathrm{~K}\left(450^{\circ} \mathrm{F}\right)$ 


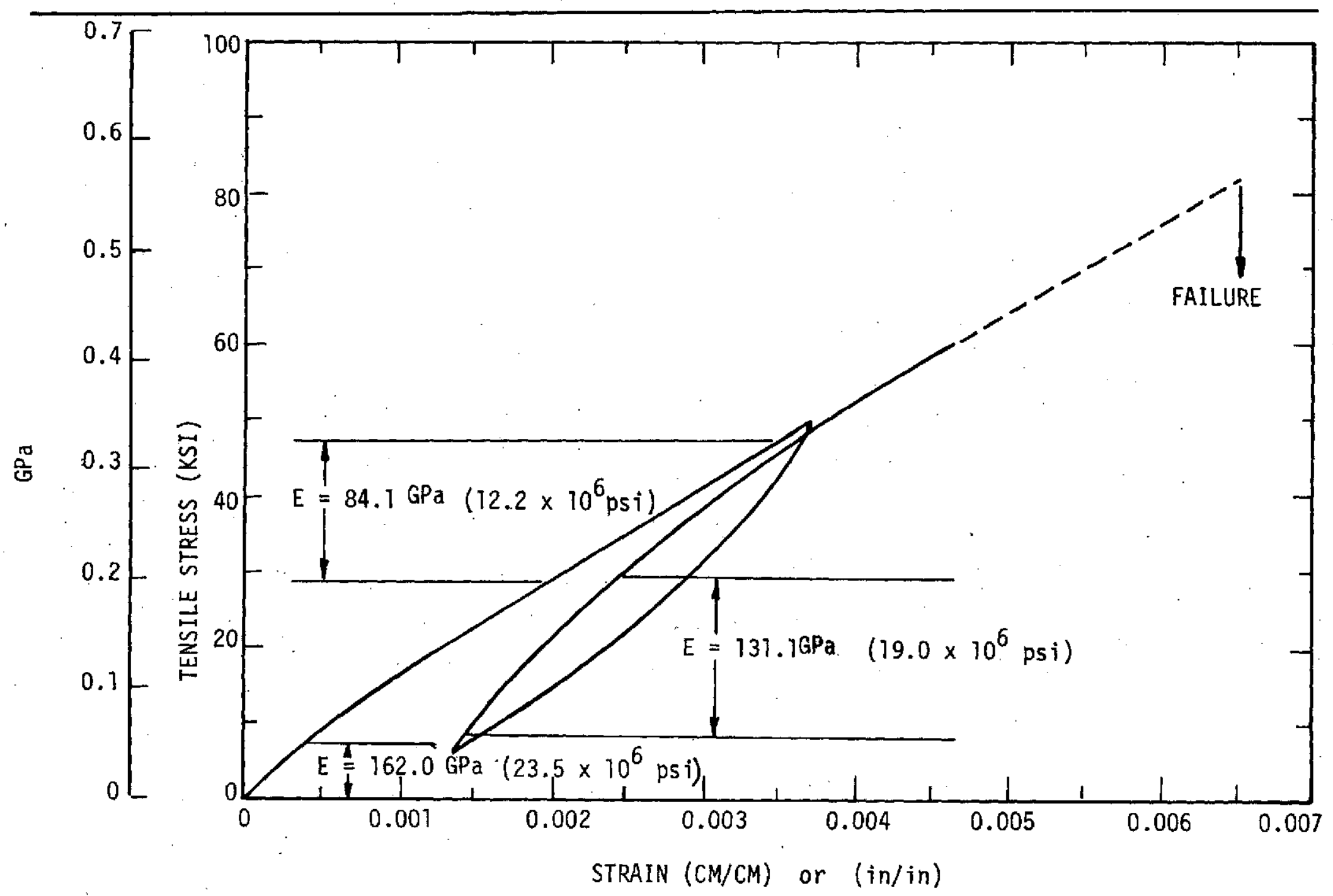

Figure 33 Specimen 25 - Room Temperature Tension Stress/Strain Curve after 1000 Hours Aging at $505 \mathrm{~K}\left(450^{\circ} \mathrm{F}\right)$ 


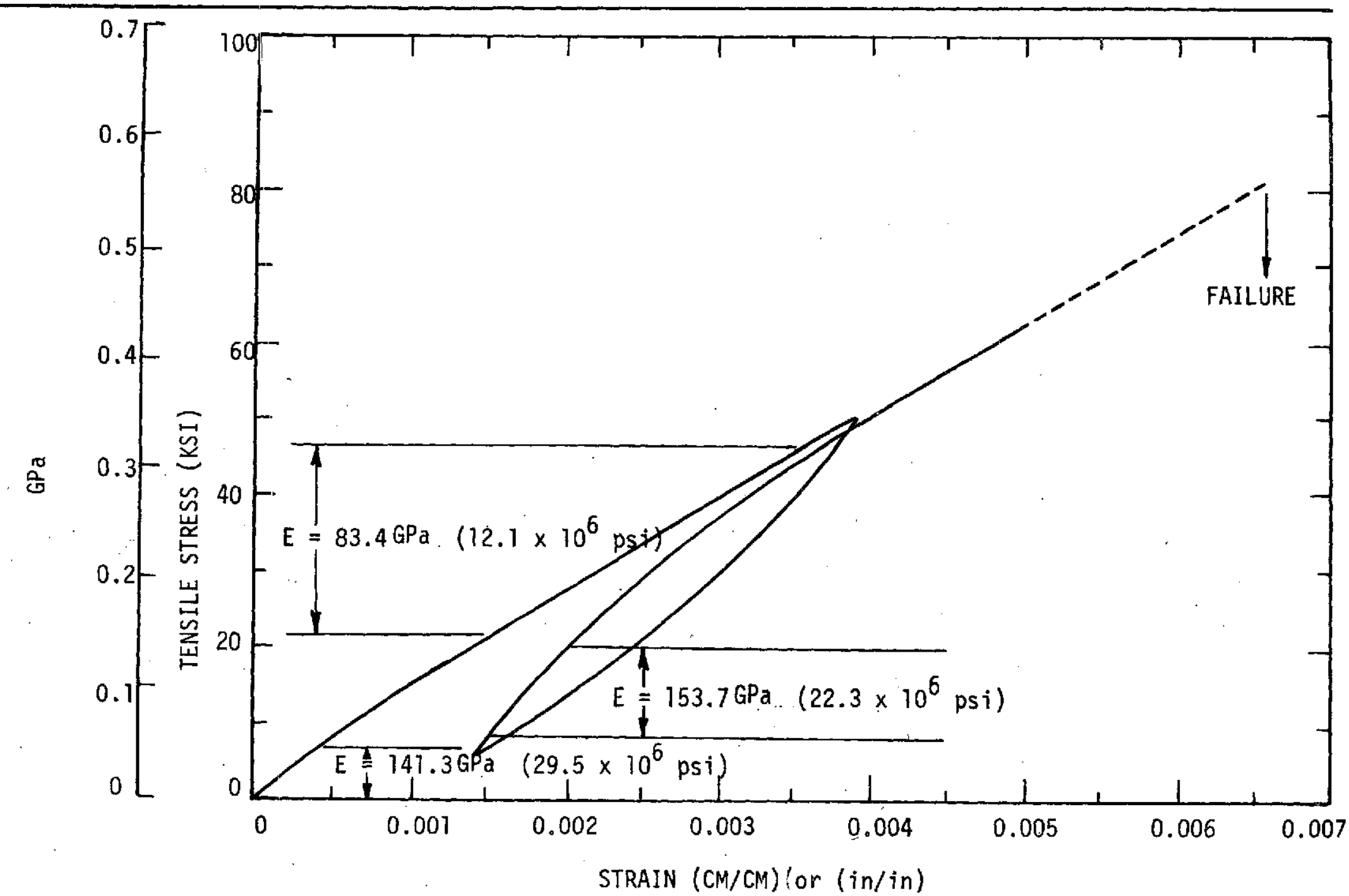

Figure 34. Specimen 26 - Room Temperature Tension Stress/Strain Curve after 1000 Hours Aging at $505 \mathrm{~K}\left(450^{\circ} \mathrm{F}\right)$ 


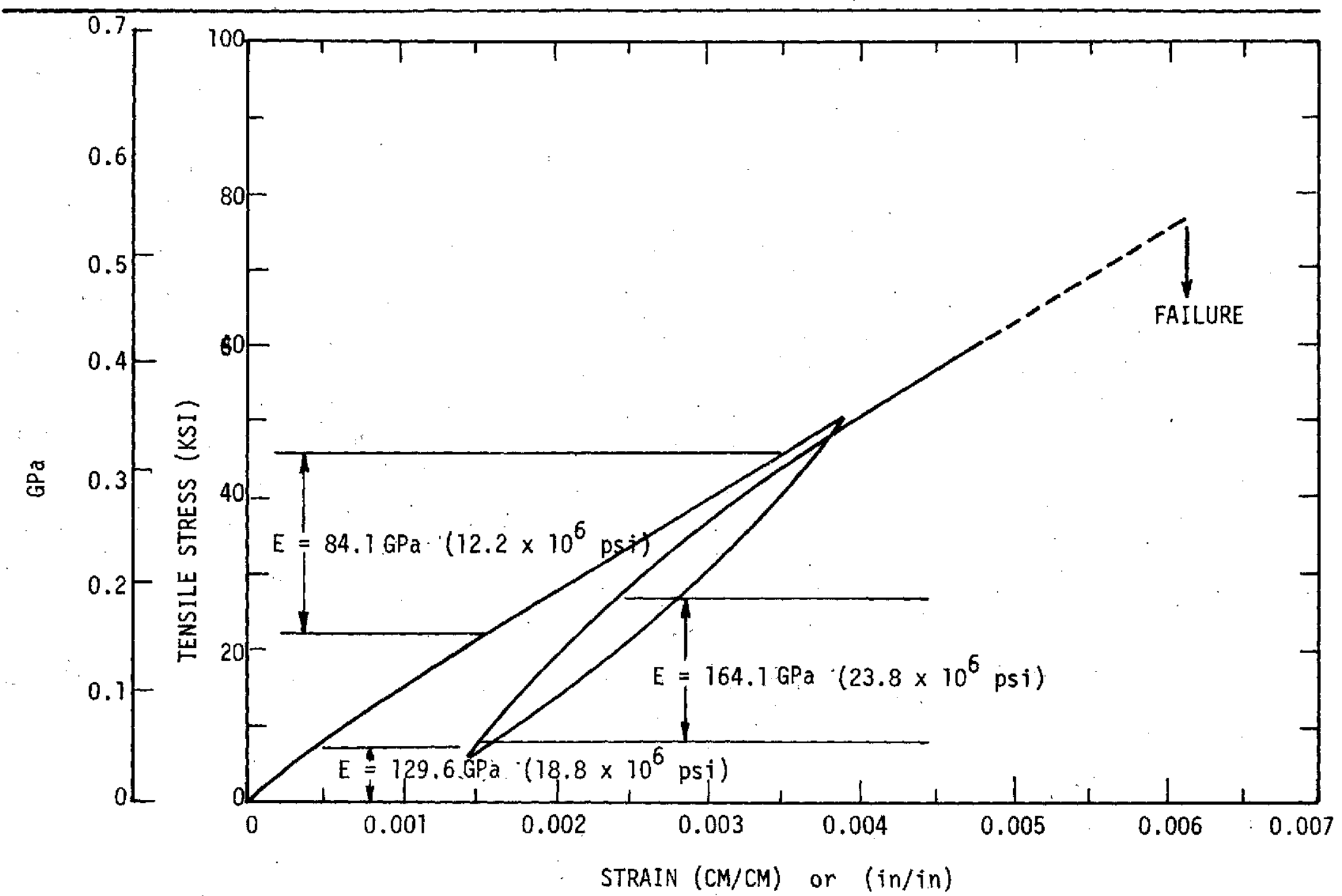

Figure 35 Specimen 27 - Room Temperature Tension Stress/Strain Curve after 1000 Hours Aging at $505 \mathrm{~K}\left(450^{\circ} \mathrm{F}\right)$

w 


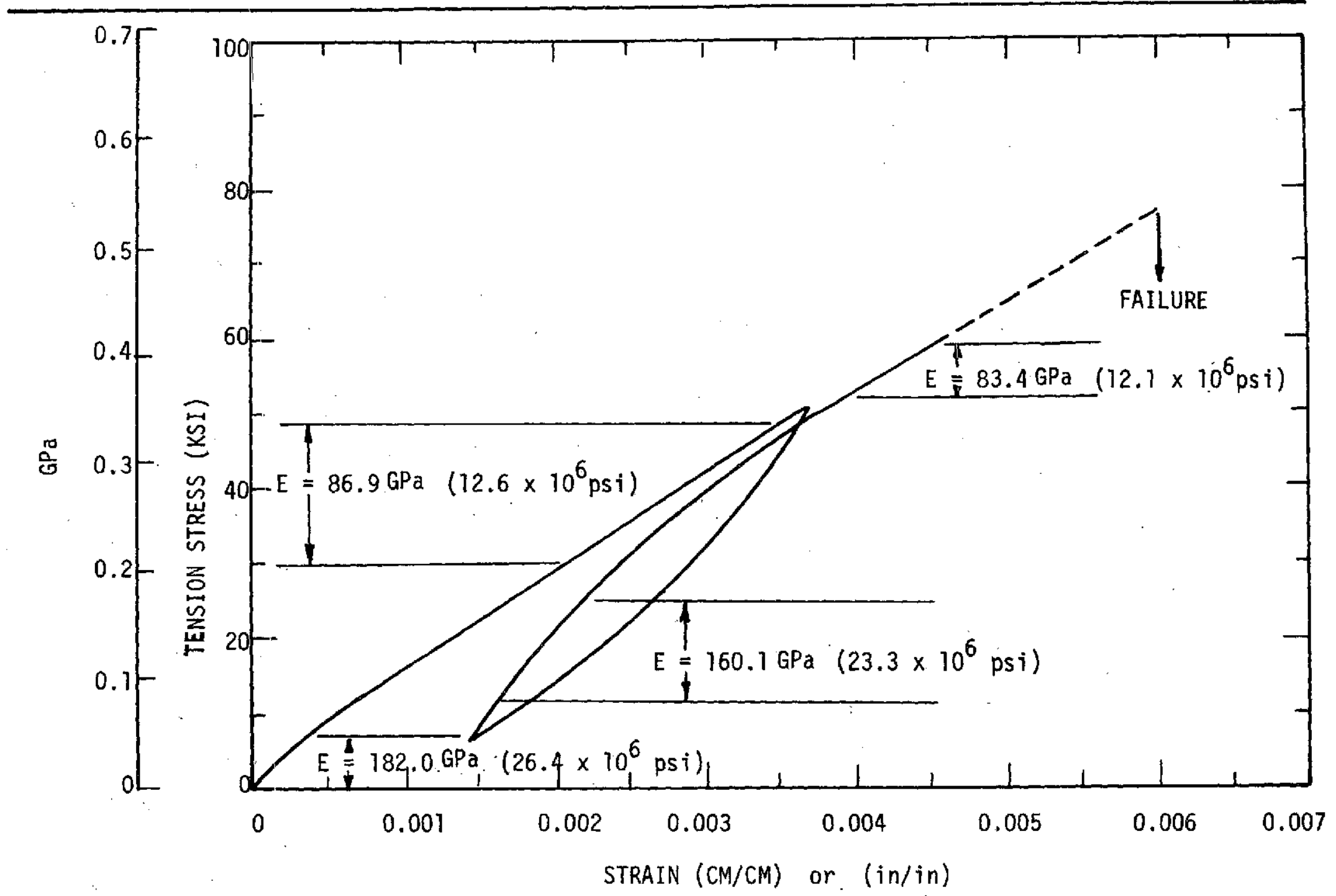

Figure 36 Specimen 28 - Room Temperature Tension Stress/Strain Curve after 1000 Hours Aging at $505 \mathrm{~K}\left(450^{\circ} \mathrm{F}\right)$ 


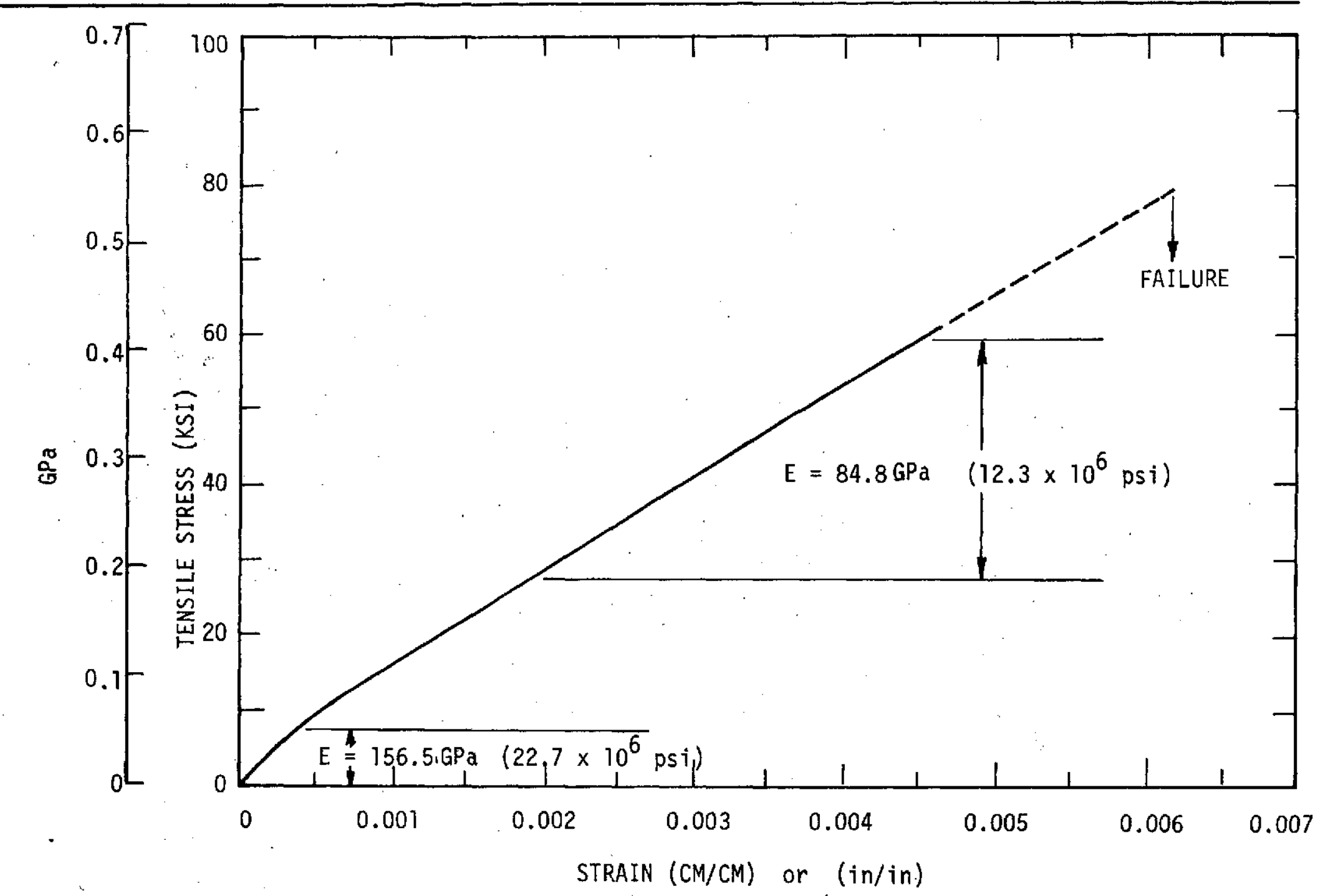

Figure 37 Specimen 29 - Room Temperature Tension Stress/Strain Curve after 1000 Hours Aging at $505 \mathrm{~K}\left(450^{\circ} \mathrm{F}\right)$ 


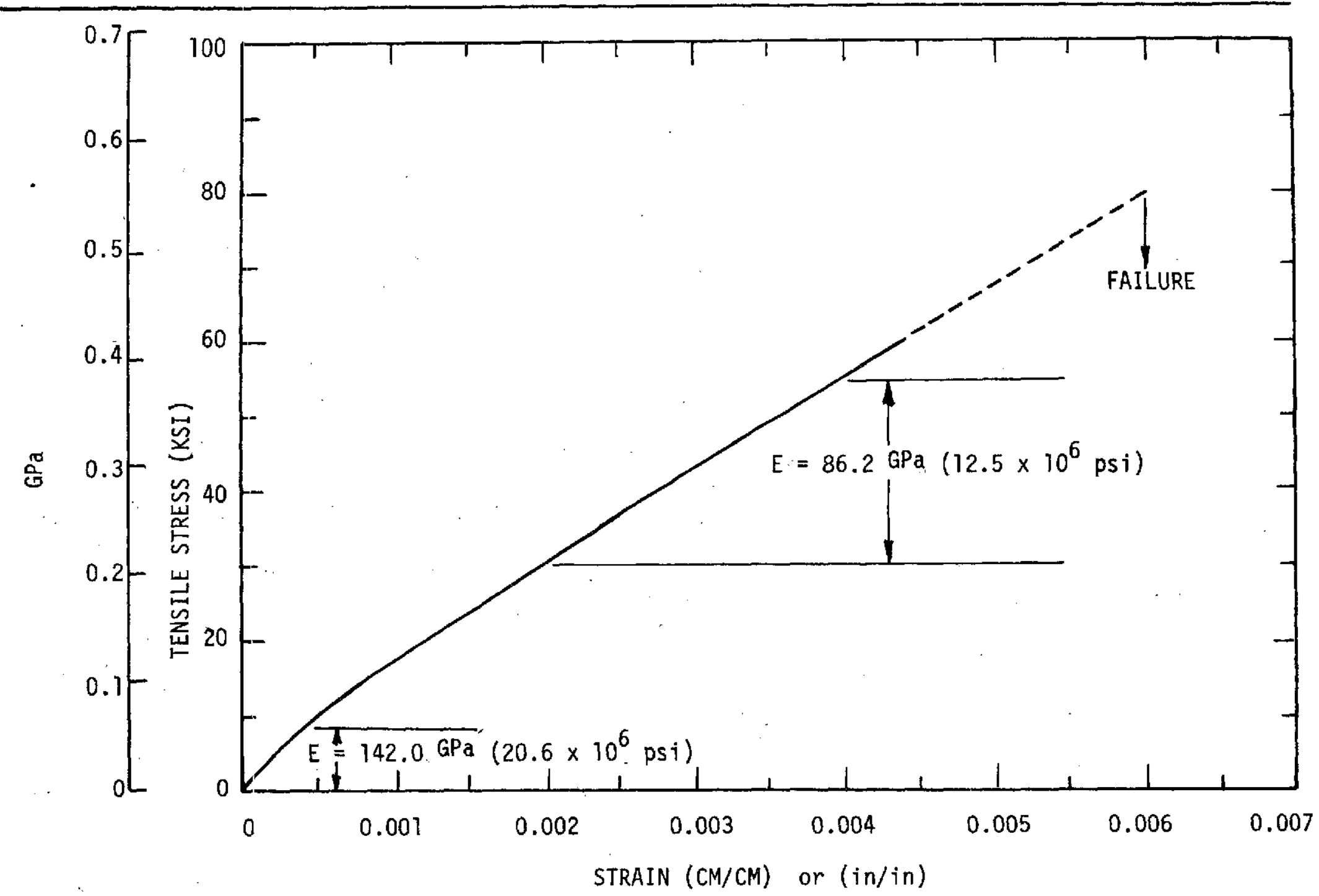

Figure 38 Specimen 30 - Room Temperature Tension Stress/Strain Curve after 1000 Hours Aging at $505 \mathrm{~K}\left(450^{\circ} \mathrm{F}\right)$ 


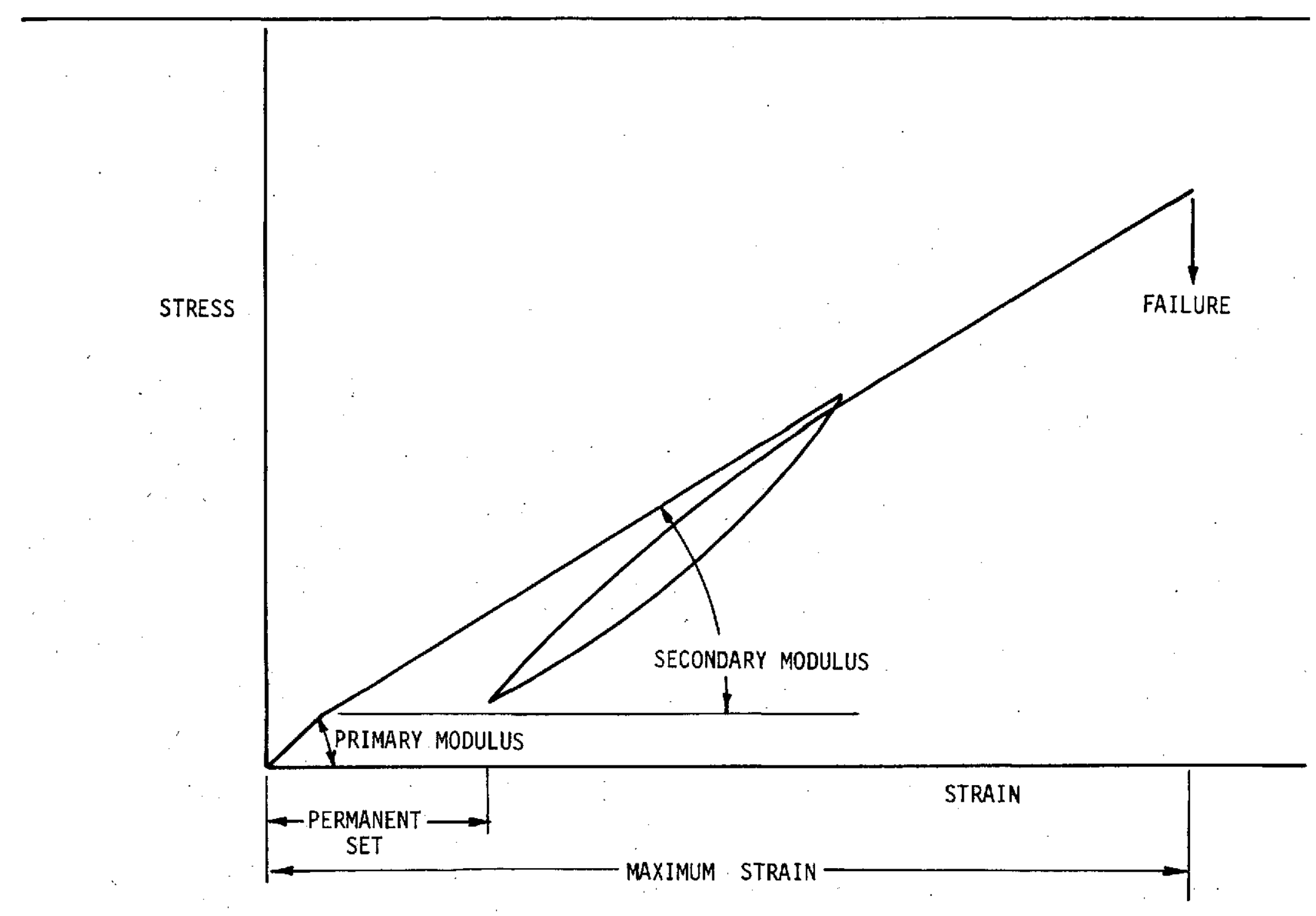

Figure 39 Schematic of Typical Tension Stress/Strain Curve 


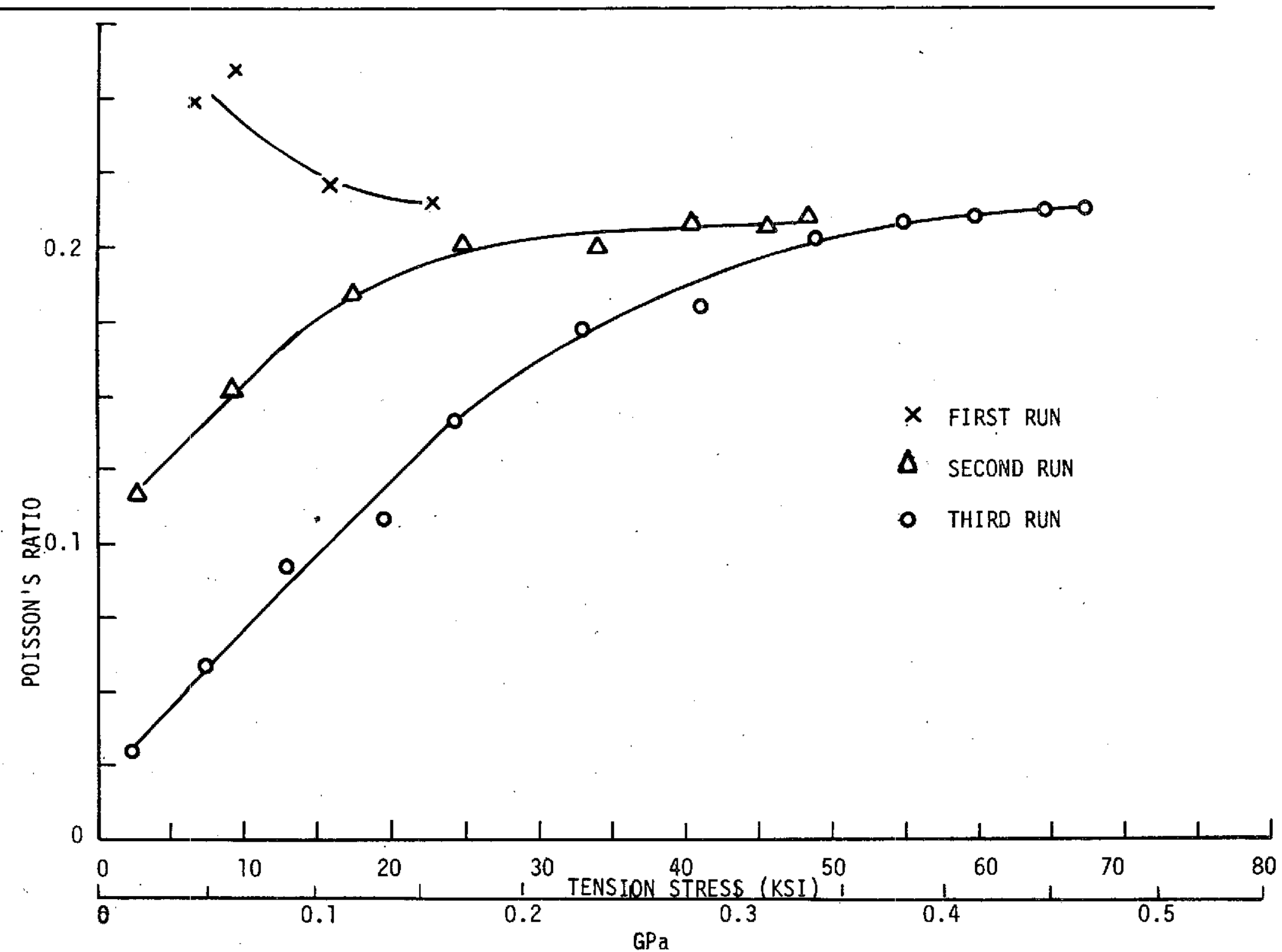

Figure 40 Specimen 11 (Side \#1) Poisson's Ratio Vs Tension Stress 


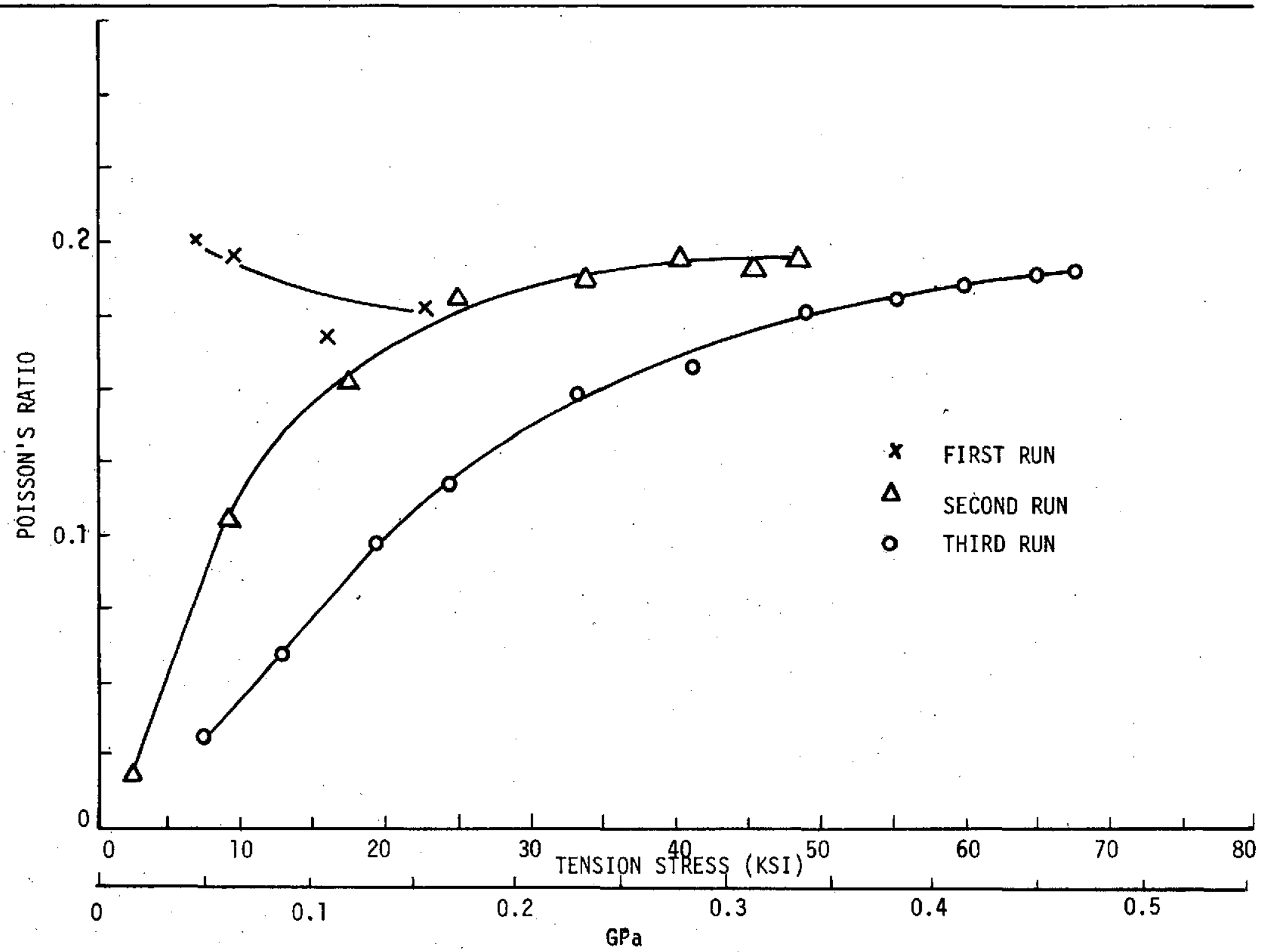

Figure 41 Specimen 11 (Side \#2) Poisson's Ratio Vs Tension Stress 


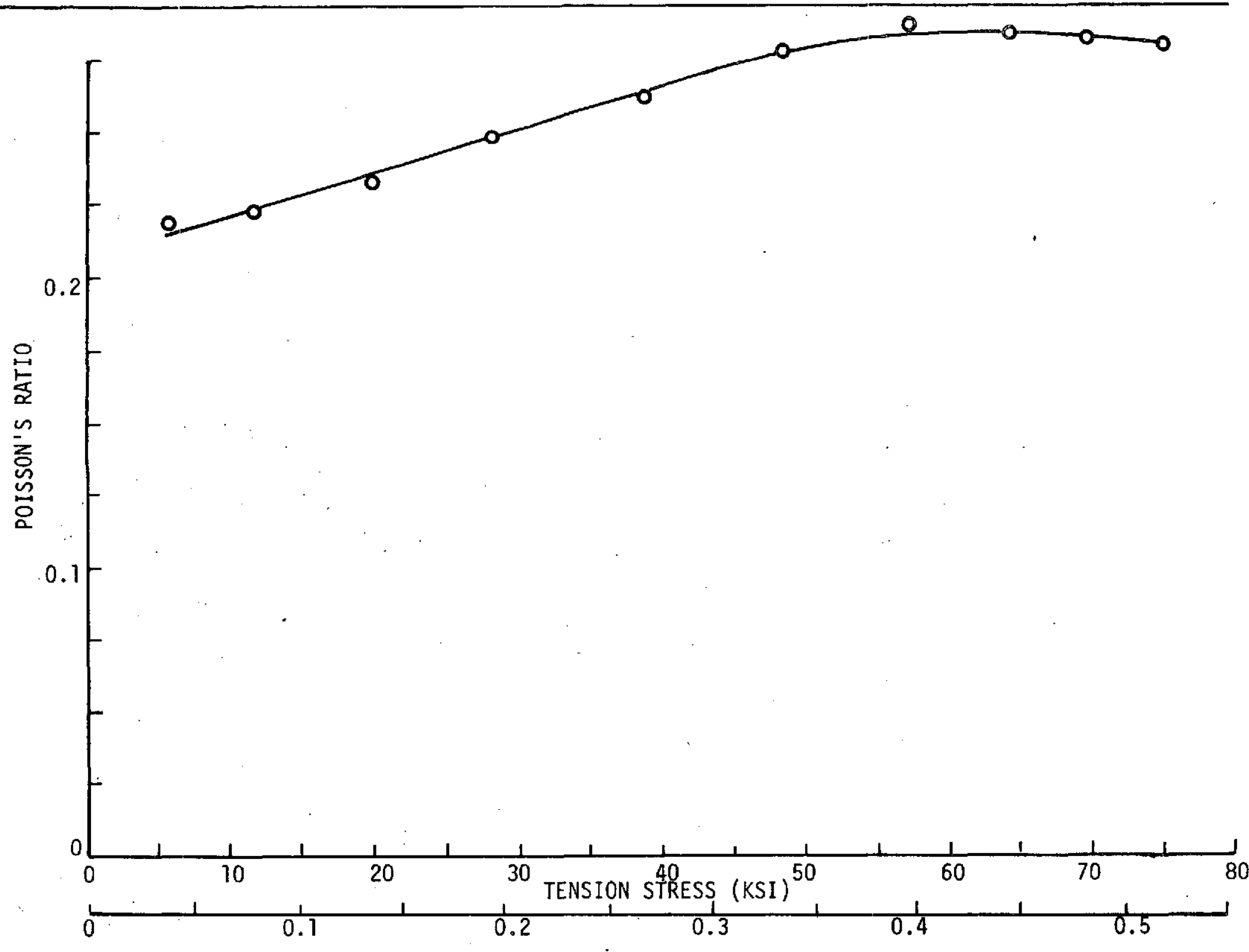

$\mathrm{GPa}$

Figure 42 Specimen 12 - Poisson's Ratio Vs Tension Stress 


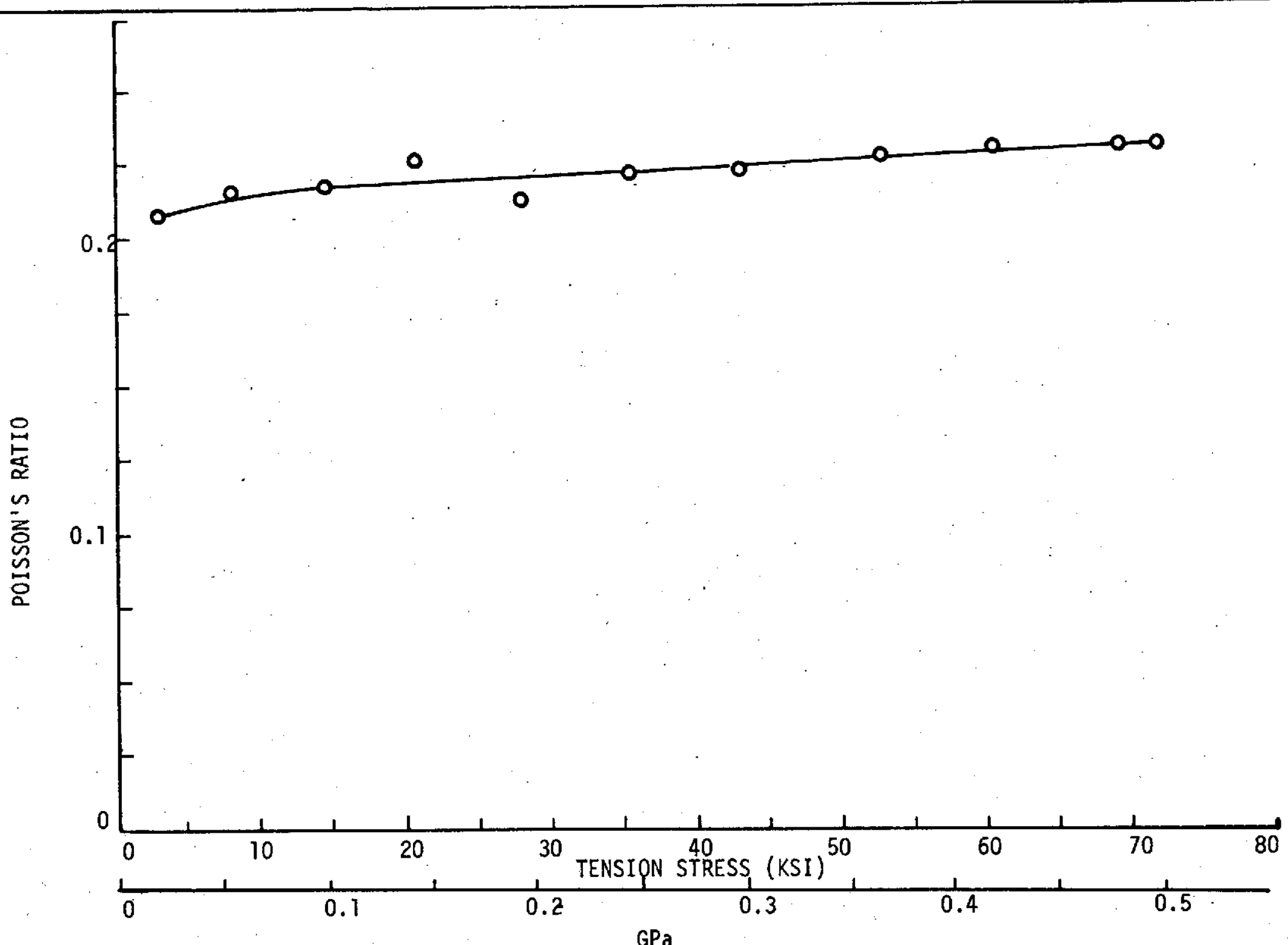

Figure 43 Specimen 13 - Poisson's Ratio Vs Tension Stress 


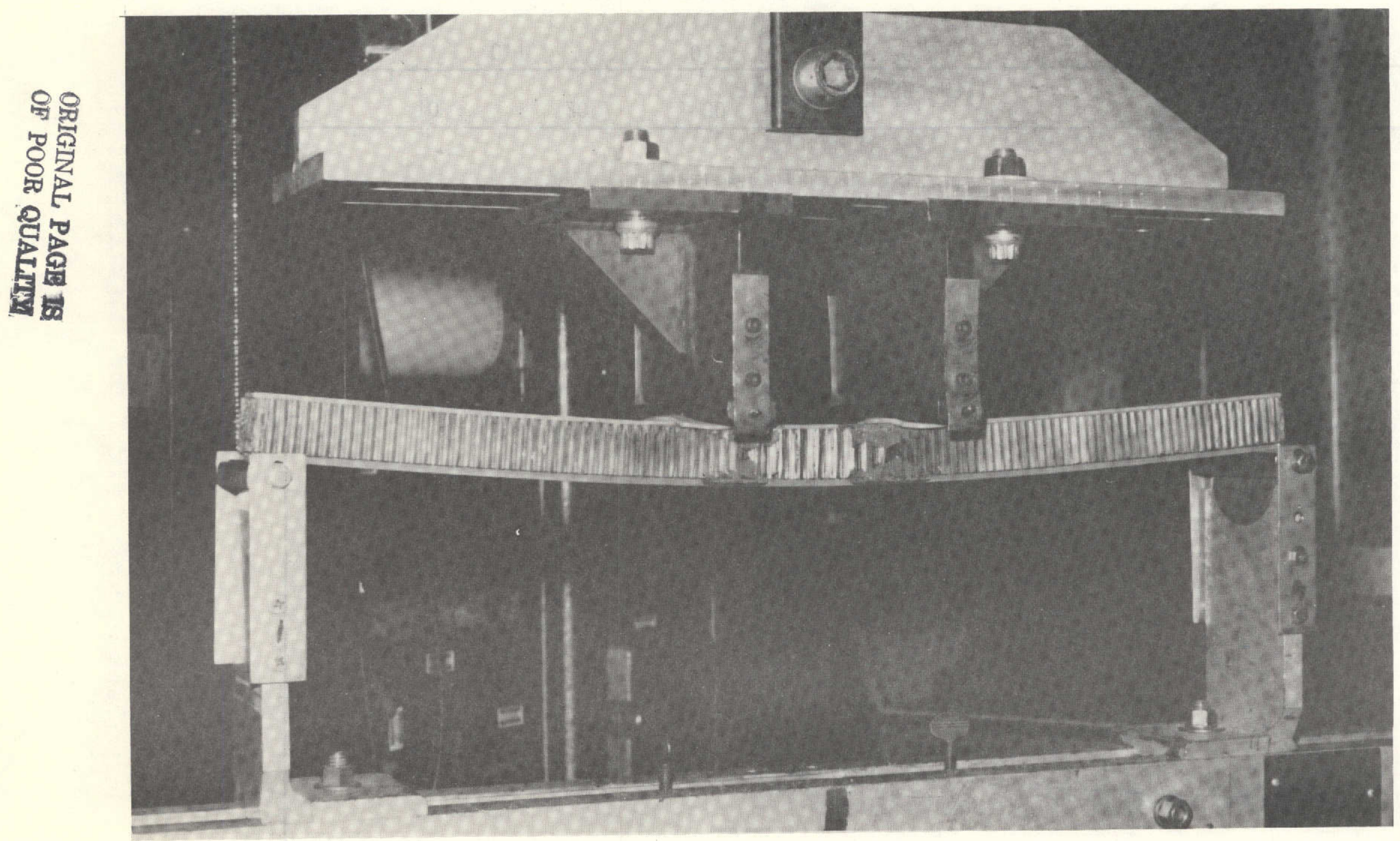

Figure 44 Four Point Bending Honeycomb Sandwich Compression Test 


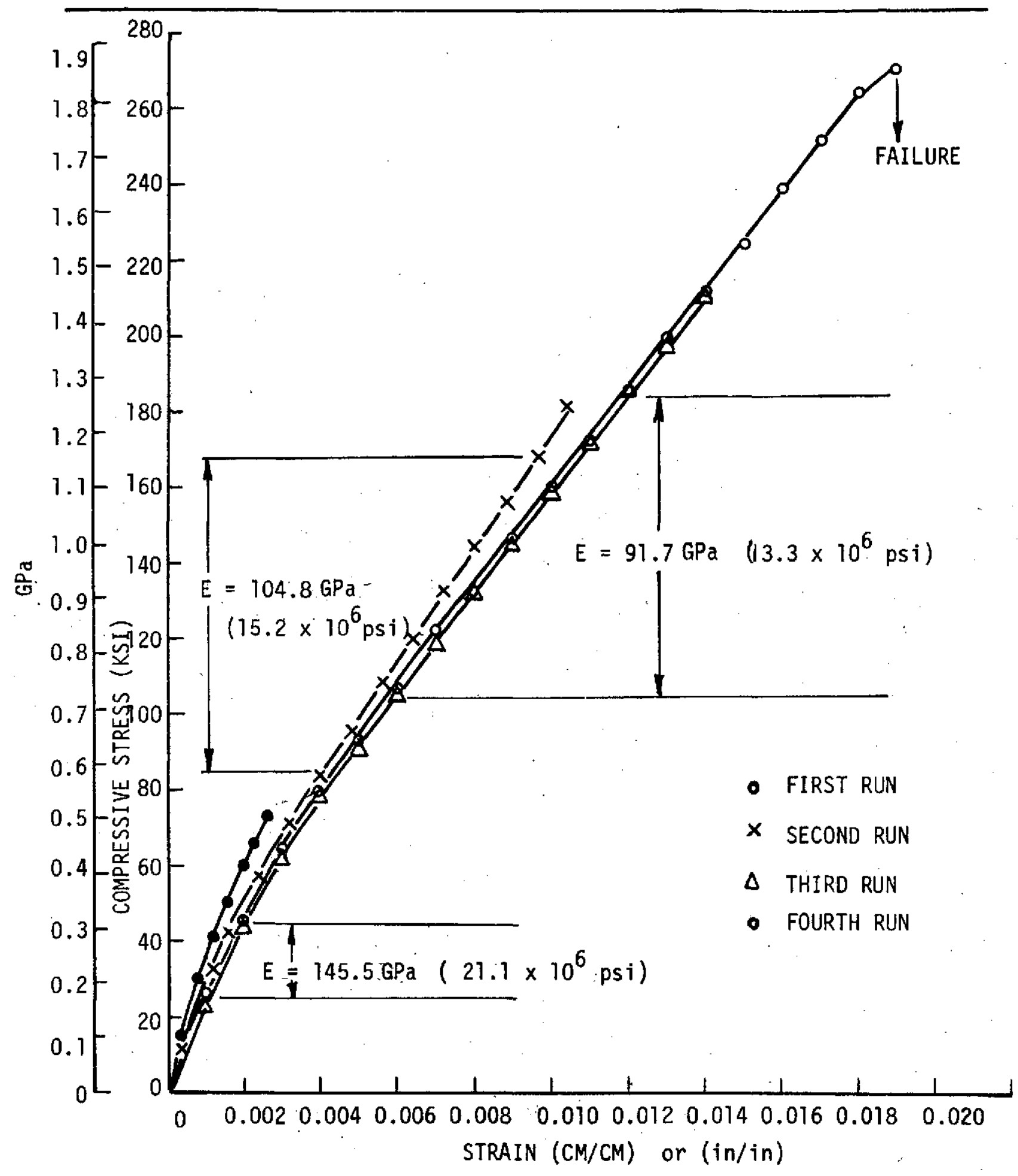

Figure 45 Specimen 11 - Room Temperature Compression Stress/Strain Curve 


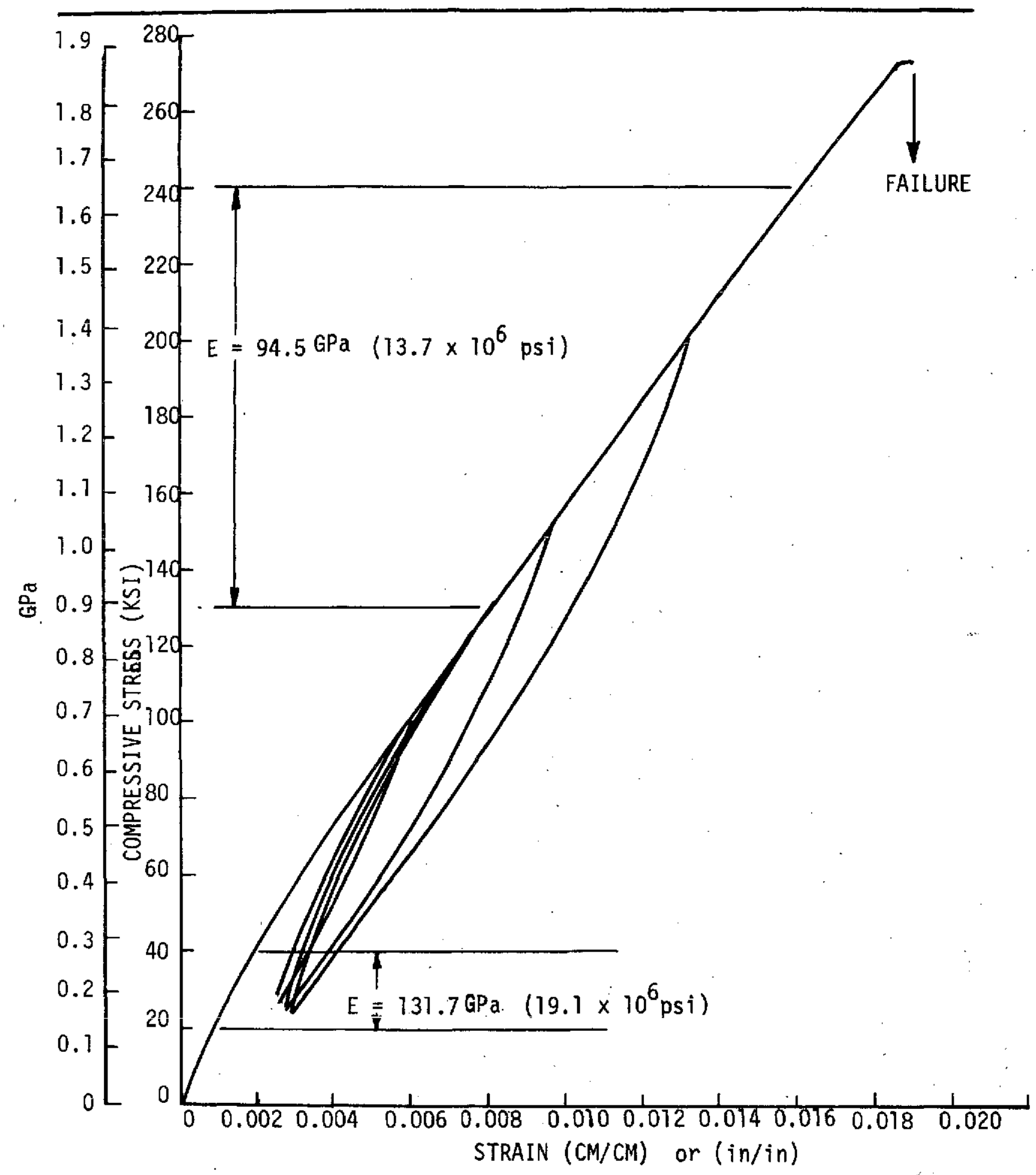

Figure 46 Specimen 12 - Room Temperature Compression Stress/Strain Curve 


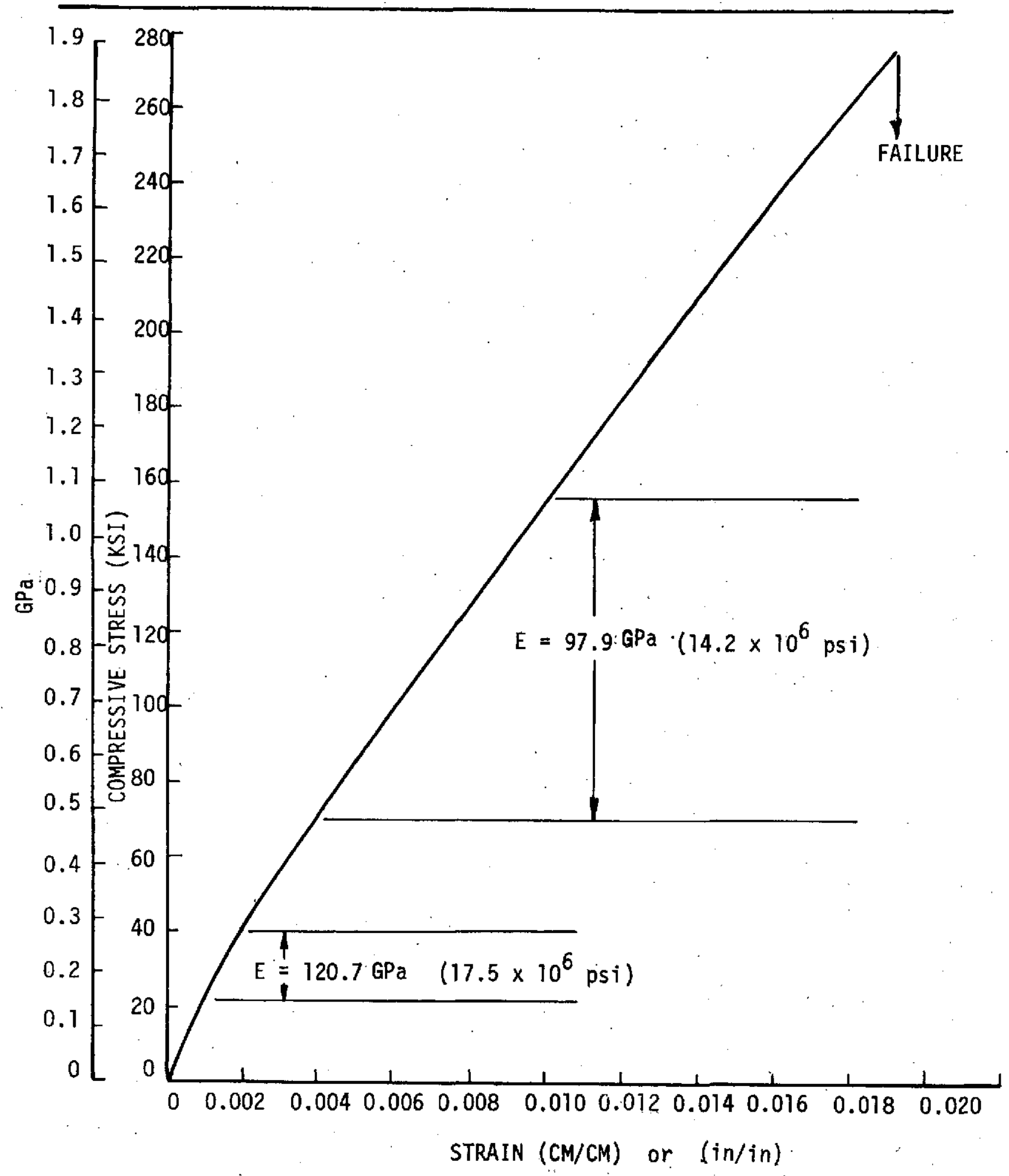

Figure 47 Specimen 13 - Room Temperature Compression Stress/Strain Curve 


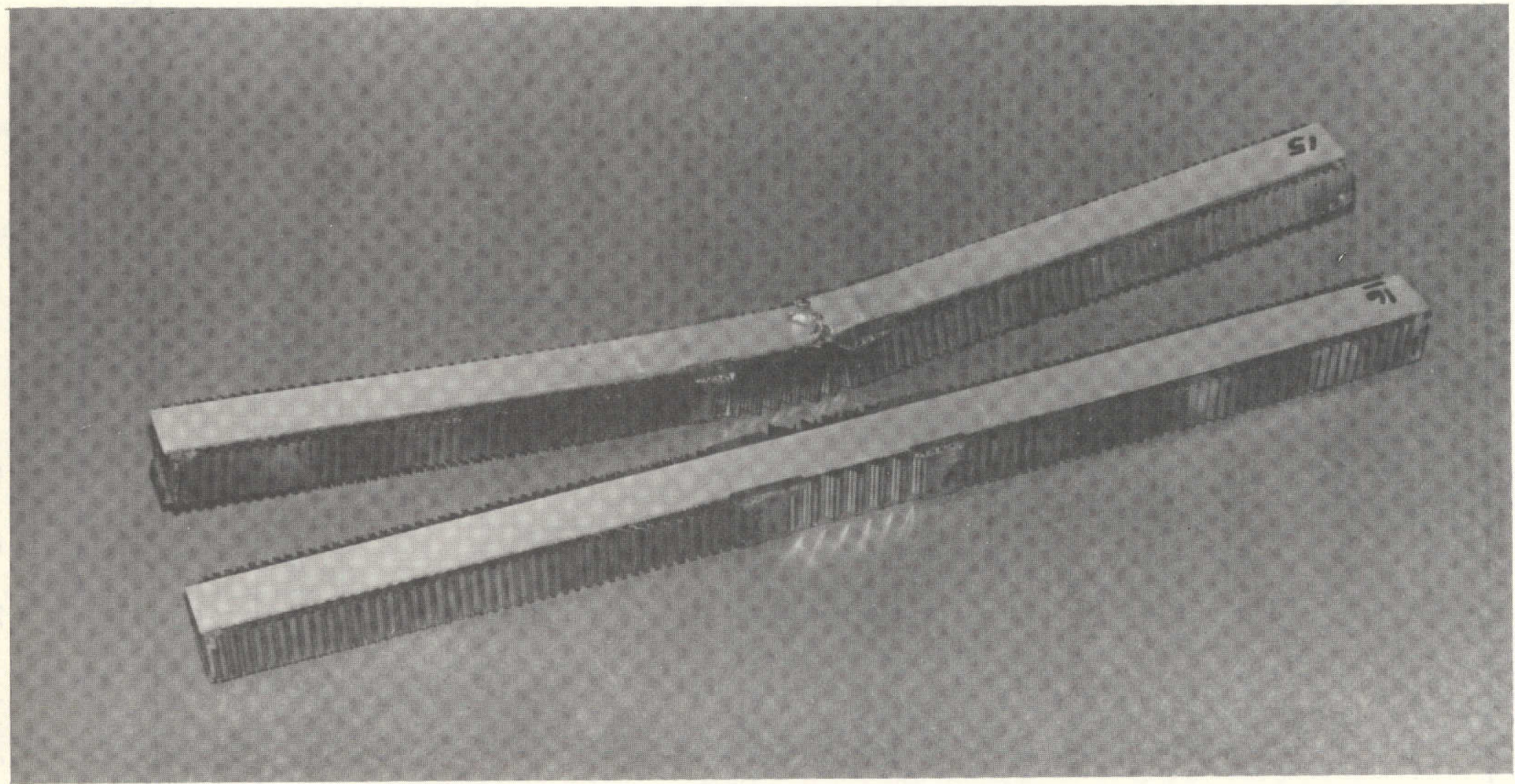

Figure 48 A Tested and An Untested Room Temperature Honeycomb Sandwich Compression Specimen 


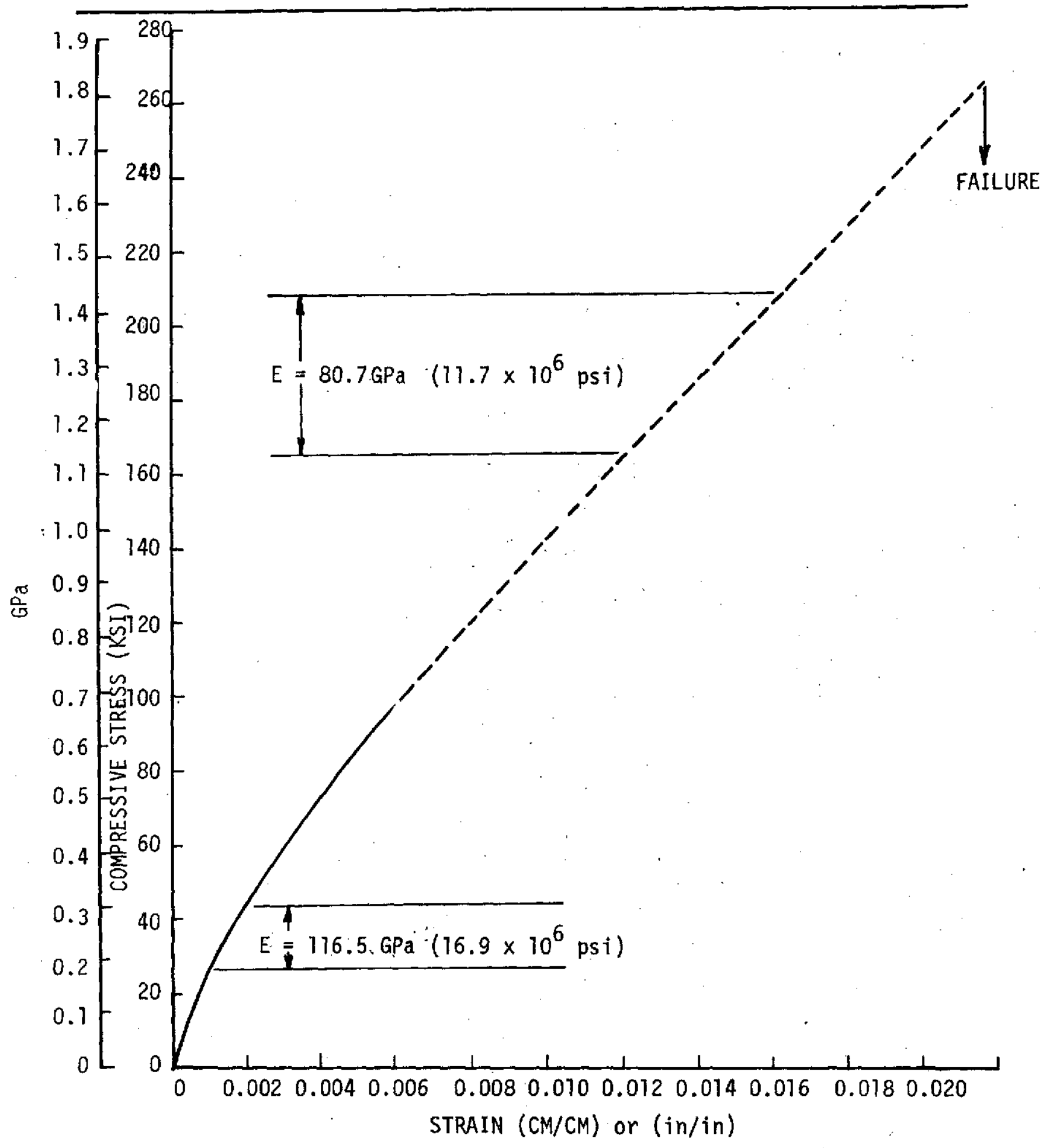

Figure 49 Specimen 14 - Room Temperature Compression Stress/Strain Curve 


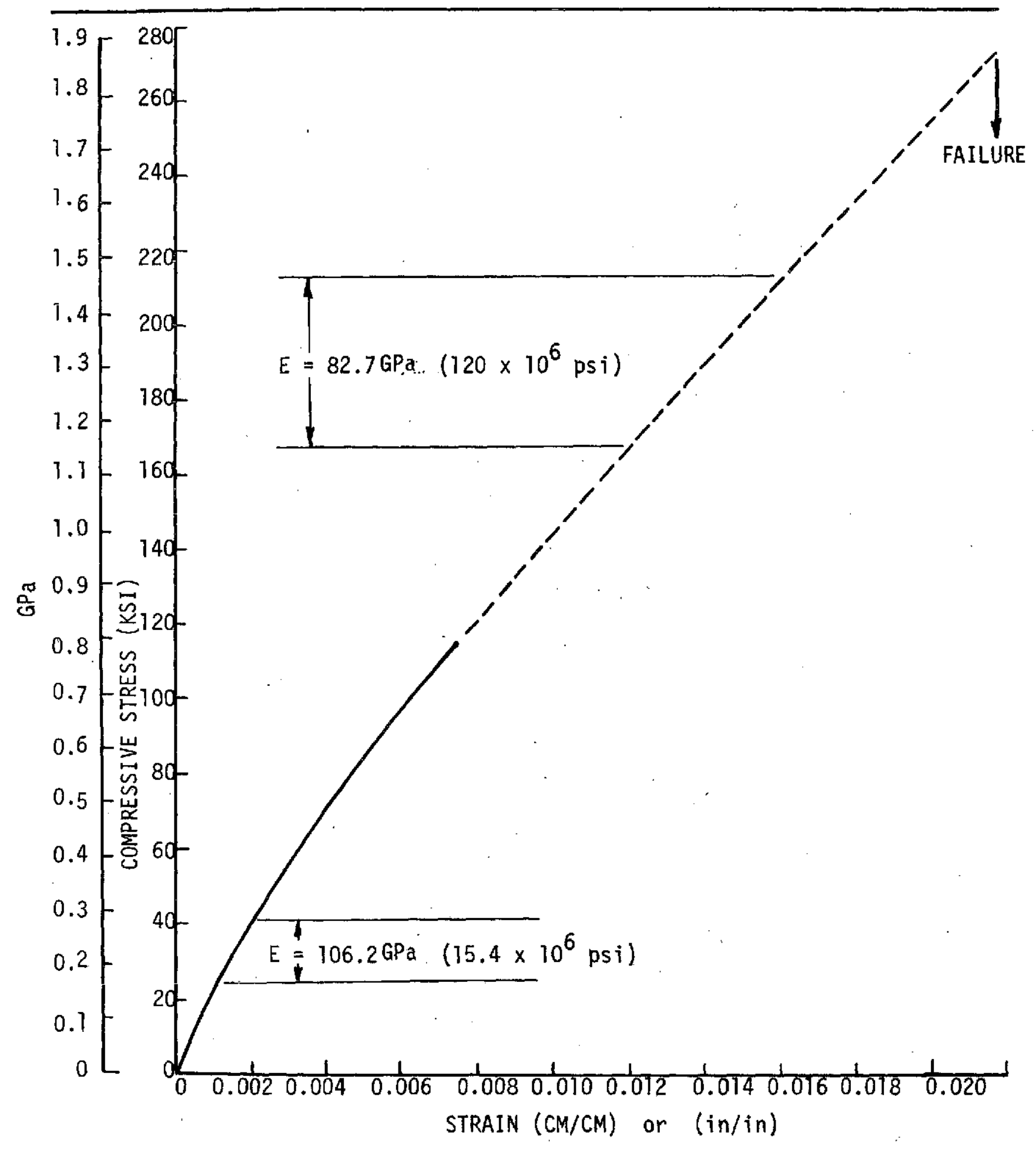

Figure 50 Specimen 15 - Room Temperature Compression Stress/Strain Curve

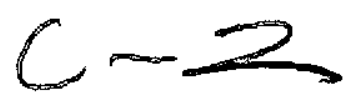




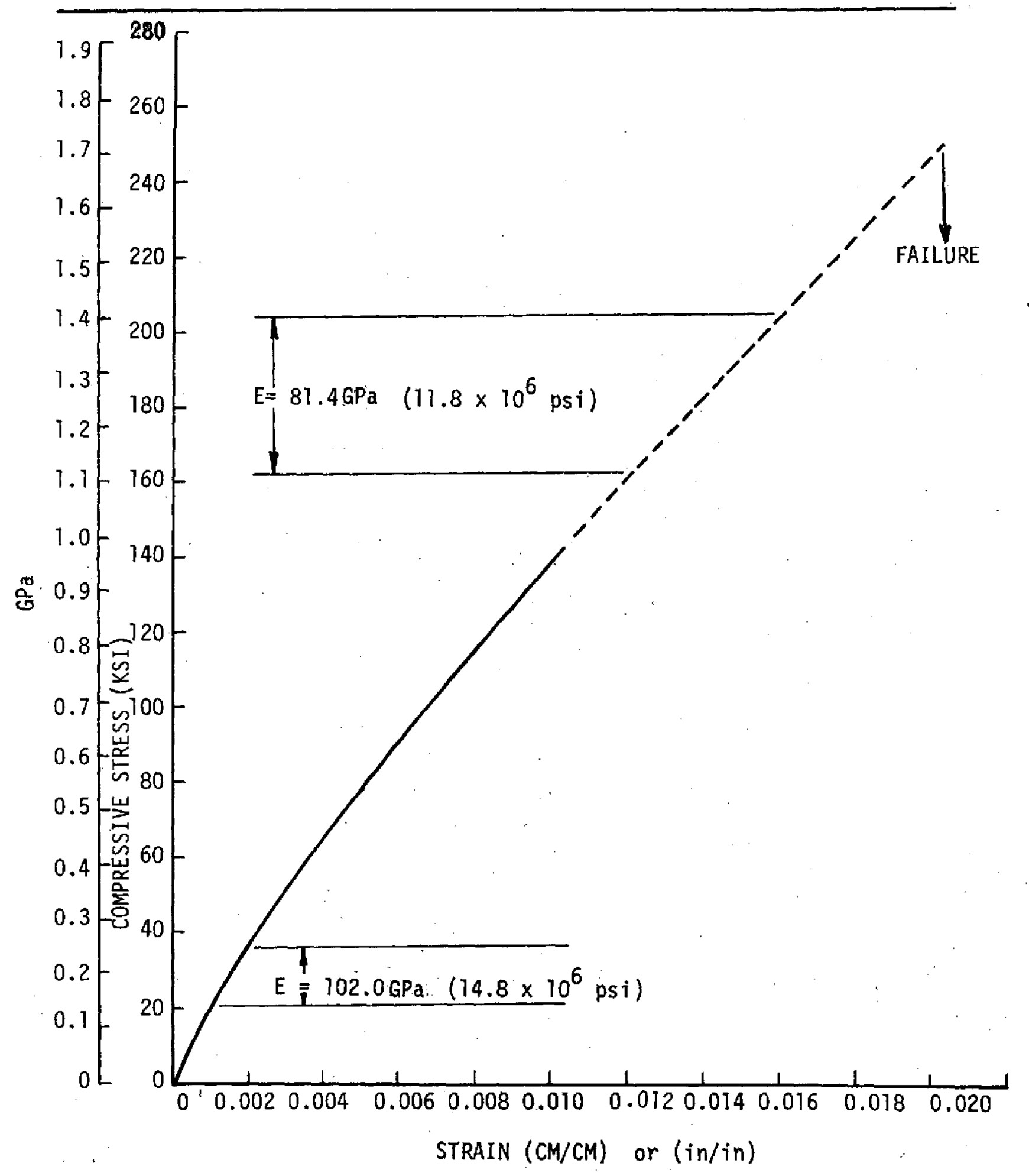

Figure 51 Specimen 16 - Room Temperature Compression Stress/Strain Curve. 


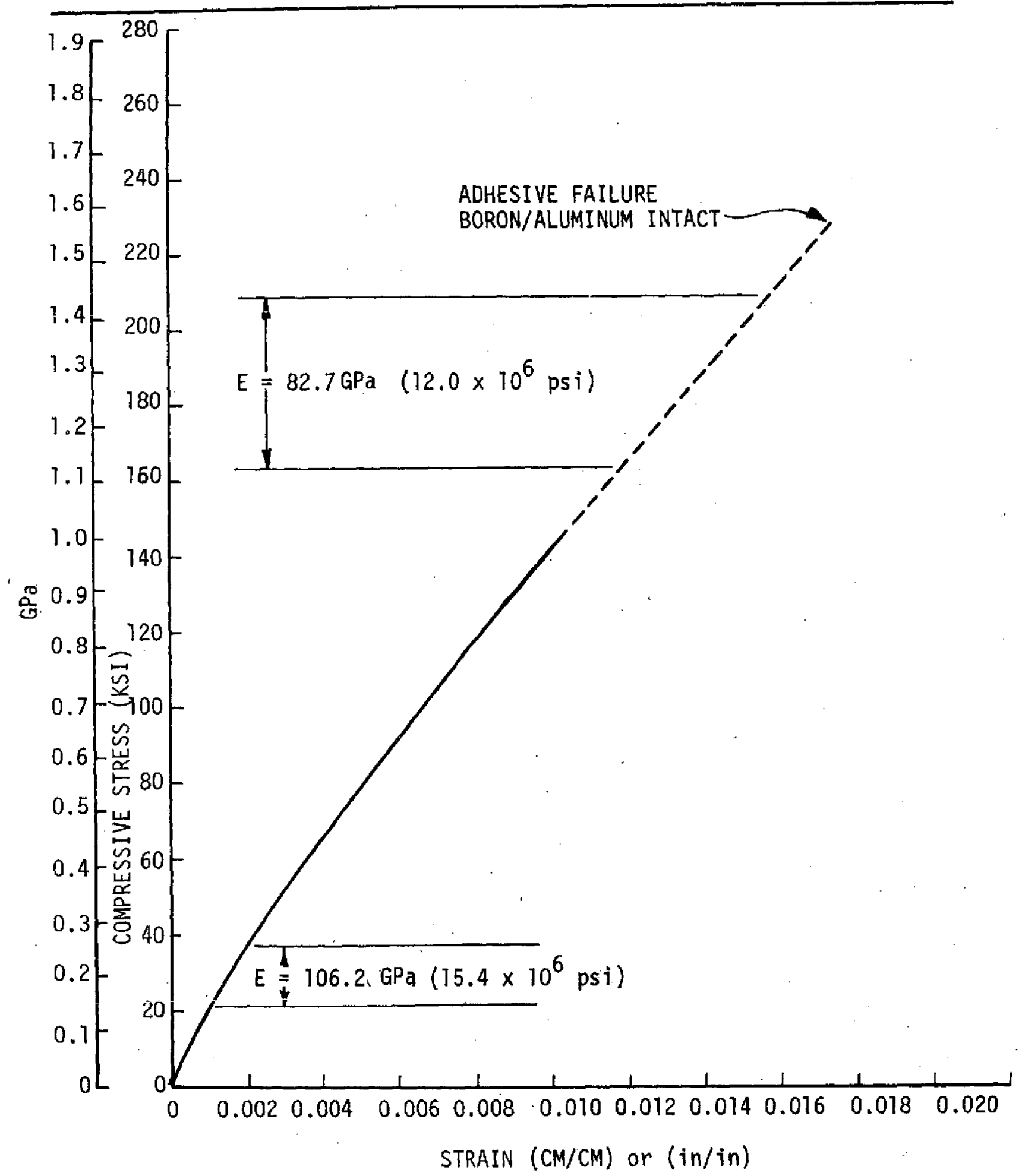

Figure 52 Specimen 17 - Room Temperature Compression Stress/Strain Curve 


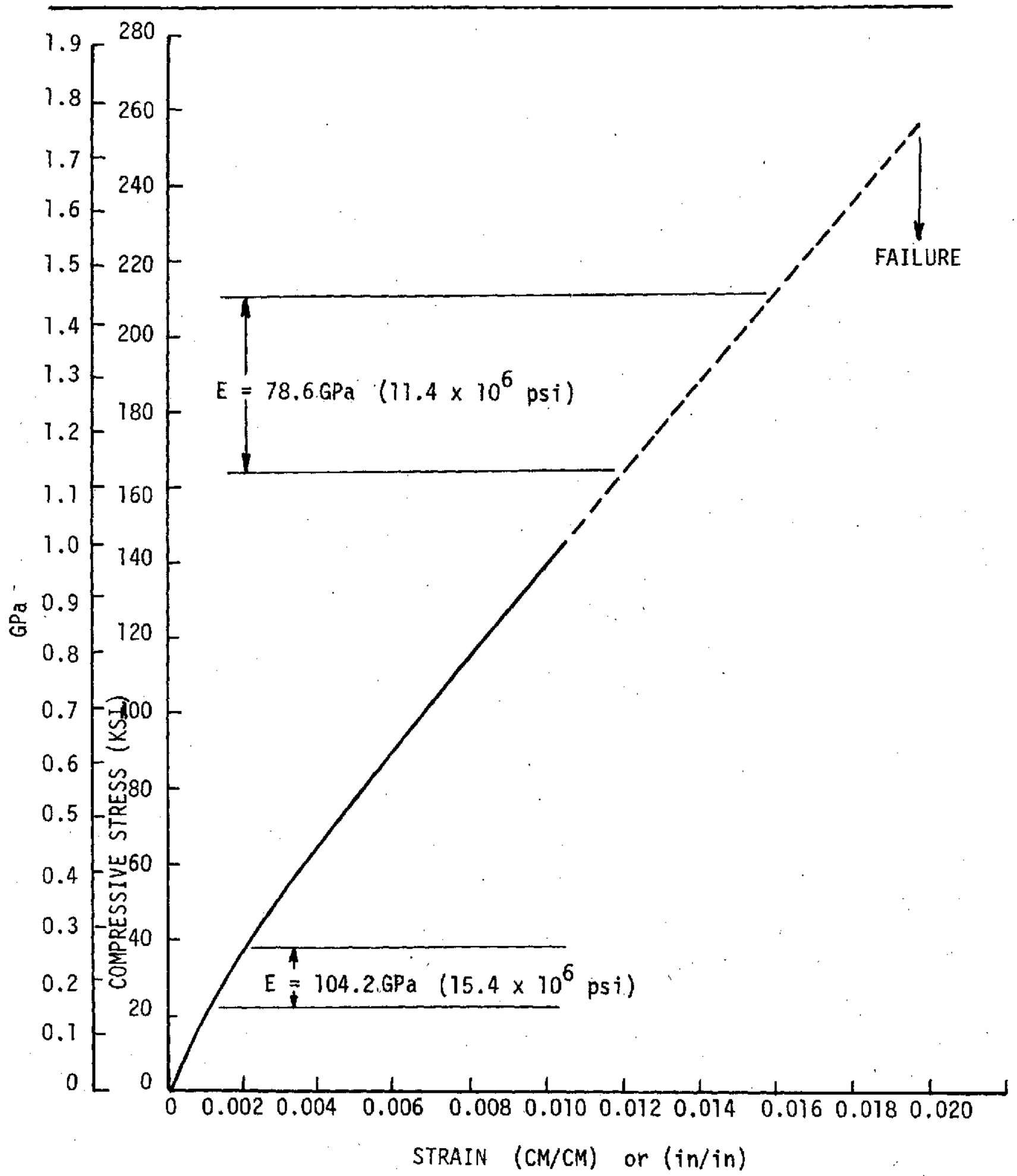

Figure 53 Specimen 18 - Room Temperature Compression Stress/Strain Curve 


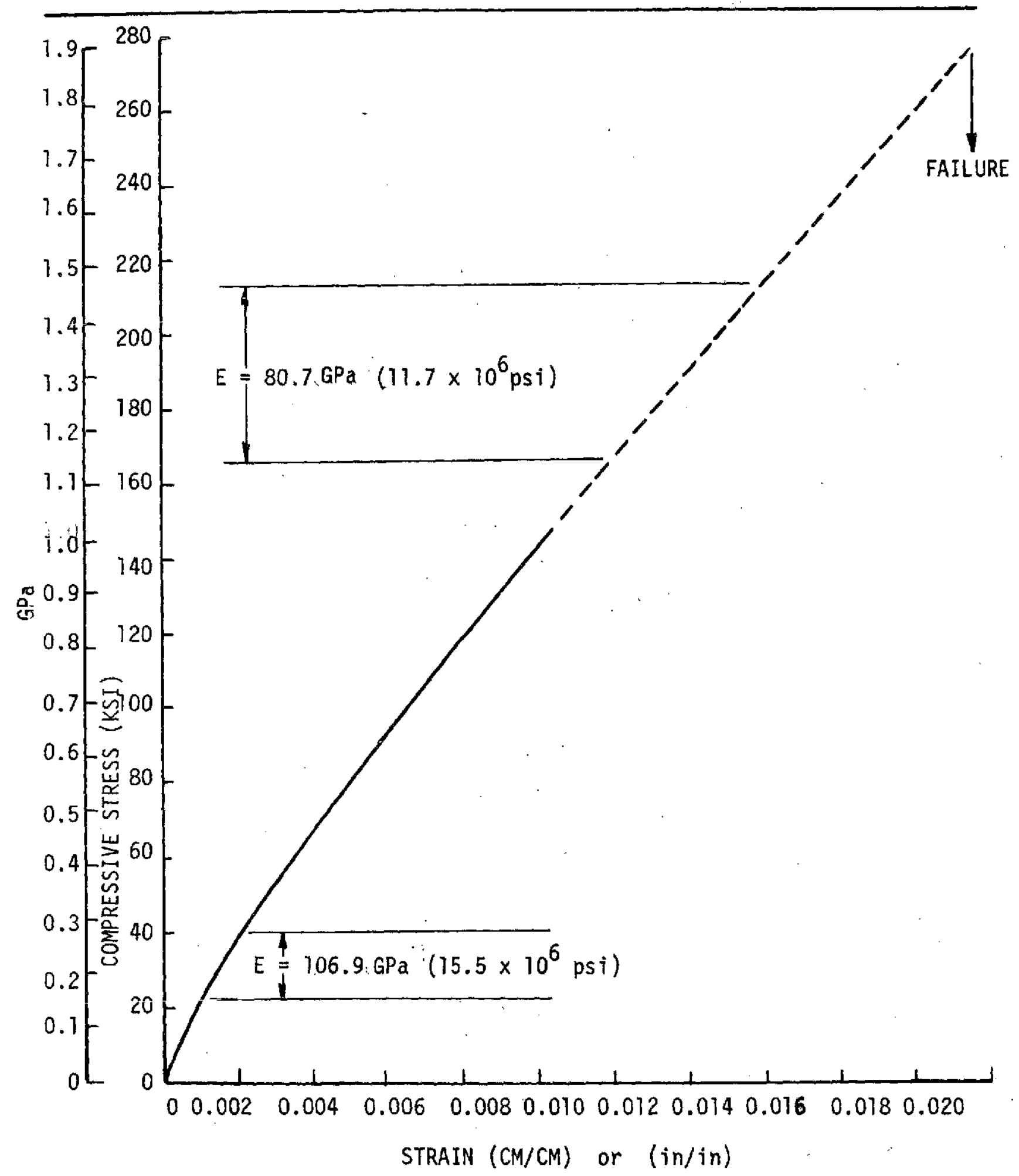

Figure 54 Specimen'19-Room Temperature Compression Stress/Strain Curve 


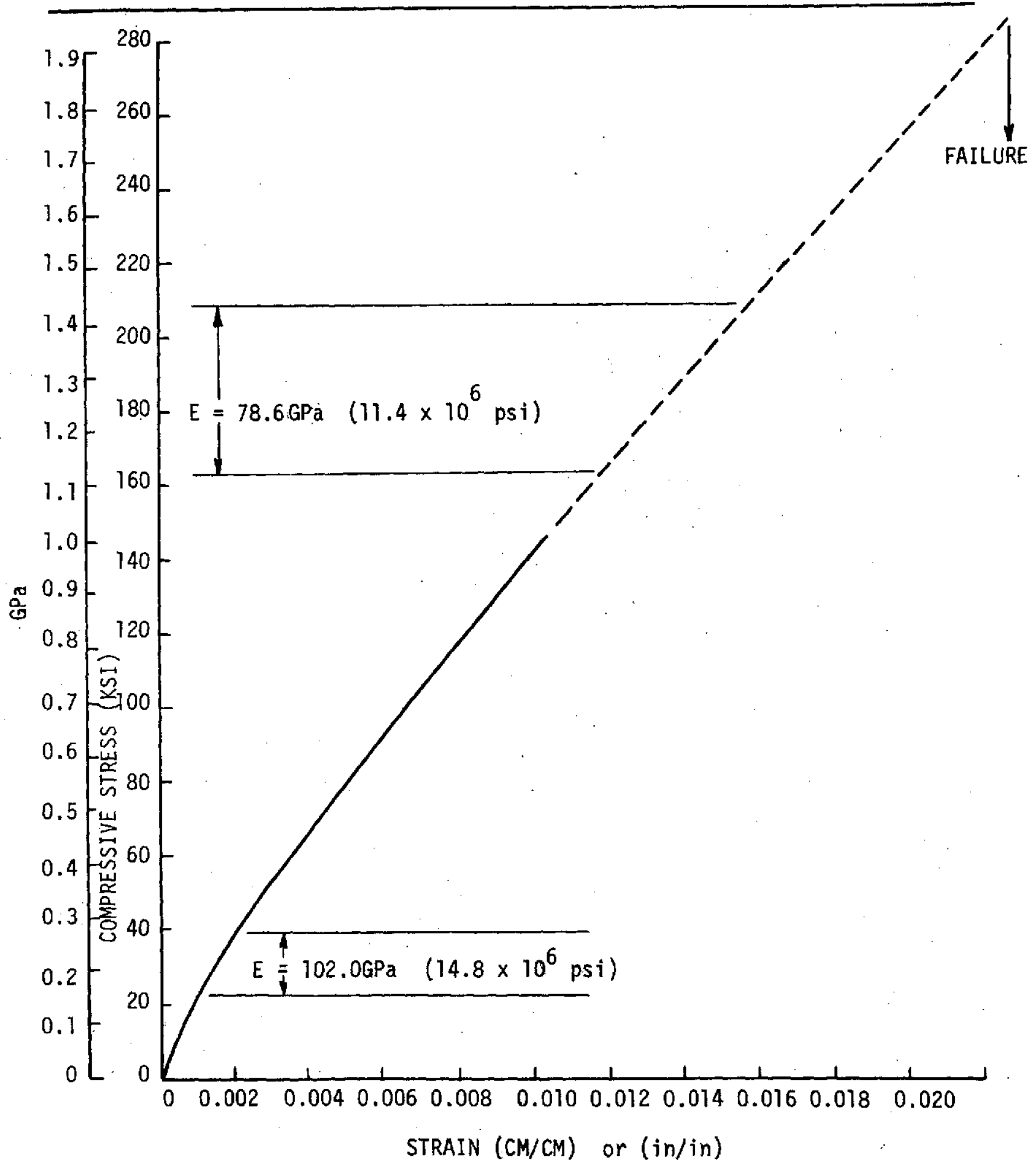

Figure 55 Specimen 20 - Room Temperature Compression Stress/Strain Curve 


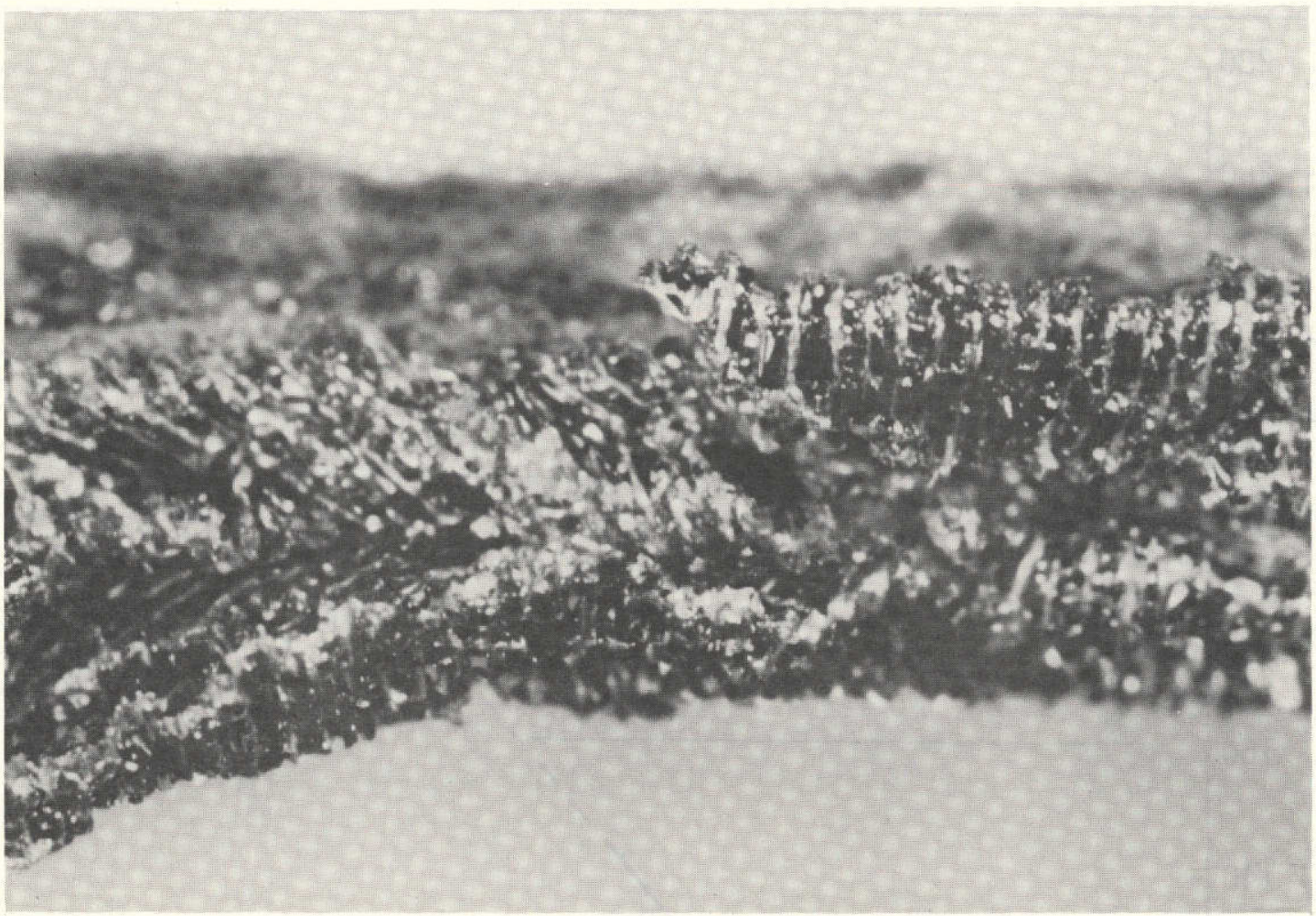

$19 \times$
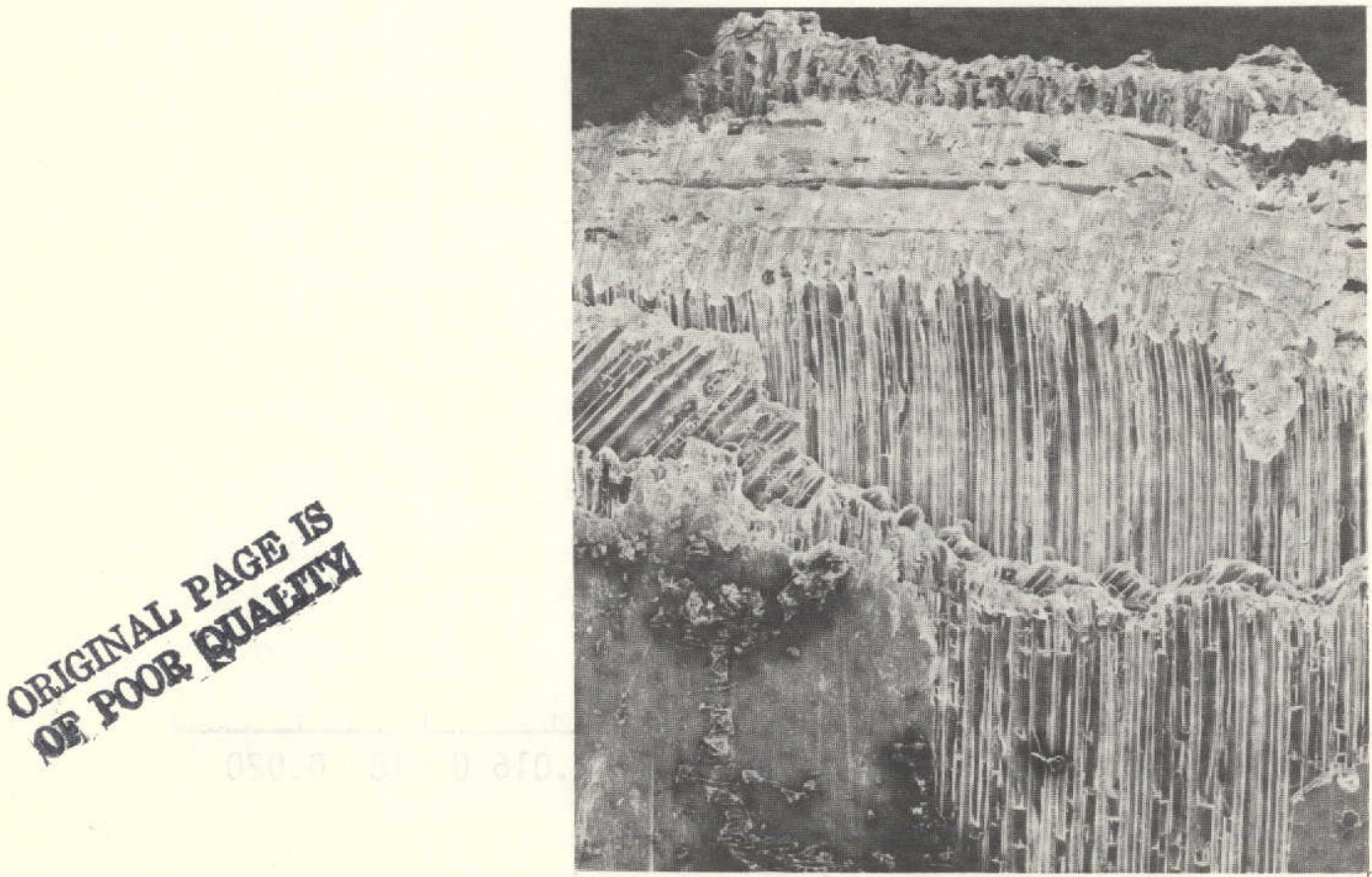

$10 \times$

Figure 56 Compression Specimen Failure Surface 


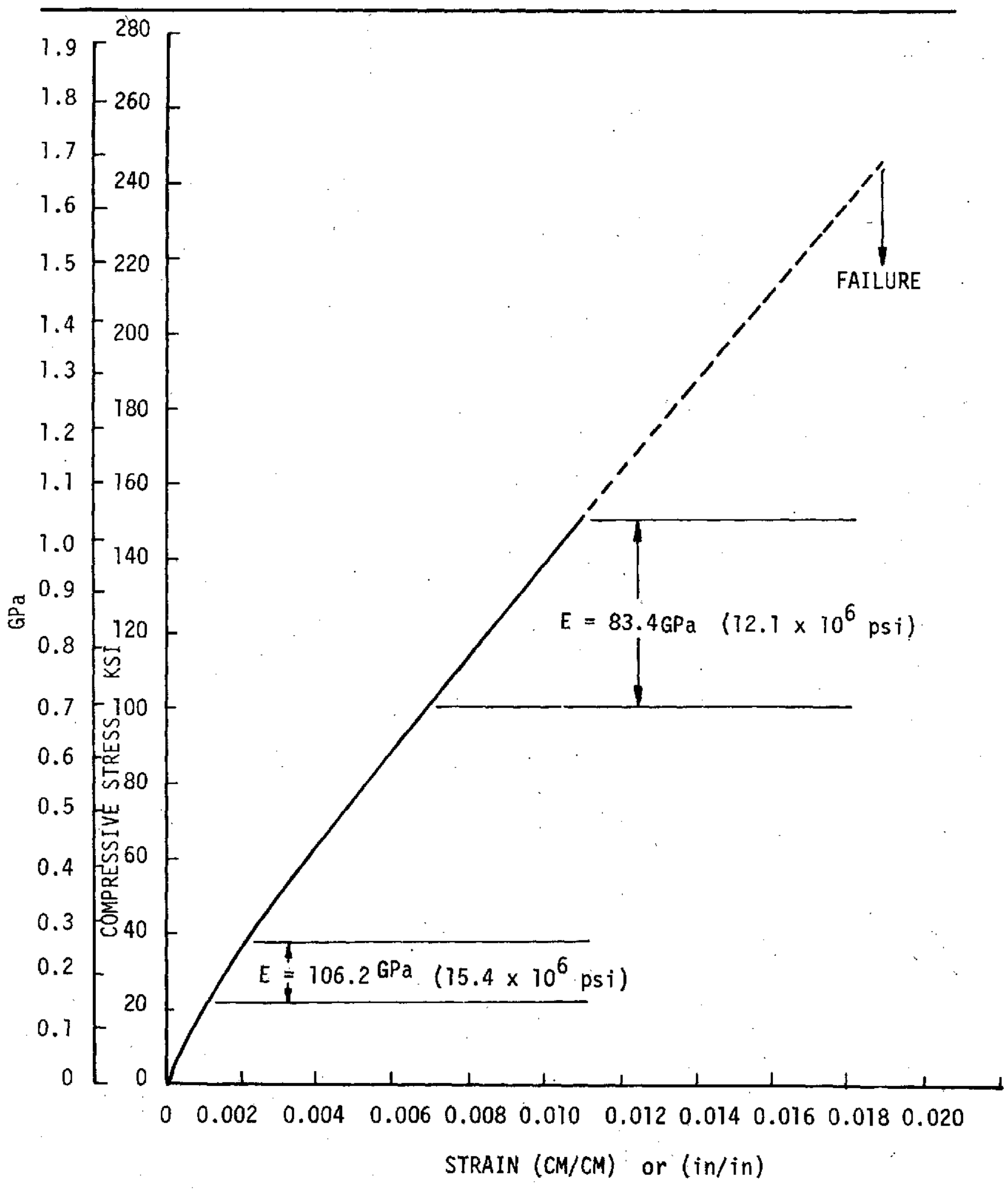

Figure 57 Specimen 21 - Room Temperature Compression Stress-Strain Curve after 1000 Hours at $505 \mathrm{~K}\left(450^{\circ} \mathrm{F}\right)$ 


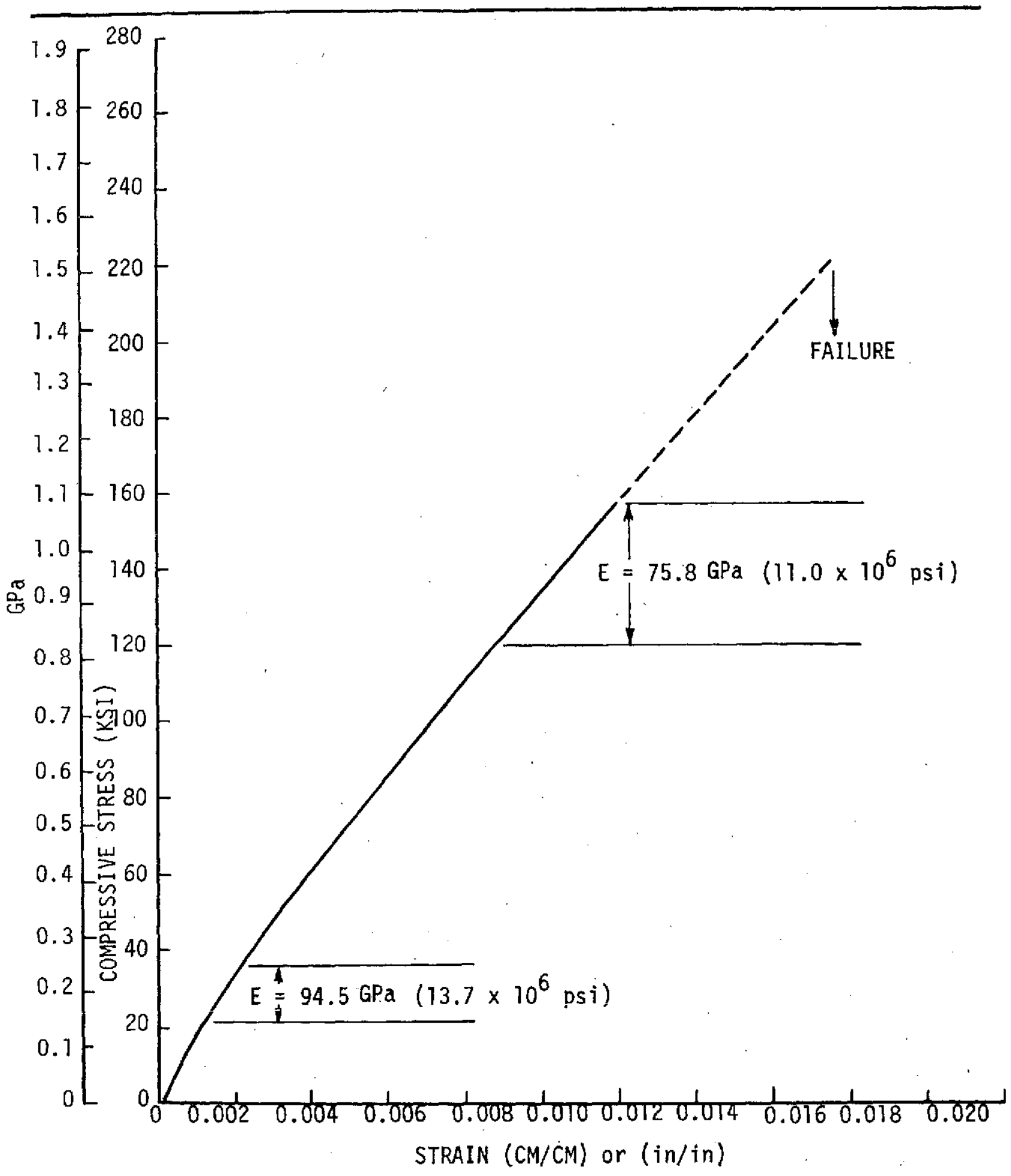

Figure 58 Specimen 22 - Room Temperature Compression Stress/Strain Curve after 1000 Hours at $505 \mathrm{~K}\left(450^{\circ} \mathrm{F}\right)$ 


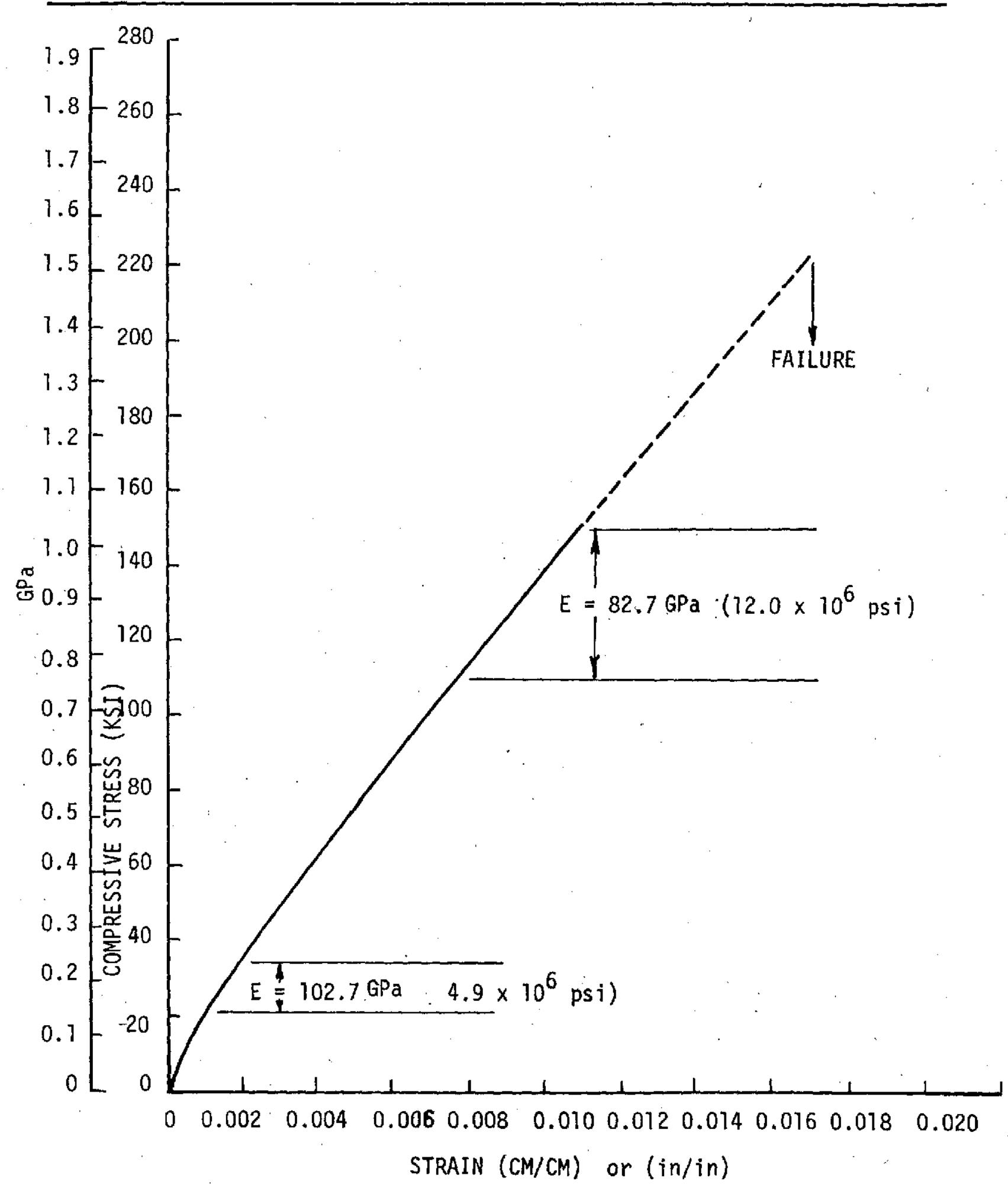

Figure 59 Specimen 23 - Room Temperature Compression Stress/Strain Curve after 1000 Hours at $505 \mathrm{~K}\left(450^{\circ} \mathrm{F}\right)$ 


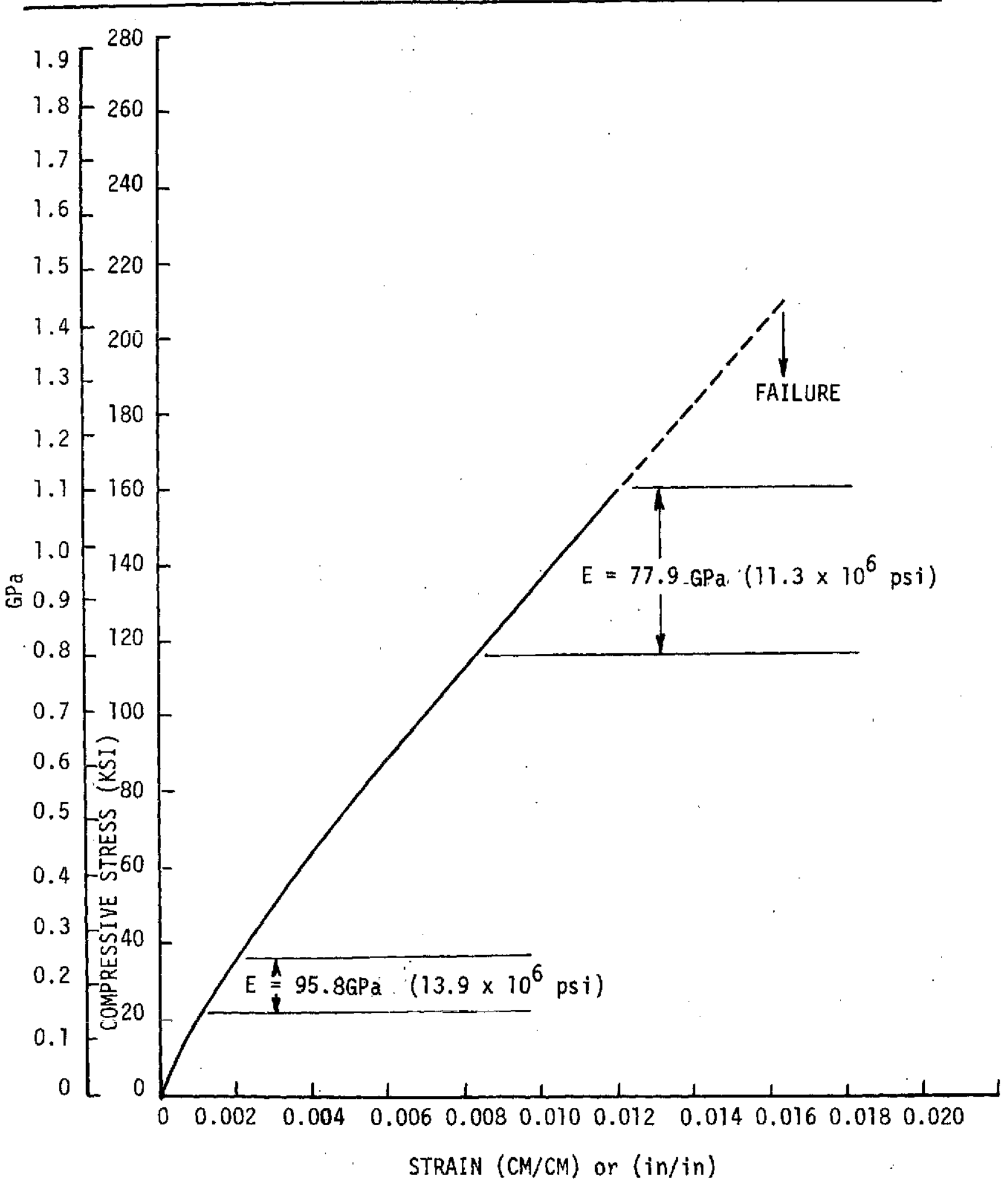

Figure 60 Specimen 24 - Room Temperature Compression Stress/Strain Curve after 1000 Hours at $505 \mathrm{~K}\left(450^{\circ} \mathrm{F}\right)$

98 


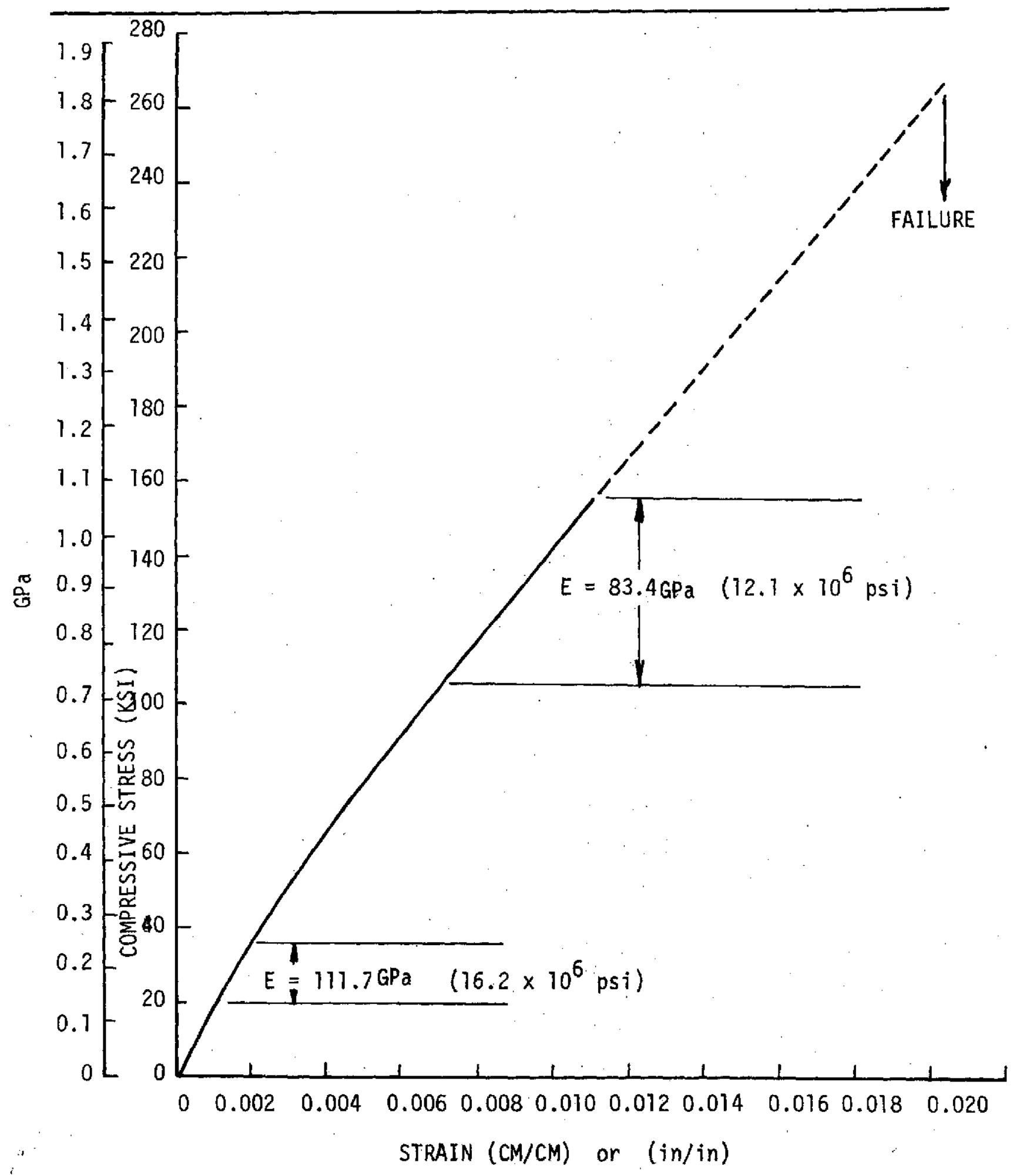

Figure 61 Specimen 25 - Room Temperature Compression Stress/Strain Curve after 1000 Hours at $505 \mathrm{~K}\left(450^{\circ} \mathrm{F}\right)$ 


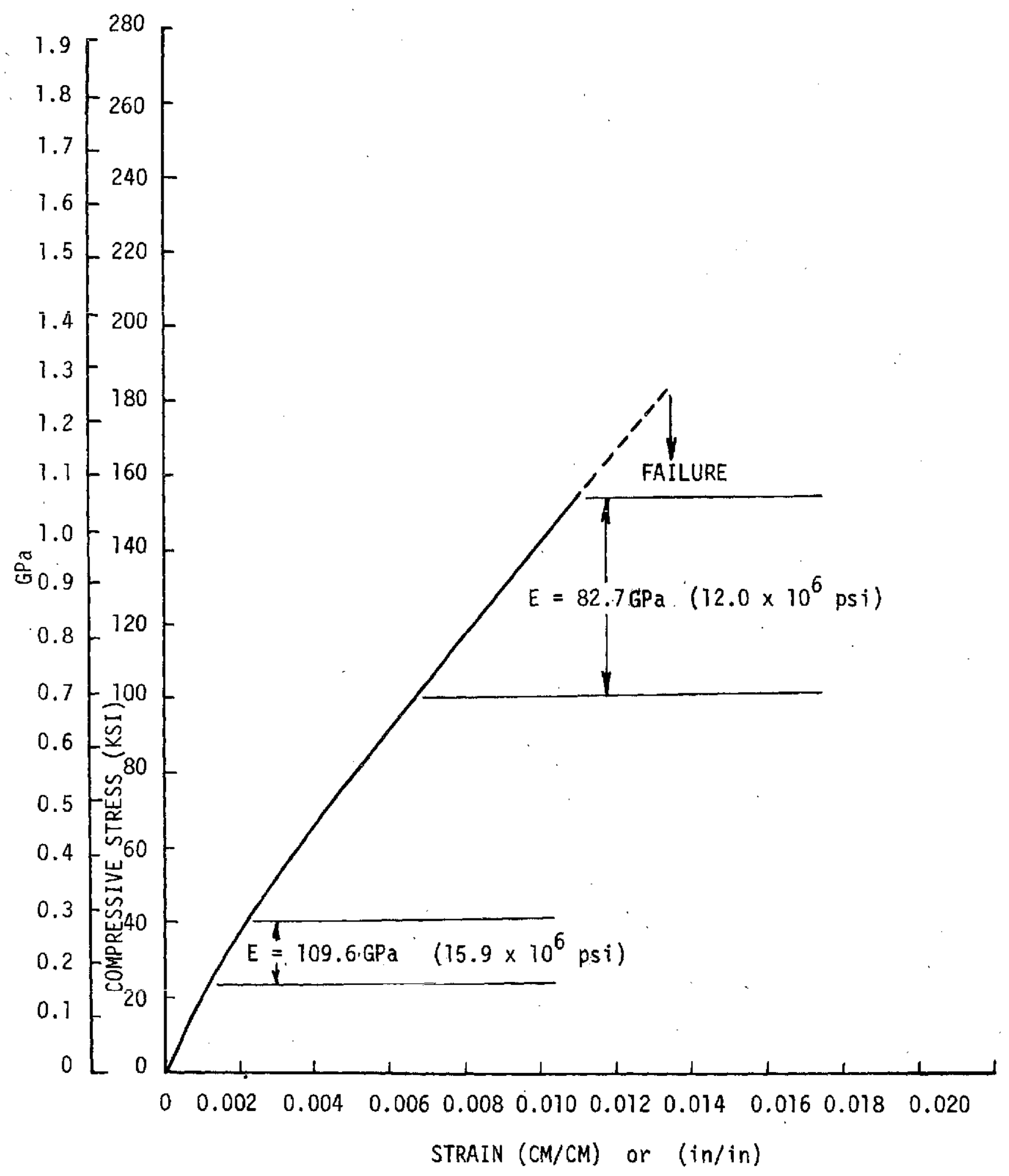

Figure 62 Specimen 26 - Room Temperature Compression Stress/Strain Curve after 1000 Hours at $505 \mathrm{~K}\left(450^{\circ} \mathrm{F}\right)$ 


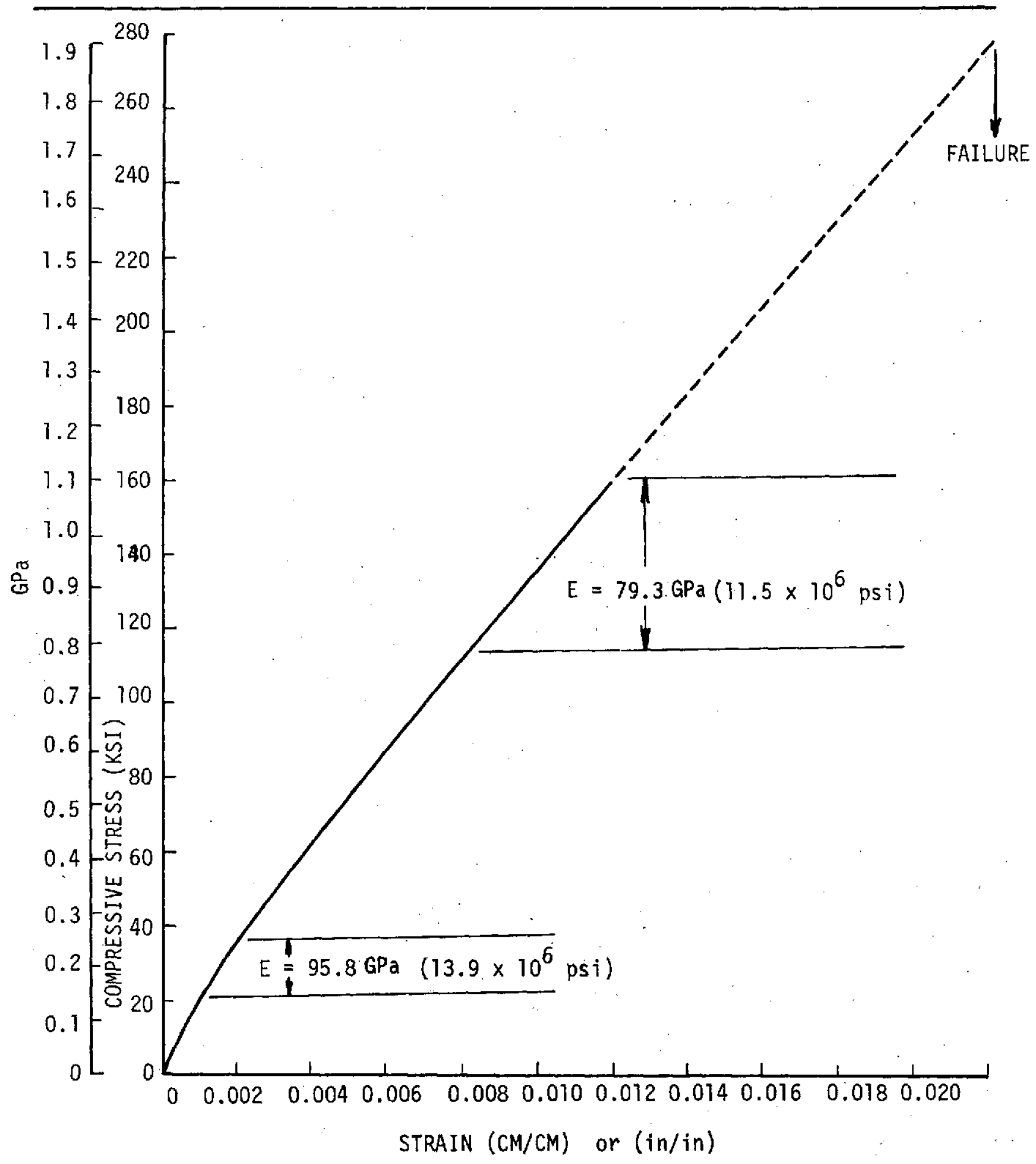

Figure 63 Specimen 27 - Room Temperature Compression Stress/Strain Curve after 1000 Hours at $505 \mathrm{~K}\left(450^{\circ} \mathrm{F}\right)$ 


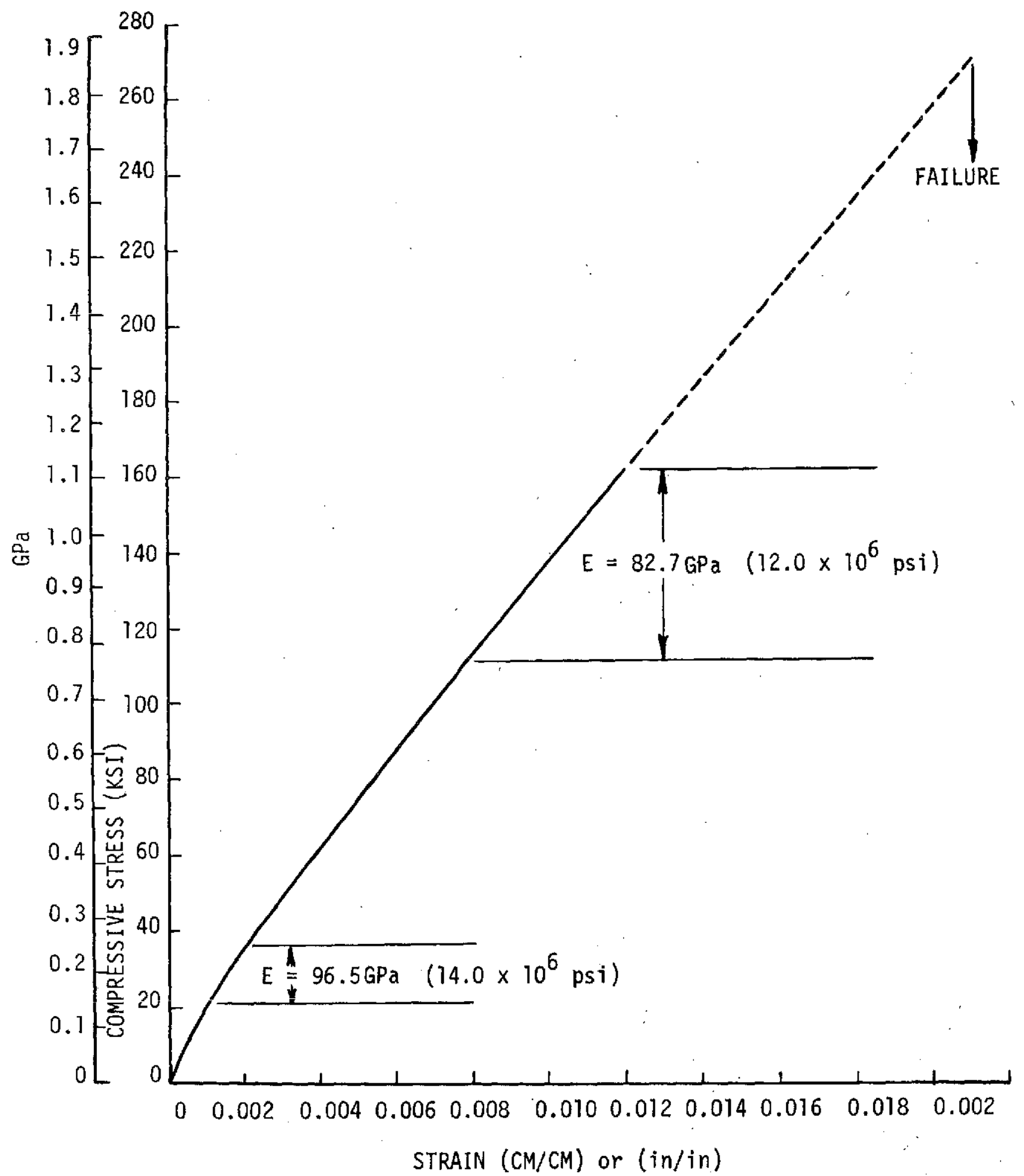

Figure 64 Specimen 28 - Room Temperature Compression Stress/Strain Curve after 1000 Hours at $505 \mathrm{~K}\left(450^{\circ} \mathrm{F}\right)$ 


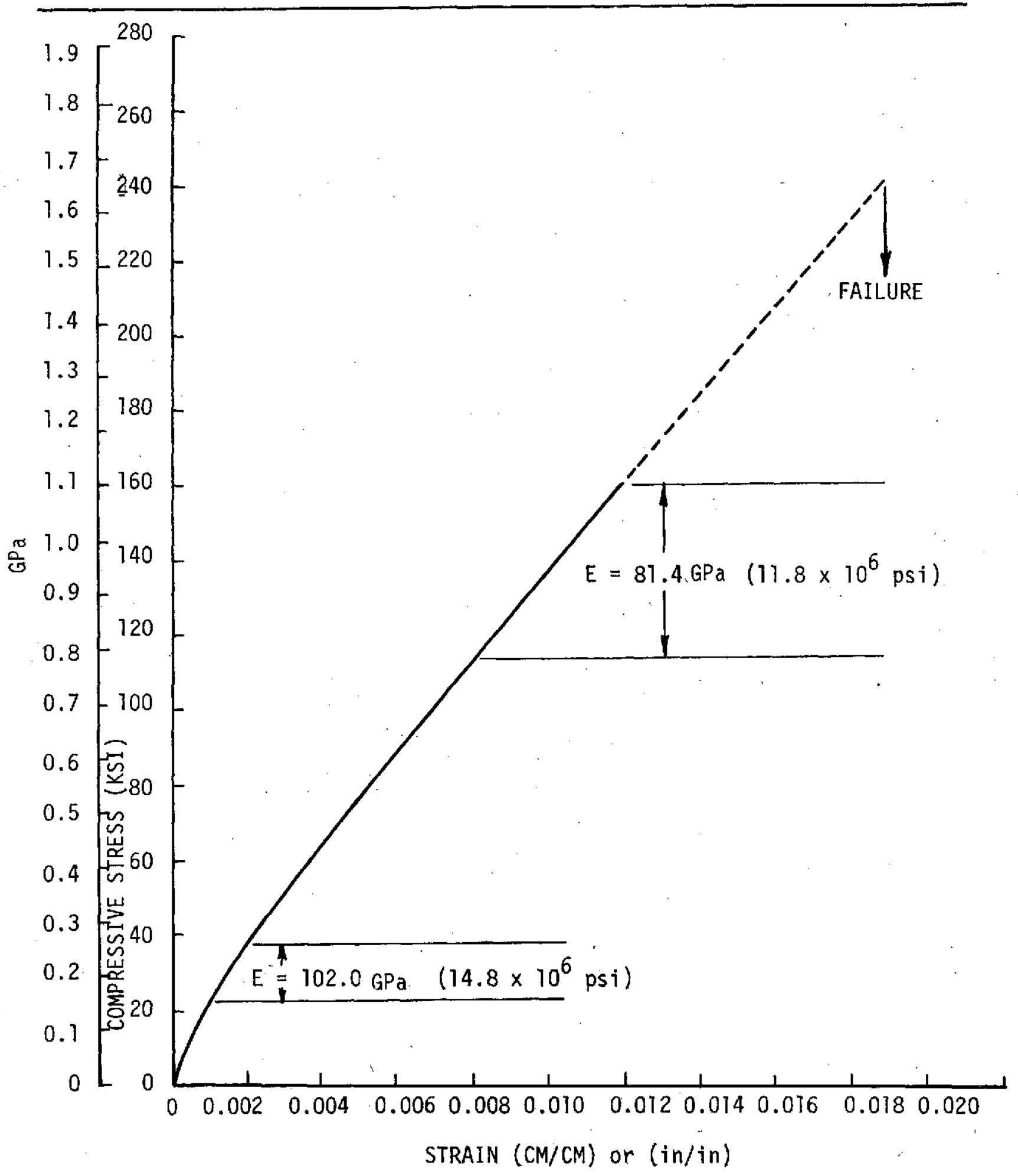

Figure 65 Specimen 29 - Room Temperature Compression Stress/Strain Curve after 1000 Hours at $505 \mathrm{~K}\left(450^{\circ} \mathrm{F}\right)$ 


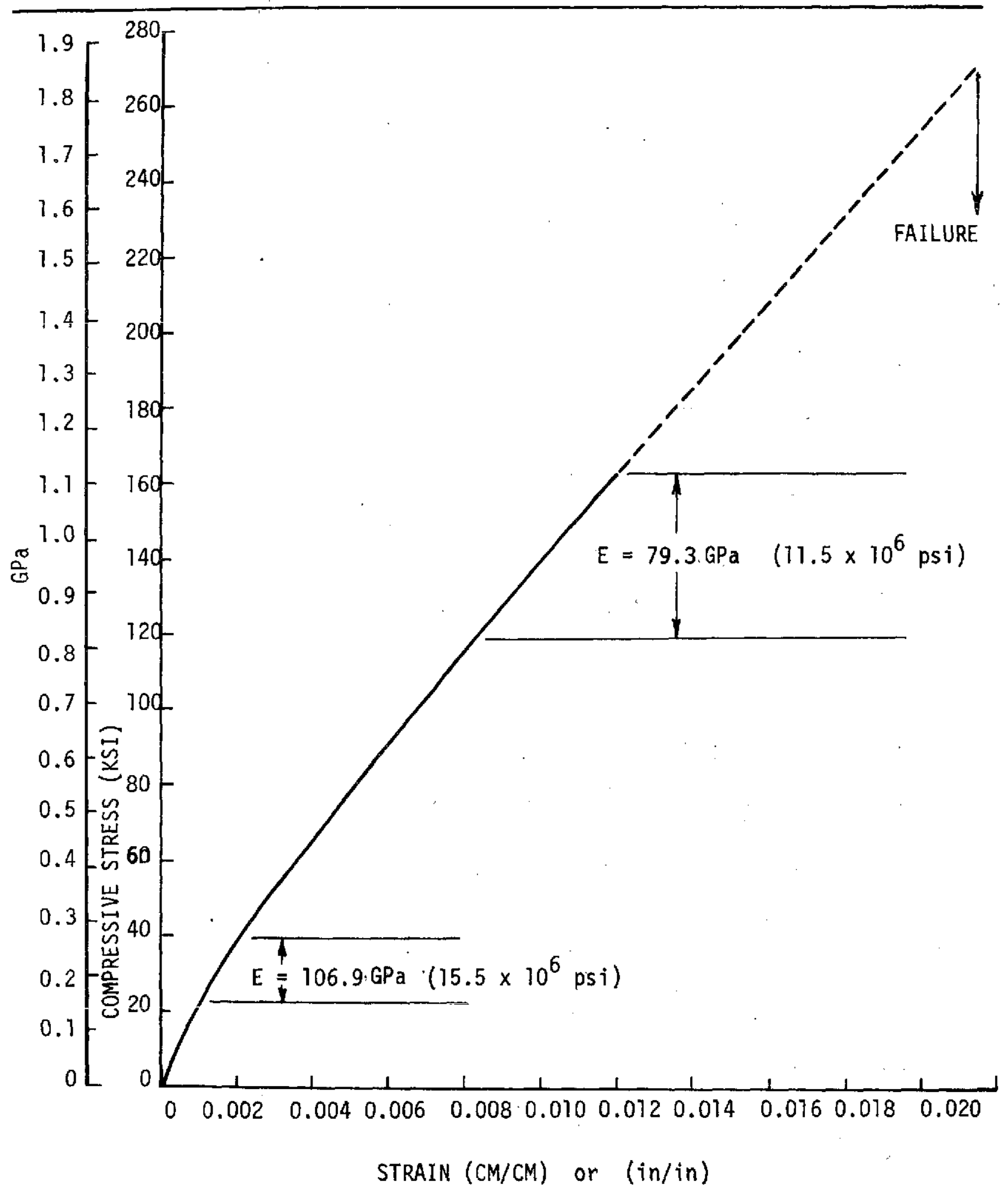

Figure 66 Specimen 30 - Room Temperature Compression Stress/Strain Curve after 1000 Hours at $505 \mathrm{~K}\left(450^{\circ} \mathrm{F}\right)$ 


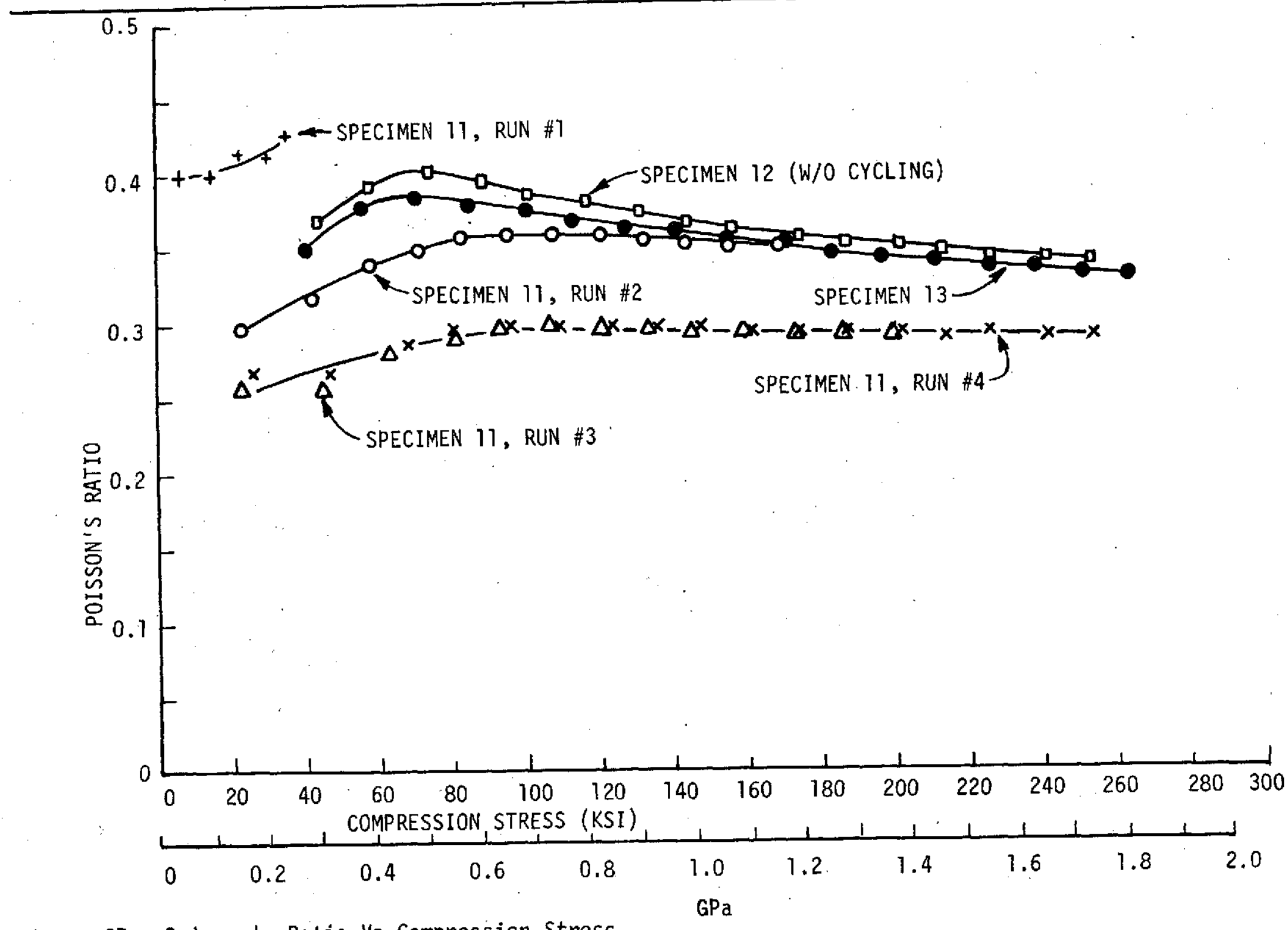

Figure 67 Poisson's Ratio Vs Compression Stress 
호

이운

䆓

曾

8

?

然 4

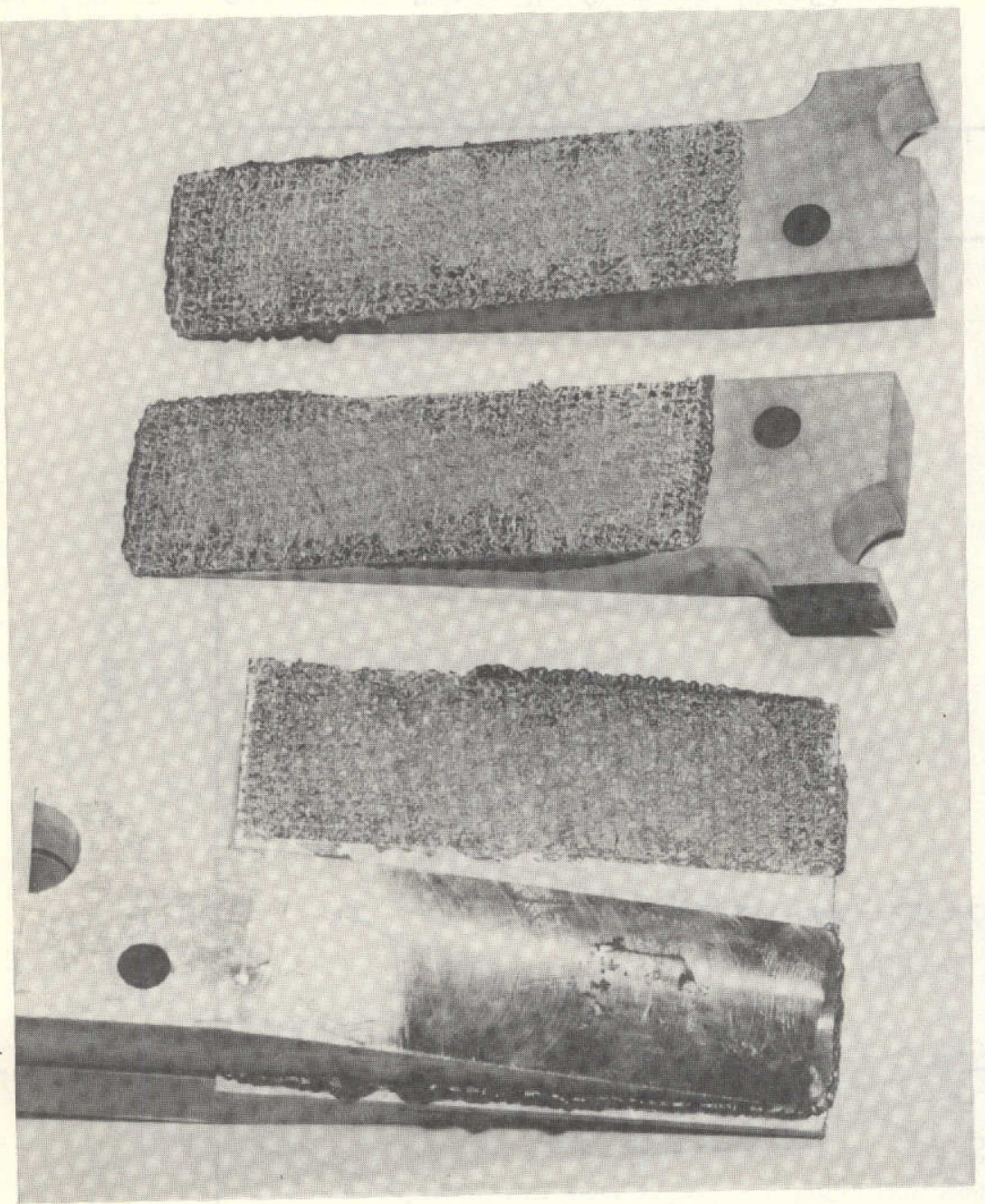

SPECIMEN \#10

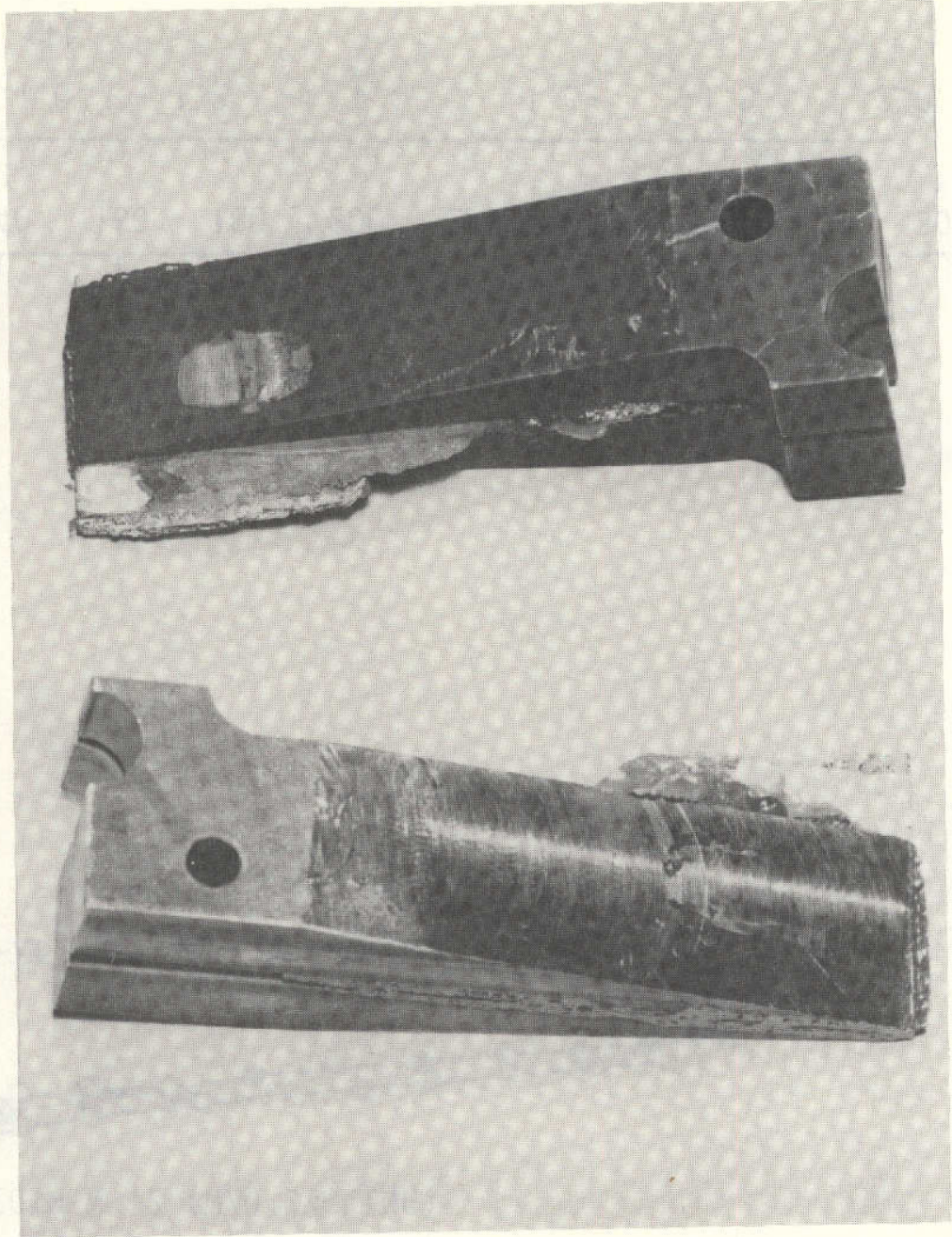

SPECIMEN \#8

Figure 68 Failed Rail Shear Specimens 


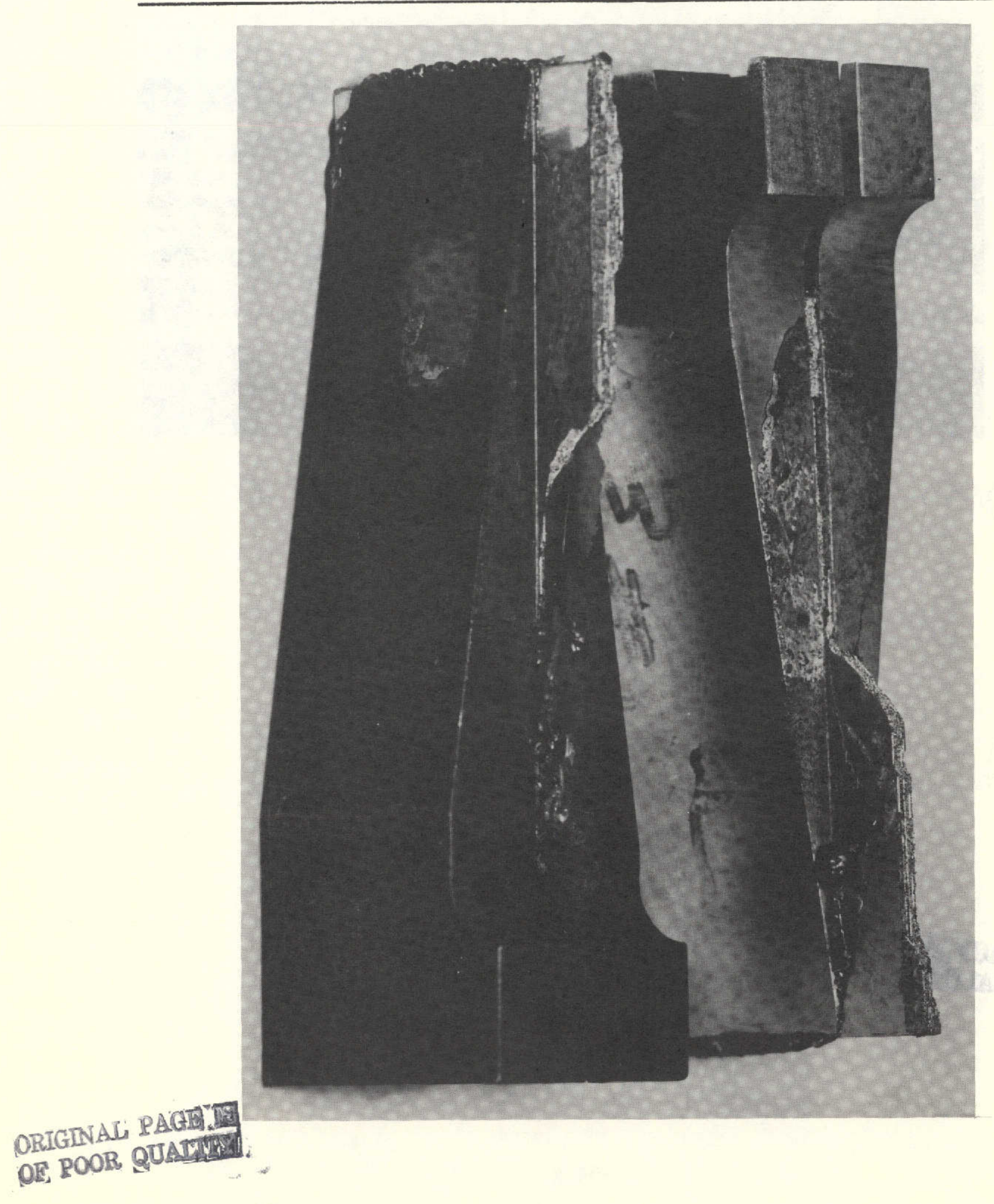

Figure 69 Failed Rail Shear Specimen 


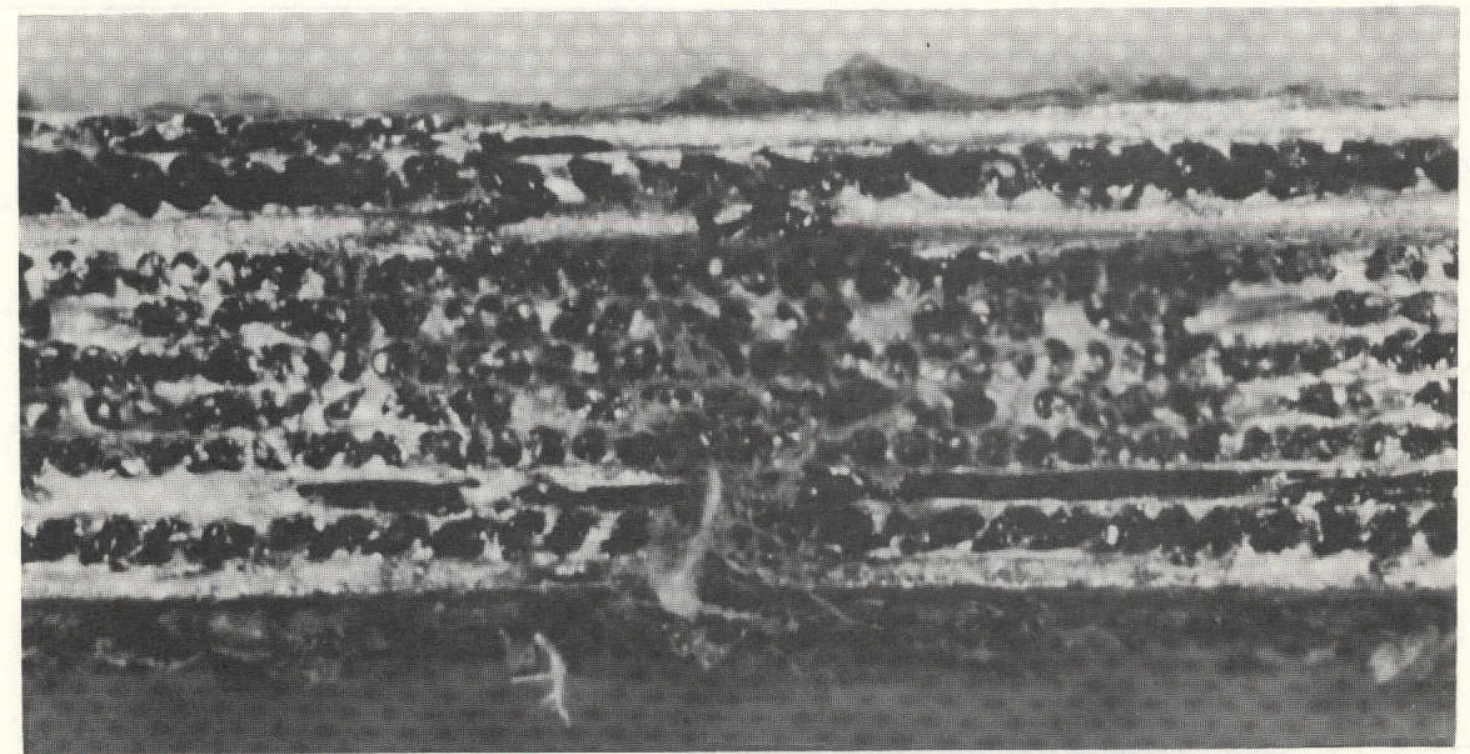

$21 \times$

difGNAL PAG II!

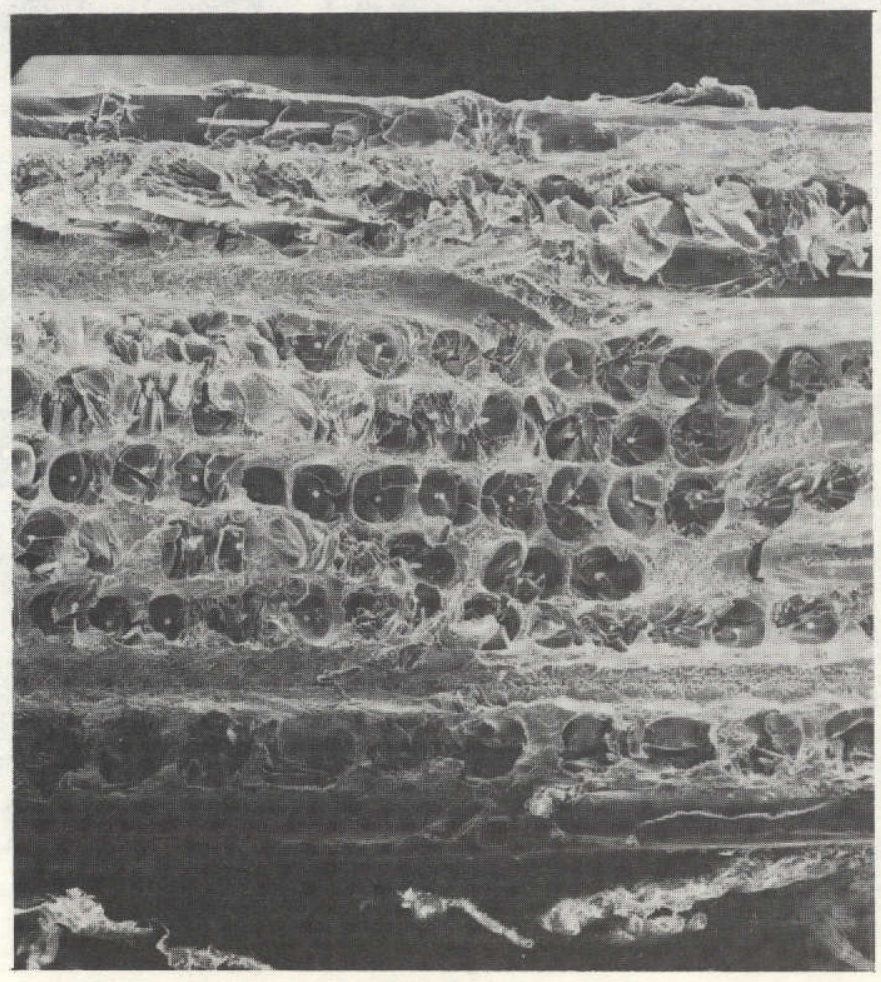

$34 x$

Figure 70 Shear Specimen Failure Surface 


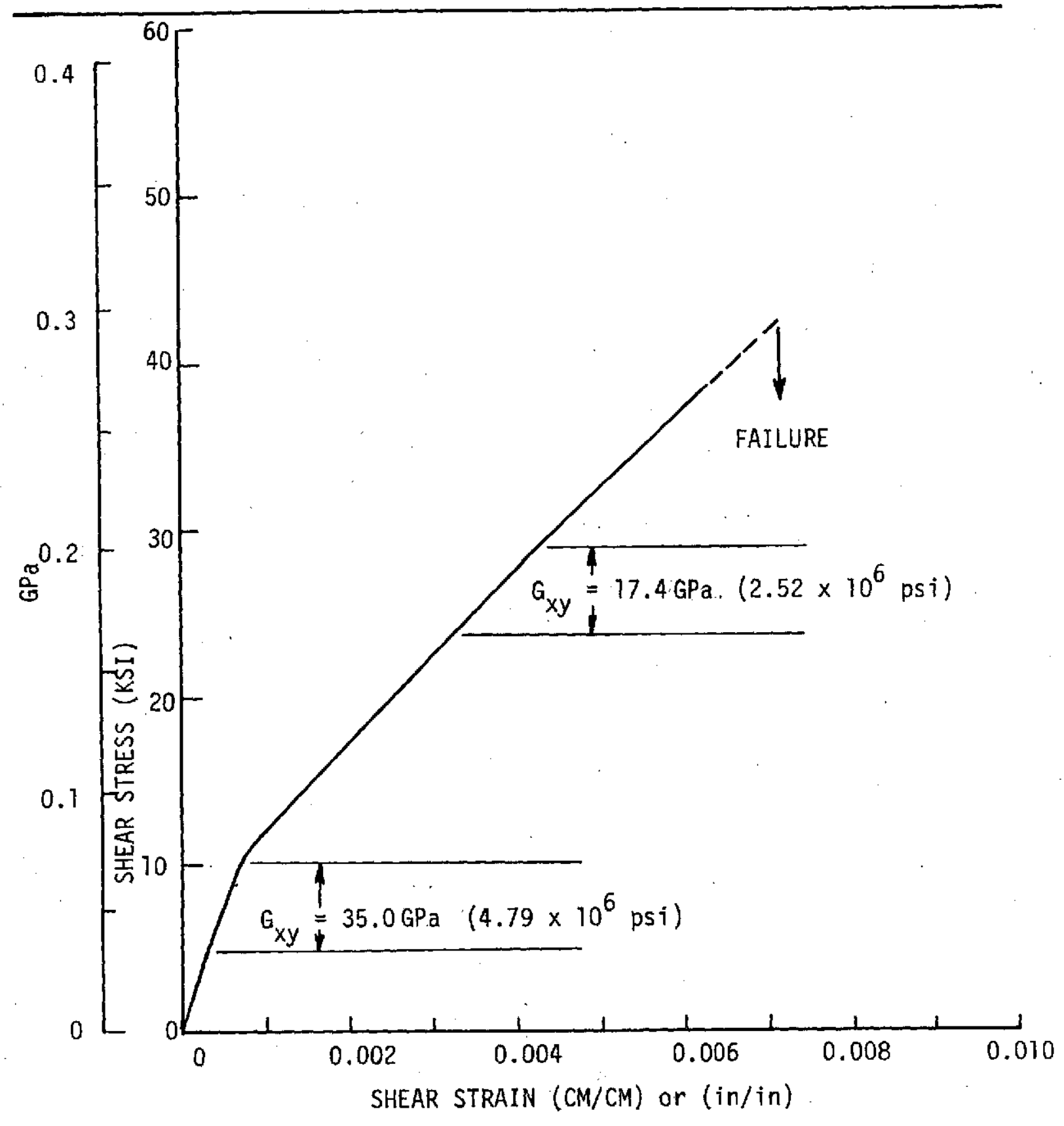

Figure 71 Specimen 11 -Room Temperature Rail Shear Stress/Strain Curve 


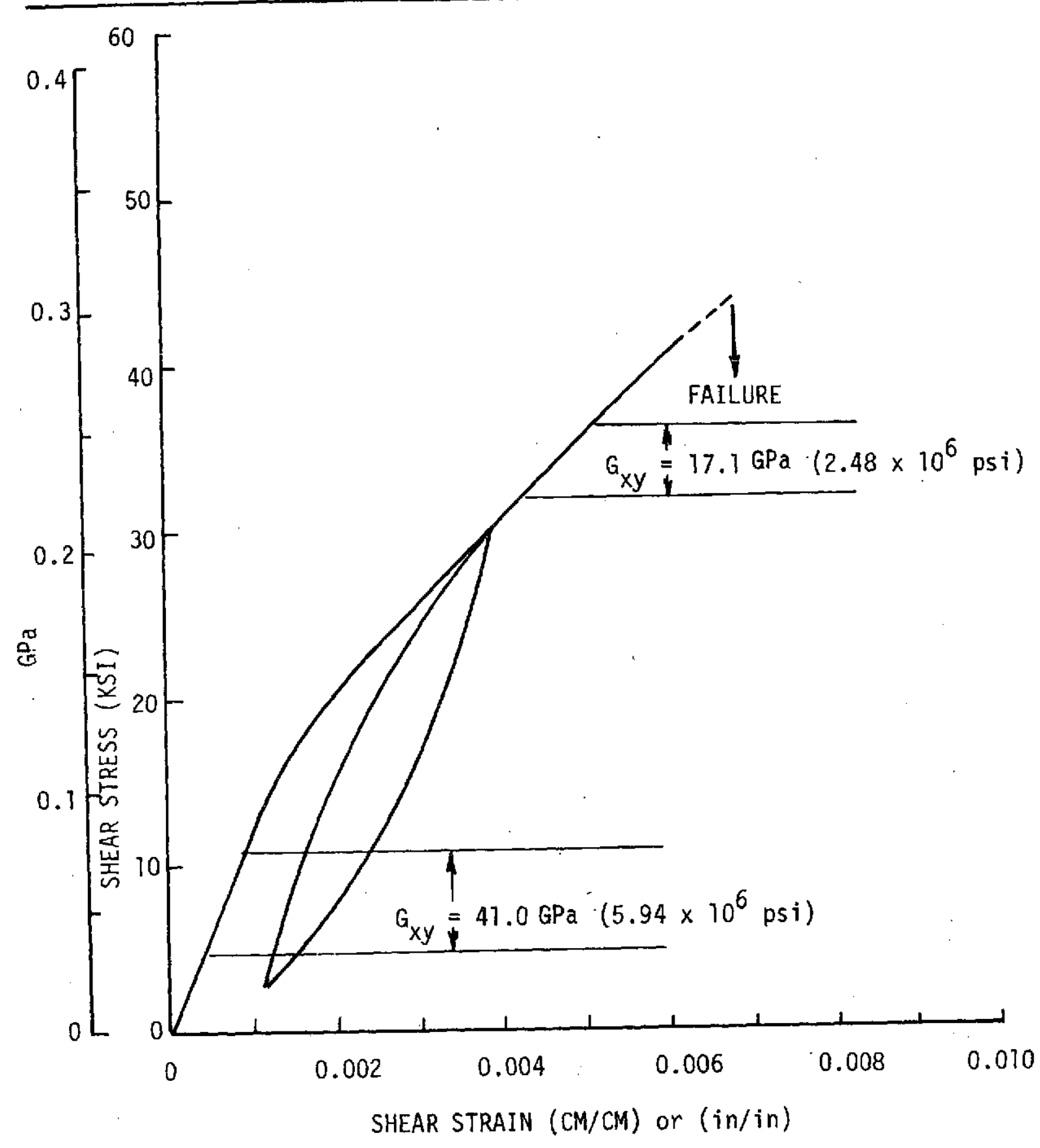

Figure 72 Specimen 12 - Room Temperature Rail Shear Stress/Strain Curve 


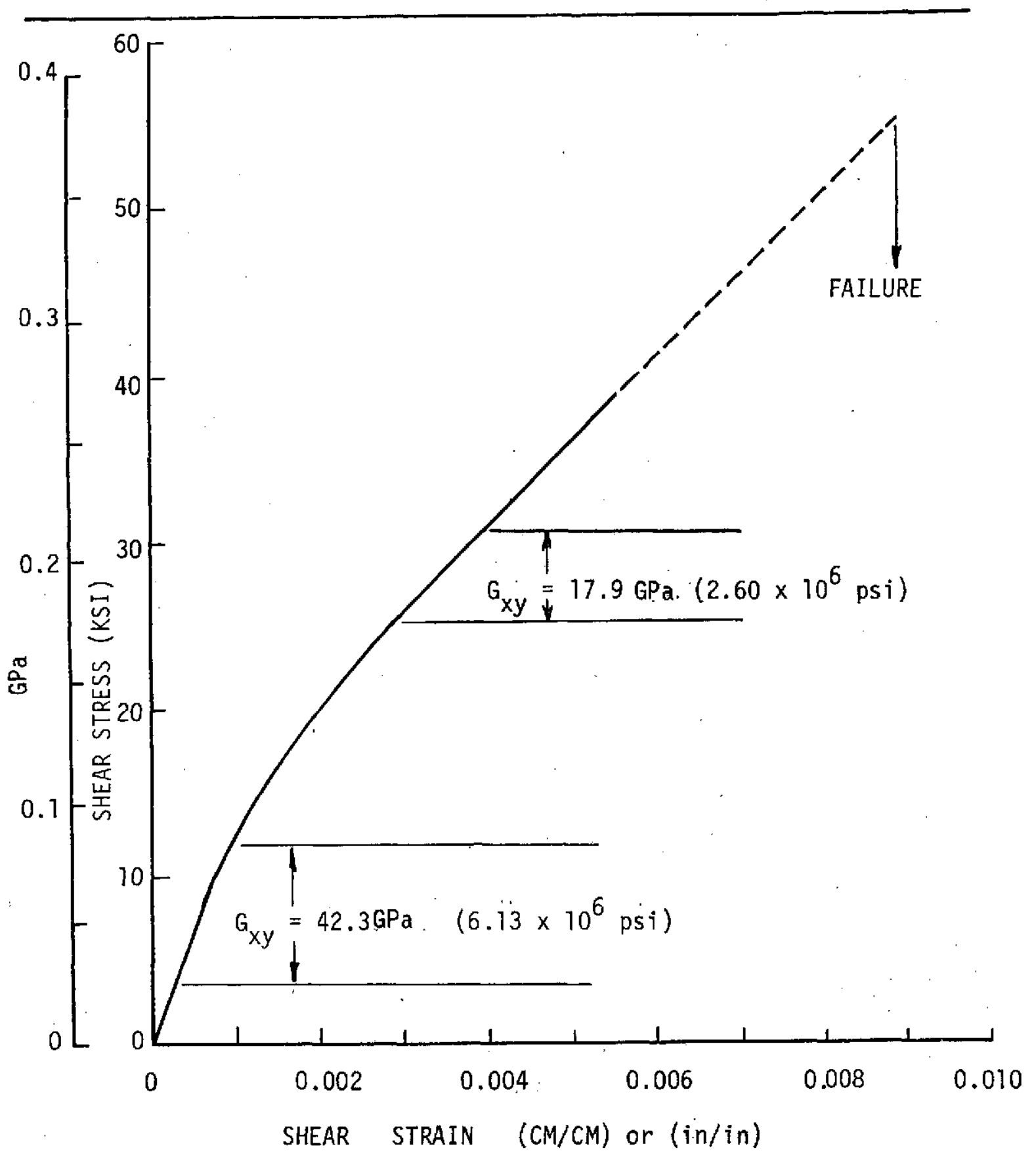

Figure 73 Specimen 13 - Room Temperature Rail Shear Stress/Strain Curve 


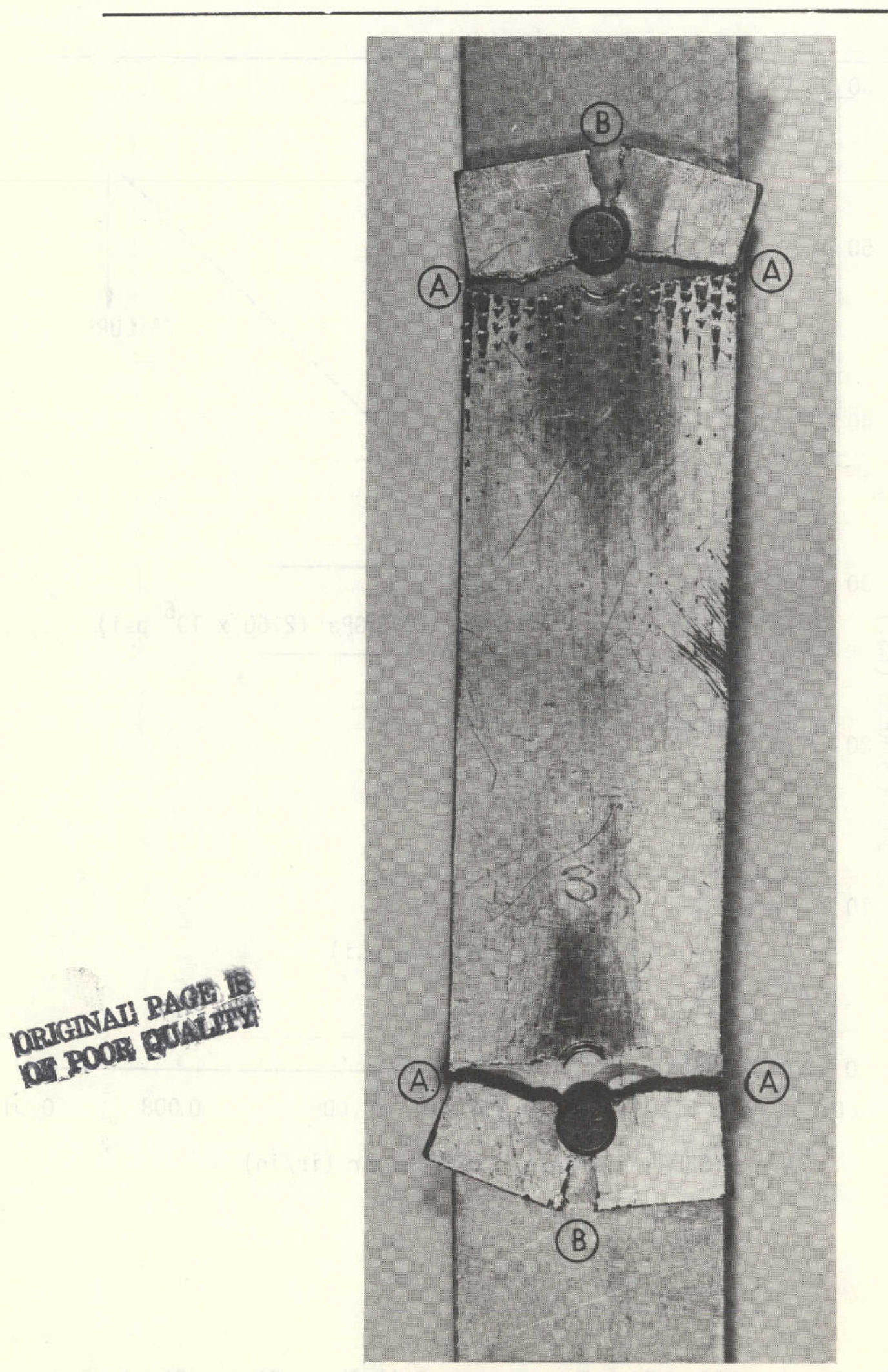

Figure 74 Mode of Failure of Bolt Bearing Specimen 

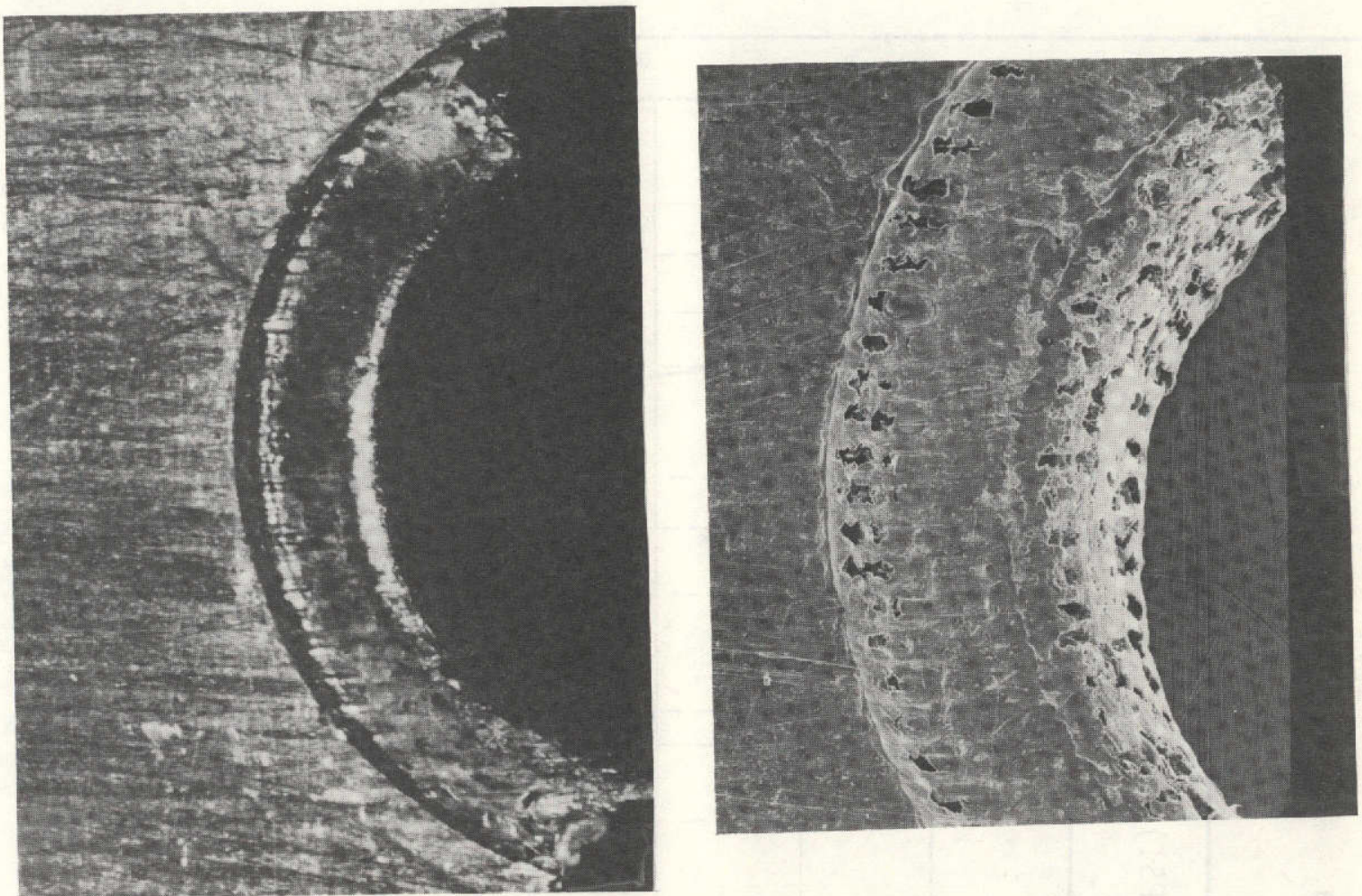

$18.5 \times$
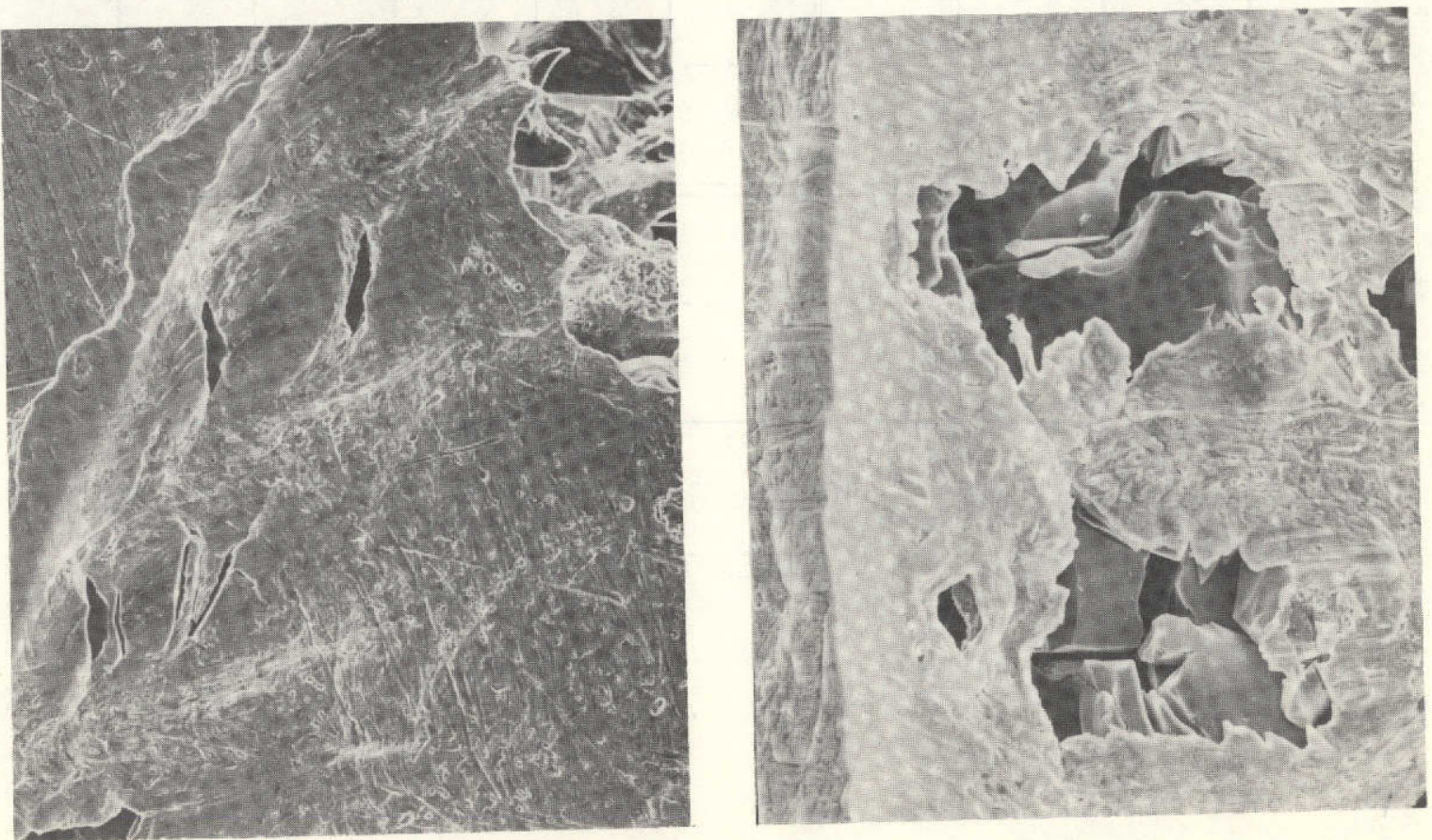

$100 \times$

$200 \times$

Figure 75 SEM Pictures of Bolt Bearing Specimen

orIG poOR o 


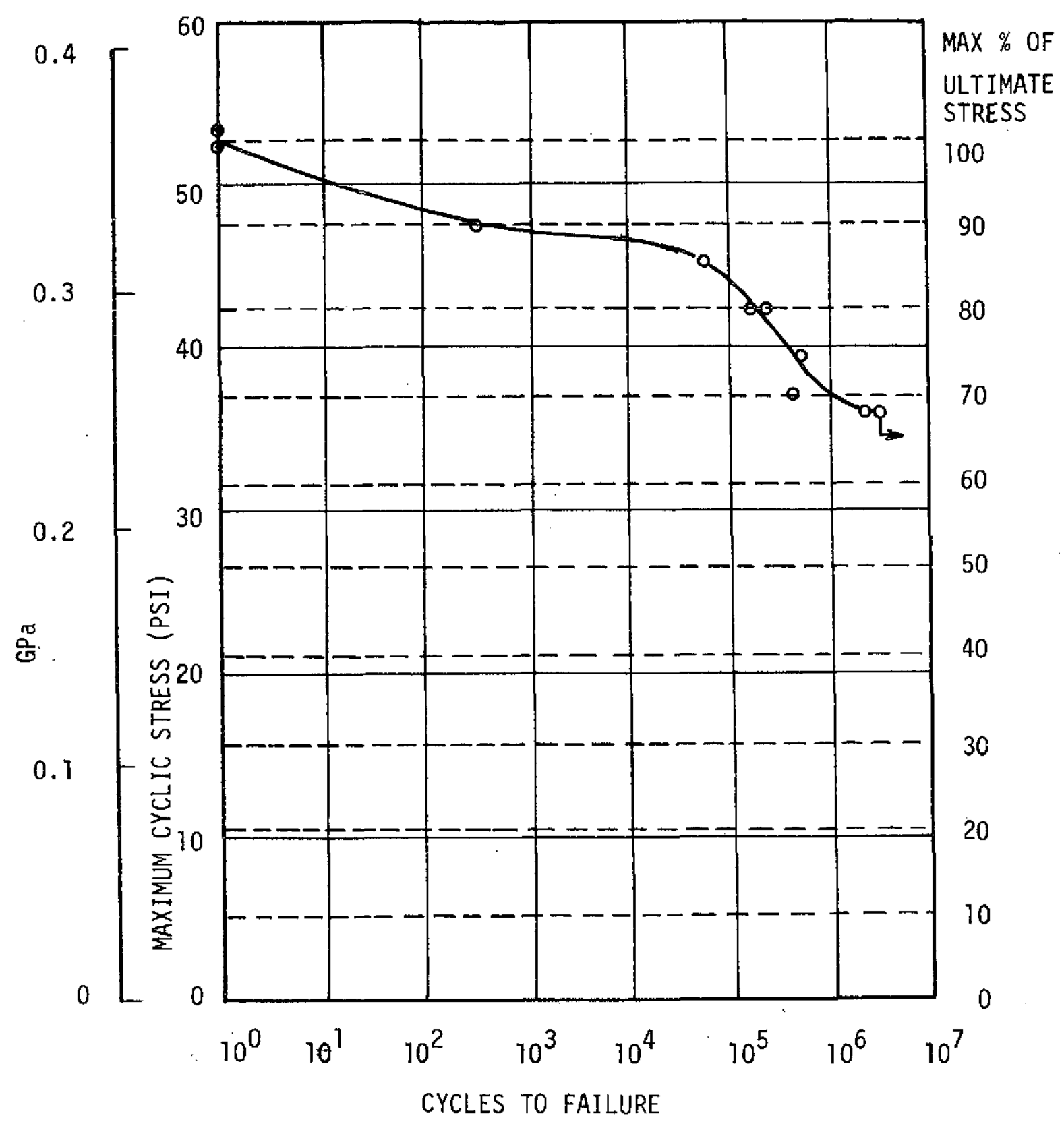

Figure 76 Constant Load Tensile Fatigue, $R=.1(0 / 45 / 0 / 90 /-45 / 90)$ S Loaded in $0^{\circ}$ Direction $2.54 \mathrm{~cm}(1$ in) Wide. Specimen with a $4.763 \mathrm{~mm}$ $(3 / 16$ in) Diameter Hole in Its Center 

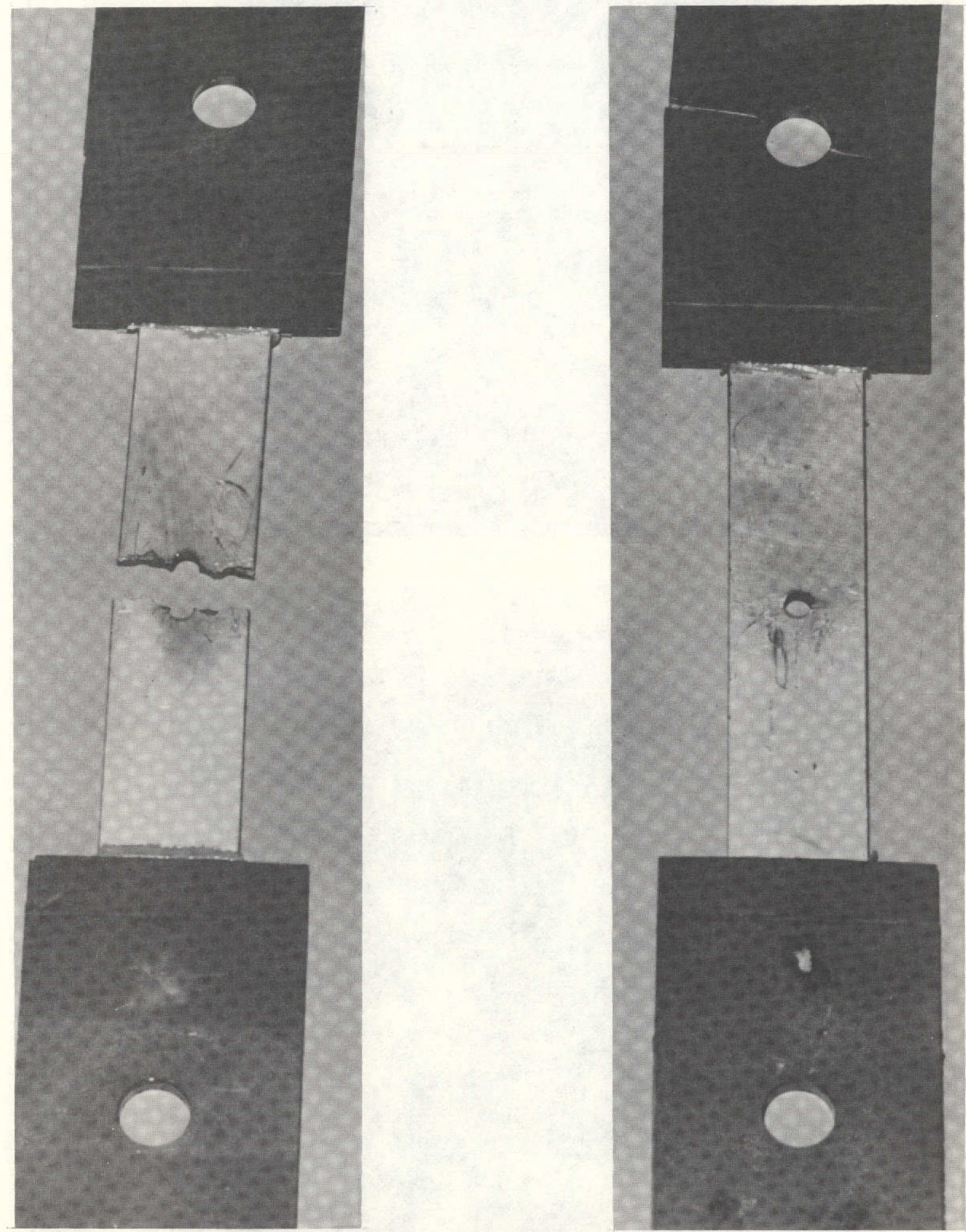

\#3 Failed at 2,362,000 Cycles

\#4 Failed in Grip

Figure 77 Failed Fatigue Specimen ORIGINAI PAGE IIS
OF POOR QUATLS 
न
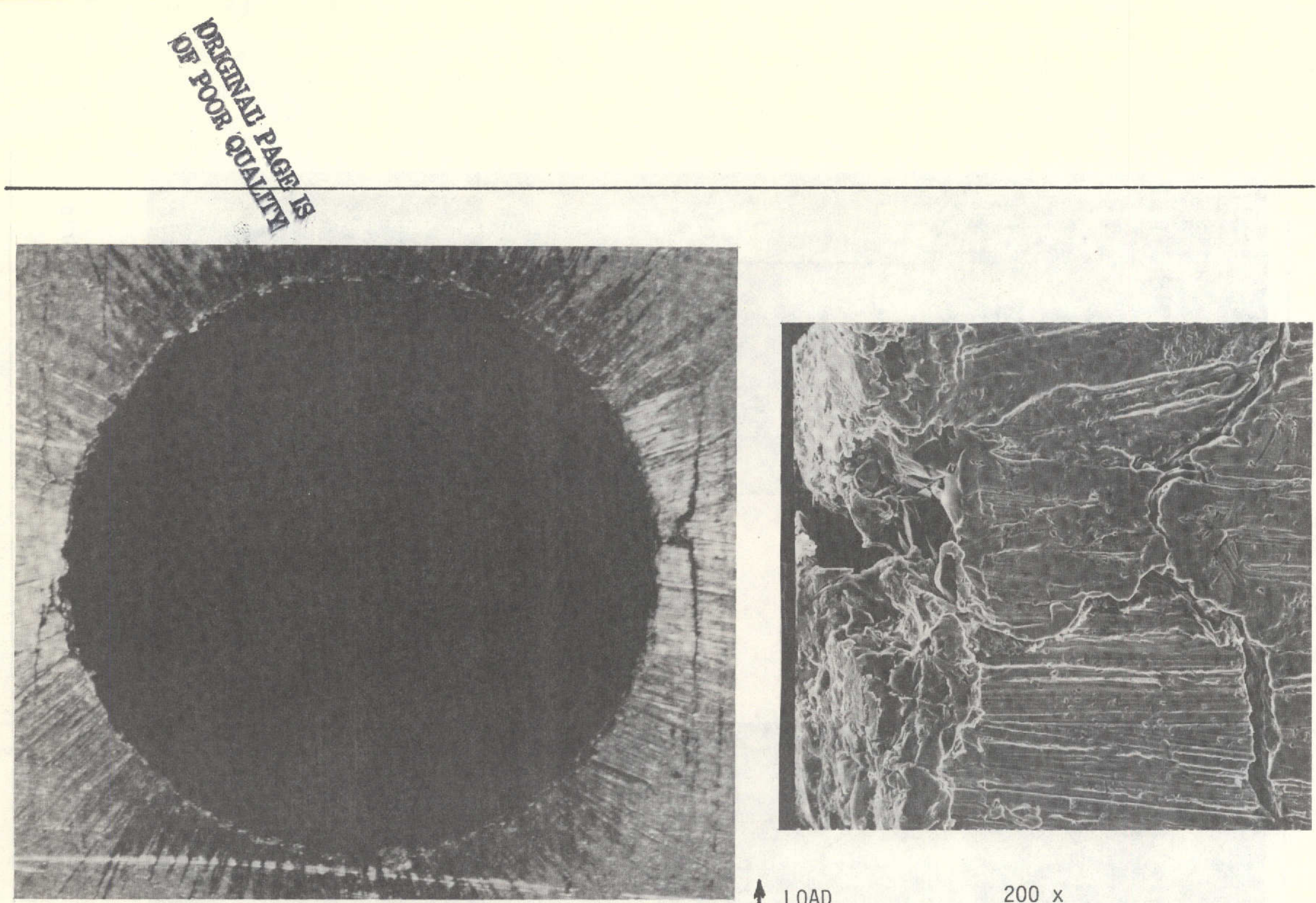

$20.6 \times$

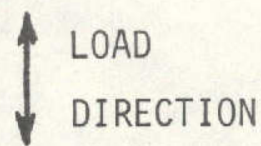

$200 \times$

Figure 78 Fatigue Crack at Edge of Hole in Fatigue Specimen 


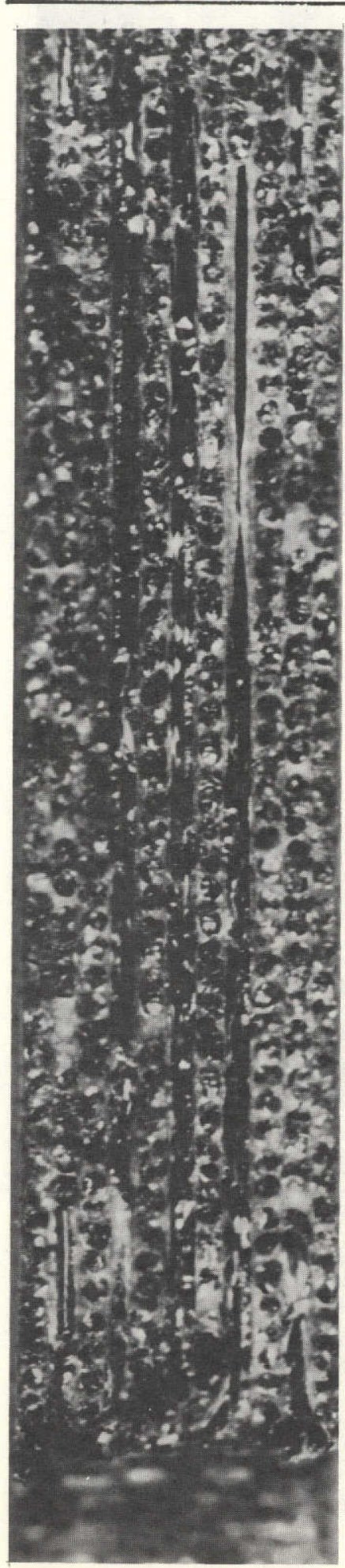

$20 \times$

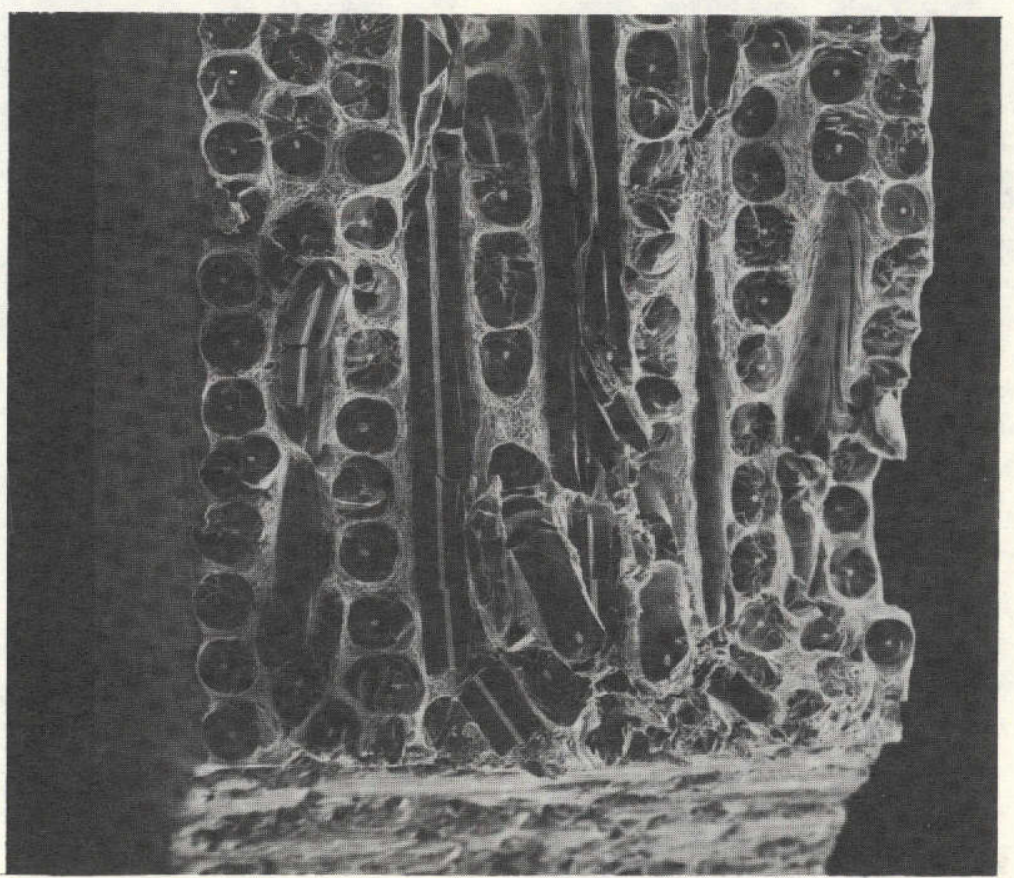

$36 \times$

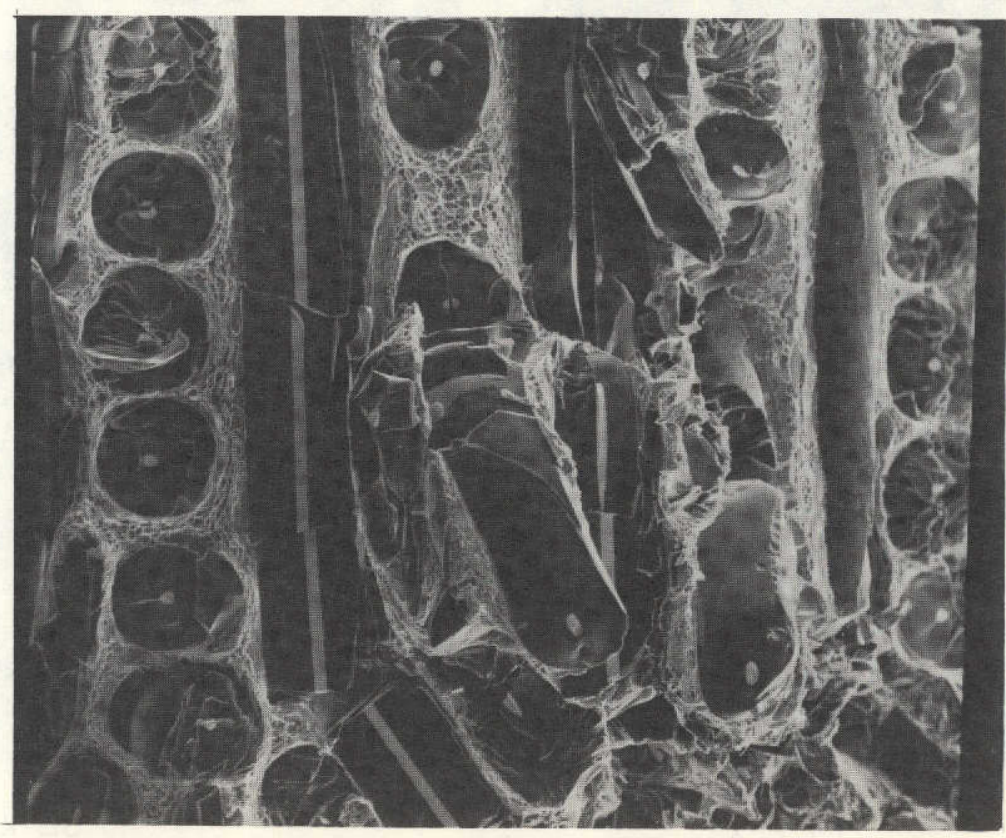

$72 \times$

Figure 79 SEM Pictures of Fatigue Specimen 2 Tested Statically in Tension to Failure 


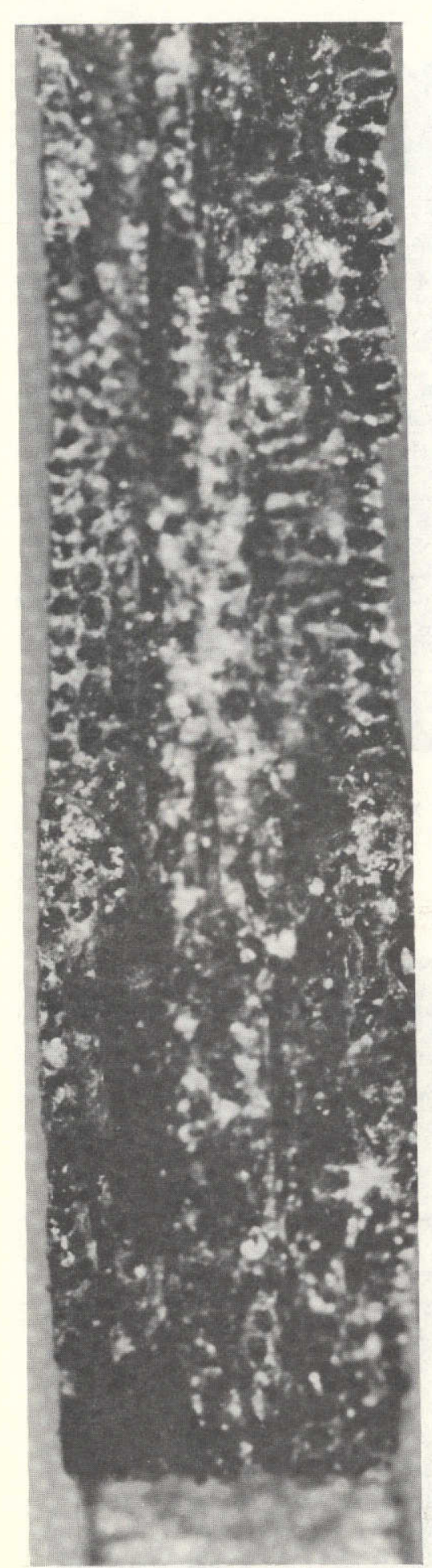

$19.2 \times$

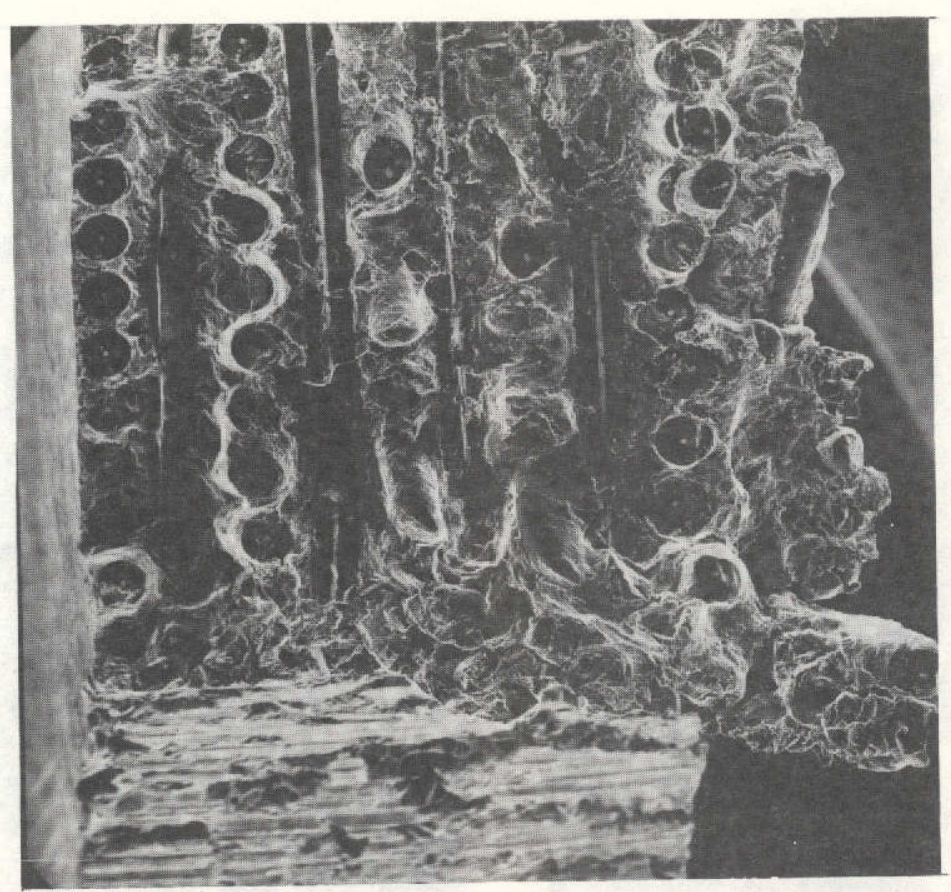

$32 x$

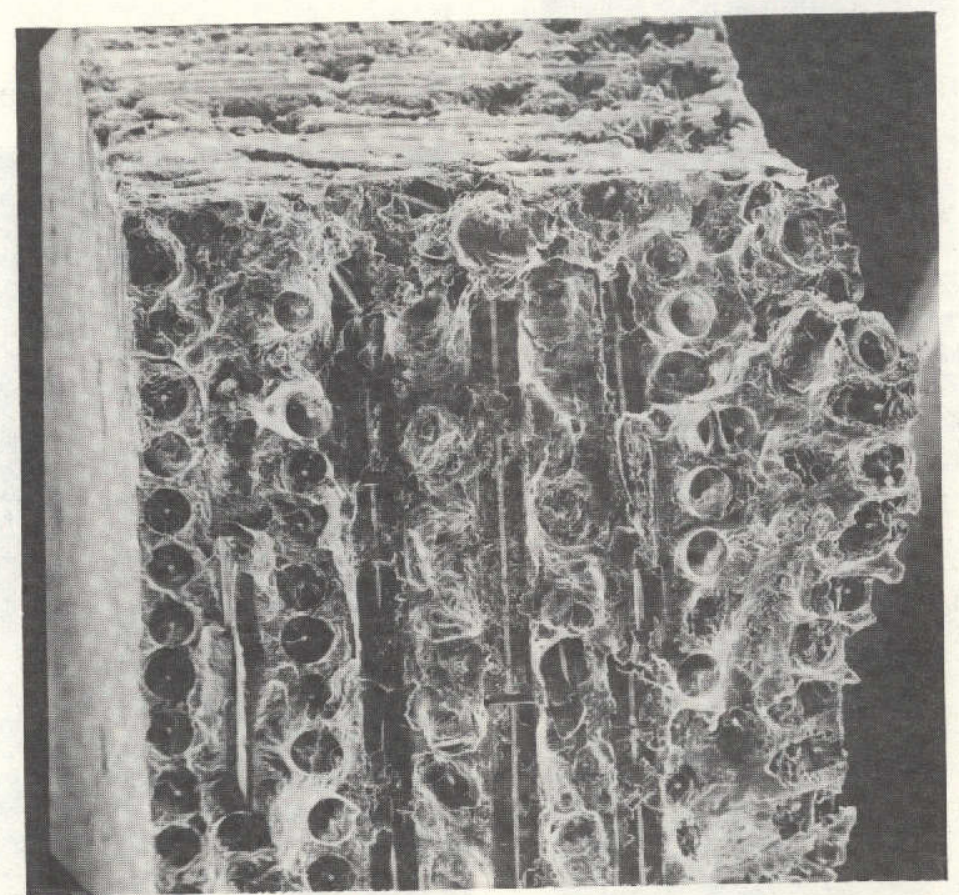

$32 \times$

Figure 80 SEM Pictures of Fatigue Specimen 3. (failed on the $2,362,000$ th cycle of a Maximum Alternating Tensile Stress of $242.8 \mathrm{MPa}(35,222 \mathrm{psi})$ 


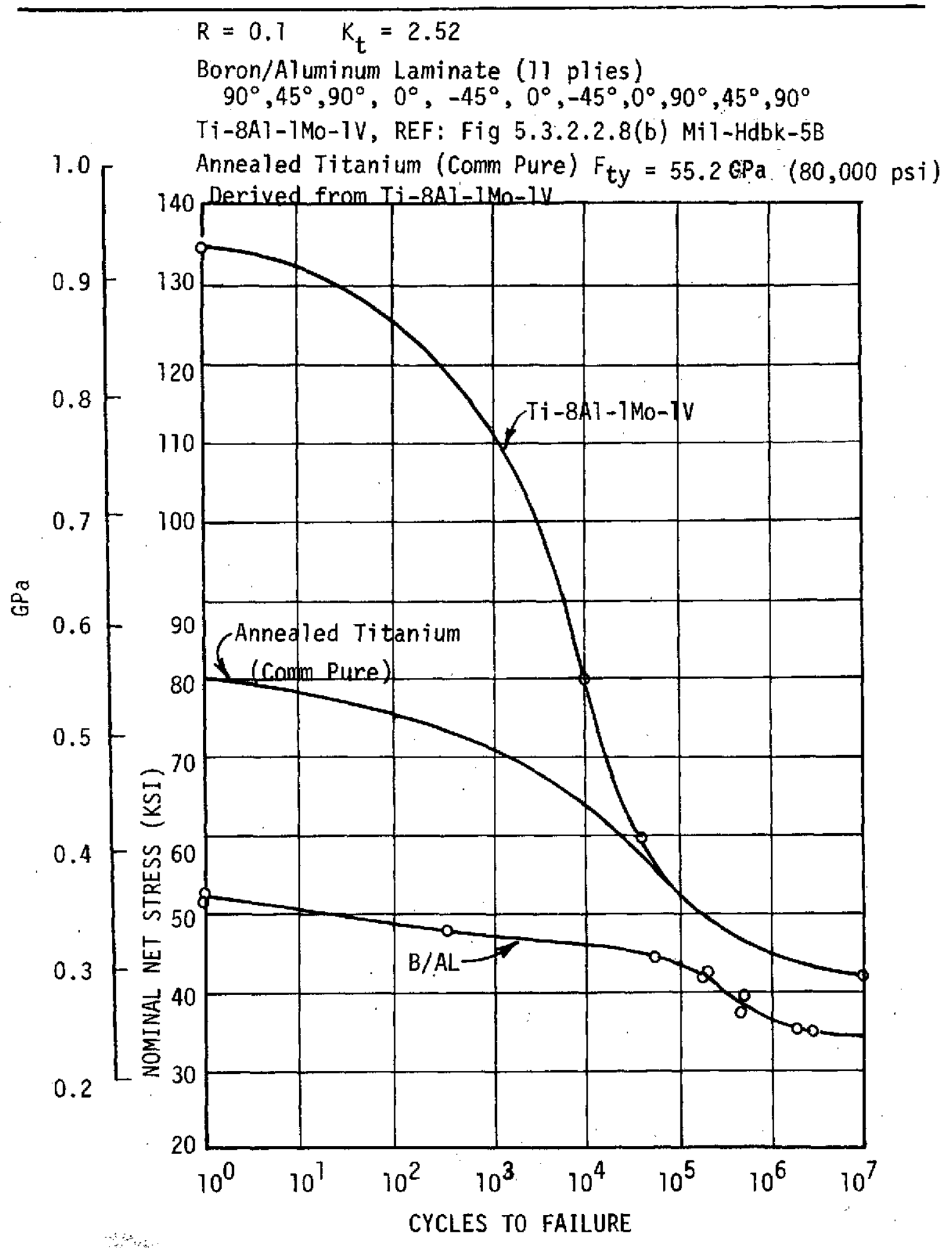

Figure 81 Fatigue Properties Comparison 


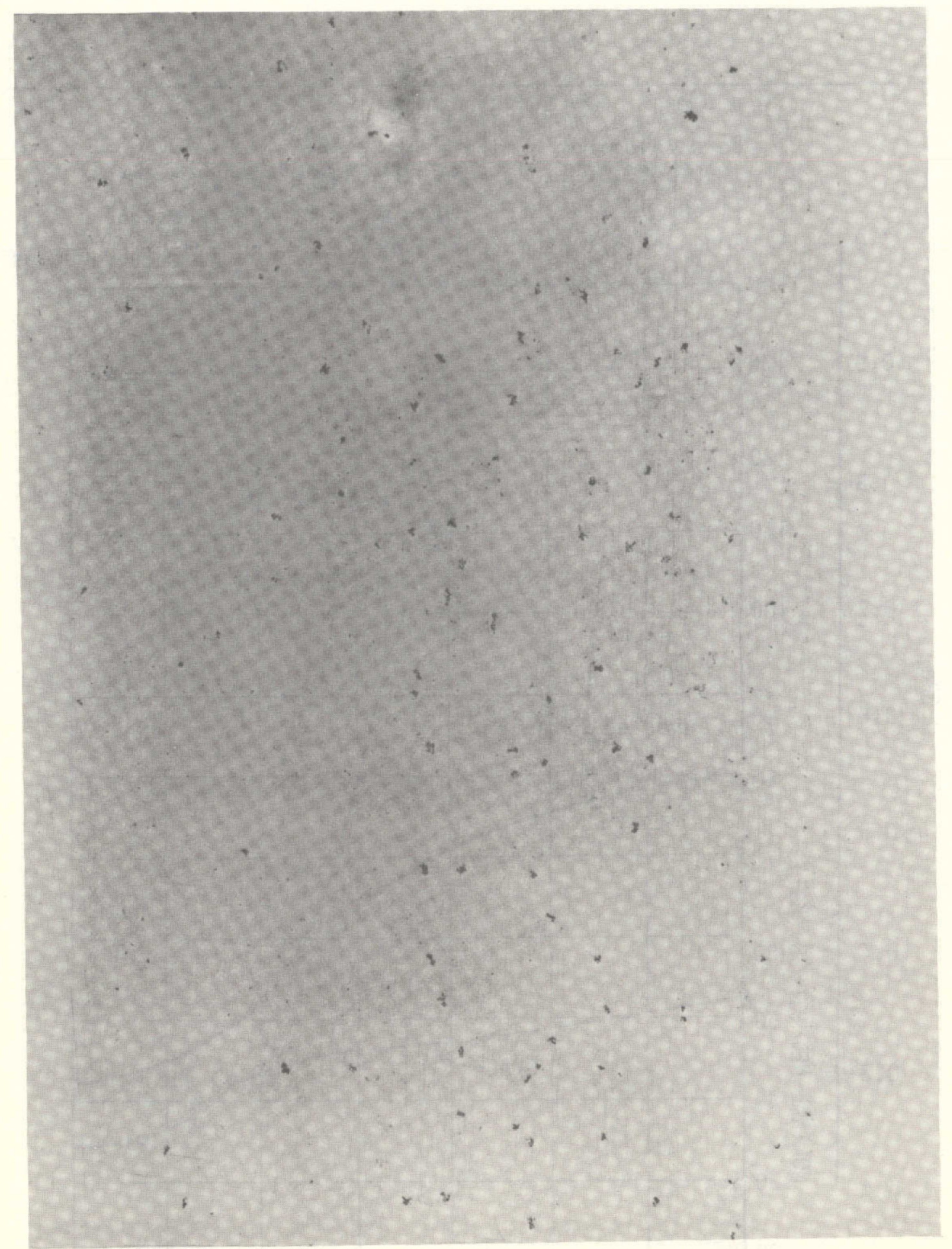

Figure 82 Surface Blemishes on Second Boron/Aluminum Aft Pylon Skin 


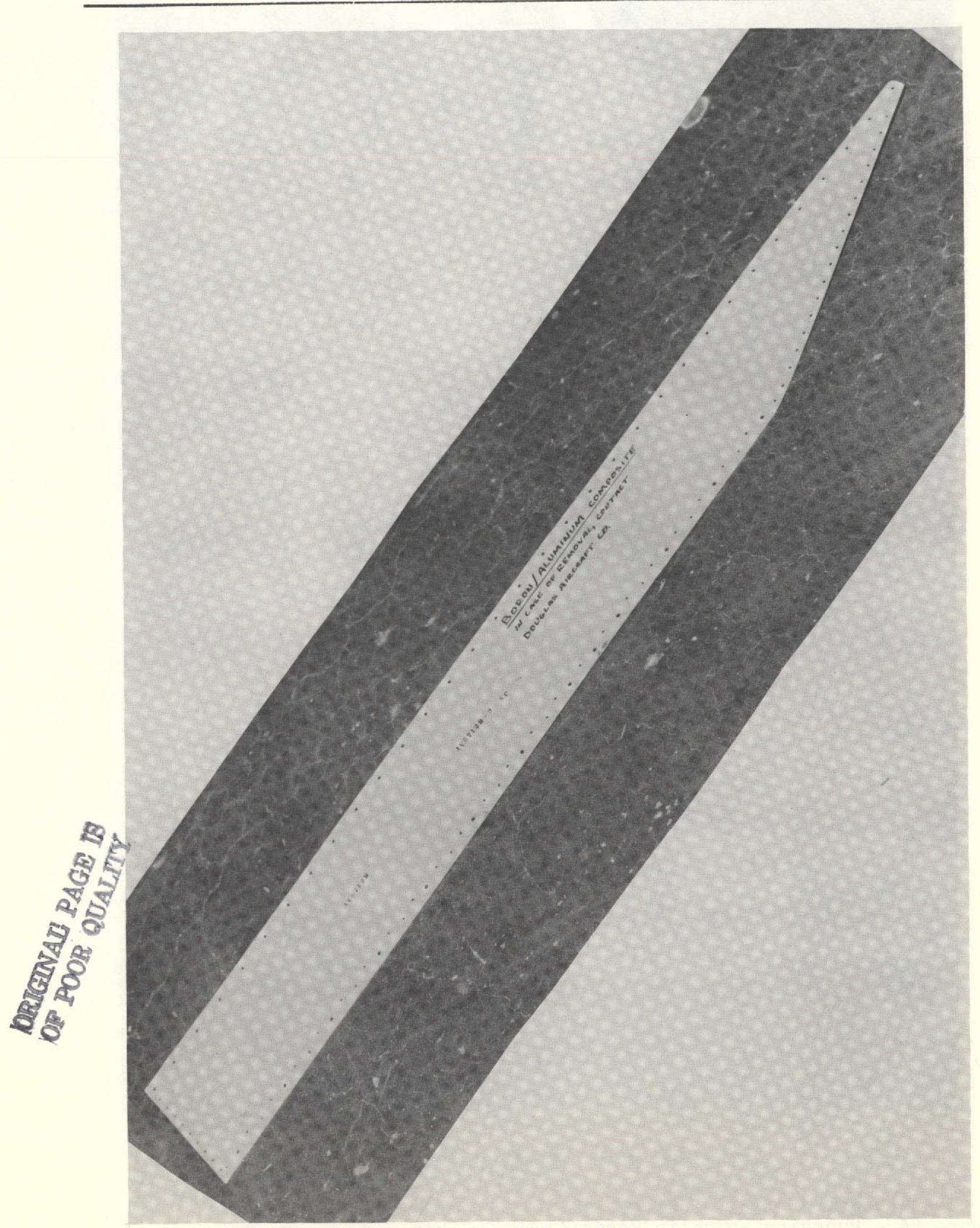

Figure 83 Boron/Aluminum Aft Pylon Skin-Edges and Corner Trimmed and Holes Punched 


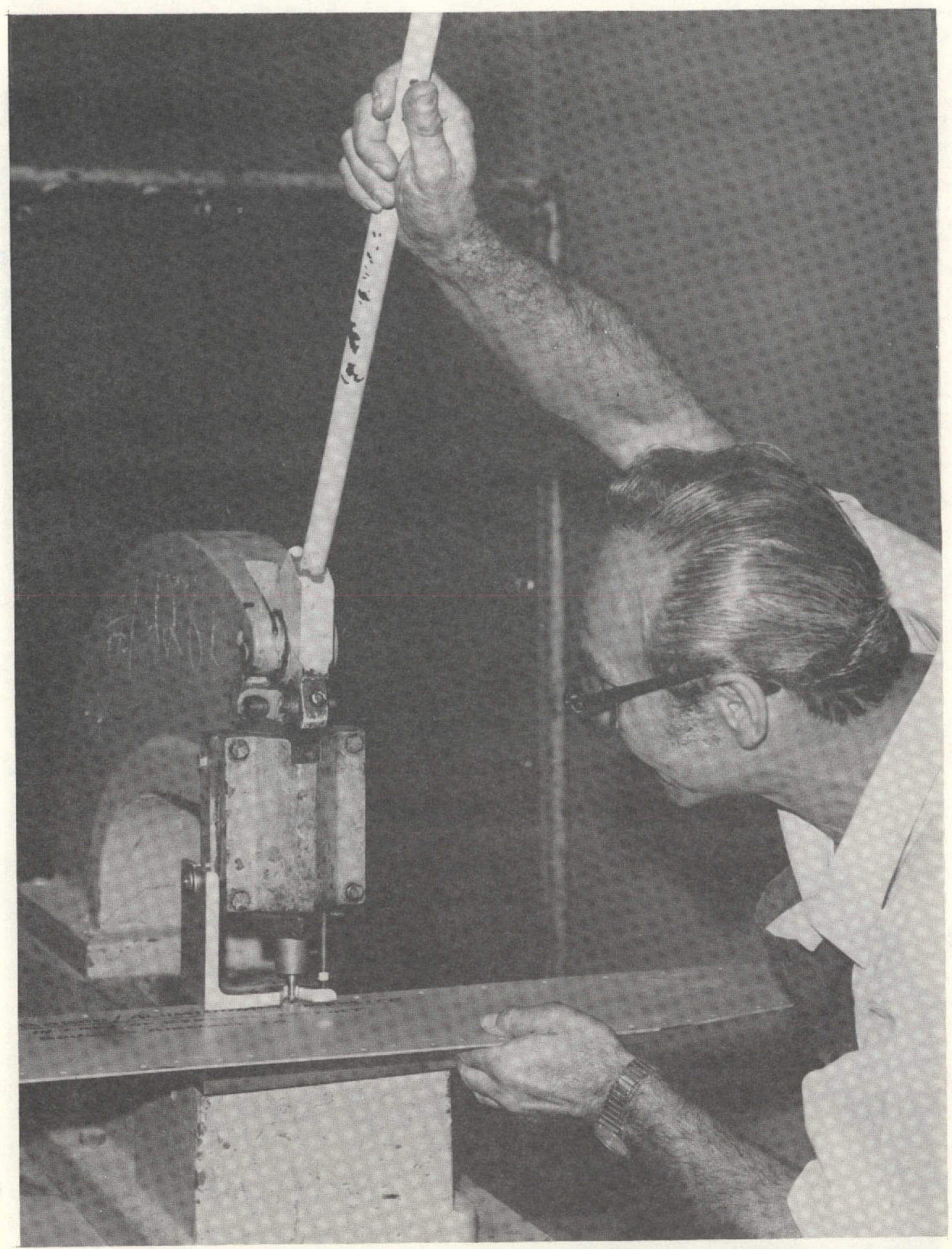

Figure 84 Punching Holes in Boron/Aluminum Skin 


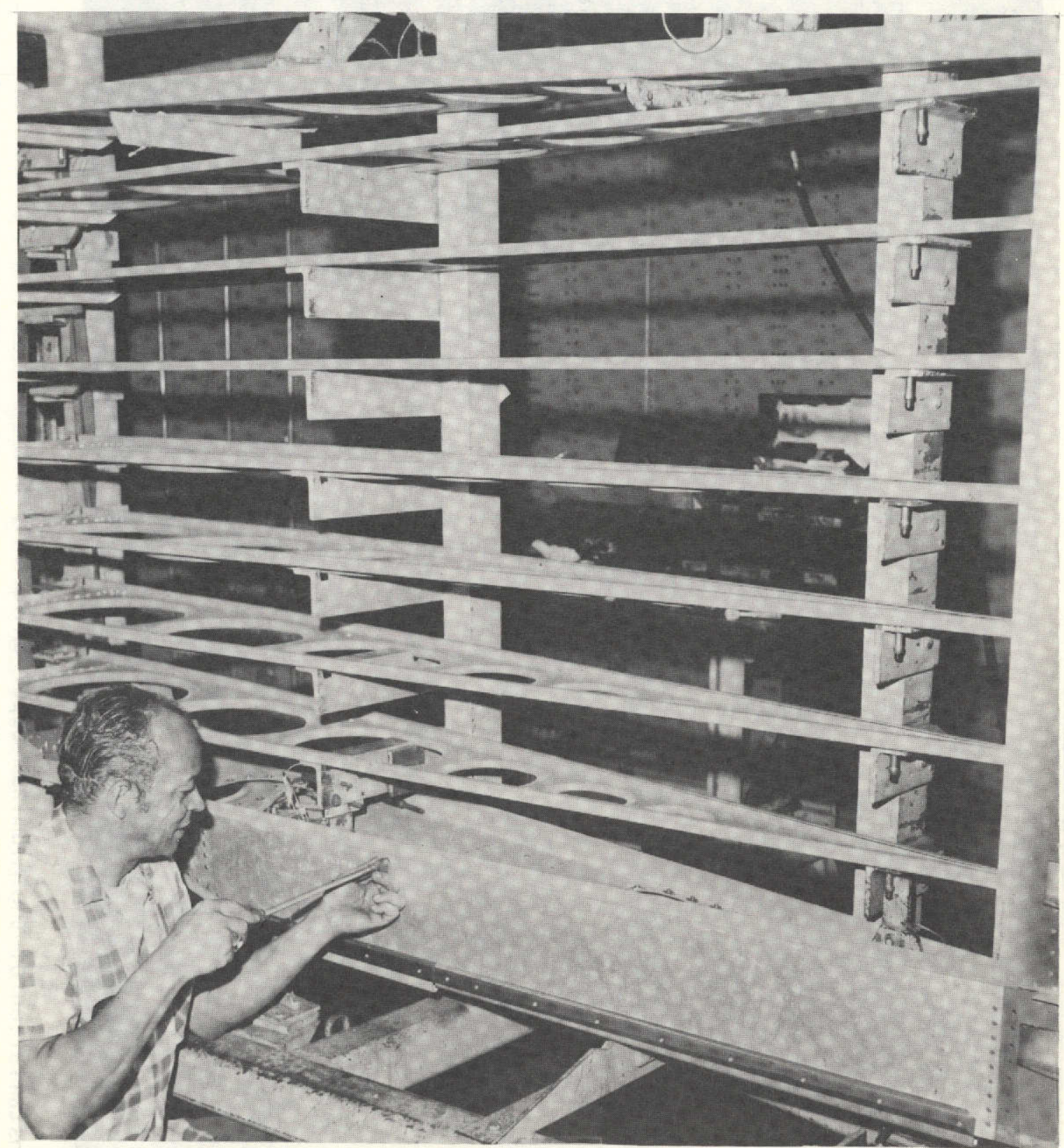

Figure 85 Installation of the Boron/Aluminum Skin Onto the Substructure 


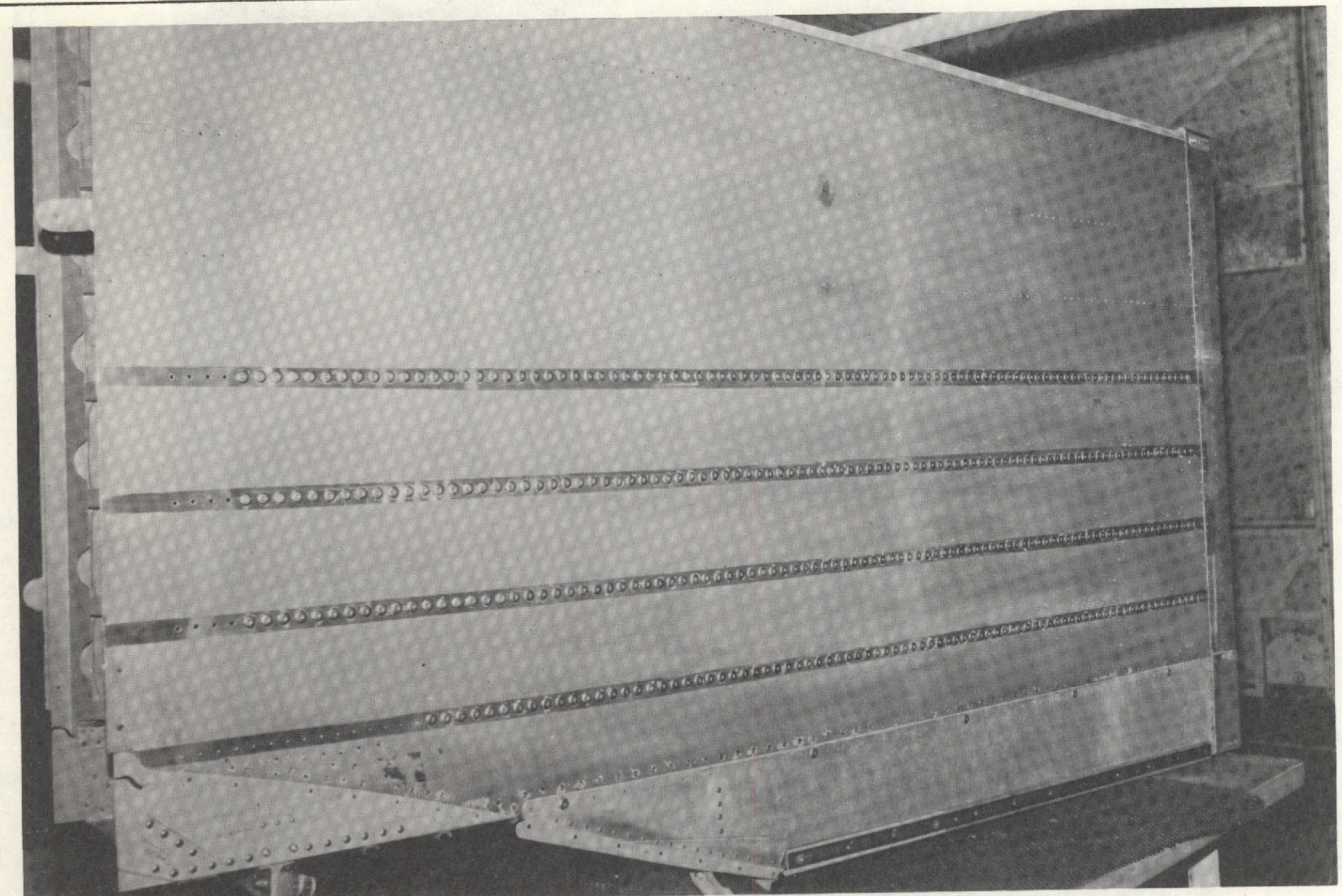

Figure 86 Installation of the Aluminum Upper Skins Onto the Substructure 


\section{APPENDIX A}

MATERIAL PROCUREMENT DIFFUSION BONDED

BORON/ALUMINUM COMPOSITE SHEETS 


\section{APPENDIX A - MATERIAL PROCUREMENT DIFFUSION BONDED BORON/ALUMINUM COMPOSITE SHEETS}

Material shall meet the following requirements:

\section{1) Material}

The material shall be furnished as composite flat sheet formed by diffusion bonding boron filaments and aluminum alloy foil such that the filaments are solidly embedded in the aluminum alloy matrix.

The boron filaments shall be $0.1422 \mathrm{~mm}$ ( 0.0056 inch) diameter and shall meet the requirements of MMS -583 , Class $C$. The a Tuminum alloy sha11 be 6067 . The finished product shall be furnished in the as-fabricated condition.

\section{2) Composition}

The composition of the composite sheet shall be 45 volume percent (minimum) boron filament, the balance being aluminum alloy.

\section{3) Composite Construction and Quantities}

All panels shall be constructed such that the boron filaments are oriented as shown in Figure Al. All panels shall have a ply orientation pattern of $90^{\circ}, 45^{\circ}, 90^{\circ}, 0^{\circ},-45^{\circ}, 0^{\circ},-45^{\circ}, 0^{\circ}, 90^{\circ}, 45^{\circ}$, and $90^{\circ}$. PTy orientations are defined in Figure $A 1$ with the $90^{\circ}$ orientation $7 y$ ing in a direction parallel to the fibers in the first ply.

Panels A through $J$ (10 panels) shall consist of 11 total pilies, and be $2.032 \mathrm{~mm}(0.080$ inch) thick.

4) Sizes

Panels $A$ through $F$ shall be $29.21 \times 57.15 \mathrm{~cm}(111 / 2 \times 221 / 2$ inch $)$. Panels $G$ through $J$ shall be $172.72 \times 20.32 \mathrm{~cm}(68 \times 8 \mathrm{inch})$. (NOTE: The $90^{\circ}$ orientation is always parallel to the second dimension).

5) Filament and Ply Alignment

All filaments comprising a single ply shall be laid parallel one to another within one degree of the long axis of the ply.

All plies of a given orientation shall be lafd down such that the fibers are parallel within one degree of the required nominal orientation. Cross-plies in the completed panel shall be oriented such that they are within one degree of the designated orientation. 
6) Dimensional Tolerances

All dimensional tolerances shall be specified in FED-STD-245 as applicable to 6061 aluminum sheet.

7) Mechanical Properties

The material shall exhibit the following target mechanical properties:

$0^{\circ}$ Orientation
Tensile ultimate strength $393 \mathrm{MPa}(57,000 \mathrm{psi}$
Tensile Modulus of Elasticity $162 \mathrm{GPa}\left(23.5 \times 10^{6} \mathrm{psi}\right) \quad 168.9 \mathrm{GPa}\left(24.5 \times 10^{6} \mathrm{psi}\right)$
Tests shall be conducted in either the $0^{\circ}$ or $90^{\circ}$ orientations, in accord-
ance with ASTM E8. Rectangular specimens may be used in lieu of reduced
section specimens. A minimum of two tests per pressing shall be conducted
in order to certify that the target mechanical properties have been met.
The test specimens shall be cut from the panels to be delivered. The test
specimens representing Panels G, $\mathrm{H}$, I, and s shall be tested in the $90^{\circ}$
orientation. (NOTE: Material for performing these tests has not been
included in the sizes shown in Figure Al and there-
fore, the fabricated width would have to be greater
to accommodate a row of tensile QC coupons).

8) Nondestructive Inspection

A through-transmission ultrasonic inspection shall be performed and a $\mathrm{C}$ scan generated of two panels (each from separate pressing) from A through $\mathrm{F}$ by the supplier per attached instructions. Other inspections shall be performed as riecessary by the supplier to ensure that the material complies with the workmanship requirements.

\section{9) Identification}

All panels shall be appropriately marked to indicate panel identification.

10) Workmanship Requirements

The material shall be of uniform quality and condition, free from exposed filaments, protruding filament ends, and burrs.

The surfaces shall be free from cracks, folds, wrinkles, laps, edge delaminations, foreign objects and other defects which would adversely affect the serviceability of the material. Light scratches, heat marks, indentations or other surface defects which can be removed without exceeding material specifications shall not be cause for rejection.

The material shall be essentially free from internal voids, delamination, crossed filament, filament misalignment and foreign matter. 
11) Responsibility for Inspection and Testing

The supplier is responsible for the performance of all inspection and test requirements specified herein. The supplier may use his own facilities or any commercial laboratory acceptable to McDonnel1 Douglas Corporation. McDonne11 Douglas Corporation reserves the right to repeat any or all of the inspections set forth herein and reject any material which does not conform to the prescribed requirements.

\section{NDI METHODS FOR A1/B PANELS}

U1trasonic C-Scan Inspection - Composite specimens shall be ultrasonically C-scanned for voids or delaminations. Immersion ul trasonic methods employing an $X-Y$ bridge scanner and facsimile paper recorder shall be used. Inspection may be conducted at 5.0 to $10.0 \mathrm{MHz}$ whichever is most applicable for the thickness of part being tested. Search units shall be short or medium focused elements, 1.27 to $1.91 \mathrm{~cm}(1 / 2$ to $3 / 4$ inch) diameter. The panels are to be tested using through transmission plate methods. Panels should be as flat as possible prior to ultrasonic inspection. The amplitude of the ultrasonic signal shall be set to $80 \%$ of vertical saturation over the best area of each panel. The amplitude gate shall be set around the transmitted signal for through-transmission (ie; $40 \%$ amplitude or less). The mode sha11 be set so areas with amplitudes above $40 \%$ will record on the paper.

Place a reference marker (lead tape or steel button approximately $6.35 \mathrm{~mm}$ ( $1 / 4$ inch) diameter or X-ray penetrameter) on the upper left hand surface of the part to be tested so that the location of discontinuities in the part can be correlated with indications on the facsimile recordings, where the part dimensions preclude the scanning and recordings of the entire part in one C-scan recording, overlap reference markers shall be imaged on two adjacent C-scan recordings. The reference marker shall be in the same positions for both $\mathrm{C}$-scan inspections.

C-scan facsimile recordings are to be shipped with specimens and are to be identifiable to each specimen. The specimen identification, date, inspection technique, and each unit size and frequency shall be indicated on the facsimile recording. Location of all reference markers shall also appear on the specimen surface. 

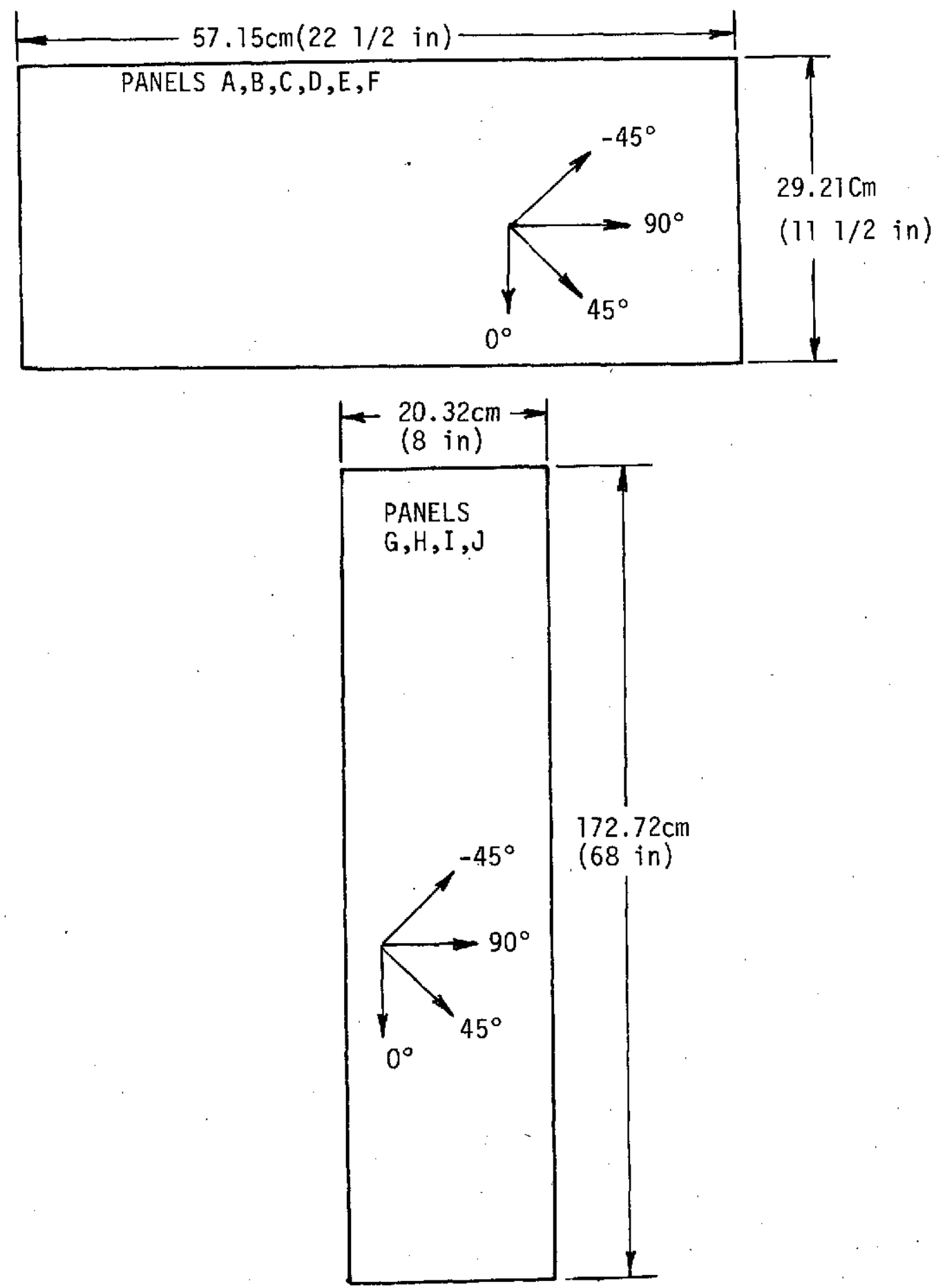

Figure Al Panel Description 

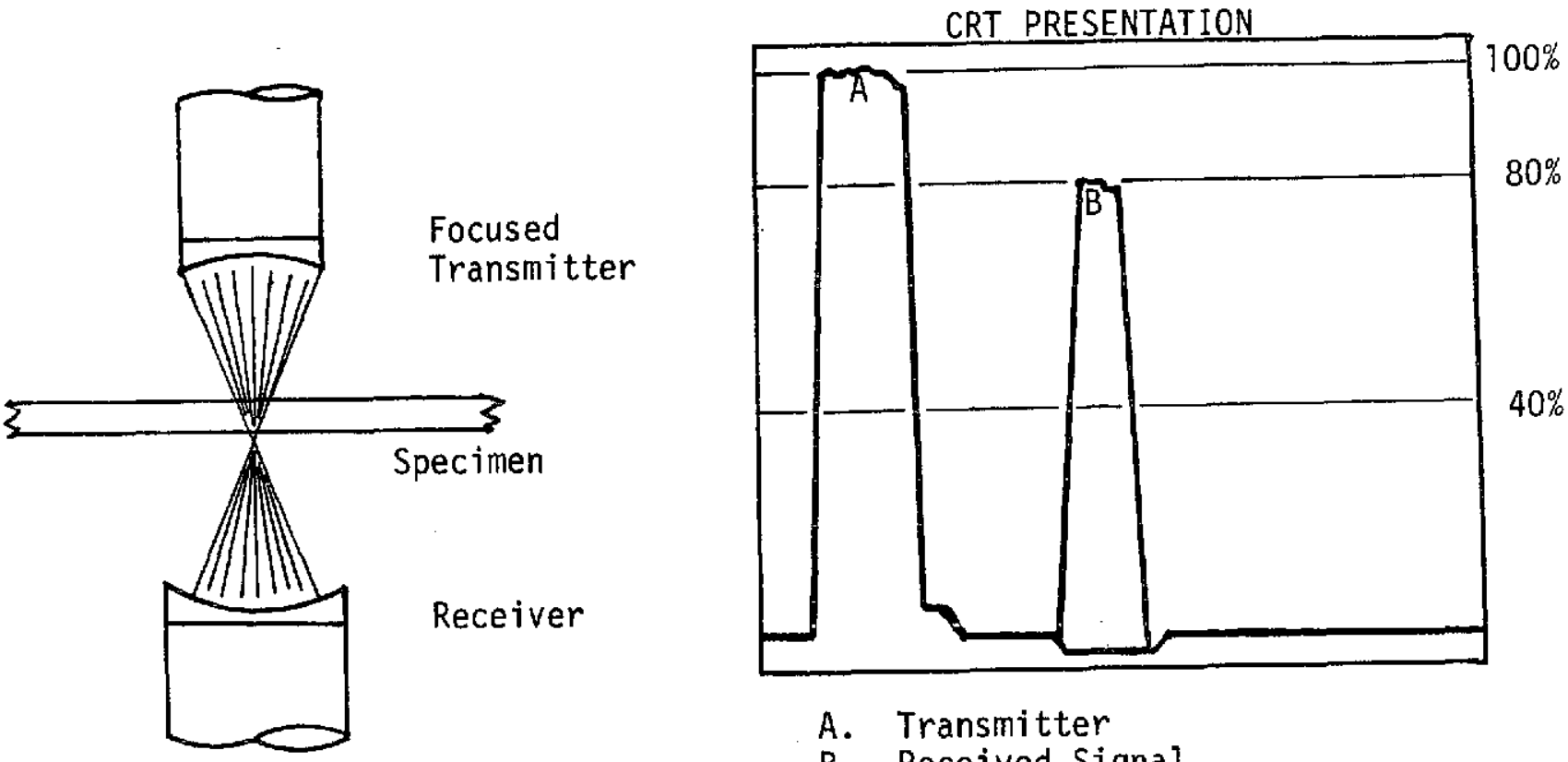

A. Transmitter
B. Received Signal

A. Thru-Transmission
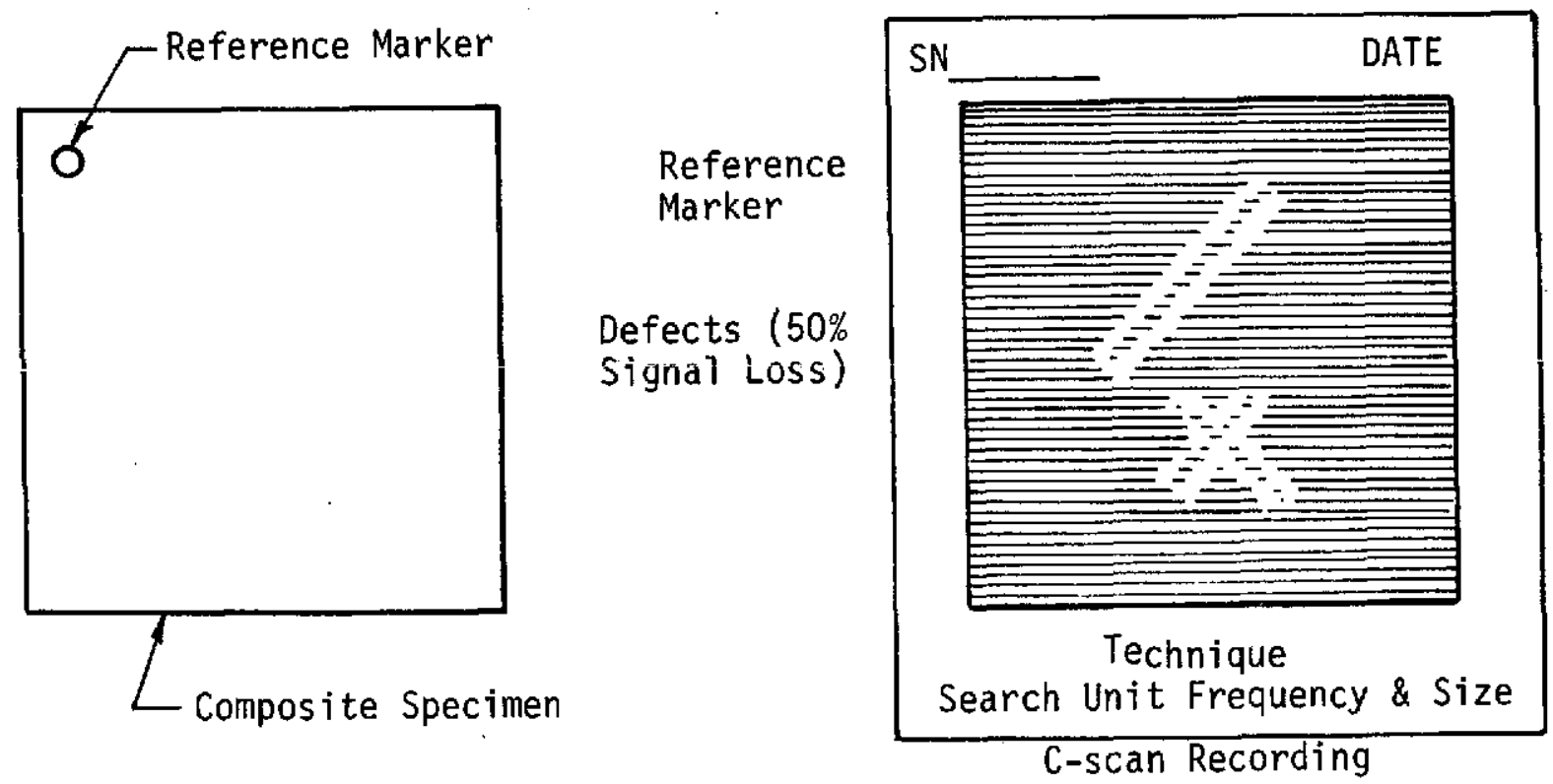

B. Part and Representative C-scan Recording, Ultrasonic C-scan Inspection of Composite Specimens 
APPENDIX B

DPS 3.67 - 67 HOLE PREPARATION

AND TRIMMING OF BORON/ALUMINUM 


\section{DOUGLAS PROCESS STANDARD}

DPS 3.67-67 HOLE PREPARATION

AND TRIMMING OF BORON/ALUMINUM

A. SCOPE AND USE

This Process Standard provides the instructions and requirements for preparation of attachment holes and edge trimming of boron/aluminum composite sheet. It shall be used only when specified on Engineering Rework Drawing AVB7129.

B. APPLICABLE SPECIFICATIONS

DPS 3.02 - Identification of Parts and Assemblies

DPS 4.025- Dissimilar Materials Protection

DPS 4.710- Minimum Fabrication Practices for Metals

C. MATERIALS AND SPECIAL EQUIPMENT

DPM NO.

5726

5417

5739

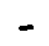

$-$

$-$

MATERIAL NAME

SPECIFICATION OR PRODUCT SOURCE

Paper Abrasive Silicon Finishing Fastcut Finishing Paper Lubricant, DAC Lube Stick Lubricant Metalworking 0il, Cut, Solvent, Cimcool Five Star Tap Magic Cutting Fluid

Punches-HSS Steel, with Prick Tip Reamers-HSS Multiple Flute Reamers Punch Press-Diacro \#2 Bench Press, Manually Operated, with Punch Adapter-Whitney-Jensen "Junior" Hand Punch

Carborundum Company

Los Angeles, $\mathrm{Ca}$ (1)

Kerns United Company

Cincinnati Milling Products

Div, Los Ange 1es, Ca

The Steco Corporation

Little Rock, Ar

DAC Stock Items

DAC Stock Items

DAC Stock Items

(DPM's are Douglas stock numbers for internal company use only).

FOOTNOTE: (1) Contact Douglas buyer for alternate approved products or sources.

D. HOLE PREPARATION REQUIREMENTS

1. Holes shall be punched (maximum material thickness $2.286 \mathrm{~mm}(.090$ in) to final size with a Diacro \#2 bench press, manually operated, with punch adapter or Whitney-Jensen "Junior" hand punch.

2. To minimize hole distortion and allow the boron fibers to shear free of burrs, punch shall be manually operated rather than machine driven to slow down punch speed. 


\section{Continued}

3. Punches shall be checked frequently for wear. To minimize wear, apply DAC lub stick (DPM 5417) around the outer periphery of entry point on the male die.

4. Holes that are undersize due to punch wear can be reamed to final size with multiple flute type reamers.

5. Punches shall be kept sharp to prevent undersize holes and protruding burrs.

6. Tap magic cutting fluid shall be applied on reamer when holes necessitate reaming.

7. Reamer shall be operated at 350 to $500 \mathrm{rpm}$. A continuous $50-65 \mathrm{~cm} / \mathrm{min}$ (20-25 in/min) feed rate shall be applied during the ream operation to reduce premature dulling of reamer.

8. Edge of holes (protruding burrs) shall be deburred with siliconecarbide paper or a steel mill file.

9. Refer to DPS 4.025 for dissimilar materials protection.

\section{E. EDGE TRIMMING REQUIREMENTS}

1. Trimming shall be accomplished with a diamond impregnated cutting wheel, operated at 1500 to $2000 \mathrm{rpm}$. Do not operate at slower speeds.

2. Metalworking lubricant (DPM 5739) shall be mixed at a ratio of one part lubricant to 30 parts water and shall be used to flood the wheel/ work interface to prevent heat build-up and diamond sparking.

3. Part to be trimmed shall be set-up within the milling machine coolant tray. Coolant must be contained within the tray to avoid abrasive injury to machine sliding surfaces. Clamp part down to prevent distortion.

4. Appearance of as-trimmed edges should be clean and not exceeding maximum of $0.762 \mathrm{~mm}(0.030$ inch) protruding burrs on both top and bottom edges. Burrs shall be removed with a mill type file. (Reference DPS 4.710$)$. Burrs protruding above. $0.762 \mathrm{~mm}(0.030 \mathrm{inch})$ indicates wheel is not cutting properly, and work should be corrected.

5. To retain material identification, parts shall be labeled immediately after edge trim per DPS 3.02 . 
APPENDIX C

MANUFACTURING PLAN FOR

BORON/ALUMINUM AFT PYLON SKIN

AVB7097-30 
Fabrication and Assembly of Boron/Aluminum Aft Pylon Skin AVB7097-30

General Plan

A skin of $6 A]-4 V$ titanium is presently used on production DC-10 aircraft in the aft pylon structure over the \#2 engine. The skin is subjected to high temperatures during service. The object of this program is to substitute a skin of boron/aluminum material for the titanium to determine the long-term effects of actual service conditions on the boron/aluminum. The skins will be removed from the aircraft after five years of service for analysis and evaluation. A total of four parts will be fabricated, with one part installed on each of three separate production DC-10 aircraft and one part sent to NASA as a spare.

The intent of the Manufacturing Plan is to provide an outline of fabrication and assembly steps similar to the planning papers normally used at Douglas but with further explanation about correct techniques and tools required to produce the parts.

General Machining and Hole Preparation

Boron/aluminum composite material requires special cutting and hole preparation processing to produce high quality components with maximum strength potentials. These mechanical operations have been documented in a Douglas Process Standard (DPS 3.67-67) and Manufacturing Engineering-Research and Development memos. The most important aspects of cutting and hole preparation are summarized as follows:

1) A11 cutting of boron/aluminum sha11 be accomplished with the Accurate Diamond Tool Company, sintered diamond slotted wheel operating at a minimum of 1524 SMPM (5000 SFPM) (1500 rpm for $35.56 \mathrm{~cm}$ (14 inch) diameter whee1). The wheel/work interface shall be flooded with Cimcool 5 Star coolant at approximately 30:1 water-coolant concentration.

2) As the products of the cut are extremely abrasive, the special coolant pumping system, work piece holding tray and the tooling department \#8 horizontal mill have been designated for boron/aluminum use exclusively.

3) Hole generation shall be accomplished by punching to full-size using special punches in the Manufacturing Development Center with the Diacro \#2 manual punch press. All punches have a conical tip to pick up transfer punch indentations for accurate hole locations. High speed steel (HSS) reamers shall be used on the boron/aluminum to bring hole diameters to drawing requirements when less than $0.127 \mathrm{~mm}(0.005 \mathrm{inch})$ undersize. A lubricant such as Tap Magic shall be used during reaming operations.

Fabrication of Skin AVB7097-30

1) Boron/aluminum sheet $2.032 \mathrm{~mm}(0.080$ inch) thick, $20.32 \times 172.72 \mathrm{~cm}(8 \times$ 68 inch) long shall be supplied by outside sources to the Manufacturing Development Center. This material shall be completely diffusion bonded and ready for layout and subsequent trimming to final net dimensions. An existing steel template, AFB70972-29,-30, shall be used to mark part 
profile and to locate all attachment holes by transfer punching through $6.35 \mathrm{~mm}$ ( 0.250 inch) diameter tooling holes. Light scribe lines shall be made through prussion blue marking dye to provide guidelines for trimming without damaging the part.

2) Each part shall be cut in the horizontal mill using the impregnated diamond wheel specified previously. Dowel pins positioned on the cutting bed plate shall be used as stops to align cut edges accurately, maintaining continuity on interrupted cuts. A total of four straight cuts shall be made on each part. The corner radius shall be generated by hand grinding the part to scribe lines using a silicone-carbide wheel.

3) The modified Diacro manual punch has been setup with full-sized punches and dies sized with $0.057 \mathrm{~mm}(0.002$ inch) diameter clearance. The workpiece shall be placed under the punch so transfer punch indentations can be aligned with the conical tip on the punch. Every hole shall be produced with a lubricated punch which reduces friction and prevents aluminum build-up on the punch.

4) Burrs on the exit side of the hole shall be removed by lightly touching the hole edge with a diamond impregnated reamer with $90^{\circ}$ included angle bevels on the reamer end. Reamer speed shall be 400-500 rpm.

5) After edge trimming and hole punching, the part will be ready for fabrication inspection prior to installation on the aircraft subassembly.

Assembly Procedures

1) The boron/aluminum skin shall be positioned on the titanium substructure and clamped in place. Preliminary tooling holes shall be drilled along the periphery of the skin from previously punched holes. Drill bushings fitted into the full-size attachmen $t$ holes in the boron/aluminum skin shall be used to assure accurate alignment of holes. Standard cleco clamps shall be installed to secure the skin to the substructure during drilling of pilot holes in the titanium details.

2) Number 30 pilot holes shall be drilled into the titanium from each of the skin holes, using the boron/aluminum skin as a drill template.

3. The boron/aluminum skin shall then be removed from the titanium substructure. All holes shall be opened to full-size per drawing requirements by drilling and reaming with conventional tools.

4) The skin shall be repositioned on the substructure and mechanical attachments shall be installed from the forward end of the structure working aft.

The boron/aluminum skin ( $\mathrm{LH}$ side) shall be installed on the substructure before the RH side titanium skin to permit accessibility for nut installations. The standard RH titanium skin (AVB7097-29) shall then be installed per normal production practice. 
5) AVB7097-30 is fabricated as a flat skin. The pylon assembly has a slight curvature to which the skin will conform. No separate forming operations shall be performed. 